Portland State University

PDXScholar

\title{
Assessment of Statewide Intersection Safety Performance
}

\author{
Christopher M. Monsere \\ Portland State University, monsere@pdx.edu \\ Todd Johnson \\ Portland State University \\ Karen Dixon \\ Oregon State University \\ Jianfei Zheng \\ Oregon State University \\ Ida Schalkwyk \\ $\mathrm{CH} 2 \mathrm{M}$ Hill
}

Follow this and additional works at: https://pdxscholar.library.pdx.edu/trec_reports

Part of the Civil Engineering Commons, and the Transportation Engineering Commons Let us know how access to this document benefits you.

\section{Recommended Citation \\ Monsere, Christopher, Todd Johnson, Karen Dixon, Jianfei Zheng, and Ida Van Schalkwyck. Assessment of Statewide Intersection Safety Performance. SPR 667, FHWA-OR-RD-18. Portland, OR: Transportation Research and Education Center (TREC), 2011. https://doi.org/10.15760/trec.77}

This Report is brought to you for free and open access. It has been accepted for inclusion in TREC Final Reports by an authorized administrator of PDXScholar. Please contact us if we can make this document more accessible: pdxscholar@pdx.edu. 


\title{
ASSESSMENT OF STATEWIDE INTERSECTION SAFETY PERFORMANCE
}

\author{
Final Report
}

SPR 667

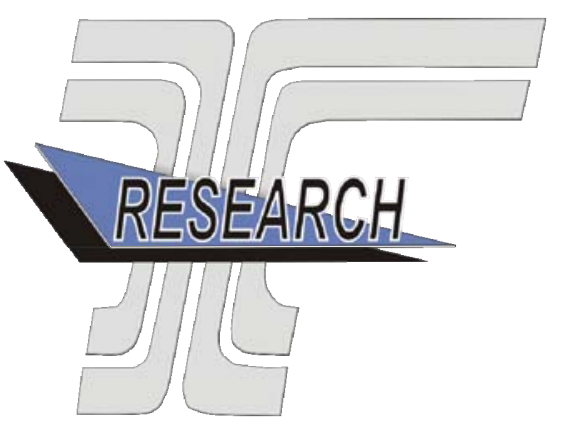





\title{
ASSESSMENT OF STATEWIDE INTERSECTION SAFETY PERFORMANCE
}

\section{Final Report}

\section{SPR 667}

\author{
by \\ Christopher M. Monsere, Ph.D., P.E., Assistant Professor \\ Todd Johnson, Graduate Research Assistant \\ Portland State University \\ Portland OR 97207 \\ Karen Dixon Ph.D., P.E., Associate Professor \\ Jianfei Zheng, Graduate Research Assistant \\ School of Civil and Construction Engineering \\ Oregon State University \\ Corvallis, OR 97331 \\ Ida Van Schalkwyk \\ CH2M Hill \\ for \\ Oregon Department of Transportation \\ Research Section \\ 200 Hawthorne Ave. SE, Suite B-240 \\ Salem OR 97301-5192 \\ and \\ Federal Highway Administration \\ 400 Seventh Street, SW \\ Washington, DC 20590-0003
}

June 2011 

Technical Report Documentation Page

\begin{tabular}{l|l}
$\begin{array}{l}\text { 1. } \\
\text { Report No. }\end{array}$ & 2. Government Accession No. \\
FHWA-OR-RD-18 & \\
\hline
\end{tabular}

4. Title and Subtitle

Assessment Of Statewide Intersection Safety Performance
3. Recipient's Catalog No.

5. Report Date

June 2011

6. Performing Organization Code 8. Performing Organization Report No.

Christopher M. Monsere, and Todd Johnson, Portland State University

Karen Dixon, Jianfei Zheng, Oregon State University

Ida Van Schalkwyk, CH2M Hill

9. Performing Organization Name and Address

Portland State University

PO Box 751

Portland, OR 97207 and

Oregon State University

220 Owen Hall

Corvallis, OR 97331
10. Work Unit No. (TRAIS)

11. Contract or Grant No.

SPR 667

13. Type of Report and Period Covered

Final Report

Oregon Department of Transportation

Research Section and

200 Hawthorne Ave. SE, Suite B-240

Salem, OR 97301-5192
Federal Highway Administration 400 Seventh Street, SW

Washington, DC 20590-0003
14. Sponsoring Agency Code

15. Supplementary Notes

16. Abstract

This report summarizes the results of an analysis of the safety performance of Oregon's intersections. Following a pilot study, a database of 500 intersections randomly sampled from around the state of Oregon in both urban and rural environments was assembled. These intersections were categorized into eight types based on number of legs (3 and 4), land use (urban or rural) and traffic control (signalized or minor stop-control). These categories were chosen to align with the intersection types in AASHTO's recently released Highway Safety Manual (HSM). Geometric and traffic control elements were supplemented by compiling crash data and volumes on the major and minor approaches. The safety performance was analyzed by three primary methods. First, crash rates were calculated and analyzed for each of the intersection groups. Crash rates determined for Oregon intersections were generally well below rates found published for other states. Since it is unlikely that such a significant difference exists in the safety performance between states, it is more likely explanation is the different reporting thresholds and Oregon's reliance on self-reporting. Second, crash patterns were tabulated for a number of crash and driver involved variables. These patterns, not before generated, will be very useful to improve identification of high crash intersection locations and improve diagnosis of these locations. Third, safety performance functions (SPFs) were created for intersections where sufficient data exist. For the purposes of this research SPFs were estimated for the rural 3-leg stop controlled and urban 4-leg signalized intersections. The SPFs developed in this modeling exercise were compared to the HSM base models calibrated to Oregon. The rural 3-leg stop models compare favorably. Within the volume range of the data used to generate the SPFs, the models compare well. The urban signalized intersection SPFs did not compare as well to the HSM base models. Further research is needed to investigate whether Oregon-specific SPFs have advantages over calibrated HSM models. The results of this analysis can be used to improve the diagnosis and identification of unusual safety performance at intersections in Oregon. The average rates are useful for peer comparisons and in calculation of critical rates. The crash patterns can be directly applied in diagnostic efforts to detect unusual patterns at intersections. The SPF modeling effort is the groundwork for further explorations and model development for Oregon facilities.

\section{Key Words}

Intersections, Safety Performance, Crash Models, Crash Patterns

\section{Distribution Statement}

Copies available from NTIS, and online at http://www.oregon.gov/ODOT/TD/TP_RES/

\footnotetext{
19. Security Classification (of this report) Unclassified
}

\section{Security Classification (of this page) Unclassified}

Reproduction of completed page authorized 


\begin{tabular}{|c|c|c|c|c|c|c|c|c|c|}
\hline \multicolumn{10}{|c|}{ SI* (MODERN METRIC) CONVERSION FACTORS } \\
\hline \multicolumn{5}{|c|}{ APPROXIMATE CONVERSIONS TO SI UNITS } & \multicolumn{5}{|c|}{ APPROXIMATE CONVERSIONS FROM SI UNITS } \\
\hline Symbol & When You Know & Multiply By & To Find & Symbol & Symbol & When You Know & Multiply B & To Find & Symbol \\
\hline \multicolumn{5}{|c|}{ LENGTH } & \multicolumn{5}{|c|}{ LENGTH } \\
\hline in & inches & 25.4 & millimeters & $\mathrm{mm}$ & $\mathrm{mm}$ & millimeters & 0.039 & inches & in \\
\hline $\mathrm{ft}$ & feet & 0.305 & meters & $\mathrm{m}$ & $\mathrm{m}$ & meters & 3.28 & feet & $\mathrm{ft}$ \\
\hline yd & yards & 0.914 & meters & $\mathrm{m}$ & $\mathrm{m}$ & meters & 1.09 & yards & yd \\
\hline $\mathrm{mi}$ & miles & 1.61 & kilometers & $\mathrm{km}$ & $\mathrm{km}$ & kilometers & 0.621 & miles & $\mathrm{mi}$ \\
\hline \multicolumn{5}{|c|}{$\underline{\text { AREA }}$} & \multicolumn{5}{|c|}{ AREA } \\
\hline in $^{2}$ & square inches & 645.2 & millimeters squared & $\mathrm{mm}^{2}$ & $\mathrm{~mm}^{2}$ & millimeters squared & 0.0016 & square inches & $\mathrm{in}^{2}$ \\
\hline $\mathrm{ft}^{2}$ & square feet & 0.093 & meters squared & $\mathrm{m}^{2}$ & $\mathrm{~m}^{2}$ & meters squared & 10.764 & square feet & $\mathrm{ft}^{2}$ \\
\hline $\mathrm{yd}^{2}$ & square yards & 0.836 & meters squared & $\mathrm{m}^{2}$ & $\mathrm{~m}^{2}$ & meters squared & 1.196 & square yards & $\mathrm{yd}^{2}$ \\
\hline ac & acres & 0.405 & hectares & ha & ha & hectares & 2.47 & acres & ac \\
\hline $\mathrm{mi}^{2}$ & square miles & 2.59 & kilometers squared & $\mathrm{km}^{2}$ & $\mathrm{~km}^{2}$ & kilometers squared & 0.386 & square miles & $\mathrm{mi}^{2}$ \\
\hline \multicolumn{5}{|c|}{ VOLUME } & \multicolumn{5}{|c|}{$\underline{\text { VOLUME }}$} \\
\hline $\mathrm{fl} \mathrm{oz}$ & fluid ounces & 29.57 & milliliters & $\mathrm{ml}$ & $\mathrm{ml}$ & milliliters & 0.034 & fluid ounces & $\mathrm{fl} \mathrm{oz}$ \\
\hline gal & gallons & 3.785 & liters & $\mathrm{L}$ & $\mathrm{L}$ & liters & 0.264 & gallons & gal \\
\hline $\mathrm{ft}^{3}$ & cubic feet & 0.028 & meters cubed & $\mathrm{m}^{3}$ & $\mathrm{~m}^{3}$ & meters cubed & 35.315 & cubic feet & $\mathrm{ft}^{3}$ \\
\hline $\mathrm{yd}^{3}$ & cubic yards & 0.765 & meters cubed & $\mathrm{m}^{3}$ & $\mathrm{~m}^{3}$ & meters cubed & 1.308 & cubic yards & $\mathrm{yd}^{3}$ \\
\hline \multicolumn{10}{|c|}{ NOTE: Volumes greater than $1000 \mathrm{~L}$ shall be shown in $\mathrm{m}^{3}$. } \\
\hline \multicolumn{5}{|c|}{$\underline{\text { MASS }}$} & \multicolumn{5}{|c|}{$\underline{\text { MASS }}$} \\
\hline $\mathrm{oz}$ & ounces & 28.35 & grams & g & g & grams & 0.035 & ounces & $\mathrm{oz}$ \\
\hline $\mathrm{lb}$ & pounds & 0.454 & kilograms & $\mathrm{kg}$ & $\mathrm{kg}$ & kilograms & 2.205 & pounds & $\mathrm{lb}$ \\
\hline $\mathrm{T}$ & short tons (2000 lb) & 0.907 & megagrams & $\mathrm{Mg}$ & $\mathrm{Mg}$ & megagrams & 1.102 & short tons $(2000 \mathrm{lb})$ & $\mathrm{T}$ \\
\hline \multicolumn{5}{|c|}{ TEMPERATURE (exact) } & \multicolumn{5}{|c|}{ TEMPERATURE (exact) } \\
\hline${ }^{\circ} \mathrm{F}$ & Fahrenheit & $(\mathrm{F}-32) / 1.8$ & Celsius & ${ }^{\circ} \mathrm{C}$ & ${ }^{\circ} \mathrm{C}$ & Celsius & $1.8 \mathrm{C}+32$ & Fahrenheit & ${ }^{\circ} \mathrm{F}$ \\
\hline
\end{tabular}




\section{ACKNOWLEDGEMENTS}

The authors thank the Oregon Department of Transportation (ODOT), Federal Highway Administration (FHWA) for funding this research. The Technical Advisory Committee has provided valuable input throughout the project. . Elizabeth Wemple (Cambridge Systematics) contributed data sources and guidance on intersection data collection in the first phases of this project. Portland State University students Chengyu Dai, Chengxin Dai and Kristie Gladhill helped with data collection efforts.

\section{DISCLAIMER}

This document is disseminated under the sponsorship of the Oregon Department of Transportation and the United States Department of Transportation in the interest of information exchange. The State of Oregon and the United States Government assume no liability of its contents or use thereof.

The contents of this report reflect the view of the authors who are solely responsible for the facts and accuracy of the material presented. The contents do not necessarily reflect the official views of the Oregon Department of Transportation or the United States Department of Transportation.

The State of Oregon and the United States Government do not endorse products of manufacturers. Trademarks or manufacturers' names appear herein only because they are considered essential to the object of this document.

This report does not constitute a standard, specification, or regulation. 


\section{TABLE OF CONTENTS}

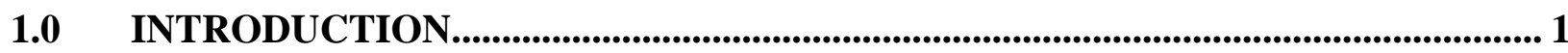

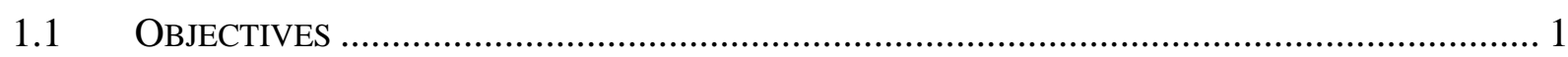

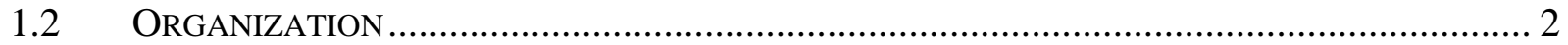

$2.0 \quad$ LITERATURE REVIEW .............................................................................................. 3

$2.1 \quad$ PART 1: INTERSECTION ELEMENTS ………………………………………………. 4

2.1.1 Geometric Elements................................................................................................................

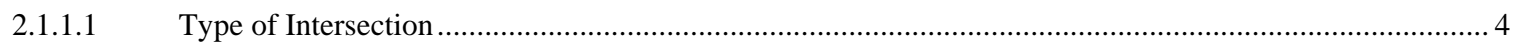

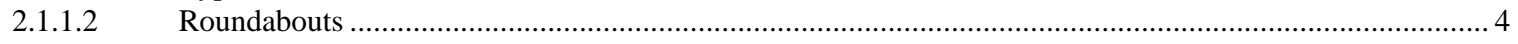

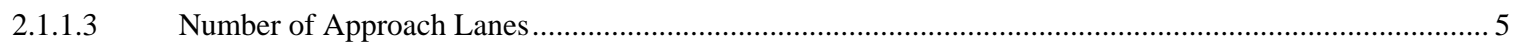

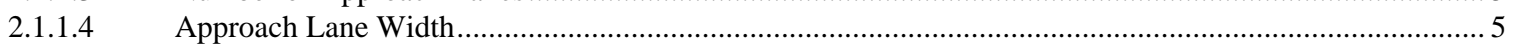

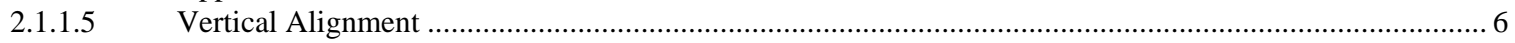

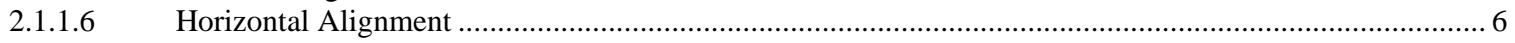

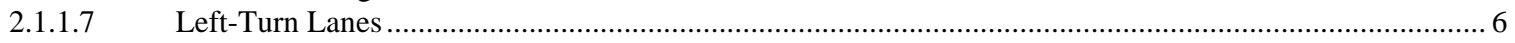

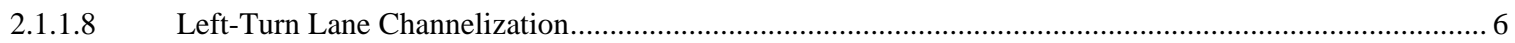

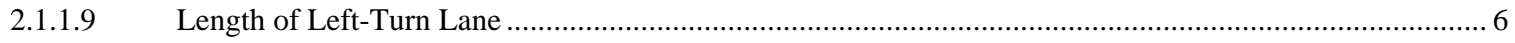

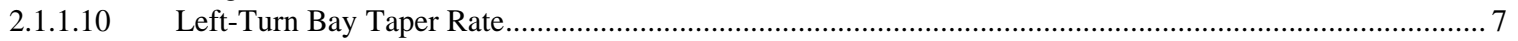

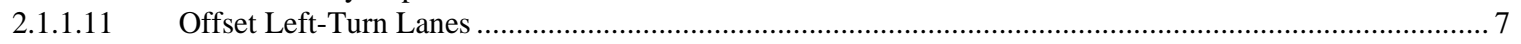

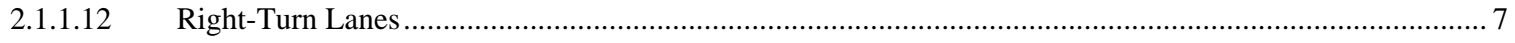

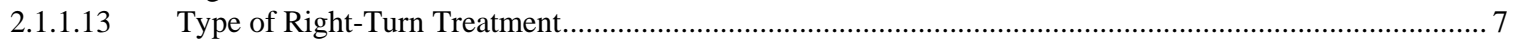

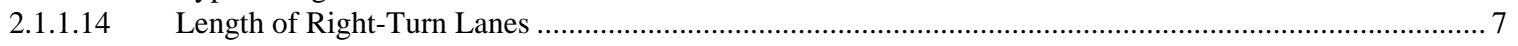

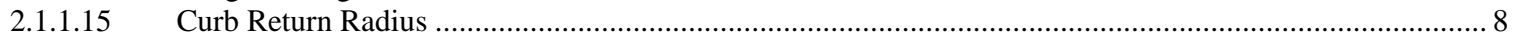

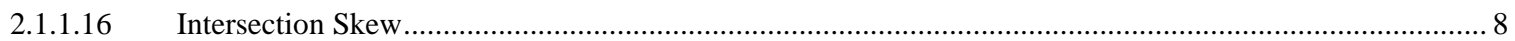

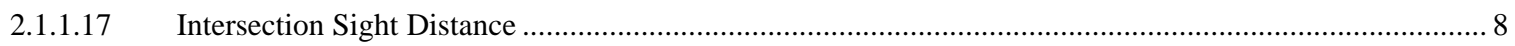

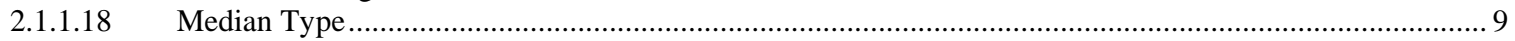

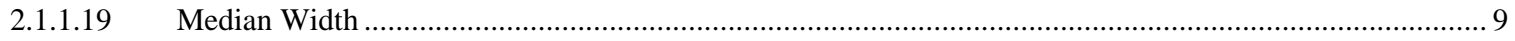

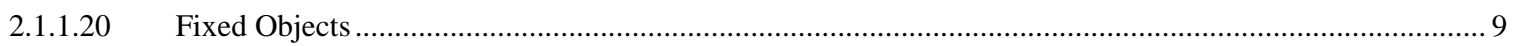

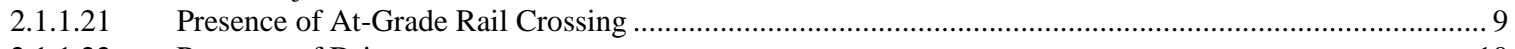

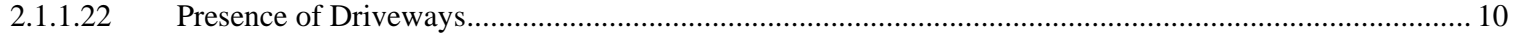

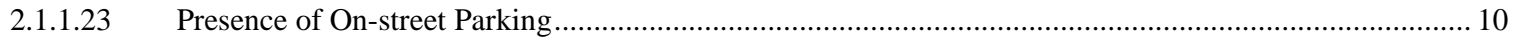

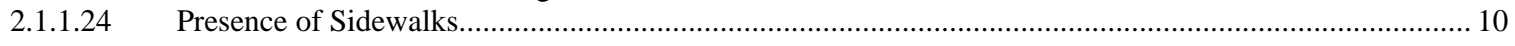

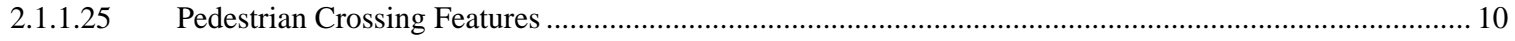

2.1.1.26 Maximum Number of Lanes Crossed by Pedestrians ….................................................................. 10

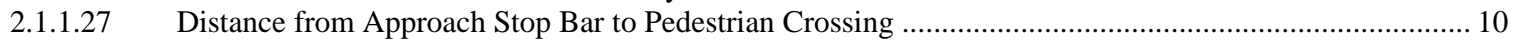

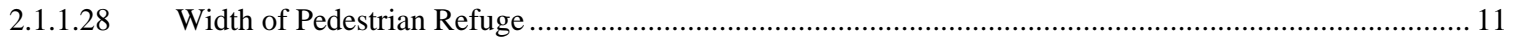

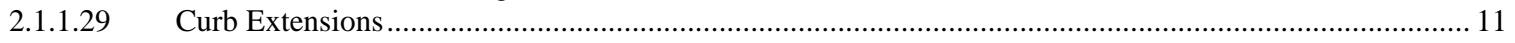

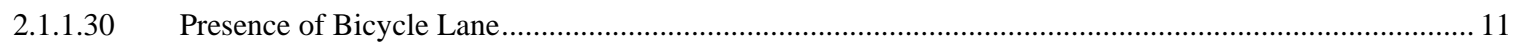

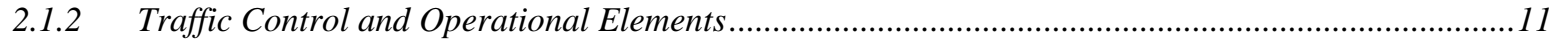

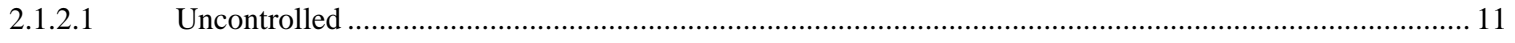

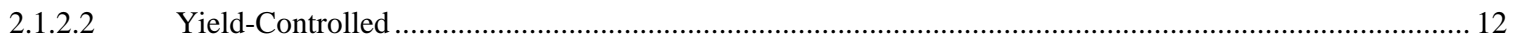

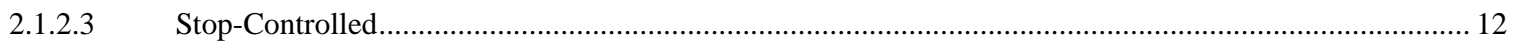

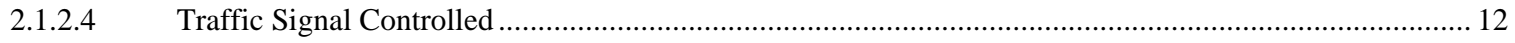

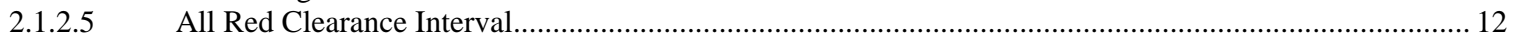

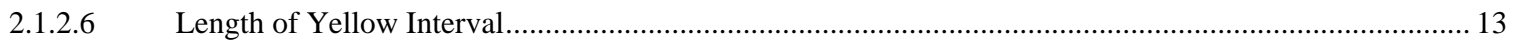

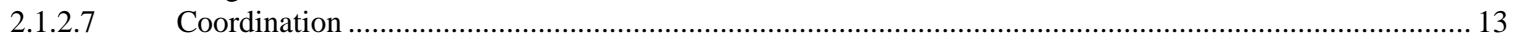

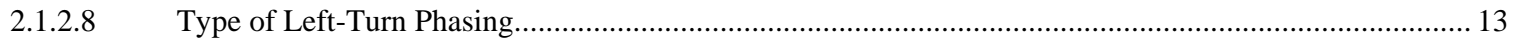

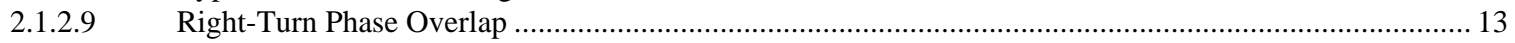

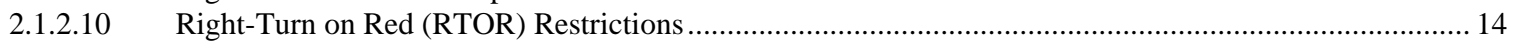

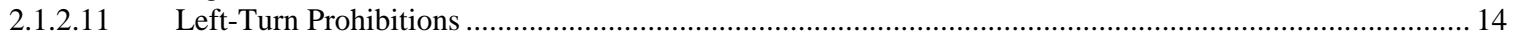

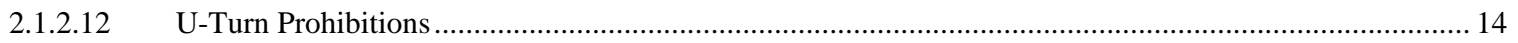

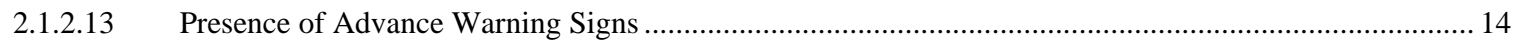

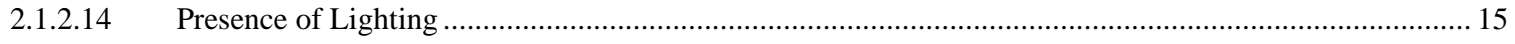

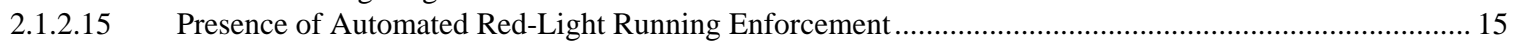




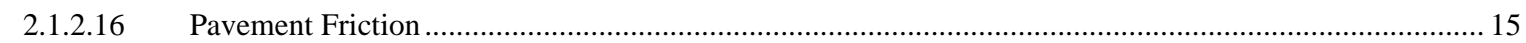

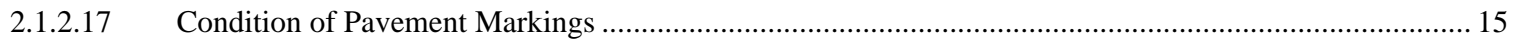

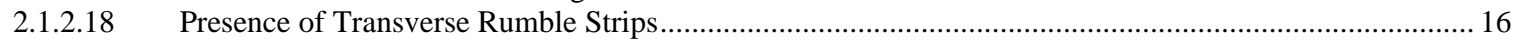

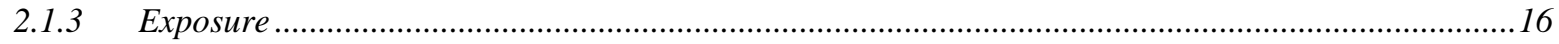

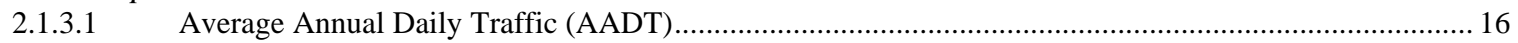

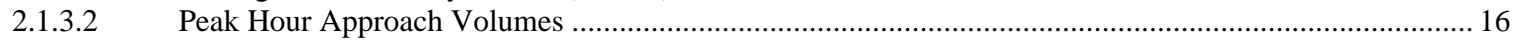

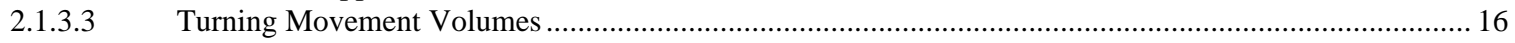

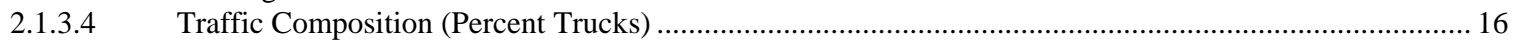

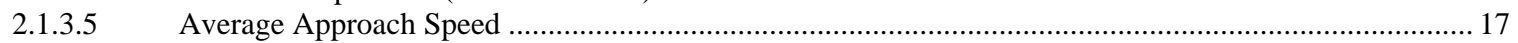

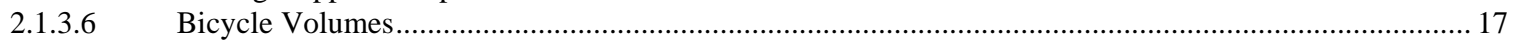

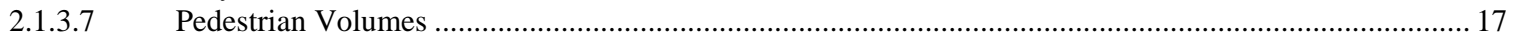

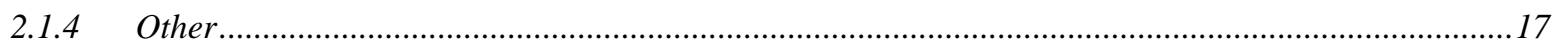

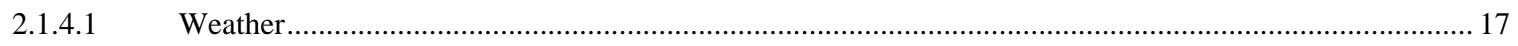

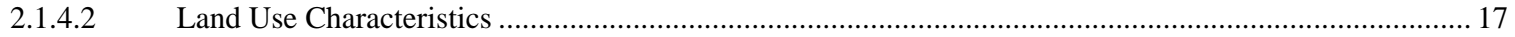

$2.2 \quad$ PART 2: Estimating SAFETy PERFORMANCE............................................................. 18

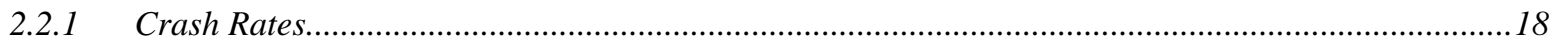

2.2.2 Crash Proportions, Direct Diagnostics and Pattern Recognition ..................................................23

2.2.3 Safety Prediction Models for Intersections.........................................................................24

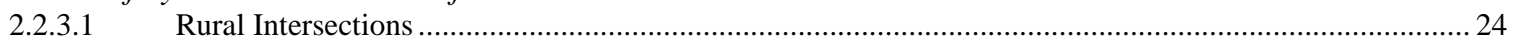

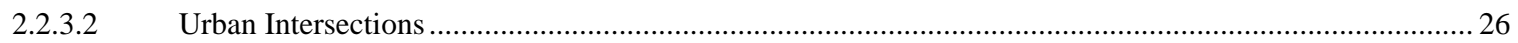

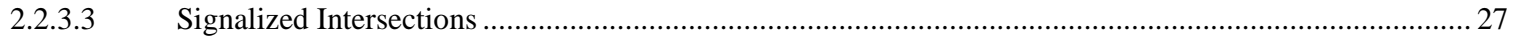

2.3 CONCLUSION........................................................................................................ 28

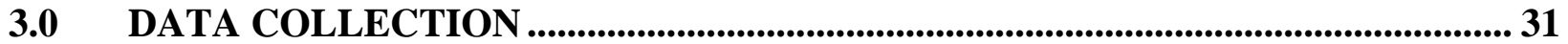

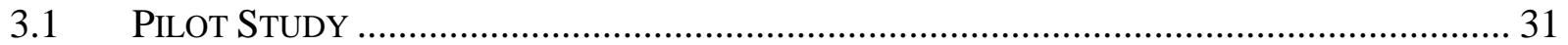

3.2 INVENTORY OF STATEWIDE INTERSECTIONS ............................................................ 32

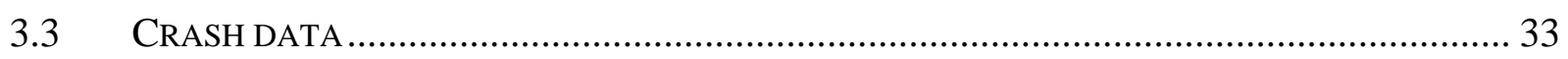

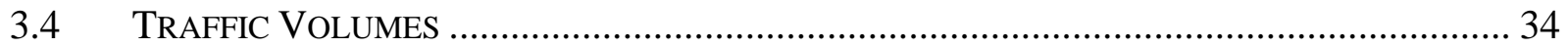

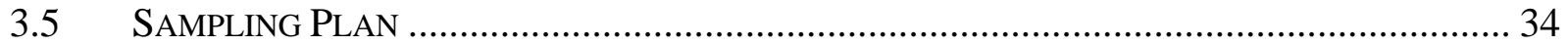

3.6 AERIAL AND STREET-LEVEL IMAGERY ……………................................................. 35

3.7 DESCRIPTION OF DATA ELEMENTS ………………................................................... 35

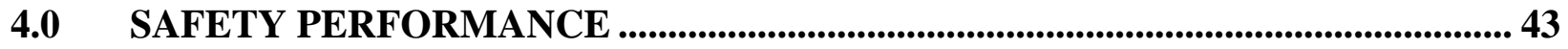

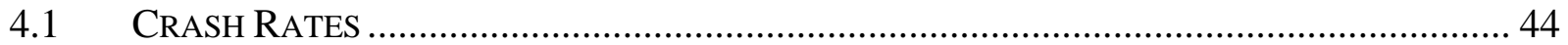

4.1.1 Discussion on Applications of Rates.......................................................................................49

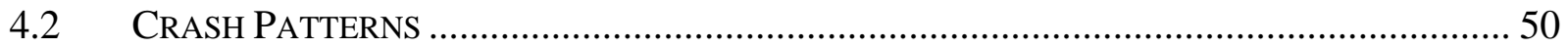

4.2.1 Crash Severity ....................................................................................................................5

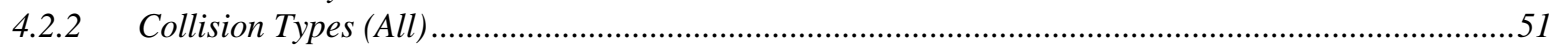

4.2.3 Collision Types (Fatal and Injury A) ........................................................................................52

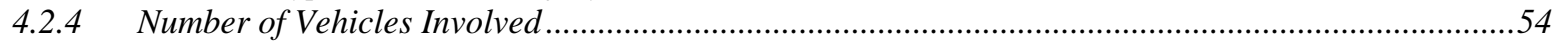

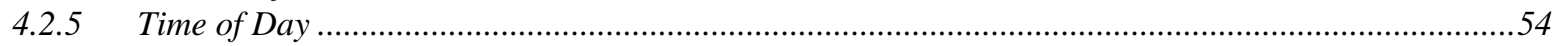

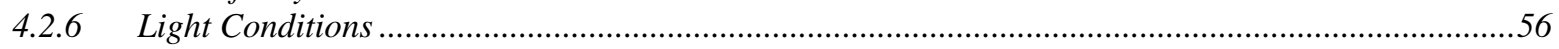

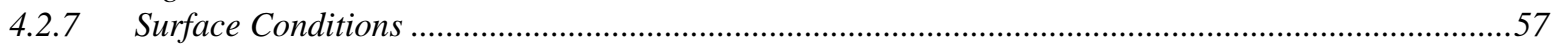

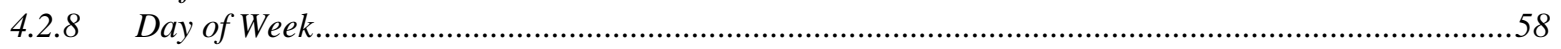

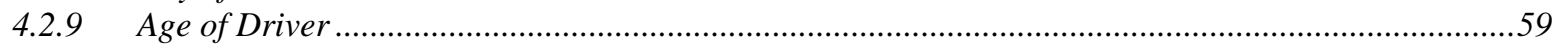

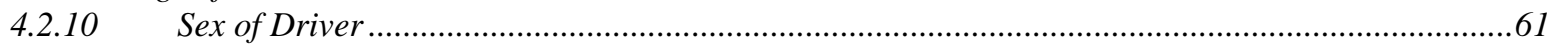

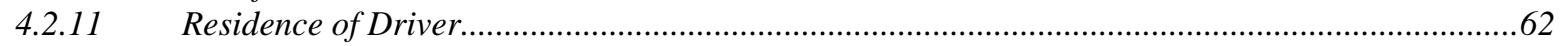

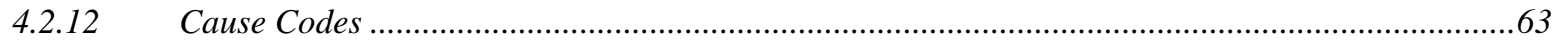

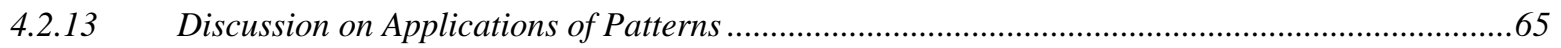

4.3 DeVELOPMENT OF SAFETY PERFoRMANCE FunCtIONS (SPF)......................................... 66

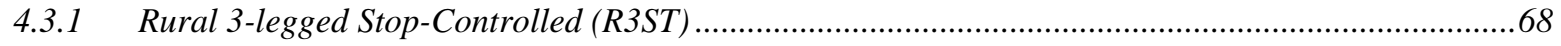

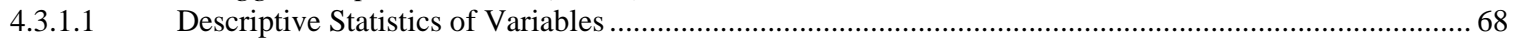

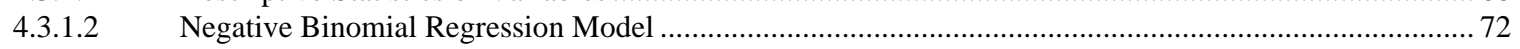

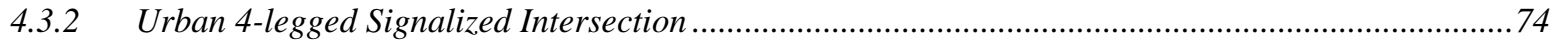




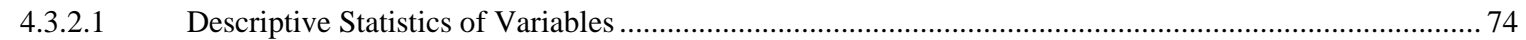

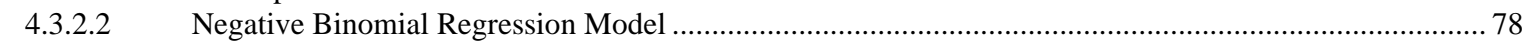

4.3.3 Comparison to Calibrated HSM Models ...............................................................................8

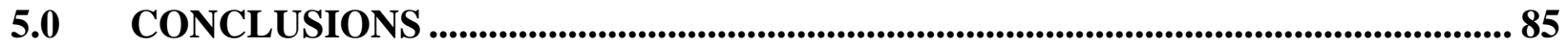

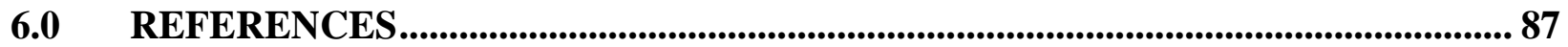

APPENDIX A: Q-Q PLOTS OF CRASH RATES

APPENDIX B: ANALYSIS OF PERFORMANCE BY SPECIFIC ELEMENTS

\section{LIST OF TABLES}

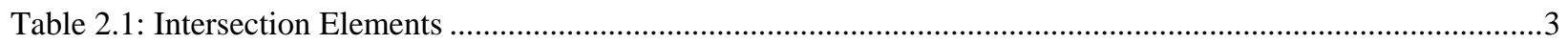

Table 2.2: Rural and Urban Intersection Average Crash Frequencies and Rate, Wisconsin......................................18

Table 2.3: Rural Intersection Geometry and Crash Rate, Wisconsin ......................................................................19

Table 2.4: Urban Intersection Geometry and Crash Rate, Wisconsin .........................................................................19

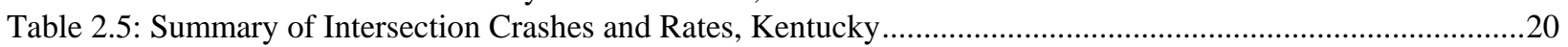

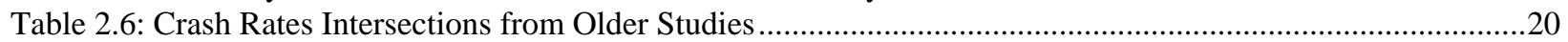

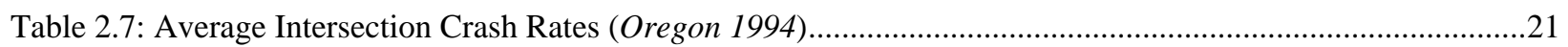

Table 2.8: Average Crash Rates Intersection - Crashes Per Million Entering Vehicles (Massachusetts) .....................22

Table 2.9: Accident and Related Data for Rural and Municipal Intersections in Iowa (1983-1987) ...........................22

Table 3.1: Intersection Elements Identified for Collection in the Full Study ...........................................................32

Table 3.2: Summary of Categorical Elements .................................................................................................39

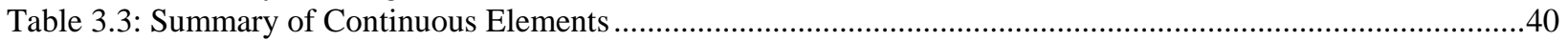

Table 4.1: Intersection Crash Rates by Land Type and Traffic Control......................................................................47

Table 4.2: Intersection Crash Rates by Type and Aggregated Volume Group ............................................................47

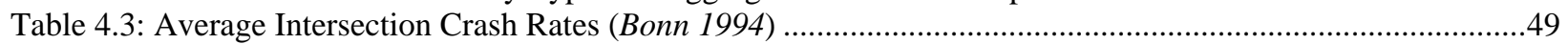

Table 4.4: Crash Severity Proportions by Intersection Type, 2003-2007 Data.........................................................50

Table 4.5: Collision Types (All Crashes) Proportions by Intersection Type, 2003-2007 Data..................................52

Table 4.6: Collision Types Proportions by Intersection Type (Fatal and Injury A Crashes), 2003-2007 Data............53

Table 4.7: Crash Proportions for Number of Vehicles Involved by Intersection Type, 2003-2007 Data ....................54

Table 4.8: Crash Proportions by Hour Group by Intersection Type, 2003-2007 Data..............................................55

Table 4.9: Crash Proportions for Lighting Condition by Intersection Type, 2003-2007 Data.....................................56

Table 4.10: Crash Proportions for Surface Conditions by Intersection Type, 2003-2007 Data...................................57

Table 4.11: Crash Proportions for Day of the Week by Intersection Type, 2003-2007 Data .....................................59

Table 4.12: Crash Proportions for Age Cohort of Driver by Intersection Type, 2003-2007 Data ..............................60

Table 4.13: US Census, Oregon Population by Age Cohort, 2000 ...........................................................................61

Table 4.14: Crash Proportions for Sex of Driver by Intersection Type, 2003-2007 Data...........................................61

Table 4.15: Crash Proportions for Residence of Driver by Intersection Type, 2003-2007 Data ...............................62

Table 4.16: Crash Proportions for Crash Cause Code by Intersection Type, 2003-2007 Data ...................................64

Table 4.17: Summary Statistics for Model Variables for Each Intersection Type ......................................................67

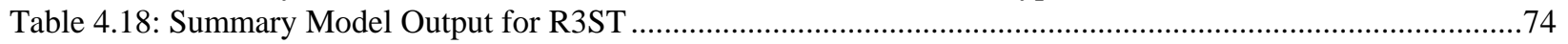

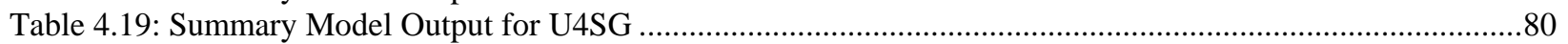




\section{LIST OF PHOTOS/FIGURES}

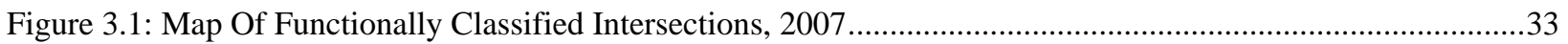

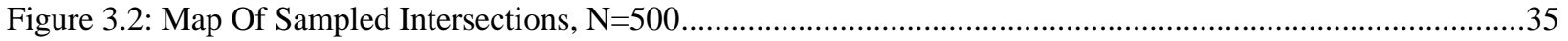

Figure 3.3: Sample Aerial Photos And Collected Data Elements, Rural Intersections. .............................................41

Figure 3.4: Sample Aerial Photos And Collected Data Elements, Urban Intersections ..............................................42

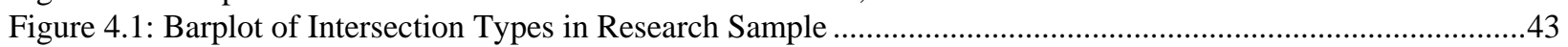

Figure 4.2: Total Entering Intersection Volume Vs Crash Frequency, 5-Year Crash Frequency ..............................44

Figure 4.3: Crash Frequency (Dots And Color Proportional To Crash Frequency) Plotted Against Major And

Minor Entering Average Volume $\quad 45$

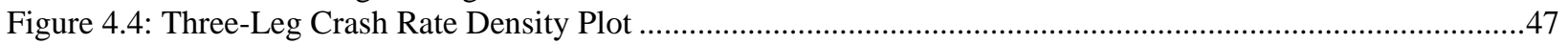

Figure 4.5: Four-Leg Crash Rate Density Plot .........................................................................................................48

Figure 4.6: Stacked Barplot of Crash Severity Proportions by Intersection Type, 2003-2007 Data..........................51

Figure 4.7: Collision Type Proportions by Intersection Type (All crashes), 2003-2007 Data ....................................52

Figure 4.8: Collision Type Proportions by Intersection Type (Fatal and Injury A Crashes), 2003-2007 Data...........53

Figure 4.9: Crash Proportions for Number of Vehicles Involved by Intersection Type, 2003-2007 Data...................54

Figure 4.10: Crash Proportions for Hour Group by Intersection Type, 2003-2007 Data...........................................55

Figure 4.11: Crash Proportions for Lighting Conditions by Intersection Type, 2003-2007 Data ...............................56

Figure 4.12: Crash Type Proportions for Surface Conditions by Intersection Type, 2003-2007 Data .......................57

Figure 4.13: Crash Type Proportions for Surface Conditions by County, 2003-2007 Data.......................................58

Figure 4.14: Crash Type Proportions By Intersection Type, 2003-2007 Data ........................................................59

Figure 4.15: Crash Proportions for Age Cohort of Driver by Intersection Type, 2003-2007 Data...........................60

Figure 4.16: Crash Proportions for Sex of Driver by Intersection Type, 2003-2007 Data ........................................62

Figure 4.17: Crash Proportions for Driver Residence by Intersection Type, 2003-2007 Data .................................63

Figure 4.18: Crash Type Proportions by Crash Cause Code, 2003-2007 Data ......................................................65

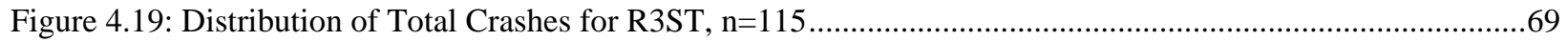

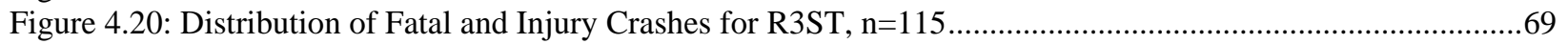

Figure 4.21: Distribution of PDO Crashes for R3ST, $\mathrm{n}=115$................................................................................

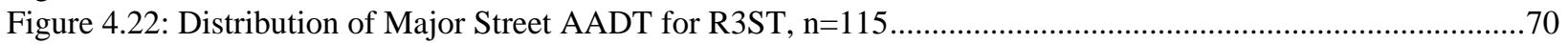

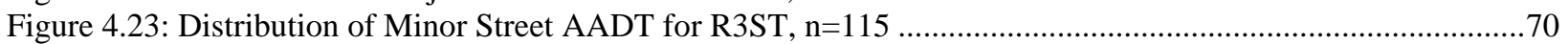

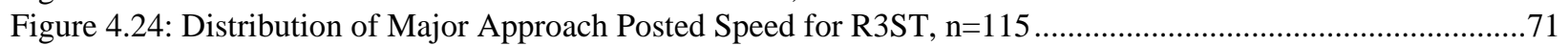

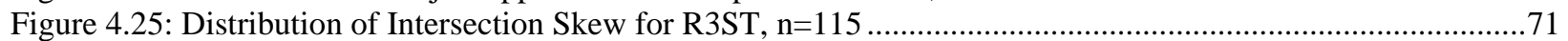

Figure 4.26: Distribution of the Number of Left, Right, and Approach Lanes for R3ST ...........................................72

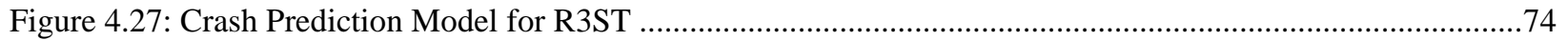

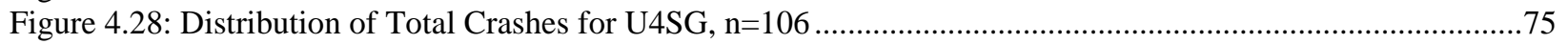

Figure 4.29: Distribution of Fatal and Injury Crashes for U4SG, n=106 ..........................................................75

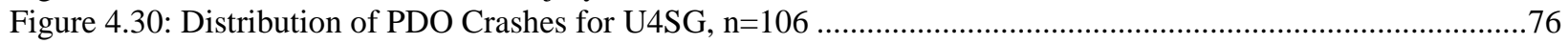

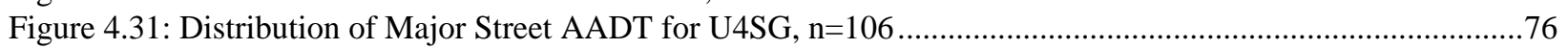

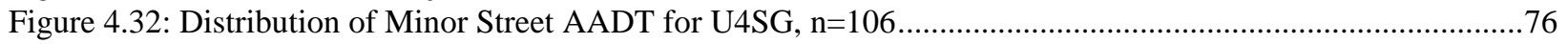

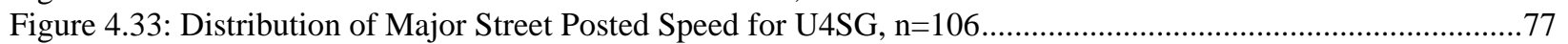

Figure 4.34: Distribution of Intersection Skew for U4SG, $n=106$..........................................................................77

Figure 4.35: Distribution of the Number of Left, Right, and Approach Lanes for U4SG............................................78

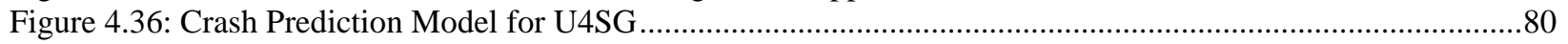

Figure 4.37: Comparison of SPF Model and HSM Calibrated Model for Oregon, R3ST .......................................81

Figure 4.38: Isocontour Plots of Total Crashes Estimated by the SPF Model and HSM Calibrated Base Model,

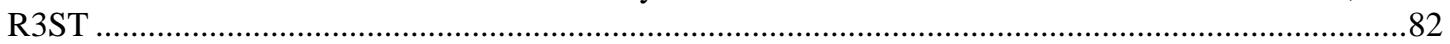

Figure 4.39: Comparison of SPF Model and HSM Calibrated Model for Oregon, U4SG ..................................................83

Figure 4.40: Isocontour Plots of Total Crashes Estimated by the SPF Model and HSM Calibrated Base Model, U4SG....... 


\subsection{INTRODUCTION}

Intersections are a key focus area for highway safety improvement programs — both because of the concentration of crashes and the high severity and frequency. According to the Federal Highway Administration, there were 33,808 fatalities on the U.S. public roadways in 2009. Nearly 21 percent of these $(7,043)$ were identified as intersection or intersection-related (FHWA 2011). In Oregon, reported intersection crash data have a similar pattern (though not as high of a percentage of the total national statistics). In 2009, 41\% of the 41,279 statewide reported crashes in Oregon occurred at intersections. These intersection crashes accounted for $17 \%$ of fatal, and $42 \%$ of injury reported crashes (ODOT 2010). This high social cost (loss of life, injury, and lost resources) has driven national and state transportation agencies to renew efforts to lower these statistics.

With the release of AASHTO’s Highway Safety Manual in 2010, there has been substantial progress in the development in quantitative safety analysis techniques for predicting crashes, screening transportation networks to identify high crash locations, and countermeasure diagnosis. As part of these new quantitative tools and to know where and when to make improvements, the long-term safety performance of facilities must first be established. The most appealing screening and diagnostic procedures attempt to identify sites with the most potential for improvement since engineering studies and efforts to reduce crashes are expensive, agencies have limited budgets to initiate those improvements, and if a site with potential is not identified, an opportunity to substantially improve safety at the location is missed (Hauer et al. 2002). Typically, the sites with most potential for improvement have a crash frequency and severity performance that deviates from the average of like sites or corridors.

In this report, the average safety performance at Oregon intersections is defined. The results and outputs can be used directly in improving Oregon's highway safety program.

\subsection{OBJECTIVES}

The objective of this research is to quantify the safety performance of typical intersections for various geometrical and operational categories (rural, urban, suburban, volumes, configuration, traffic control, geography). The objective can be broken down into two sub-objectives:

- To assemble a statewide inventory of intersections including location, geometry, control and volume data.

- To characterize by a variety of geometric, operational, and volume features the safety performance of typical intersections. This performance will include both statistical summaries and exploration of the applicability of predictive models.

To accomplish these objectives a large, random sample of intersections - with a wide variety of spatial, volume, traffic control, and other characteristics — were assembled. Using these data, 
summary statistics such as crash frequency, crash rate, and distributions of crashes by type and other variables are computed across a range of intersection types. These summary data provide information on the long-term average patterns for intersections which is useful both to detect unusual patterns and as input in the appropriate statistical diagnostic techniques. Pattern detection (in particular) has the advantage providing information usable in the selection of appropriate countermeasures (a key intent of network screening). Predictive crash models are developed to further explore the geometric, operational and traffic elements that contribute to intersection safety.

\subsection{ORGANIZATION}

The remainder of this report is organized in the following chapters:

- Chapter 2: Literature Review - Current practices and published literature were reviewed for material that related to the project.

- Chapter 3: Data Collection - A description of the pilot study and data collection procedures.

- Chapter 4: Safety Performance - Results of the analysis - including rates, patterns, analysis of specific elements, and safety performance functions.

- Chapter 5: Conclusions - Conclusions and recommendations are presented. 


\subsection{LITERATURE REVIEW}

This literature review on the safety performance of intersection is presented in two parts. In Part $\mathbf{1}$ a review of geometric, operation, traffic control, and other features identified in past studies are reviewed. The purpose of the review is not to quantify crash reductions - rather it is to identify trends. The elements reviewed are shown in Table 2.1. In Part 2, the methods for pattern diagnostics and modeling the safety performance at intersections are presented.

Table 2.1: Intersection Elements

\begin{tabular}{|c|c|}
\hline Geometric Elements & Traffic Control and Operational Features \\
\hline \multirow{29}{*}{ 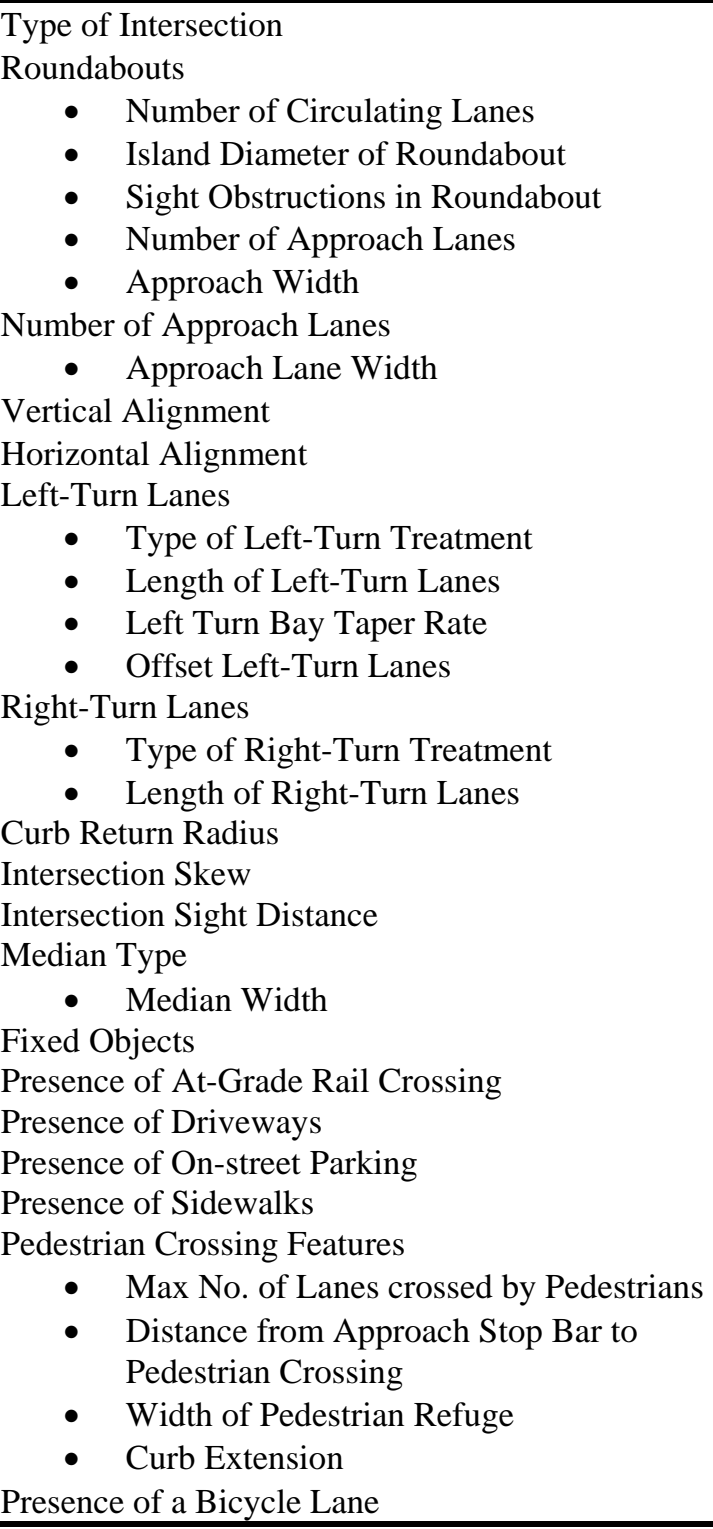 } & Type of Traffic Control \\
\hline & - Uncontrolled \\
\hline & - $\quad$ Yield-Controlled \\
\hline & - STOP-Controlled \\
\hline & - Traffic Signal Controlled \\
\hline & Signal Timing \\
\hline & - All Red Clearance Interval \\
\hline & - Yellow Clearance Interval \\
\hline & - $\quad$ Type of Left-Turn Phasing \\
\hline & - $\quad$ Right-Turn Arrow Overlap \\
\hline & - $\quad$ Lead or Lag Left-Turn \\
\hline & $\begin{array}{l}\text { Turn Prohibitions } \\
\text { • } \quad \text { Right-Turn on Red } \\
\text { • } \quad \text { Left-Turn Prohibitions } \\
\text { • } \quad \text { U-Turn Prohibitions } \\
\text { Advance Warning Signs }\end{array}$ \\
\hline & Lighting \\
\hline & Red-Light Camera Enforcement \\
\hline & Pavement Friction \\
\hline & Pavement Marking Conditions \\
\hline & Presence of Trans. Rumble Strips \\
\hline & \\
\hline & Exposure \\
\hline & Average Annual Daily Traffic \\
\hline & Peak Hour Approach Volumes \\
\hline & Turning Movement Volumes \\
\hline & Traffic Comp. (Percent Trucks) \\
\hline & Average Approach Speed \\
\hline & Bicycle Volumes \\
\hline & Pedestrian Volumes \\
\hline & +2 \\
\hline & Land-Use Characteristics \\
\hline & Urban and Rural \\
\hline
\end{tabular}




\subsection{PART 1: INTERSECTION ELEMENTS}

\subsubsection{Geometric Elements}

Geometric design features are any of the physical aspects that define a highway. Each section describes the previous work (if any) that relates to how the element affects the safety performance of intersections.

\subsubsection{Type of Intersection}

The type of intersection refers to the general geometric configuration defined by the number of entering legs and is commonly used to classify intersections for safety comparisons. The majority of intersections have either three or four legs.

There is a strong correlation between the number of legs and entering volumes and conflict points. As such, most of the literature suggests that 3-leg intersections have better safety performance than 4-leg intersections. Bauer and Harwood (1996) used regression modeling to estimate crashes at intersections. Their results indicated that an estimated 1.1 crashes per year could be expected at rural 4-leg STOP-controlled intersections and 3-leg intersections could expect 0.6 crashes. The same pattern is seen in urban settings where 2.2 crashes per year were estimated at 4-leg STOP controlled intersections versus 1.3 crashes per year at 3-leg intersections. From these findings the authors concluded that crash rates are approximately 50\% lower at 3-leg intersections than they are at 4-leg intersections. Knapp and Campbell (2005) also found that at both urban and rural sites, the crash frequencies and average crash rates at 4-leg intersections were higher than at 3-leg intersections. Rural three-legged intersections saw a higher average crash rate than urban intersections did. The authors believed that the outcome was the results of a series of very high-volume urban intersections with very few crashes. At four-legged intersections, both rural and urban intersections had similar average crash rates.

Other intersection types could include multi-leg, " $\mathrm{Y}$ " configuration, and offset or paired “T” intersections. In a comparative study of intersections, Hanna et al. (1976) found that "Y" intersections have around 50\% higher crash rates than T intersections. Offset intersections have crash rates that are around 43\% less than crash rates at standard cross intersections. Other reviews of existing research have also confirmed that offset or paired $\mathrm{T}$ intersections have fewer crashes than conventional cross intersections (Monsere 2001).

\subsubsection{Roundabouts}

While roundabouts could be classified by the number of legs, they are different enough that they should be considered as a separate category. Geometric elements that are specific to roundabout include:

- Number of circulatory lanes, 
- Circulatory width,

- Inscribed diameter,

- Bicycle facility,

- Entry width,

- Number of entry lanes,

- Entry radius,

- Exit width,

- Number of exit lanes,

- Exit radius,

- Pedestrian facility,

- Crosswalk location (distance from yield line); and

- Roundabout - splitter island width.

There does not appear to published literature that attempts to quantify the safety performance based on these geometric elements with the exception of the number of circulatory lanes (probably because U.S. experience with roundabouts is relatively new). Most studies have found crash reduction when conversions from all-way STOPcontrolled intersections to roundabouts at both rural and urban sites (Rodegarts 2007). An FHWA study found in a before-after study that, after building a roundabout, a reduction of $37 \%$ for all crash types at small, medium, and large roundabouts took place (FHWA 2000). One study found that crash reduction is larger for single-lane roundabouts than for two-lane designs in urban and suburban settings.

\subsubsection{Number of Approach Lanes}

The number of approach lanes is correlated with entering volumes (exposure). As such, the literature suggests that safety performance decreases as the number of lanes increases. Harwood et al. (2002) found that unsignalized intersections in both rural and urban areas with one approach lane have a higher number of crashes when compared to intersections with two or more approach lanes. Knapp and Campbell (2005) observed that average annual crash frequencies in both rural and urban settings at four-lane major road intersections were higher than the respective crash frequencies at two-lane major roadways. In this study, four-lane facilities averaged lower crash rates in both rural and urban settings.

\subsubsection{Approach Lane Width}

As reviewed by Harwood et al. (2002), the prevailing body of research indicates that increasing the combined widths of the approach lanes and, in some cases, the width of the shoulder at intersections leads to decreased crash rates. Potts et al. (2007), however, did 
not find any statistically significant evidence that narrow approach lanes on arterials lead to increased crashes.

\subsubsection{Vertical Alignment}

Steep upgrade approaches to intersections cause difficulty because vehicles accelerate more slowly, resulting in increased time during which the vehicle is exposed in the conflict area of the intersection. Steep downgrade approaches to intersections require longer stopping distances resulting in increased crash potential (Harwood et al. 2002). Despite this, Hanna et al.(1976) found the crash rates for intersections with steep grades (greater than five percent) were lower than the average accident rate for all intersections. The average accident rates were 0.97 per million entering vehicles for intersections with a five percent or more approach grade when compared with a 1.17 accident rate for all intersections in the study.

\subsubsection{Horizontal Alignment}

Whenever possible, most intersections are not placed on a horizontal curve. However, no studies exist that indicate and an ideal distance from the beginning of the curve (tangent point) to intersection from a crash perspective (most likely because of the rare occurrences) (Harwood et al. 2002).

\subsubsection{Left-Turn Lanes}

At intersections, left-turning crashes are often severe-especially at high-speed intersections. As such, there have been numerous studies performed on the safety effect of left-turn lanes. Most, but not all, of these studies show that for intersections, the addition of a left-turn lane improves safety. Gluck et al. (1999) showed through a synthesis of previous research that crash rates, when adding left-turn lanes, are decreased by about $18 \%-77 \%$. Harwood et al. (2002) found crash reductions of $10 \%-66 \%$ with the addition of a left-turn lane depending on the type of intersection. Most studies have been generic about the presence of a left-turn lane (i.e. whether or not one exists) — additional features relating to left-turn lanes are presented in the following sections.

\subsubsection{Left-Turn Lane Channelization}

Left-turn channelization can be accomplished with pavement markings, traffic islands, median dividers, and signage. Channelizing turn lanes is generally thought to improve positive guidance and driver operations. Harwood et al. (2002) found that having rural four-leg unsignalized intersections with channelized left-turn lanes and curbed channelization reduced crashes by $57 \%$ while painted left-turn channelization for the same intersection types reduced crashes by only $23 \%$.

\subsubsection{Length of Left-Turn Lane}

The intent of extending a turn lane is to increase storage and space for deceleration of turning vehicles. When turning lanes do not have enough storage, queue overflow 
occurs. Overflow reduces through lane performance and increases traffic conflicts. Yu et al. (2007) show that left-turn lanes with recurring overflow characteristics have a 35\% higher rear-end crash rate than left-turn lanes that do not. Excessive overflow in Yu et al.’s study were determined through field observations.

\subsubsection{Left-Turn Bay Taper Rate}

While it does not appear that any studies have been performed on the effects of taper rate to crash data, there is a correlation between taper rates and overflow that is addressed by Yu et al. (2007).

\subsubsection{Offset Left-Turn Lanes}

Offsetting left-turn lanes lead to an improved line-of-sight. This allows left-turning vehicles to see more of the oncoming through traffic. While common in practice, very little empirical evidence exists on the effects of offsetting turn lanes. One paper by Naik (2005) studied three intersections in Lincoln, Nebraska that have employed offset leftturn lanes. From a nine year before-after case study, it was shown that left-turn related crashes were reduced 1.5\% with the installation of offset left-turn lanes (not statistically significant).

\subsubsection{Right-Turn Lanes}

Right-turn lanes can improve intersection capacity and safety by removing decelerating vehicles from the main travel lanes. Harwood et al. (2000) concluded from an expert panel's engineering judgment that crashes would be reduced 5\% at minor stop-controlled and $2.5 \%$ at signalized intersections when right turn lanes are added on one approach in rural areas. For applications on both approaches, these percentages can be doubled. In another study, Harwood et al. (2002) found that addition of a right-turn lane can reduce crashes by 4-40\% depending on the site. However, Vogt (2008) used a negative binomial model with Minnesota crash data and concluded that at 3-leg intersections the addition of a right-turn lane increased crashes by $27 \%$. Their explanation is that the locations with right-turn lanes have more crashes than the locations without and that the traffic patterns at these locations show high turning movement traffic onto the mainline. Like left-turn lanes, most studies have generic about the presence of a right-turn lane (i.e. whether or not one exists), there are however some additional features that may be considered. These are summarized in the following subsections.

\subsubsection{Type of Right-Turn Treatment}

Bauer and Harwood (1996) found that right-turn channelization resulted in a decrease in both total multiple-vehicle accidents and fatal and injury multiple-vehicle accidents.

\subsubsection{Length of Right-Turn Lanes}

Harwood et al. (2002) collected right turn data because similarly to left-turn bay lengths, sites with inadequate storage will likely experience more rear-end crashes. While that 
study indicates crash reduction using the Empirical Bayes method at four intersections with lengthened left-turn lanes, the data did not exist for sites with lengthened right-turn lanes.

\subsubsection{Curb Return Radius}

The curb return radius is based on functional class. If curb radii are too small, lane encroachments may result in traffic conflicts and increased crash potential. The review did not find studies that directly link changes in curb return radii to crash rates. Curb return radii are especially important for pedestrians and other vulnerable users. Generally smaller radii result in lower turning speeds which is beneficial for pedestrians (FHWA 2000).

\subsubsection{Intersection Skew}

Intersection skew (i.e. intersections that do not intersect at 90 degree angles) are generally thought to present operational and safety related challenges. At skew intersections drivers may have difficulties judging gaps and turning their head for a good field of view. Skewed intersections are generally related to right-angle type crashes associated with limited sight distance (Rodegerdts et al. 2004). In some comparison studies such as Burchett and Maze (2005), a binary value is used to indicate whether or not a skew exists. Other studies (typically ones employing regressions models) use a continuous measurement of the angle of skew. They measure skew as the deviation from 90 degrees of the minor leg in the increasing direction of travel. In instances of two minor legs, the skew is averaged. Vogt and Bared (1998) found that four-leg intersections have fewer crashes when there is no skew.

\subsubsection{Intersection Sight Distance}

There are three measures of sight distance that could possibly affect safety performance at intersections. These are:

- Intersection sight distance,

- Stopping sight distance; and

- $\quad$ Sight distance to traffic control device.

These distances can be measured as compliance with design policy (based on the type of intersection, approach, and turning maneuver). However, determining these data generally requires a field visit with documented procedures. Field-based methods of determining sight distances are tedious. As such, there are a limited number of studies with these data. One study by Smith et al. (2002) used sighting and target rods to determine sight distances that conform to the AASHTO standards. Harwood et al. (2000) determined appropriate accident modification factors (AMFs) from a panel of experts. The AMFs for intersection sight distance at intersections with STOP control on the minor leg (s) are: 
- 1.05 if sight distance is limited in one quadrant of the intersection.

- 1.10 if sight distance is limited in two quadrants of the intersection.

- 1.15 if sight distance is limited in three quadrants of the intersection.

- 1.20 if sight distance is limited in four quadrants of the intersection.

Sight distance in a quadrant is considered limited if the available sight distance is less than the sight distance specified by AASHTO policy for a design speed of $12 \mathrm{mph}$ less than the major road design speed. However, sight distance in this instance can only be considered limited from the roadway alignment or the terrain at two-way STOPcontrolled or YIELD-controlled intersections.

\subsubsection{Median Type}

Knapp and Campbell (2005) found that intersections on divided roadways in Wisconsin have lower crash rates than intersections on undivided roadways. At divided rural intersections there was a crash rate of 0.79 crashes per million entering vehicles (MEV) compared to the undivided rural intersections, which observed a crash rate of 1.01 crashes per MEV. Squires and Parsonson (1989) found that raised medians had lower accident rates for most conditions. They found that approaches with raised medians had crash rates around 40 percent lower than similar intersections with painted medians. Harwood et al. (2002) found that accident frequencies at rural four-leg signalized intersections decrease as median width increases. In contrast, at both signalized and unsignalized intersections in urban and suburban areas, accident frequencies were found to increase with increasing median width.

\subsubsection{Median Width}

Harwood et al. (1995) have shown in urban areas that multiple-vehicle crash frequency increases as median width increases for widths between $14 \mathrm{ft}$ and $80 \mathrm{ft}$, unlike in rural areas where multiple-vehicle crash rates tend to be lower for wider medians.

\subsubsection{Fixed Objects}

The presence of fixed-objects along a roadway can increase crashes, especially on rural high-speed facilities. A study done by Dixon et al. (2008) found that a large number of crashes into fixed objects on urban corridors occurred at intersections. Historically a 1.5 $\mathrm{ft}$ offset between the curb face and fixed objects is used as a minimum to allow for the opening of car doors. The study performed by Dixon et al. (2008) concluded that in an urban setting, fixed objects would ideally be placed a lateral distance of 6 feet from the curb face and that objects within 2 feet would be crashworthy. Ideally fixed object counts should be collected for these two distances.

\subsubsection{Presence of At-Grade Rail Crossing}

One major concern with at-grade rail crossings near intersections is the potential of queues forming which extend into the rail crossing area. This situation is of particular 
concern at signalized intersections or intersections controlled by a STOP sign. Approximately $36 \%$ of all public railroad highway grade crossings have a road intersection within 75 feet (Tustin et al. 1986).

\subsubsection{Presence of Driveways}

Harwood et al. (2002) counted driveways that were within 250 feet of the intersection. Typically, and not surprisingly, roads with low access point densities and with access point management plans have lower crash rates.

\subsubsection{Presence of On-Street Parking}

Harwood et al. (2002) consider parking in the zone of the intersection if it is within 250 feet of the intersection. Cottrell states that the removal of on-street parking increases safety for both automobiles and cyclists (2005). Parking was considered by Carter et al. (2007) in their development of a "Bicycle Intersection Safety Index" as a potential influence on bicycle safety.

\subsubsection{Presence of Sidewalks}

For pedestrians, the presence of sidewalks is considered an important aspect of providing a safe route for non-motorized travel. Currently, minimum sidewalk widths are typically designed to safely accommodate people with disabilities, and to encourage people, especially children, to walk as a social activity. The Oregon DOT recommends that sidewalks have a minimum of 5 feet width; 6 feet is considered standard (ODOT 2007).

\subsubsection{Pedestrian Crossing Features}

One study from Zegeer et al. (2005) concluded that under no condition was the presence of a marked crosswalk at an uncontrolled midblock or intersection location associated with a significantly lower pedestrian crash rate. They also saw that on multilane roads with traffic volumes greater than 12,000 vehicles per day, having a marked crosswalk was associated with a higher pedestrian crash rate. Signage or raised medians were suggested to reduce the potential for crashes at these sites.

\subsubsection{Maximum Number of Lanes Crossed by Pedestrians}

A study from Zegeer et al. (2005) found that crash statistics did not differ significantly on 2-lane streets between marked and unmarked crosswalk sites. Conversely, they found that unmarked crosswalks on streets with more than two lanes were safer than marked crosswalks.

\subsubsection{Distance from Approach Stop Bar to Pedestrian Crossing}

As the stop bar is located further from the intersection right-turn-on-red conflicts are reduced. In essence, more right-turn-on-red vehicles make a complete stop behind the stop line, and the reaction time for drivers in identifying pedestrians is increased as reported by Rodgerts et al. (2004). 


\subsubsection{Width of Pedestrian Refuge}

Zegeer et al. (2004) found that a raised median was associated with a significantly lower pedestrian crash rate at multilane sites with both marked and unmarked crosswalks. The authors only measured median width, not the width of pedestrian refuge.

\subsubsection{Curb Extensions}

In a site specific study in Albany, Oregon, it was found that more frequent yielding behavior from motorists occurred at intersections with curb extensions. Also of benefit to pedestrians are improved sight distance, elimination of exposure to turning vehicles, and shorter crossing distances which result from the installation of curb extensions (Johnson 2005).

\subsubsection{Presence of Bicycle Lane}

Carter et al. (2007) included the presence (or lack of) a bicycle lane and other geometric and operational features in their development of a "Bicycle Intersection Safety Index". Using video, the authors developed a rating system of perception and analysis to index models for through, right turn, and left turning bicycle movements. In their models, they found interactions with presence of a bicycle lane and right turn lanes, as well as, cross street traffic. The research indicated that these factors influenced measured and perceived cyclist safety.

It could be surmised, that there are other features to consider, such as the land and shoulder width and geometric configuration. A wider bicycle lane while advantageous in eliminating sideswipe crashes between cyclists and motorists could potentially increase exposure to pedestrians due to longer crossing distances. Furthermore, bicycle lanes in conjunction with on-street parallel parking may limit sight distance and reduce conspicuity of the bicyclist or pedestrian and increase the potential of obstruction collisions.

\subsubsection{Traffic Control and Operational Elements}

Traffic control devices are instrumental in the effective and efficient operation of our current transportation networks. Different types of traffic control are installed based on a variety of factors, typically using AADT as the primary justification for a particular traffic control mechanism. In addition to traffic control devices, restrictions on particular movements at intersections also have a statistically significant impact on crash frequency at intersections. Traffic control and operational elements typically have shorter functional life spans than geometric features at intersections.

\subsubsection{Uncontrolled}

Poch and Mannering (1996) found that crash frequencies at uncontrolled intersections are lower when compared to signalized intersections. These findings are more likely due to the low volumes and traffic characteristics on roads that have an uncontrolled 
intersection. At unsignalized intersections there are higher percentages of angle and turning crashes and fewer rear-end crashes when compared with signalized intersections (Neuman et al. 2003).

\subsubsection{Yield-Controlled}

Although there is approximately a 3 percent decrease in crashes with the installation of yield signs at intersections, yield-controlled intersections do not appear to have any statistically significant effect on the number of crashes (Elvik and Vaa 2004). In instances where yield signs are installed in two-directions, speeds on the non-yieldcontrolled main road increase while speeds on the yield-controlled road tend to decrease. In instances where STOP signs are replaced with yield signs, the number of injury crashes increases by roughly $40 \%$ and the number of property damage crashes increases by about 15\% (Elvik and Vaa 2004).

\subsubsection{Stop-Controlled}

From a synthesis of previous research done by Elvik and Vaa (2004) it was concluded that adding two-way STOP signs reduces the number of injury crashes by $35 \%$ at fourway junctions and by $20 \%$ at three-way junctions. It was also found that there were no statistically significant measures for property damage only crashes. Lastly, the conclusion was drawn that four-way STOP installations reduce the number of crashes by about $45 \%$.

\subsubsection{Traffic Signal Controlled}

Traffic signal control reduces the total number of crashes by about $30 \%$ at four leg intersections and by 15\% at 3 leg intersections (Elvik and Vaa 2004). However, traffic signals lead to more rear-end incidents, but fewer crashes involving vehicles crossing the intersection. There are many operational strategies related to signalization that traffic engineers have used in efforts to reduce the frequency and severity of collisions. Other elements that may be considered include the number of signal heads per approach and the size of signal heads.

\subsubsection{All Red Clearance Interval}

The red clearance interval is a commonly used optional interval that follows the yellow change interval and precedes the next conflicting green interval. The purpose is to provide additional clearance time and allow time for vehicles that entered the intersection during the yellow-change interval to clear the intersection. Because drivers may not notice the all-red indication, there is a potential for a reduction in crashes by making sure all vehicles have cleared the intersections. Innovative signal detection, such as that implemented in the City of Portland, may allow an all-red phase to be operated only when vehicles are in the intersection. A potential drawback is that all-red clearance intervals can reduce intersection capacity and that routine drivers may become accustomed to the additional clearance time, thereby reducing the potential benefits (Souleyrette et al. 2004; Roper 1991; Retting and Green 1997). 


\subsubsection{Length of Yellow Interval}

A properly timed yellow interval is a key operational component of signalized intersections. Yellow intervals that are too short or too long can lead to signal violations, as drivers develop expectancies of what the yellow interval should be based on past experiences and behave accordingly. In a recent study, researchers at the Insurance Institute for Highway Safety estimated the potential crash effects associated with these modifications, and a modest reduction in injury crashes was observed (Retting et al. 2002).

\subsubsection{Coordination}

The Model Inventory of Roadway Elements (MIRE) specifies a signalization type using the following elements: uncoordinated fixed time (pre-timed), traffic actuated, linear coordination, system coordination, pushbutton-actuated, and other (Council et al. 2007). In addition to improving capacity and traffic flow, good signal coordination can also generate measurable reduction in crash frequency and severity. In a well-progressed system, vehicles travel in platoons that are generally not required to stop at a series of traffic signals. This can potentially reduce rear-end crashes that are related to stopping at traffic signals. In addition, for pedestrians and vehicles at minor street unsignalized intersections, progression generally creates more and longer gaps in the traffic stream, which can reduce crashes contributed to by poor gap acceptance. This increased gap allows for increased distance and opportunity to make turning and crossing movements, resulting in less risk taking behavior and crash frequency (Zador et al. 1984).

\subsubsection{Type of Left-Turn Phasing}

Hauer (2004) performed an exhaustive literature review on the effects of having protected, permissive, protected-permissive, or permissive-protected left-turn signalization at a particular intersection. Hauer concluded (with relative statistical certainty) that changing from permissive (and permissive-protected and protectedpermissive) to protected signalization will reduce left-turn crashes by $70 \%$. All other changes to left-turn signalization have led to mixed results in studies so no conclusive results are reported here. Antonucci et al. (2004) and Hauer (2004) both conclude that implementations of "leading" left-turns or "lagging" left-turns have not lead to conclusive results as to which provides more in terms of reduced collision frequency.

\subsubsection{Right-Turn Phase Overlap}

The right turn arrow overlap provides an opportunity for vehicles turning right to perform right-turn maneuvers during amber, all-red, or cross traffic signal phases. These are sometimes coupled with channelized turn lanes, no u-turn for cross traffic prohibitions, or flashing yellow signals in the cross-traffic permissive U-turn (and left turn) opposing maneuvers. No studies could be identified which found significant reduced crash experience from the right-turn arrow overlap. 


\subsubsection{Right-Turn on Red (RTOR) Restrictions}

In 1975 the U.S. federal government passed an act encouraging states to develop an energy conservation plan to qualify for federal funding. Allowing the right-turn-on-red maneuver was one of the ways for states to conserve energy. By 1980 all 50 states had adopted and legalized this maneuver. In a report to Congress as required by the Energy Policy Act of 1992, the Office of Traffic Safety Programs at the National Highway Traffic Safety Administration (1995) argues that since the number of crashes due to RTOR is very small, the impact on traffic safety has also been negligible. However, when RTOR crashes do occur, a pedestrian or bicyclist is frequently involved. They also made the case that it is hard to separate crash data from the vehicles that made a rightturn on red and those that only made a right-turn unless the crash data delineates these two behaviors (theirs did not). Typically RTOR restrictions are put in place when there are sight distance issues, geometries or operational characteristics that would lead to unexpected conflicts, an exclusive pedestrian phase, high pedestrian volumes, or a high number of right-turn-on-red crashes (Zeeger 1985).

\subsubsection{Left-Turn Prohibitions}

Intuitively, having a left-turn prohibition at an intersection reduces the number of potential conflicts. There are multiple papers that evaluate the crash impacts realized from replacing left-turns with a right-turn and u-turn combination. One such paper from Gluck shows that at driveways, the elimination of direct left-turns and the replacement with U-turns leads to a 20 percent crash rate reduction (Gluck et al. 1999).

\subsubsection{U-Turn Prohibitions}

The Oregon motor vehicle code requires signs posting for legal U-turns (unlike other states where U-turns are legal unless prohibited). Most of the more recent studies performed with regards to U-turns deal with implementation at unsignalized median openings. It is known that U-turns at signalized intersections on major arterials tend to degrade the level of service due to conflicts with right-turning vehicles. One limited study was performed by Brich and Cottrell Jr. (1994) that showed that having restricted U-turn and/or left-turn signage led to a $63 \%$ crash rate reduction for the particular restricted movement.

\subsubsection{Presence of Advance Warning Signs}

Dynamic advance warning flashers are used to notify approaching motorists of an impending traffic signal change (from green to red) ahead. These signs are interconnected with the downstream traffic signal and inform drivers of its status by showing yellow flashing lights or with a changeable message sign. These are typically used on high-speed approaches to an isolated traffic signal where visibility of the signal may be somewhat limited. It is clearly important to time the warning such that it does not encourage drivers to accelerate to the traffic signal to avoid being stopped. The introduction of advance-warning flashers on the approaches to a signalized intersection 
appears to be associated with a reduction in right-angle collisions (Sayed 1999; Box and Gibby et al. 1992).

\subsubsection{Presence of Lighting}

For intersections (especially rural) the addition of lighting is thought to improve safety performance. In a six year before-after study, it was shown that at 47 intersections had a statistically significant 49 percent reduction in night crashes after the installation of lighting (Walker and Roberts, 1976). A meta-analysis of 37 domestic and international studies including the Walker study came to the conclusion that lighting reduces fatal, injury, and property-damage only crashes by 65, 30, and 15 percent respectively (Elvik 2004). The meta-analysis also states that road lighting has a greater effect on pedestrian accidents and a greater effect at intersections.

\subsubsection{Presence of Automated Red-Light Running Enforcement}

Council et al. (2004) perform a study in seven jurisdictions on the impacts of red-light cameras with respect to safety. They show that total right-angle crashes decrease by $24.6 \%$ and total rear-end crashes increase by $14.9 \%$ where red-light cameras are used. A worldwide evaluation of automated enforcement found similar decreases in right-angle crashes and increases in rear-end crashes across the board (Decina 2007). Furthermore the worldwide study found that crash severity was reduced at sites with installed automated red light running enforcement.

\subsubsection{Pavement Friction}

On all roadway sections, the available stopping distance is also influenced by the amount of tire-pavement friction present. The friction provided by the tire-pavement interaction is most heavily influenced by vehicle speed. However, other factors, including pavement age and structural condition, traffic volume, road surface type and texture, aggregates used, pavement mix characteristics, tire conditions, and presence of surface water can contribute to skid resistance. A vehicle will lose traction when the required frictional force to maintain the travel direction exceeds the available friction at the tire-pavement interface. This can happen on dry pavement at high speeds but is more common on wet pavement where a small amount of water can significantly reduce pavement surface friction (Dahir 1990; Bray 2003; Hanley et al. 2000).

\subsubsection{Condition of Pavement Markings}

While there is a general consensus that degraded marking conditions may impact safety, previous research has not shown any relationships (Debaillon et al. 2007). The studies that do exist typically try to quantify crash rates using before/after studies and do not collect data measuring pavement marking conditions over time prior to restriping operations. A study by Bahar et al. showed that the intensity of pavement markings at non-intersection locations on California highways beyond minimum standards have no effect on safety (Bahar et al. 2006). While intersection marking retroreflectivity may prove important for safety, no information could be found specifically regarding 
intersections. Retroreflectivity data will not be collected since other crosswalk conditions such as lighted beacons will have more of an impact on crash statistics.

\subsubsection{Presence of Transverse Rumble Strips}

While transverse rumble strips have proven effective in alerting drivers to slow, there are not conclusive studies suggesting their ability to reduce crashes at intersections. This geometrical feature is included in the MIRE (Council et al. 2007).

\subsubsection{Exposure}

The amount of exposure at a particular intersection has a strong correlation with its observed safety performance. This section summarizes the primarily measures of exposure and how other studies have collected this data. The following identifies some potential data elements.

\subsubsection{Average Annual Daily Traffic (AADT)}

Poch and Mannering (1996) gathered afternoon peak period and midday traffic volumes in Bellevue, WA and converted the data to daily counts using standard expansion formulas. Where data were missing, they used yearly expansion figures to fill in gaps. There are numerous studies showing that approach traffic volumes have a strong relationship to intersection crashes. Bauer and Harwood (1996) put a high importance on having both major and minor road AADTs. They contend that the variability in crash data is primarily explained by AADT.

\subsubsection{Peak Hour Approach Volumes}

Peak hour approach volumes could prove useful for an intersection with a majority of crashes during a peak or off-peak period. Unfortunately, these data are not often collected in any routine or consistent format.

\subsubsection{Turning Movement Volumes}

In a study by Kweon (2007) in northern Virginia, hourly traffic volume data by turning movement and left-turn signal phase data were extracted from Synchro files obtained from VDOT. Turning movements are important data to collect because there are relationships between crash frequency for a specific crash types and the turning movement volumes most related to that crash type. These data are generally difficult to obtain.

\subsubsection{Traffic Composition (Percent Trucks)}

No studies were found on the effects of safety at intersections with regards to the vehicle compositions. 


\subsubsection{Average Approach Speed}

There is a direct link between speed and crash severity, with crash severity increasing with increased speeds. One of the major crash related concerns associated with approach speeds are differentials in speed between traffic flows. Higher travel speed increases reaction/response distance yet there is not conclusive research around intersections that shows an influence of approach speed on crash frequency. Actual speed data are challenging to obtain, most often posted speed is used as a surrogate measure.

\subsubsection{Bicycle Volumes}

If motor vehicle volumes can be considered difficult to obtain, bicycle and pedestrian volumes are even more challenging. Allen et al. (1998) suggest that bicyclists (and pedestrians) per hour of green is a better measurement than bicycles per hour. The volumes in the Allen study were obtained through videotape.

\subsubsection{Pedestrian Volumes}

The Zegeer et al. (2005) study used collected pedestrian data at 2000 sites. They collected data for 1 hour at minimum at all locations. Sample sites were used for collecting full-day data to develop scaling factors for the other collected data. At many local and state jurisdictions, pedestrian counts are very difficult to obtain and rarely done systematically.

\subsubsection{Other}

\subsubsection{Weather}

There are not studies that quantify the effects of rain, snow, fog, or sleet at intersections. It is possible because the weather is very complicated and difficult to extrapolate from weather station information. For example, rain could cause a lack of visibility, lack of stopping friction (especially if the rain occurs after a dry period). Vogt and Bared (1998) attempted to collect weather data for their model, however, the data were not sufficiently local for use.

\subsubsection{Land Use Characteristics}

One of the most common classifications is the urban, suburban, and rural definitions. In the Knapp and Campbell (2005) study, one of their major classifications was between urban and rural intersections. It is expected that traffic classifications, road users, road characteristics, and driver expectations vary between rural and urban sites. This definition can be determined spatially. Specific land-use types such as the presence of bus stops and presence of schools do may also be considered. 


\subsection{PART 2: ESTIMATING SAFETY PERFORMANCE}

In Part 2, statistical summaries, methods for pattern diagnostics and modeling the safety performance at intersections are reviewed.

\subsubsection{Crash Rates}

At the most basic level of intersection safety performance, the establishment of long-term averages for specific facility types or average can be a useful measure. These data can be summarized by a number of intersectional features (e.g. signalized or unsignalized, three-leg or four) and/or locations (e.g. urban or rural). Surprisingly, these basic summaries of intersection performance are rarely calculated.

In the published literature, three statewide summaries of intersection performance were identified (Wisconsin, Kentucky, Utah). One such study was performed by Knapp and Campbell (2005) in Wisconsin using three years of crash data from 2001 to 2003, exploring more than 33,000 crashes at 1,700 intersections. Both rural intersections with three or more crashes per year and urban intersections with five or more crashes per year were used in their study.

The authors collected the number of approach legs, type of traffic control, presence of a median, number of major roadway lanes, the existence of left turn lane, and entering volumes for each intersection on the Wisconsin highway system. They then grouped each intersection into one of 18 general intersection geometric categories. Two examples of these intersection geometric categories are three-leg two-lane major roadway with no left-turn lane and four-leg four-lane major divided 55+ mph roadway with signal or dual left-turn. These categories were made to simplify comparisons with crash data. Samples of their results are presented in Table 2.2, Table 2.3, and Table 2.4. In their study, they were able to compare rural to urban crash rates and found that they are both comparable at 0.94 and 0.96 crashes per million entering vehicles respectively. They also compared intersection by type, number of lanes on the major roadway, median presence, and left-turn lane presence.

Table 2.2: Rural and Urban Intersection Average Crash Frequencies and Rate, Wisconsin

\begin{tabular}{l|c|c|c|c}
\cline { 2 - 4 } & $\begin{array}{c}\text { Average Annual Crash } \\
\text { Frequency (Crashes per Year) }\end{array}$ & $\begin{array}{c}\text { Crash Rate } \\
\text { (per Million Entering Vehicles) }\end{array}$ \\
\cline { 2 - 5 } & Rural & Urban & Rural & Urban \\
\hline All Intersections & 3.58 & 7.87 & 0.94 & 0.96 \\
\hline Intersections by Traffic Control & \multicolumn{3}{c}{0.88} & 1.00 \\
\hline Signal & 6.43 & 9.60 & 0.96 & 0.88 \\
\hline Through-Stop & 2.90 & 4.98 & 0.88 & 1.02 \\
\hline Four-Way Stop & 3.09 & 4.40 & 1.00 & 1.33 \\
\hline Intersections by Annual Average Dailv Entering Volume (Vehicles) \\
\hline$<15,000$ & 2.80 & 5.03 & 0.74 & 0.87 \\
\hline 15,000 to 25,000 & 5.03 & 6.16 & 0.77 & 0.82 \\
\hline$>25,000$ & 9.77 & 11.24 & \multicolumn{3}{c}{} \\
\hline
\end{tabular}

${ }^{1}$ Use urban values with caution due to small sample size.

Source: Knapp and Campbell (2005) 
Table 2.3: Rural Intersection Geometry and Crash Rate, Wisconsin

\section{Crash Rate}

(per Million Entering Vehicles)

\begin{tabular}{|c|c|c|c|c|c|c|c|}
\hline Category & $\begin{array}{c}\begin{array}{c}\text { Number } \\
\text { of } \\
\text { Intersections }\end{array} \\
\end{array}$ & $\begin{array}{c}\text { Number } \\
\text { of } \\
\text { Crashes }\end{array}$ & Avg. & Min. & Max. & $\begin{array}{l}\text { Std } \\
\text { Dev. }\end{array}$ & $\begin{array}{c}\mathbf{8 5}^{\text {th }} \\
\text { Percentile } \\
\text { (Approx.) }\end{array}$ \\
\hline \multicolumn{8}{|c|}{ Rural Intersections by Number of Approach Legs } \\
\hline Three-Leg & 69 & 588 & 0.86 & 0.22 & 4.10 & 0.55 & 1.4 \\
\hline Four-Leg & 281 & 3,858 & 0.99 & 0.28 & 3.46 & 0.54 & 1.2 \\
\hline \multicolumn{8}{|c|}{ Rural Intersections by Number of Major Roadway Lanes } \\
\hline Two-Lane & 221 & 2,310 & 1.02 & 0.29 & 4.10 & 0.56 & 1.5 \\
\hline Four-Lane & 136 & 2,272 & 0.86 & 0.22 & 3.26 & 0.47 & 1.3 \\
\hline \multicolumn{8}{|c|}{ Rural Intersections by Median Existence } \\
\hline Undivided & 247 & 2,683 & 1.00 & 0.22 & 4.10 & 0.56 & 1.5 \\
\hline Divided & 110 & 1,899 & 0.87 & 0.28 & 3.26 & 0.47 & 1.2 \\
\hline \multicolumn{8}{|c|}{ Rural Intersections by Left-Turn Lane Existence } \\
\hline Left-Turn Lane & 222 & 3,195 & 0.91 & 0.28 & 3.26 & 0.45 & 1.4 \\
\hline No Left-Turn Lane & 135 & 1,387 & 1.05 & 0.22 & 4.10 & 0.64 & 1.5 \\
\hline
\end{tabular}

185 percent of the database rural intersections have a safety measure at or below this level.

Source: Knapp and Campbell (2005)

Table 2.4: Urban Intersection Geometry and Crash Rate, Wisconsin

\section{Crash Rate}

(per Million Entering Vehicles)

\begin{tabular}{l|c|c|c|c|c|c|c}
\hline & $\begin{array}{c}\text { Number } \\
\text { of } \\
\text { Intersections }\end{array}$ & $\begin{array}{c}\text { Number } \\
\text { of } \\
\text { Crashes }\end{array}$ & Avg. & Min. & Max. & $\begin{array}{c}\text { Std } \\
\text { Dev. }\end{array}$ & $\begin{array}{c}\mathbf{8 5}^{\text {th }} \\
\text { (Approntile } \\
\text { (Aprox.) }\end{array}$ \\
\hline
\end{tabular}

Urban Intersections by Number of Approach Legs

\begin{tabular}{l|c|c|c|c|c|c|c}
\hline Three-Leg & 90 & 1,681 & 0.80 & 0.23 & 3.46 & 0.50 & 1.1 \\
\hline Four-Leg & 650 & 18,371 & 0.98 & 0.17 & 6.85 & 0.55 & 1.4 \\
\hline
\end{tabular}

Urban Intersections by Number of Major Roadway Lanes

\begin{tabular}{l|c|c|c|c|c|c|c}
\hline Two-Lane & 134 & 2,341 & 1.07 & 0.30 & 6.85 & 0.74 & 1.5 \\
\hline Four-Lane & 647 & 18,747 & 0.94 & 0.17 & 4.15 & 0.50 & 1.4 \\
\hline
\end{tabular}

Urban Intersections by Median Existence

\begin{tabular}{l|c|c|c|c|c|c|c}
\hline Undivided & 279 & 5,470 & 1.07 & 0.30 & 6.85 & 0.65 & 1.5 \\
\hline Divided & 502 & 15,618 & 0.90 & 0.17 & 4.15 & 0.48 & 1.4 \\
\hline
\end{tabular}

185 percent of the database urban intersections have a safety measure at or below this level.

Source: Knapp and Campbell (2005)

Green and Agent (2003) updated earlier work by Agent and Pigman (1993). They developed crash rates for 7,097 intersections involving two or more state maintained roadways. They extensively used GIS software to solve challenges relating to crash and traffic volumes. While their approach was specific to Kentucky, there are some helpful methodologies presented. To help solve the duplicate intersection identification common in crash databases, they attempted to establish the latitude and longitude of each intersection. Scripts were also written using spatial joins to establish entering volumes which allowed them to process a significant amount of data 
easily. As shown in Table 2.5, the average crash rates calculated for Kentucky are much lower than what have been reported for Wisconsin.

Cottrell and Mu (2005) developed intersection crash rates for the Utah DOT for the purposes of network screening. They used a ten years (1994-2003) and three years (2001-2003) of crash data. However, they did not classify intersections by any distinguishing geometrical or operational feature other than DOT district. Pant and Kashayi (2007) took the approach of developing "base crash rates" for the Ohio DOT using Automatic Interaction Detection (AID) and stepwise multiple regression technique. Rather than develop average rates, they developed models for eight intersection types.

Table 2.5: Summary of Intersection Crashes and Rates, Kentucky

\begin{tabular}{|c|c|c|c|c|c|}
\hline \multicolumn{2}{|c|}{ Highway Type } & $\begin{array}{c}\text { Number of } \\
\text { Crashes }\end{array}$ & $\begin{array}{l}\text { Number of } \\
\text { Intersections }\end{array}$ & $\begin{array}{c}\text { Number of } \\
\text { Intersections } \\
\text { with a } \\
\text { CRF = } 1\end{array}$ & $\begin{array}{c}\text { Average } \\
\text { Crash Rate } \\
\text { (C/MV) }\end{array}$ \\
\hline \multirow[t]{4}{*}{ Rural } & Two-Lane & 7,800 & 2,489 & 266 & 0.31 \\
\hline & Three-Lane & 54 & 9 & 2 & 0.31 \\
\hline & Four-lane Divided & 350 & 67 & 8 & 0.26 \\
\hline & Four-lane Undivided & 100 & 13 & 2 & 0.37 \\
\hline \multirow[t]{4}{*}{ Urban } & Two-Lane & 6,589 & 762 & 105 & 0.43 \\
\hline & Three-Lane & 465 & 31 & 7 & 0.51 \\
\hline & Four-lane Divided & 1,689 & 102 & 19 & 0.43 \\
\hline & Four-lane Undivided & 1,731 & 3,624 & 19 & 0.57 \\
\hline
\end{tabular}

Source: Green and Agent (2003)

There are a handful of older studies that have done similar summaries. In a study by Hanna et al. (1976), 300 intersections in 42 rural Virginia cities (population average of 15,000) were analyzed and the crash rates for various intersection geometries were reported. A total of 2,300 crashes from 24 months (1969-1973) were considered. No data was presented on the operating speeds, volumes, or type of stop control (two-way, three-way, four-way). A roundabouts brochure by Leif Ourston includes 1989 crash data from California state highways (Ourston 2001). Crash rates were reported for rural, suburban, urban 4-way and T-intersections. Ogden presents fatality rates presented by Barton from research in Australia (Ogden 1996) that are shown in Table 1. Again, T-intersections have lower rates. All of these studies are summarized in Table 2.6.

Table 2.6: Crash Rates Intersections from Older Studies

\begin{tabular}{cccccccc}
\hline \multirow{2}{*}{$\begin{array}{c}\text { Intersection } \\
\text { Type }\end{array}$} & Traffic Control & $\begin{array}{c}\text { Hanna et al. } \\
\text { (Rural City) }\end{array}$ & $\begin{array}{c}\text { CalTrans } \\
\text { (Suburban) }\end{array}$ & $\begin{array}{c}\text { CalTrans } \\
\text { (Urban) }\end{array}$ & $\begin{array}{c}\text { CalTrans } \\
\text { (Rural) }\end{array}$ & $\begin{array}{c}\text { Barton } \\
\text { (Rural) }\end{array}$ & $\begin{array}{c}\text { Barton } \\
\text { (Urban) }\end{array}$ \\
\hline \multirow{nyyyyyyy}{*}{ 4-Way Cross } & Signalized & 1.47 & 0.77 & 0.54 & 0.98 & $2.5^{1}$ & 1.7 \\
& Stop or Yield & 1.27 & 0.42 & 0.32 & 0.40 & 5.2 & 2.4 \\
\hline T-intersection & Signalized & 0.82 & 0.47 & 0.37 & 0.49 & $2.1^{1}$ & 1.4 \\
& Stop or Yield & 0.79 & 0.26 & 0.17 & 0.26 & 3.3 & 1.5 \\
\hline
\end{tabular}

Notes: ${ }^{1}$ High speed 
There are likely such summaries tabulated at other state and local levels that are not easily accessible in the literature. As an example, the authors have obtained an unpublished, internal Oregon DOT memorandum dated Sept 2, 1994 (TRA-03-01) by Eric Bonn that summarized average intersection crash rates in Oregon (Bonn 1994). A total of 413 intersections - consisting of the intersection of two state highways and those where recent manual counts had been conducted - were used to develop these rates. A number of variables affecting intersection crash performance were considered but due to data limitations only data on road character (urban/rural and functional class), number of legs, direction of travel, signalization, and ADT were collected. Using these data, average crash rates by these aggregations were prepared. For each of the categories, Bonn calculated the average crash rate, the $95^{\text {th }}$ percentile confidence interval and the "Top $10 \%$ Cut-off" (i.e. the $90^{\text {th }}$ percentile rate, of which only $10 \%$ of the sample exceed). Using this value, Bonn commented that the commonly cited rule-of-thumb 1.0 crashes/MEV for Oregon intersections appears reasonable. Bonn recommended a larger data set to allow more factors to be considered. It does not appear that these rates have been updated.

Table 2.7: Average Intersection Crash Rates (Oregon 1994)

\begin{tabular}{||c|r|r|r|r||}
\hline \multicolumn{5}{||c|}{ BY RURALURBN AND SIGNALIZEDIUNSIGNALIZED } \\
\hline \hline Classification & $\begin{array}{c}\text { Number of } \\
\text { Intersections }\end{array}$ & $\begin{array}{c}\text { Average } \\
\text { Rate }\end{array}$ & $\begin{array}{c}95 \% \\
\text { Confidence } \\
\text { Interval }\end{array}$ & $\begin{array}{c}\text { Top- } \\
10 \% \\
\text { Cut-Off }\end{array}$ \\
\hline Total & 413 & 0.34 & \pm 0.05 & 0.98 \\
Signalized & 128 & 0.40 & \pm 0.06 & 0.81 \\
Unsignalized & 285 & 0.31 & \pm 0.07 & 1.03 \\
Beacon & 44 & 0.45 & \pm 0.19 & 1.24 \\
\hline Total Urban & 171 & 0.34 & \pm 0.05 & 0.75 \\
Signalized & 98 & 0.40 & \pm 0.06 & 0.80 \\
Unsignalized & 73 & 0.27 & \pm 0.07 & 0.68 \\
\hline Total Rural & & & & \\
Signalized & 242 & 0.34 & \pm 0.08 & 1.11 \\
Unsignalized & 30 & 0.42 & \pm 0.13 & 0.89 \\
\hline \hline
\end{tabular}

\begin{tabular}{||l|r|r|r|r||}
\hline \multicolumn{5}{|c|}{ BY HIGHWAY LEVEL OF IMPORTANCE } \\
\hline \hline Classification & $\begin{array}{c}\text { Number of } \\
\text { Intersections }\end{array}$ & $\begin{array}{c}\text { Average } \\
\text { Rate }^{*}\end{array}$ & $\begin{array}{c}95 \% \\
\text { Confidence } \\
\text { Interval }\end{array}$ & $\begin{array}{c}\text { Top- } \\
10 \% \\
\text { Cut-Off }\end{array}$ \\
\hline Total & 413 & 0.34 & \pm 0.05 & 0.98 \\
\hline Access & 100 & 0.31 & \pm 0.06 & 0.71 \\
Oregon & 109 & 0.26 & \pm 0.06 & 0.65 \\
Statewide & 70 & 0.39 & \pm 0.14 & 1.17 \\
Regional & 134 & 0.40 & \pm 0.11 & 1.25 \\
Districtwide & & & & \\
\hline
\end{tabular}

Source: Bonn 1994 (unpublished internal Oregon DOT memorandum) * Accidents per million entering vehicles 
Indeed, a limited internet search identified some additional summaries published by state DOTs (though this should not be considered complete or comprehensive). MassHighway provides average intersection crash rates by district as shown in Table 2.8. These rates are "obtained from crash rate worksheets that have been submitted to MassHighway as part of the review process for an Environmental Impact Report or Functional Design Report”. In effect, the published intersection crash rates are derived only from those locations being considered for improvement (which biases the sample).

Table 2.8: Average Crash Rates Intersection - Crashes Per Million Entering Vehicles (Massachusetts)

\begin{tabular}{l|c|c}
\hline \multicolumn{1}{c|}{ Location } & Signalized Intersections & Unsignalized Intersections \\
\hline Statewide & 0.80 & 0.60 \\
\hline District 1* & $0.92 *$ & $0.40 *$ \\
\hline District 2 & 0.85 & 0.67 \\
\hline District 3 & 0.87 & 0.69 \\
\hline District 4 & 0.78 & 0.58 \\
\hline District 5 & 0.75 & 0.58 \\
\hline
\end{tabular}

* - District 1 should use Statewide Rates due to low sample total

Source: http://www.mhd.state.ma.us/default.asp?pgid=content/traffic/crashRateInfo\&sid=about

The Iowa DOT published an intersection crash rate summary by intersection class and traffic volume. The summary published on their website is out-of-date since it is based on 1983-1987 data. These rates are shown in Table 2.9.

Table 2.9: Accident and Related Data for Rural and Municipal Intersections in Iowa (1983-1987) BY INTERSECTION CLASS

\begin{tabular}{|c|c|c|c|c|c|c|c|c|}
\hline \multirow[b]{2}{*}{ Field Description } & \multicolumn{4}{|c|}{ RURAL } & \multicolumn{4}{|c|}{ MUNICIPAL } \\
\hline & $\begin{array}{c}\text { Primary } \\
\text { with } \\
\text { Primary }\end{array}$ & $\begin{array}{l}\text { Primary } \\
\text { with } \\
\text { Secondary }\end{array}$ & $\begin{array}{l}\text { Secondary } \\
\text { with } \\
\text { Secondary }\end{array}$ & $\begin{array}{l}\text { Total } \\
\text { Rural }\end{array}$ & $\begin{array}{l}\text { Primary } \\
\text { with } \\
\text { Primary }\end{array}$ & $\begin{array}{c}\text { Primary } \\
\text { with } \\
\text { City Street }\end{array}$ & $\begin{array}{l}\text { City Street } \\
\text { with } \\
\text { City Street }\end{array}$ & $\begin{array}{c}\text { Total } \\
\text { Municipal }\end{array}$ \\
\hline Number of Intersections & 93 & 345 & 134 & 572 & 162 & 1,129 & 1,553 & 2,844 \\
\hline Average Number of Accidents / Year & 1.6 & 1.1 & 0.8 & 1.1 & 4.8 & 4.1 & 3.0 & 3.6 \\
\hline Average Dollar Loss / Year * & $\$ 52,200$ & $\$ 44,200$ & $\$ 37,300$ & $\$ 43,900$ & $\$ 53,800$ & $\$ 43,100$ & $\$ 26,800$ & $\$ 34,800$ \\
\hline Average Daily Entering Vehicles & 4,500 & 4,000 & 2,200 & 3,600 & 12,800 & 12,800 & 10,500 & 11,500 \\
\hline Average Accident Rate / MEV & 1.0 & 0.8 & 1.0 & 0.9 & 1.0 & 0.9 & 0.8 & 0.8 \\
\hline $\begin{array}{l}\text { Lower Limits of Statistical Rates } \\
90 \% \text { Confidence Level }(\mathrm{K}=1.282)\end{array}$ & 1.9 & 1.8 & 2.8 & 2.1 & 1.7 & 1.6 & 1.6 & 1.6 \\
\hline $95 \%$ Confidence Level $(K=1.645)$ & 2.1 & 2.0 & 3.2 & 2.4 & 1.9 & 1.8 & 1.8 & 1.8 \\
\hline $99.5 \%$ Confidence Level $(K=2.576)$ & 2.8 & 2.7 & 4.1 & 3.2 & 2.4 & 2.3 & 2.4 & 2.4 \\
\hline
\end{tabular}

BY TRAFFIC VOLUME CLASS

\begin{tabular}{|c|c|c|c|c|c|c|c|c|c|c|c|c|}
\hline \multirow[b]{2}{*}{ Field Description } & \multicolumn{6}{|c|}{ RURAL } & \multicolumn{6}{|c|}{ MUNICIPAL } \\
\hline & $\begin{array}{c}1 \\
- \\
999\end{array}$ & $\begin{array}{c}1,000 \\
- \\
2,499\end{array}$ & $\begin{array}{c}2,500 \\
- \\
4,999\end{array}$ & $\begin{array}{l}5,000 \\
- \\
9,999\end{array}$ & $\begin{array}{l}10,000 \\
\& \\
\text { Over }\end{array}$ & $\begin{array}{l}\text { Total } \\
\text { Rural }\end{array}$ & $\begin{array}{c}1 \\
- \\
2,499\end{array}$ & $\begin{array}{c}2,500 \\
- \\
4,999\end{array}$ & $\begin{array}{c}5,000 \\
- \\
9,999\end{array}$ & $\begin{array}{c}10,000 \\
- \\
24,999\end{array}$ & $\begin{array}{l}25,000 \\
\& \\
\text { Over }\end{array}$ & $\begin{array}{c}\text { Total } \\
\text { Municip. }\end{array}$ \\
\hline Number of Intersections & 68 & 191 & 191 & 97 & 25 & 572 & 85 & 363 & 988 & 1,238 & 170 & 2,844 \\
\hline Average Number of Accidents / Year & 0.5 & 0.8 & 1.1 & 1.7 & 3.8 & 1.1 & 0.9 & 1.5 & 2.0 & 4.6 & 10.6 & 3.6 \\
\hline Average Dollar Loss / Year * & $\$ 46,400$ & $\$ 38,200$ & $\$ 43,700$ & $\$ 47,600$ & $\$ 67,100$ & $\$ 43,900$ & $\$ 20,600$ & $\$ 20,500$ & $\$ 20,100$ & $\$ 43,500$ & $\$ 94,700$ & $\$ 34,800$ \\
\hline Average Daily Entering Vehicles & 650 & 1,750 & 3,600 & 6,750 & 14,500 & 3,650 & 1,900 & 3,900 & 7,450 & 15,050 & 30,450 & 11,500 \\
\hline Average Accident Rate / MEV & 2.1 & 1.2 & 0.9 & 0.7 & 0.7 & 0.9 & 1.3 & 1.0 & 0.7 & 0.8 & 1.0 & 0.8 \\
\hline Lower Limits of Statistical Rates & & & & & & & & & & & & \\
\hline $90 \%$ Confidence Level $(K=1.282)$ & 3.7 & 2.1 & 1.4 & 1.3 & 1.3 & 2.1 & 2.9 & 1.9 & 1.4 & 1.5 & 1.6 & 1.6 \\
\hline 95\% Confidence Level $(K=1.645)$ & 4.1 & 2.4 & 1.6 & 1.5 & 1.5 & 2.4 & 3.3 & 2.2 & 1.6 & 1.7 & 1.8 & 1.8 \\
\hline $99.5 \%$ Confidence Level $(K=2.576)$ & 5.2 & 3.0 & 2.0 & 1.9 & 1.9 & 3.2 & 4.3 & 2.8 & 2.1 & 2.2 & 2.2 & 2.4 \\
\hline 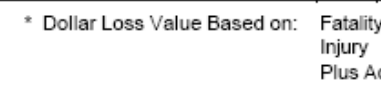 & $\begin{array}{r}y-\$ 435,0 \\
-\$ 15,00 \\
\text { ctual Prop }\end{array}$ & erty Dama & & & & & & & $\begin{array}{l}\text { Bureau } \\
\text { lowa De } \\
\text { Prepare }\end{array}$ & $\begin{array}{l}\text { rtment of } \\
\text { lanuary, } 1\end{array}$ & $\begin{array}{l}\text { Transpo } \\
989\end{array}$ & ion \\
\hline
\end{tabular}

Source: http://www.iowadot.gov/crashanalysis/pdfs/average_intersection_crash_rates_1989.pdf 


\subsubsection{Crash Proportions, Direct Diagnostics and Pattern Recognition}

As an alternative to crash prediction models (described in the next section) for screening and diagnostics, there is a body of work that has documented the usefulness of testing for either excess proportions or searching for a pattern of excess proportions. All of the methods require some established baseline of the typical or long-run average proportions of crash types, severities, or other parameters for a specific set of facility types.

The excess proportions method was first proposed by Heydecker and Wu (1991) and demonstrated in a recent paper by Lyon et al. (2007). This method is also available in SafetyAnalyst software and is documented as a potential screening method in the Highway Safety Manual (AASHTO 2010). The method essentially tests if there is an "unusually high proportion of a specific accident type". The method requires establishing a limiting proportion from the representative sample then calculating the probability that the observed proportion exceeds the sample proportion based on a betanormal distribution. The sample variance (of the representative locations) and two parameters $\alpha$ and $\beta$ are required to use the method which is straightforward once the representative sample proportions have been identified. For example, if the proportion of interest is rear-end collision and urban, signalized, 4-leg intersections the first step would be to identify the representative sample of crash patterns at these location. Once these have been identified, the probability can easily be calculated.

Kononov and Janson (2003) identified crash trends at intersections on rural and urban Colorado highways using a method that they refer to as “direct diagnostics". They argue that an overrepresentation of one kind of crash relative to other kinds may be a better indicator of susceptibility to targeted countermeasures than a high frequency relative to other locations. Diagnostics techniques are compared to a medical doctor determining what ails a patient. It also has the benefit of producing strong indicators without requiring a comprehensive set of traffic counts. For example, a high proportion of speed-related crashes relative to other causes at an intersection could indicate that the site is a good candidate for speed camera deployment. This diagnostic assessment requires the development of proportions that could be considered normal for streets of similar characteristics.

The method calculates the probability that an observed percentage of a crash classification will exceed the average percentage distribution for a similar facility. For example, say there have been 20 rear-end crashes out of 61 total crashes observed at a location that is a rural principal arterial. The question to be asked is: Is it "normal" to have 32.8\% (20/61) of the total crashes be rear-end? Using the method described by Kononov and Janson (2003), the probability that this proportion is "typical" can be calculated assuming crashes are Bernoulli trials with the following formula:

$$
P(X \geq x)=1-\sum_{i=0}^{x-1} \frac{n !}{(n-i) ! i !} p^{i}\left(1-p_{i}\right)^{n-i} \text {, where }
$$

$\mathrm{x}=$ the observed count of the crash type to test

$\mathrm{n}=$ total number of crash types at the location

$\mathrm{p}=$ the expected proportion of the crash types 
In the above example, the observed percentage is 32.8\% (20/61). All rural principal arterials had $18.9 \%$ rear-end crashes. Thus the calculation determines how likely is $32.8 \%$ rear-end crashes if the average of all rural principal arterials is $18.9 \%$. Using the formula, the probability of observing these 20/61 rear-ends crashes at a "normal” rural principal arterial section is:

$$
P(X \geq x)=1-\sum_{i=0}^{20-1} \frac{61 !}{(61-i) ! i !} 0.189^{i}(1-0.189)^{61-i}=0.007 \text {, or } 0.7 \%
$$

In other words, there is a very small chance that this proportion, 20/61, would be observed at a "typical” location and so this value (32.8\%) is considered unusual. The most important task in applying the methodology is creating and identifying the diagnostic norms. While not mentioned in the paper, other discussions with the author indicate that a relatively long time period and large sample has been used to identify these diagnostic norms. Normal proportions were calculated for roads with similar qualities in the following categories: urban/rural, number of lanes, divided/undivided, signalized/unsignalized.

\subsubsection{Safety Prediction Models for Intersections}

Safety prediction efforts at the intersection level are quite limited. This fact is a result of the high costs associated with data collection and the limited availability of data across multiple time periods. Predictive crash models are regression models that are used to estimate the frequency of crashes based on a set of explanatory variables. The interactions of human behavior, traffic conditions, road characteristics, vehicle information, and the environment are the elements that have a role in a crash event. It is believed that variations in crash frequencies among sites and among times depend on these five elements. If information about these factors were known with certainty, models could be developed that would precisely determine crash events. But this data is not known. Human behavior and vehicle information data, statistically significant variables as they are, are largely left unaccounted for in developed predictive models.

As Miaou (1996) points out, there are some concerns in developing models due to errors in available data, underreporting in crashes, omitted variables, levels of aggregation in data, imprecise mean functions, and correlations between sites. However, the predictive power of models far outweighs the drawbacks as long as these limitations and drawbacks are recognized. Models are still powerful explanatory and predictive tools. In the presentation of the literature review for intersection safety prediction models, rural intersections are discussed first, followed by urban intersections, and then signalized intersections.

\subsubsection{Rural Intersections}

Bauer and Harwood (1998) developed a series of intersection models using negative binomial (NB) regression for rural STOP-controlled intersections (note that the models include independent variables at the $90 \%$ confidence level rather than at the $95 \%$ level). The major and minor ADT independent variables were used as external exposure parameters. This approach is often referred to as the multiplicative modeling approach. They distinguished between three-leg and four-leg intersections. For rural four-leg STOP controlled intersections, all but mountainous terrain (compared with rolling terrain) 
conditions were associated with increased crash frequency. This was true for overall crash frequency and crashes involving injuries or fatalities. For rural three-leg STOP controlled intersections, flat terrain (compared to rolling terrain) was associated with decreased crash frequency, as was the width of the outside shoulder on the major roadway. The other independent variables were associated with higher crash frequencies. When only reviewing fatal and injury crashes at three-leg rural STOP-controlled intersections, only the outside shoulder width on the major roadway and crossroads that prohibit free right turns were associated with reductions in expected fatal and injury crash frequency.

Vogt and Bared (1998) presented models for predicting overall crash frequency at three and four-leg intersections on rural roadways, finding that volume and speed are both correlated positively with crash frequency. Vogt (1999) built on this effort and spent further time developing NB models for four-lane by two-lane stop-conrolled and twolane by two-lane signalized rural intersections. Athough he noted small sample sizes as a concern, the findings of the study provided valuable lessons, for example, that major roadway volumes had different impacts on overall crash frequency than on injury and fatal crash frequency. The parameter estimates for the different functional classes of the major roadway also varied in magnitude, suggesting diferent impacts depending on functional class.

The models by Vogt and Bared (1998) and Vogt (1999) provided the basis for the Interactive Highway Safety Design Model (IHSDM) prediction algorithm for crashes at rural intersections. The IHSDM is a safety forcasting tool funded and developed by FHWA and partners. In validation efforts by Lyon et al. (2003) and Oh et al. (2003) considered the issue of model transferability. They found that traffic volumes at intersections were often highly correlated with other explanatory variables and concluded that inclusions of both variables would bias parameter estimates without adjustment. They suggested that differences in driver population and environmental factors (including weather) be accounted for with a correction factor because of inter-correlation with volumes. Models with expanded sets of independent variables tended to perform poorer across jurisdictions, and the researchers questioned the validity of the parameter estimates of these "full" models. The use of models with merely traffic volumes was then recommended.

In order to study the effectiveness of countermeasures at rural intersections (signalized and multilane STOP-controlled), Oh et al. (2004) used data from Georgia, California, and Michigan. In terms of traffic flow, the findings of the study suggested that traffic flow is the most reliable independent variable to predict crash frequency. This finding was noted by Lyon et al. (2003). In all cases, increases in major and minor roadway volumes were associated with increased crash frequency. The analysis of parameter estimates also confirmed that there is a non-linear relationship between crashes and volumes. Increased turning volumes at the three-leg intersections were associated with increases in injury intersection crashes. Speed was included as an independent variable but findings suggested that the effect of speed on overall crash frequency was inconsistent. At fourleg STOP-controlled intersections higher speed limits were associated with increased 
injury crash frequencies while higher speed limits at signalized intersections were associated with reduced safety. The researchers argued that the varying behavior of posted speed as an independent variable may be the result of inconsistency between posted and operating speed and that the reduced crashes associated with higher posted speeds may reflect the reduced ability of a driver to adequately estimate the available gap for turning movements.

In order to further improve the two and four lane rural intersection predictive models for the IHSDM, Washington et al. (2005a) and Washington et al. (2005b) embarked on an extensive effort to validate and calibrate models developed by Vogt and Bared (1998), Vogt (1999), and Harwood et al. (2000). The project reviewed AADT-only and fully parameterized models. Base models, representing AADT only models that were developed for typical known site characteristics, were recommended for use in the IHSDM. Accident Modification Factors (AMFs) can then be applied to these base models where site characteristics differed from the base condition. For all these models, AADT was positively correlated with overal and injury crash frequencies.

In a more recent modeling development effort, Kim et al. (2007) developed binomial multilevel models for the distribution of three different crash types at two-lane rural intersections: angled-crashes, rear-end crashes, and sideswipe crashes. The researchers used data from Georgia. No statistically significant variables were found to improve fit, likely because of reported small sample sizes (16 in total). Angle-crashes on the other hand were more likely during clear daylight conditions when traffic volumes were not included as part of the model. The researchers argued that independent variables other than traffic volumes captured exposure in a more sufficient manner and that the purpose of the model would be to predict crash type rather than crash frequency. Rear-end crashes are more likely to occur during adverse weather. Comparison of the distribution of angle crashes between signalized and unsignalized intersections indicated that angle crashes are more likely to occur at unsignalized intersections. Rear-end crashes were more likely at signalized intersections. The higher probability of angle crashes and rear-end crashes at signalized intersections are consistent with the turning movement control function of the signal installation and the observed effect of a new signal installation (i.e. an increase in expected rear-end frequency).

\subsubsection{Urban Intersections}

Golias (1992) focused his efforts on obtaining an approach that could be followed to quantify the contribution of traffic flow to urban priority controlled intersection crashes. He reviewed work as early as 1953 but was unable to find any functional relationship between crash frequency and traffic flow that was identified for urban intersections. Using four-legged priority intersections, he formulated an exposure index, consisting of the product of all entering flows, across streams that cross or merge. The exposure index is an extension of recommendations presented by Hakkert and Mahalel (1978) on the inclusion of measures of conflicting movements at the intersection into the modeling process. 
Four years after Golias (1992), Poch and Mannering (1996) published results of urban intersection crash models that covered overall, rear-end crash frequency, angle, and approach-turn crash frequency. The dataset represented observations by intersection approach rather than per intersection. As the observations are correlated, this may violate the independence assumption of error terms (because observations are correlated). The authors discussed the results of likelihood ratio tests hoping that this approach would not significantly affect the parameter estimates and significance levels. The findings of the modeling effort may demonstrate the difference in effect of independent variables related to flow, functional class, and speed limits. For overall crash frequency, factors such as left- and right-turn ADT, and total opposing approach volume were all associated with increased crash frequency while some control related variables and indicators related to the functional class of the minor approach were negatively correlated with crashes. An interesting phenomenon was the difference in the elasticity estimates for approach and opposing approach speed limits, the first being positive and the second being negative. The researchers commented that it is possibly resulting from high correlation between the two speed variables. For rear-end crashes the opposing left turn volume is associated with a reduction in rear-end crash frequency, while other volumes (total intersection volume and right turn volume) were positively correlated with the crash outcome. The location of the intersection also had an impact, with a central business district location reducing the rear-end frequency. When reviewing annual angle crash frequencies, volumes were positively correlated (total and left-turn), while the functional class and speed limit also impacted the frequency. A different pattern emerged with approach-turn crashes where opposing left-turn volumes were negatively correlated with this crash type and the total and left turn traffic were associated with increases in approach-turn crash frequencies.

Meanwhile, in a series of efforts to support the development of the Interactive Highway Safety Design Model (IHSDM) tool, Bauer and Harwood (1998) developed a series of overall crash frequency and injury crash frequency for urban intersection models using NB regression. The ADT of the minor and major approaches to the intersections were used as external exposure parameters. In all the models, increase in any of the volume related variables resulted in an increase in the particular predicted frequency. These two exposure measures accounted for most of the variation in the observed crash frequencies. The particular functional class of the major roadway also impacted crash frequency differently through both the magnitude and direction of parameter estimates. The researchers commented that the goodness-of-fit of overall crash frequency models were consistently better than those for the KABC (injury) crash frequency models.

\subsubsection{Signalized Intersections}

Following a slightly different approach to the crash prediction modeling process of intersection crashes than those discussed earlier in this section, Persaud and Nguyn (1998) aggregated data by time period, crash severity, and environment character. Cognizant of the different levels of information available during the project development process, they developed models at two levels. Level 1 models only used entering flows to

estimate frequencies of rear-end crashes, right-angle crashes, and turning crashes. Level 2 models represented a project development stage with detailed information such as 
knowledge of the movement patterns of vehicles prior to the intersection crashes. The researchers argued that this process supports regional transferability, a serious concern in the wider application of prediction models (Washington et al. 2005b). Level 1 is of particular relevance in terms of the effect of flows. The sum of the entering flows was always; regardless of the environment, crash type, or movements prior to crashes; associated with an increase in crash frequency. The modeling of the frequency of different crash categories rather than overall crash frequency also showed improvement in regional transferability.

Abdel-Aty and Keller (2005) used ordered probit modeling for analysis of the overall severity distributions while regression tree models were used for more in-depth analysis of each severity type. The findings of the study is consistent with the higher expected severity levels of left-turn, angle, and head-on crashes; and the lower expected severity of injuries associated with rear-end and sideswipe crashes. The regression tree analysis showed that the major roadway volume explained the largest variation in propertydamage only crashes. In the ordered probit model the results were different, with increased volumes being associated with higher injury levels. Speed limits on the minor road were consistently significant between both modeling approaches. Their research indicated that there are several benefits to approaching modeling at intersections on a by crash type basis to estimate distribution of crash severity.

Persaud et al. (2005) engaged in a multi-jurisdictional evaluation of the safety impact of red-light running cameras. Different safety prediction models were developed for the different groupings of cities within each larger region. This was done because of inconsistencies in crash reporting. NB regression was used for this effort. The frequency of the different crash types were calculated by applying a factor for the typical distribution of these crashes at the intersections. Consistent with the findings of most intersection related crash prediction models discussed earlier in this chapter, traffic volume remained the measure that explained most of the variation in crashes at the intersections. Spillover effects were noted as a concern but were not incorporated in the analysis.

\subsection{CONCLUSION}

The review of the literature has identified a long list of intersection elements that may affect the safety performance of intersections. Many of these elements are not routinely collected as part of state data activities and can only be obtained through manual data collection efforts. It is clear from the summaries presented that crash rates vary considerably from state-to-state. This can be attributed to crash reporting practices, intersections sampled, driver behavior, and other differences. This supports development of an Oregon-specific effort. The Bonn study serves as a good starting point and a historical benchmark. In the summaries, the most common aggregation were at a relatively high level such as: intersection type, rural or urban, type of traffic control, volume (or functional) class, number of approach lanes and presence of left-turn lanes are the most common elements for which summary statistics are developed for intersections. Secondary data (such as specific dimensions of elements) have not been used in the statistical summaries. Interestingly, all summaries used total crashes and did not develop separate injury rates or rates 
by any other crash category or causation. Roundabouts were not included as separate category in any summaries reviewed, probably because of the relatively few numbers. Any pedestrian or bicycle elements were also absent.

The number of intersections in these studies varied significantly (Wisconsin 1,700; Kentucky 7097; Hanna et al. 300; Bonn 431; Iowa 3,416) for those summaries that reported these data. The number of intersections studied is related to the ability to aggregate the data into meaningful categories. All of the summaries are "snapshots" in time and do not appear to be routinely updated. While the statistical summaries have useful information, just presenting rate data may not fully exploit the usefulness of collecting the information in these intersection databases. Summarizing the crash data in terms of typical diagnostics appears to be very valuable effort. These diagnostics can be calculated even without the need for major and minor volume data.

The literature on crash prediction at the intersection level highlights the correlational relationship of intersection characteristics with crash frequency, crash severity, and particular crash types are complex. In nearly every model, volumes were a significant variable. 


\subsection{DATA COLLECTION}

This chapter briefly summarizes the approach used to assemble the data used in the assessment of intersection safety performance.

\subsection{PILOT STUDY}

As part of the research design, a small pilot study was collected to establish the feasibility of data collection of various elements. In the literature review, sixty-two individual geometric, operational, traffic control, and other features found to influence safety performance at intersections. The pilot study attempted to collect field data on all of these elements (1) to determine the degree of difficulty in collecting these elements at intersections, and (2) to conduct preliminary data analysis to estimate the influence of each element on intersection safety.

To accomplish this, 340 intersections throughout Oregon were sampled. The sample was comprised of: (1) 51 intersections chosen at random from a list of flashing-yellow intersections, (2) 49 signalized intersections from the Highway Safety Manual (HSM) preliminary calibration research project, and (3) 240 intersections where state operated roadways intersect (since we have easy access to both minor and major volumes). Though it is clear that the above sample of intersections is biased, the intersections were geographically distributed throughout the state and had sufficient diversity in number of legs, traffic control type and other features for the pilot study needs.

Of the identified 62 elements from the literature review, it was clear that some elements would not be feasible to collect in the full study. Thus data were not collected on: 1) sight distance to the intersection, 2) sight distance to traffic control device, 3) the number of fixed objects within 250 feet of an intersection, 4) pavement quality, and 5) pavement marking quality. In addition, 6) clearance intervals (yellow and all-red indications) were not obtained due to a lack of access to signal timing data throughout jurisdictions. While it was possible to find average daily traffic counts, detailed 7) turning volumes, 8) peak-hour volumes, 9) bicycle and pedestrian volumes, and 10) truck volumes simply do not exist on a uniform statewide level. Few intersections in Oregon have transverse rumble strips on the minor approach therefore this element was not collected. Omitting these elements reduced the task of data collection for the pilot project to 48 individual elements at each intersection.

Each of the remaining data elements were collected for the 340 intersections. A graphical method was used to make an assessment about how each element influenced intersection safety using a series of three sets of box plots showing the element plotted by entering volume, crash frequency, and crash rate. A sample of these plots (revised for the full study elements and intersections) is presented in Appendix A. An assessment was made on the difficulty of data collection and whether the element was included in the Highway Safety Manual and presented to the Technical Advisory Committee as an interim report. In the end, the elements shown in Table 3.1 were recommended for inclusion in the full research sample procedure. 
Table 3.1: Intersection Elements Identified for Collection in the Full Study

\begin{tabular}{|c|c|}
\hline Geometric Elements & Traffic Control and Operational Features \\
\hline $\begin{array}{l}\text { Type of Intersection } \\
\text { Number of Approach Lanes } \\
\text { Left-Turn Lanes } \\
\bullet \quad \text { Number of Left Turn Lanes } \\
\text { • Length of Left-Turn Lanes } \\
\text { Right-Turn Lanes } \\
\text { • Number of Right Turn Lanes } \\
\text { • Type of Right-Turn Treatment } \\
\text { Intersection Skew } \\
\text { Median } \\
\bullet \quad \text { Median Type } \\
\text { • Median Width } \\
\text { Presence of Sidewalks } \\
\text { Pedestrian Crossing Features } \\
\bullet \quad \text { Max No. of Lanes crossed by Pedestrians } \\
\text { Presence of a Bicycle Lane }\end{array}$ & 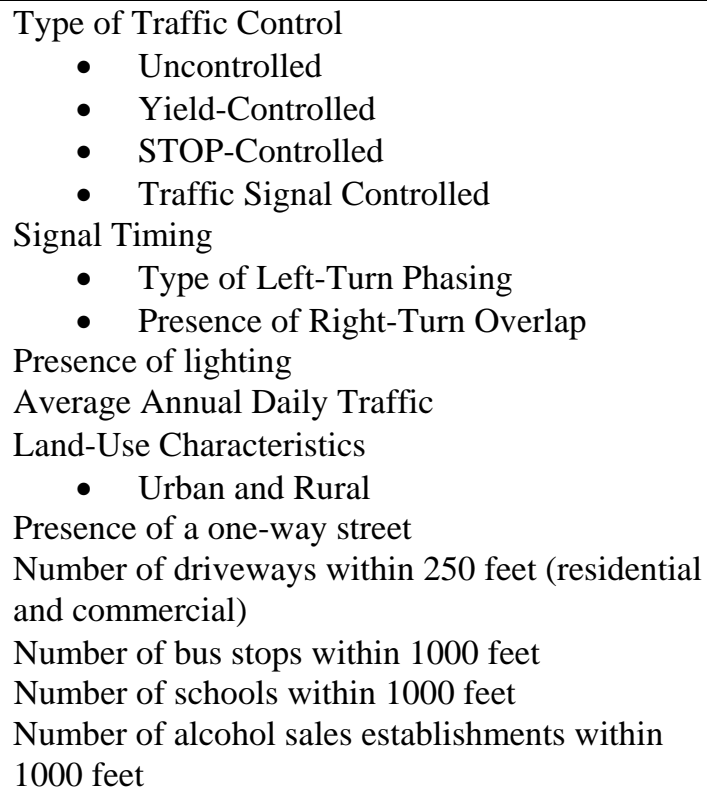 \\
\hline
\end{tabular}

\subsection{INVENTORY OF STATEWIDE INTERSECTIONS}

One challenge in the data collection procedure was to develop an inventory of intersections from which to collect data. As part of the effort to assemble information on minor street traffic volumes, a GIS layer was created that identified the intersection of roads functionally classified as minor and major collectors and minor and principal arterials (which did not exist previously). Interstate highways and their supporting off-ramps and on-ramps and functionally classified local streets were excluded. In general, urban and rural land use characteristics were determined from urban growth boundaries (Oregon Department of Land Conservation and Development 2009) and cities with a population greater than 5,000. This resulted in a state map of functionally classified intersections, seen in Figure 3.1. In the figure there are 11,133 intersections, 4,717 of which are located in rural areas and 6,416 located in urban areas. 


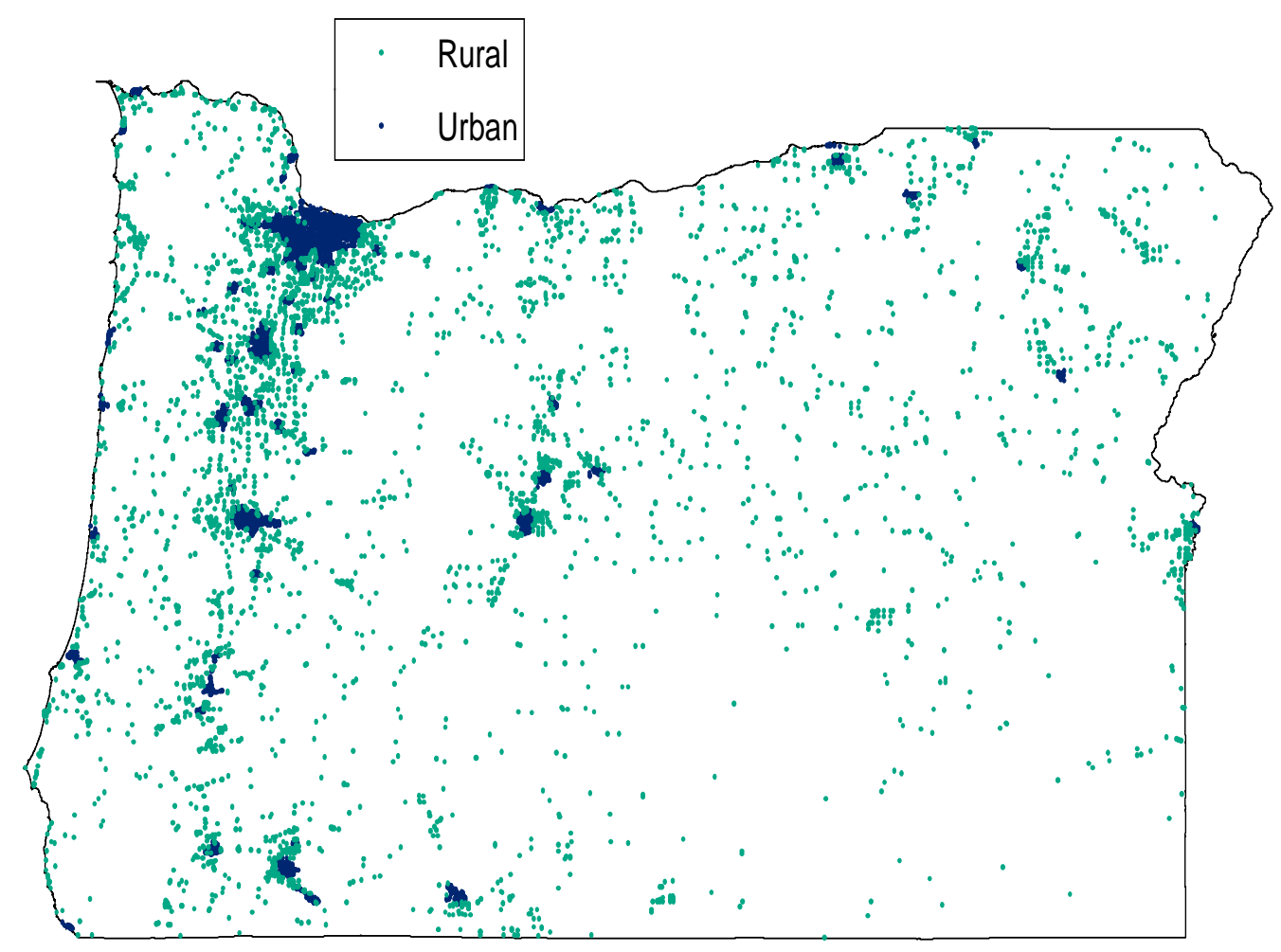

Figure 3.1: Map Of Functionally Classified Intersections

\subsection{CRASH DATA}

Two units in ODOT have responsibility and oversight for crash reporting, these include the Driver and Motor Vehicles (DMV) Services Division, and the Crash Analysis and Reporting (CAR) Unit. Currently, private citizens are required to file an Oregon Traffic Accident and Insurance Report within 72 hours if they are involved in a crash that results in injury, death, more than $\$ 1,500$ damage to their vehicle, or more than $\$ 1,500$ damage and towing of another vehicle. These reporting thresholds changed in 1998 from $\$ 500$ to $\$ 1000$ and in 2004 from $\$ 1000$ to $\$ 1500$.

One key element in the definition of geometric elements is to define the functional area of an intersection which helps guide which elements should or should not be included. Stover (1996) provided some guidance on the issues based on operating characteristics. Other studies summarized previously have focused on the definitions used in the crash databases (typically 250 feet). ODOT Crash Analysis and Reporting Unit defines crashes at intersections as those that have occurred within 50 -feet as well as through a data field labeled "intersection-related". The intersection-related field is the checked in the judgment of the coder if the "crash is related to the movement or control of traffic through a nearby intersection (ODOT $2007 \mathrm{pg}$. 45)" such as a rear-end crash. In this research crashes were selected with the following criteria:

- within \pm .01 miles (52.8 feet) of the intersection milepost or secondary intersection milepost; and/or 
- within \pm .05 miles (264 feet) of the intersection milepost or secondary intersection milepost and the intersection-related flag marked.

Secondary intersection mileposts on state highways are places where right or left turning lanes branch off and intersect with the road at a different location creating an island. Crashes were queried for the most recent five years of data from 2003-2007.

\subsection{TRAFFIC VOLUMES}

The principal exposure measures include average annual daily traffic on both the minor and major approach legs. Oregon DOT's traffic volume and counting programs provide valuable, consistent, and historical data state highways (often the major legs). However, there is currently no similar resource for non-state facilities. In our data collection efforts, we attempted to obtain non-state highway volumes by contacting individual agencies, obtaining published data from the internet, and contacting traffic counting firms. These efforts proved challenging and generated inconsistent data. During the course of the project, ODOT produced a GIS layer of all functionally classified roads in the state. This file includes volume data for a large number of roads (though it has many outdated counts).

Some assumptions were made to fill gaps in the traffic exposure data. In cases where traffic counts by approach are different, it was assumed $1 / 2$ of the ADT per leg was entering. If minor volume counts were missing for any of the analysis years, we estimated the unknown volume by the multiplying the $\mathrm{AADT}_{\text {major }}$ (which is known for each year) by the ratio of $\left(\mathrm{AADT}_{\text {major }} /\right.$ $\mathrm{AADT}_{\text {minor }}$ ) for the year where the minor AADT is known. It should be noted that none of the more desired traffic characteristics were available in any consistent form (peak hour approach volumes, turning movement volumes, percent trucks, average approach speed, bicycle volumes, or pedestrian volumes).

\subsection{SAMPLING PLAN}

The research database was created using a mostly random stratified sampling plan. First, the intersections shown in Figure 3.1 were filtered for only intersections for which minor volumes were available for at least one year in 2003-2007. From this sub-sample, intersections were then randomly sampled. An intersection was sampled and all relevant data elements were collected. As part of this the land use-type-traffic control was determined. The sampling plan had the objective of having between 50-100 intersections of each land use-type-traffic control category. However, it was clear that since rural signalized intersections are rare it would be time consuming to yield a statistically significant sample. We identified rural signalized locations from a variety of sources and specifically selected these intersections for the sample. The final intersection sample ended up with 500 intersections with 129 or roughly 25\% of these coming from the pilot study. Of the 500 intersections, 202 are found in rural areas and 298 are located in urban areas. Only 3-leg and 4-leg intersections were sampled. These are shown spatially in Figure 3.2. 


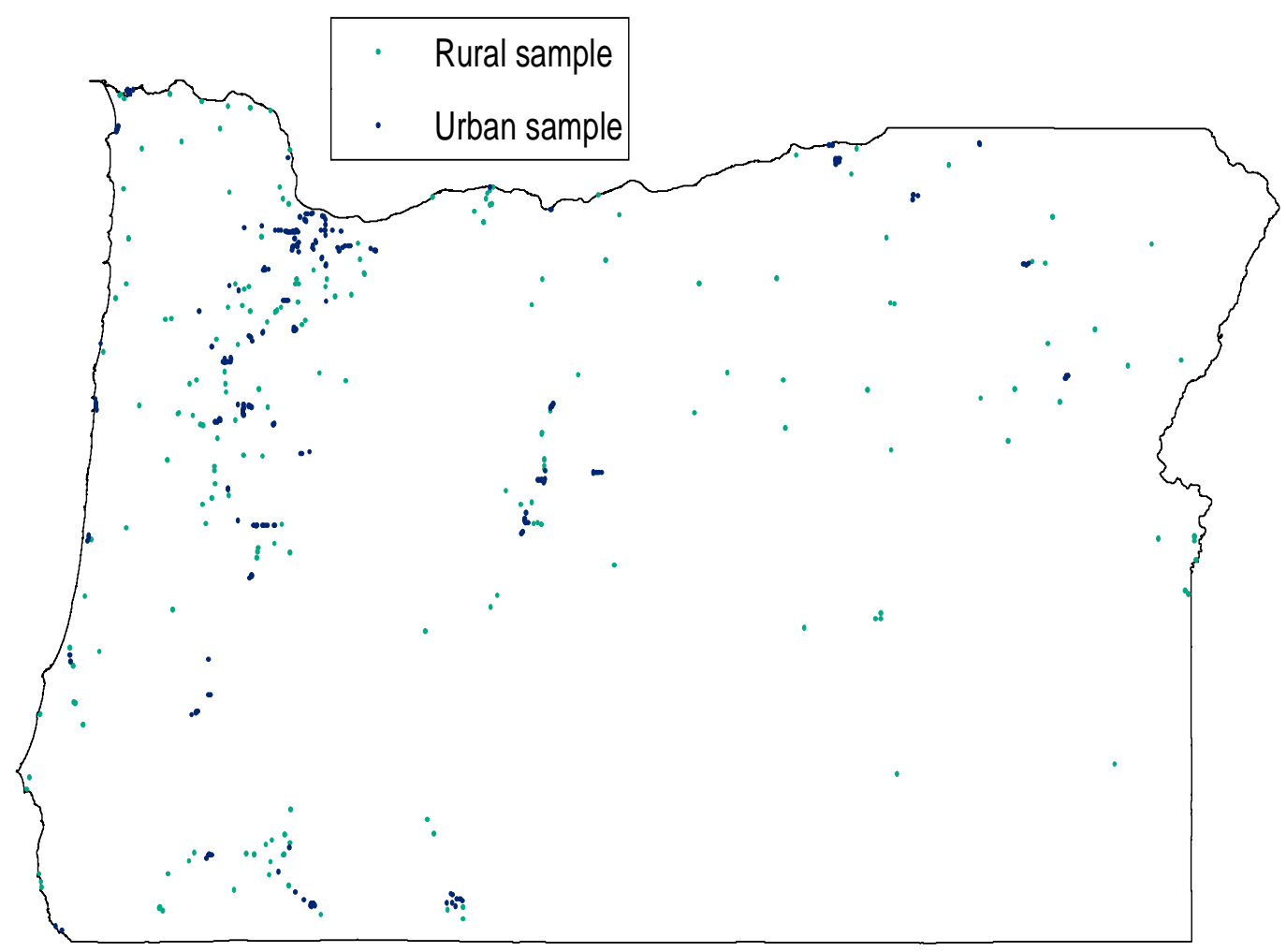

Figure 3.2: Map Of Sampled Intersections, $N=500$

\subsection{AERIAL AND STREET-LEVEL IMAGERY}

All of the geometric and traffic control elements in this research were collected using either aerial or street-level imagery (site visits were not performed). In general, the intersection elements collected across the state of Oregon using aerial photography were subject to limitations based on resolution quality. We found that the most effective tool for aerial photography was Google Earth due to its measuring capabilities. As a supplementary source, city and country websites as well as Microsoft Bing maps were used.

To complement the aerial photography, street-level imagery provided by ODOT’s digital video log and, where available, Google Earth's Street View were used. Our data collection efforts were done remotely, using various data and resources that are described in the following section. As part of the data validation and quality control, a script was written that extracted the aerial Google map tiles and added some of the key data elements to the image. Samples of these tiles are shown in Figure 3.3 for rural intersections and Figure 3.4 for urban intersections.

\subsection{DESCRIPTION OF DATA ELEMENTS}

A summary of the data elements collected and the summary statistics are shown in Table 3.1 and Table 3.2. A brief text description of the data element and how it was collected follows: 
Average Annual Daily Traffic (Major and Minor, by year)

- See description in previous section.

Crash Frequency and Severity

- Number and type of crashes reported at the intersection or coded as intersection related for each year from 2003-2007. Data were retrieved from ODOT’s Statewide Crash Data System (CDS).

Type of Intersection

- Number and orientation of legs were easily gathered from aerial photography and digital video log. Only three and four leg intersections were included in the sample.

Total Number of Approach Lanes (Major and Minor)

- Count of total number of approach lanes in both directions at intersections were collected from aerial photography and street-level imagery.

Total Number of Left-Turn Lanes (Major and Minor)

- Count of the number of left turn lanes on all approaches were collected from aerial photography and street-level imagery.

Length of Left-Turn Lanes (Major and Minor)

- Left-turn bay length measured in feet from the stop bar to the onset of the bay taper or in the absence of that to the end of the lane striping. Data were collected from aerial photography with Google distance measurement tool.

Total Number of Right-Turn Lanes (Major and Minor)

- Count of the number of right-turn lanes present were collected from aerial photography.

Type of Right-Turn Treatment (Major and Minor)

- Classification of right-turn lane type by raised/depressed channelization and painted channelization at right-turn lanes. Channelized right turns are in the state's Integrated Transportation Information System (ITIS) database, finding this information on local roads required the use of aerial photography.

Intersection Skew

- Skew was measured as the degree offset from 90 degrees, thus roads perpendicular to the major road would have a 0 degree skew and roads near parallel to the major road would approach a 90 degree skew value. In the few cases where the approaches met at different skew angles, the highest measurement of skew was recorded. Measurements consistent 
with the HSM procedure were collected from aerial photography and street-level imagery.

Type of Median (Major and Minor)

- The type of median was aggregated based on categories used by Knapp and Campbell (2005). Medians were categorized as solid median barrier, earth, grass, or paved median barrier. Data were collected from aerial photography and street-level imagery.

Median Width (Major and Minor)

- The median width (feet) was measured directly at the intersection; islands or separated roadways upstream of the intersection were not measured. We measured instances where painted lines were 4 or more feet apart. These data were collected with aerial photography and the Google distance measurement tool (supplemented on state highways with data from ITIS).

Presence of Sidewalks (Major and Minor)

- A binary variable, the presence of whether sidewalks are present at the intersection functional area. Data were collected from aerial photography and street-level imagery.

Maximum Number of Lanes Crossed by Pedestrians

- Maximum number of lanes a pedestrian would need to cross, typically found crossing on leg of the major approach. Data were collected from aerial photography and street-level imagery.

Presence of a Bicycle Lane (Major and Minor)

- A binary variable, the presence of bicycle lanes in the intersection functional area. Data were collected from aerial photography and street-level imagery.

Type of Traffic Control

- Intersections were classified as either minor STOP-controlled or signalized. Data were collected from aerial photography and street-level imagery.

Type of Left-Turn Phasing (Major and Minor)

- Left-turn phasing was estimated from signal heads, signal head configuration, and/or traffic movements from static images in street-level imagery such as digital video log or Google's street view. It was not possible to determine phase order such as lead-lag, only if protected and permissive phases existed. 
Presence of Right-Turn Arrow Overlap (Major and Minor)

- A binary variable, the presence of approaches with a protected right-turn arrow visible in street-level imagery such as digital video log or Google's street view.

Presence of Lighting

- A binary variable, the presence of lighting on any approach. Data were collected from street-level imagery.

Posted speed (Major)

- For the major approach only, the posted speed (mph) was collected from Oregon DOT’s Road Inventory files or street-level imagery.

Land-Use Type

- In general, urban and rural land use characteristics were determined from urban growth boundaries (Oregon Department of Land Conservation and Development 2009) and cities with a population greater than 5,000. Initially, a strict definition was used but on further consideration intersections were visually inspected to determine character. Some intersections in cities with very close to 5,000 population were clearly urban as well as some intersections within city limits or UGB were clearly rural.

One-way street (Major and Minor)

- A binary variable, the presence of a one-way street at one or more approaches. Data were collected from street-level imagery.

Number of driveways within 250 feet (residential and commercial)

- The number of driveways within 250 of any direction from the intersection. Data were collected from street-level imagery. The data element was included in the HSM.

Number of bus stops within 1,000 feet

- Count of bus stops within 1,000 feet of the intersection. Aerial photography (Google earth and distance measurement tool). Data were collected using Google earth layer for transit stops. This may have omitted rural bus stops or other transit agencies who do not participate in sharing information with Google. The data element was included in the HSM.

Number of alcohol sales establishments within 1,000 feet

- Count of alcohol sales establishments within 1,000 feet of the intersection. Aerial photography (Google earth and distance measurement tool). Data were collected using Google Earth layer for establishments that may sell alcohol legally in Oregon. This may 
have omitted locations who do not participate in sharing information with Google. The data element was included in the HSM.

Number of schools within 1,000 feet

- Count of schools within 1,000 feet of the intersection. Aerial photography (Google earth and distance measurement tool). Data were collected using Google Earth layer for schools. The data element was included in the HSM.

Table 3.2: Summary of Categorical Elements

\begin{tabular}{|c|c|c|c|c|c|c|c|}
\hline \multirow[b]{2}{*}{ Element } & \multirow[b]{2}{*}{ Category } & \multicolumn{2}{|c|}{ Count } & \multirow[b]{2}{*}{ Element } & \multirow[b]{2}{*}{ Category } & \multicolumn{2}{|c|}{ Count } \\
\hline & & Major & Minor & & & Major & Minor \\
\hline \multirow[t]{2}{*}{ LAND_TYPE } & Rural & 202 & & PROTECT_RT & yes & 7 & 7 \\
\hline & Urban & 298 & & & no & 493 & 493 \\
\hline \multirow[t]{4}{*}{ FACILITY_TYPE } & 3SG & 62 & & ONE_WAY & yes & 24 & 14 \\
\hline & $3 S T$ & 192 & & & no & 476 & 486 \\
\hline & $4 S G$ & 126 & & LIGHTING & yes & 293 & \\
\hline & $4 \mathrm{ST}$ & 120 & & & no & 207 & \\
\hline \multirow[t]{2}{*}{ LT_PHASE } & No left turn & 91 & 135 & SIDEWALK & yes & 248 & 226 \\
\hline & Permissive & 29 & 59 & & no & 252 & 274 \\
\hline \multicolumn{2}{|c|}{ Permissive-Protected } & 27 & 8 & BIKE_LANE & yes & 111 & 44 \\
\hline \multicolumn{2}{|r|}{ Protected } & 107 & 51 & & no & 389 & 456 \\
\hline & Split & 1 & 2 & & & & \\
\hline \multirow[t]{4}{*}{ MEDIAN_TYPE } & $\begin{array}{r}\text { Earth, grass, } \\
\text { or paved } \\
\end{array}$ & 60 & 13 & & & & \\
\hline & Solid median & 32 & 12 & & & & \\
\hline & TWLT Lane & 62 & 1 & & & & \\
\hline & No Median & 344 & 471 & & & & \\
\hline
\end{tabular}


Table 3.3: Summary of Continuous Elements

\begin{tabular}{l|r|r|r|r|r}
\hline Element & Mean & Median & Std.dev. & Min & Max \\
\hline ADT_MAJ & 13179 & 10885 & 9771.4 & 187 & 48760 \\
\hline ADT_MNR & 3038 & 1671 & 4048.1 & 15 & 29410 \\
\hline ADT_TOTAL & 16217 & 13427 & 12199.1 & 297 & 63308 \\
\hline APPRO_LANE_NUM_MAJ & 2.87 & 2 & 1.01 & 2 & 6 \\
\hline APPRO_LANE_NUM_MNR & 1.69 & 2 & 0.80 & 1 & 6 \\
\hline SKEW & 11.2 & 0 & 15.55 & 0 & 75 \\
\hline NO_OF_PED_CROSSINGS & 1.50 & 0 & 1.73 & 0 & 5 \\
\hline MAX_LANES_PED_CROSS_SIGNAL & 3.95 & 4 & 1.58 & 0 & 7 \\
\hline DRIVEWAY_COM_NUM & 2.72 & 2 & 3.17 & 0 & 17 \\
\hline DRIVEWAY_RES_NUM & 0.88 & 0 & 1.82 & 0 & 12 \\
\hline SCHOOL_NUM & 0.37 & 0 & 0.74 & 0 & 5 \\
\hline BUS_STOPS_NUM & 1.16 & 0 & 2.30 & 0 & 14 \\
\hline ALCOHOL_SALES_NUM & 2.64 & 2 & 3.13 & 0 & 17 \\
\hline LEFT_TURN_NUM_MAJ & 0.79 & 1 & 0.84 & 0 & 3 \\
\hline LEFT_TURN_NUM_MNR & 0.46 & 0 & 0.74 & 0 & 4 \\
\hline LEFT_TURN_MIN_LENGTH_MAJ & 153.93 & 125 & 105.26 & 0 & 670 \\
\hline LEFT_TURN_MIN_LENGTH_MNR & 125.66 & 110 & 79.23 & 0 & 500 \\
\hline RIGHT_TURN_NUM_MAJ & 0.36 & 0 & 0.62 & 0 & 4 \\
\hline RIGHT_TURN_NUM_MNR & 0.35 & 0 & 0.61 & 0 & 2 \\
\hline RIGHT_TURN_MAX_LENGTH_MAJ & 169.79 & 120 & 174.00 & 0 & 1800 \\
\hline RIGHT_TURN_MAX_LENGTH_MN & 159.19 & 125.5 & 153.81 & 0 & 1100 \\
\hline R & 12.02 & 12 & 11.69 & 2 & 100 \\
\hline MEDIAN_WIDTH_MAJ & 9.30 & 7 & 7.88 & 2 & 33 \\
\hline MEDIAN_WIDTH_MNR & 41.03 & 40 & 11.00 & 20 & 55 \\
\hline POSTED_SPEED & & & & & 0 \\
\hline & & & & & \\
\hline
\end{tabular}


6473 SG Rural $45 \mathrm{mph}$
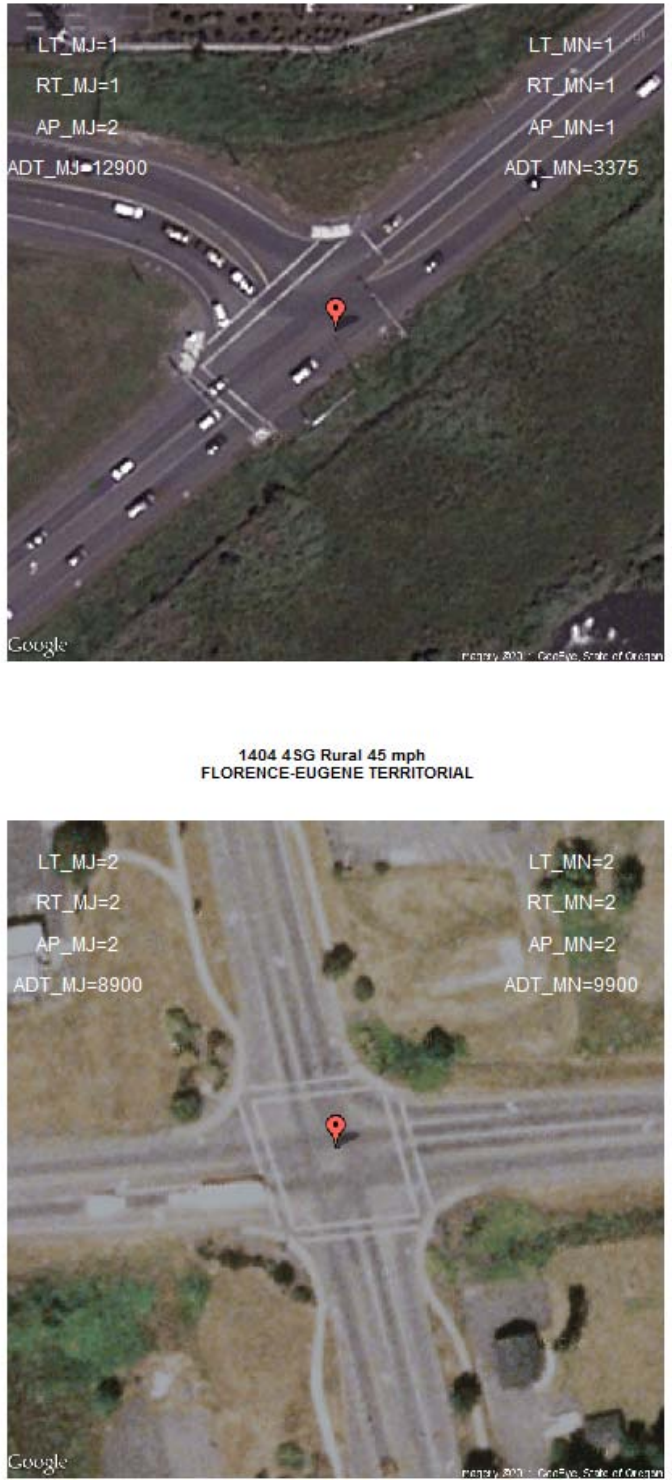

5553 ST Rural $55 \mathrm{mph}$

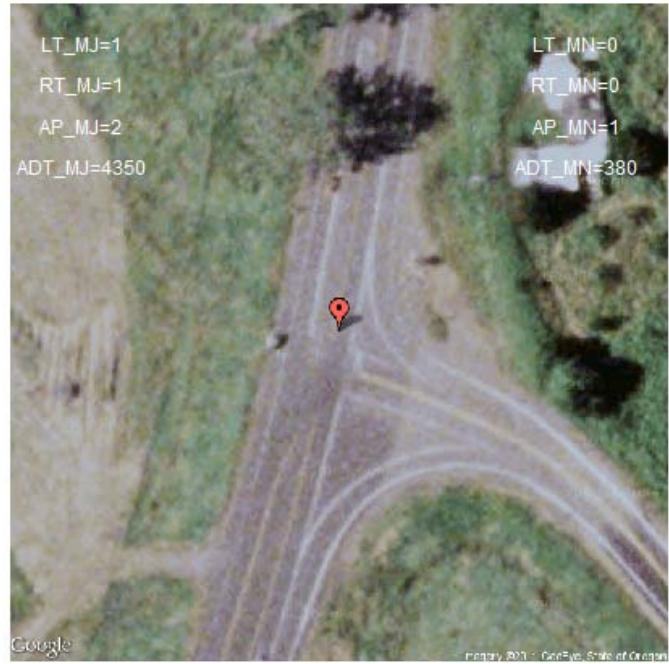

2064 4ST Rural $55 \mathrm{mph}$

PACIFIC HIGHWAY WE ST Parker

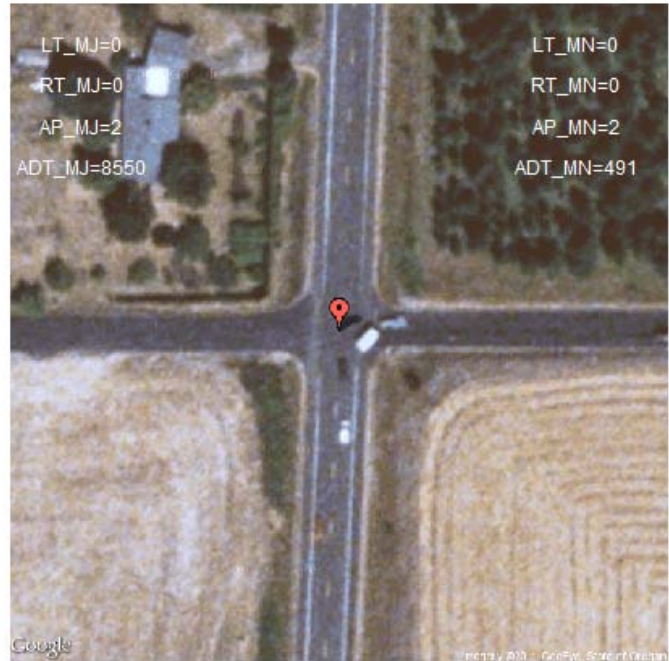

Figure 3.3: Sample Aerial Photos And Collected Data Elements, Rural Intersections. 
$58083 S \mathrm{G}$ Urban $35 \mathrm{mph}$

BEAYERTON-HILLSDALE Jamieson

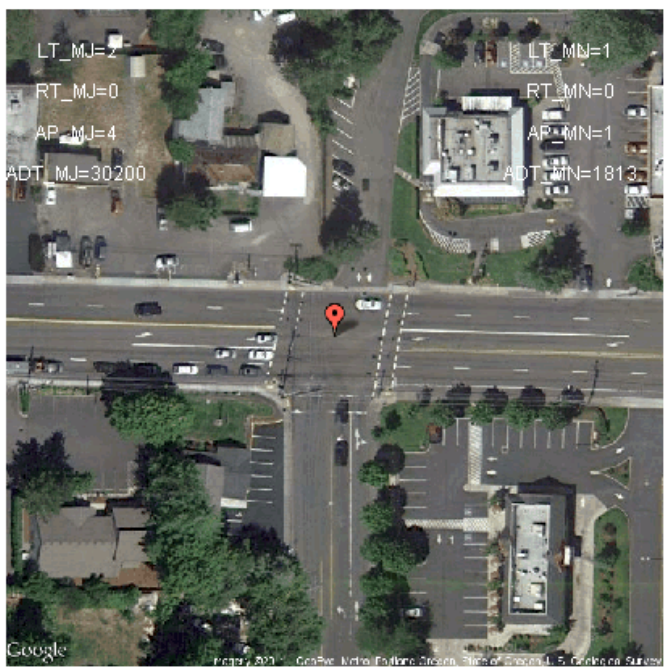

4229 4SG Urban $40 \mathrm{mph}$

MCKENZIE 42nd

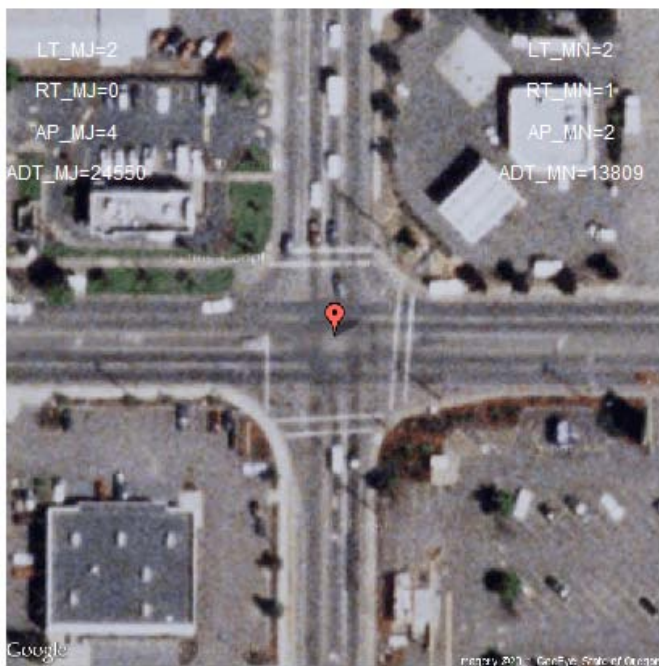

$582635 \mathrm{~T}$ Urban $25 \mathrm{mph}$

CASCADE HWH SDUTH Ste

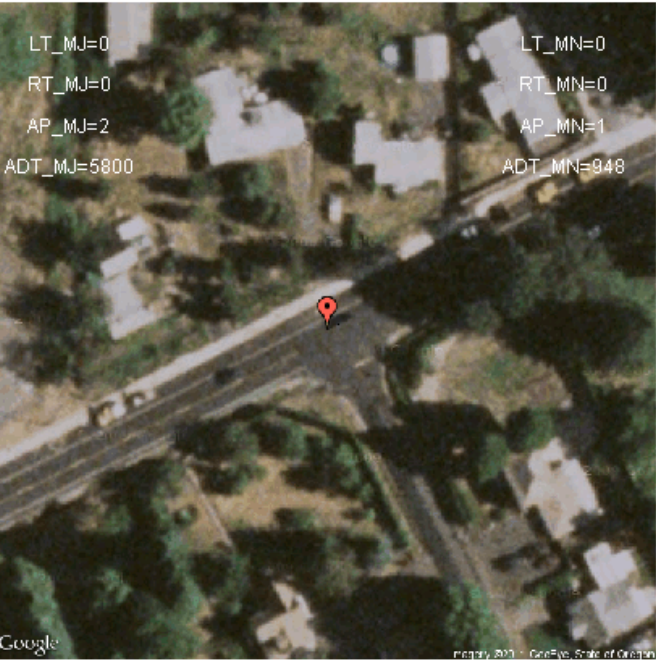

107414 ST Urban $35 \mathrm{mph}$

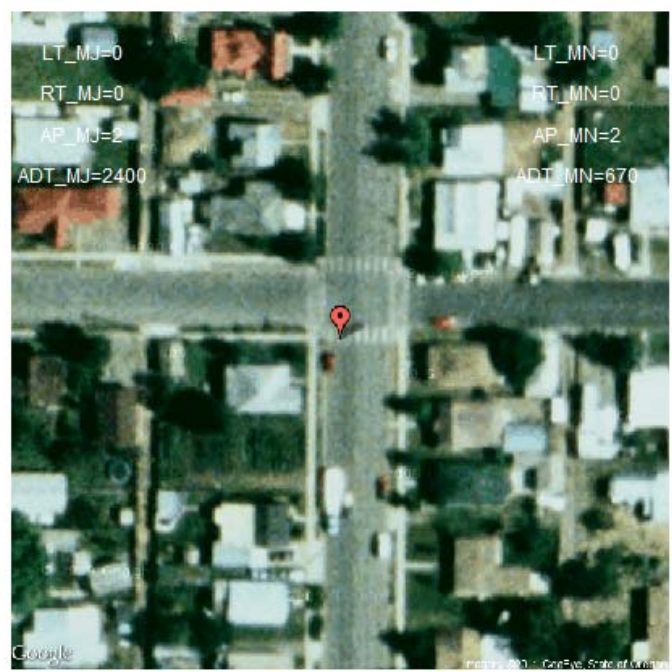

Figure 3.4: Sample Aerial Photos And Collected Data Elements, Urban Intersections 


\subsection{SAFETY PERFORMANCE}

This chapter explores the safety performance of intersections in three sections: 1) crash rates; 2) crash patterns; and 3) through the development of safety performance functions for a subset of the intersection types. Additional descriptive analysis of all of the specific elements is presented in Appendix B. In all of the sections, the primary manner in which intersections are presented relate to type of traffic control (signalized or stop-control on minor approach), the number of approach legs (three or four), and the adjacent land use (rural or urban). In this chapter, the following abbreviations are used:

- 3-leg signalized

- 3-leg minor stop-control

- 4-leg signalized

- 4-leg minor stop-control
3SG

3ST

4SG

4ST

Land use - rural (R_) or urban (U_) - is appended to the intersection type to complete the terminology and labeling. Figure 4.1 summarizes the number of intersections in the sample. Signalized intersections in rural environments are relatively uncommon and resulted in a very low sample rate for these intersection types. Only seven rural 3-leg signalized intersections were sampled; 20 rural 4-leg signalized intersections.

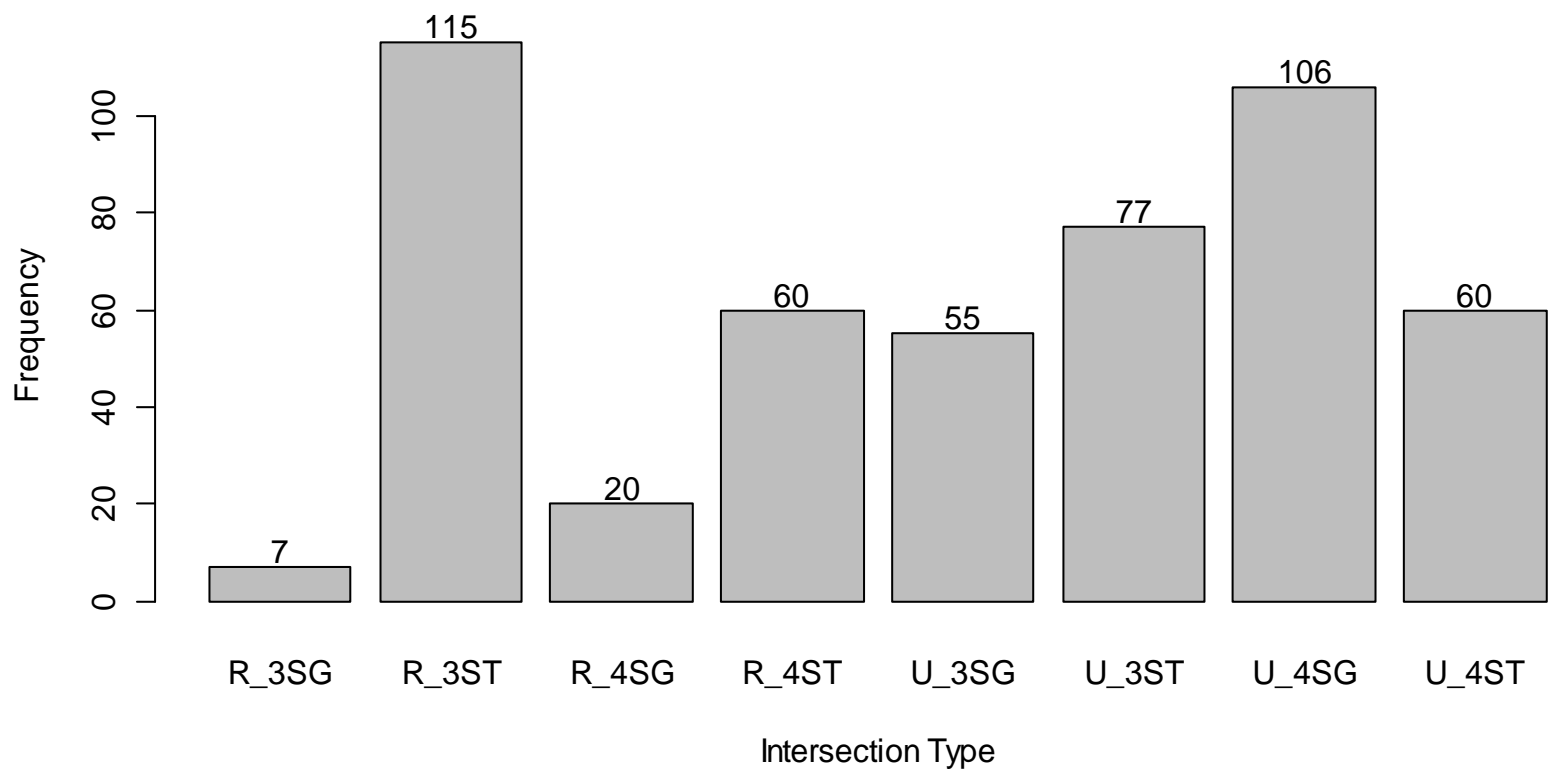

Figure 4.1: Barplot of Intersection Types in Research Sample 


\subsection{CRASH RATES}

The literature and experience suggest that there is a strong relationship between the traffic volumes entering an intersection and the observed crash frequency. Figure 4.2 shows the 5-year crash frequency plotted against total entering intersection volume for all of the sampled intersections. As expected, the plot shows that crash frequency generally increases with exposure.

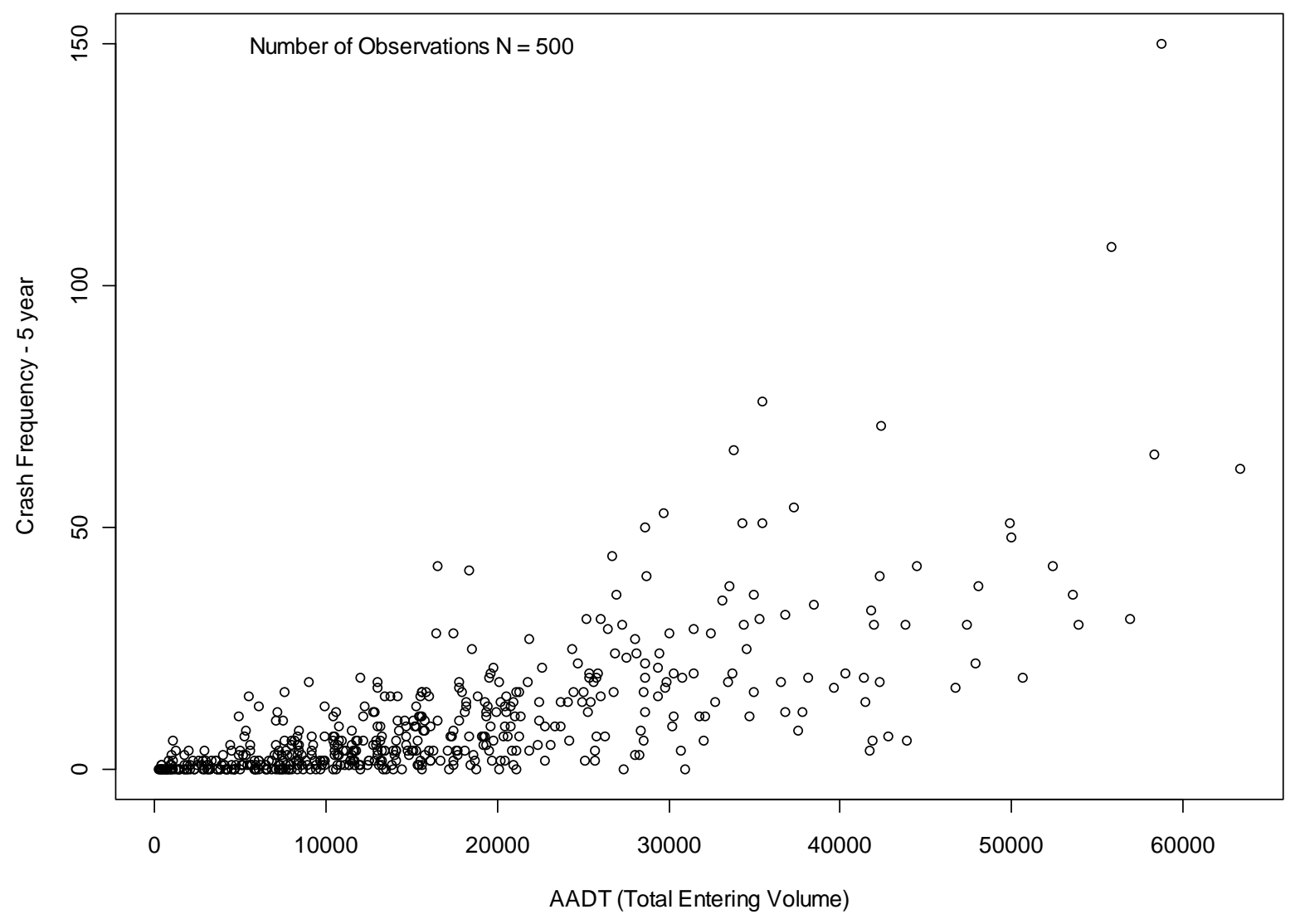

Figure 4.2: Total Entering Intersection Volume vs. Crash Frequency, 5-Year Crash Frequency

In Figure 4.3, the same data are shown but major and minor volumes separated. The plot shows major and minor entering volume with the third dimension (crash frequency represented by proportional dots). The largest dot in the figure represents an intersection that had 150 crashes in the 5 year period. Note the $y$-axis is from $0-30,000$ vehicles and $x$-axis is from $0-50,000$ vehicles. The plot shows that the separate contributions of major and minor volumes to the crash frequency. For any major entering volume, crash frequency increases with increasing minor volumes (the plotted dots get larger and the color shading indicates more crash frequency). It is clear that exposure contributes to crash frequency but that major and minor volumes have different influences - the specific contributions of each will be estimated in the modeling section of this chapter (4.3). 


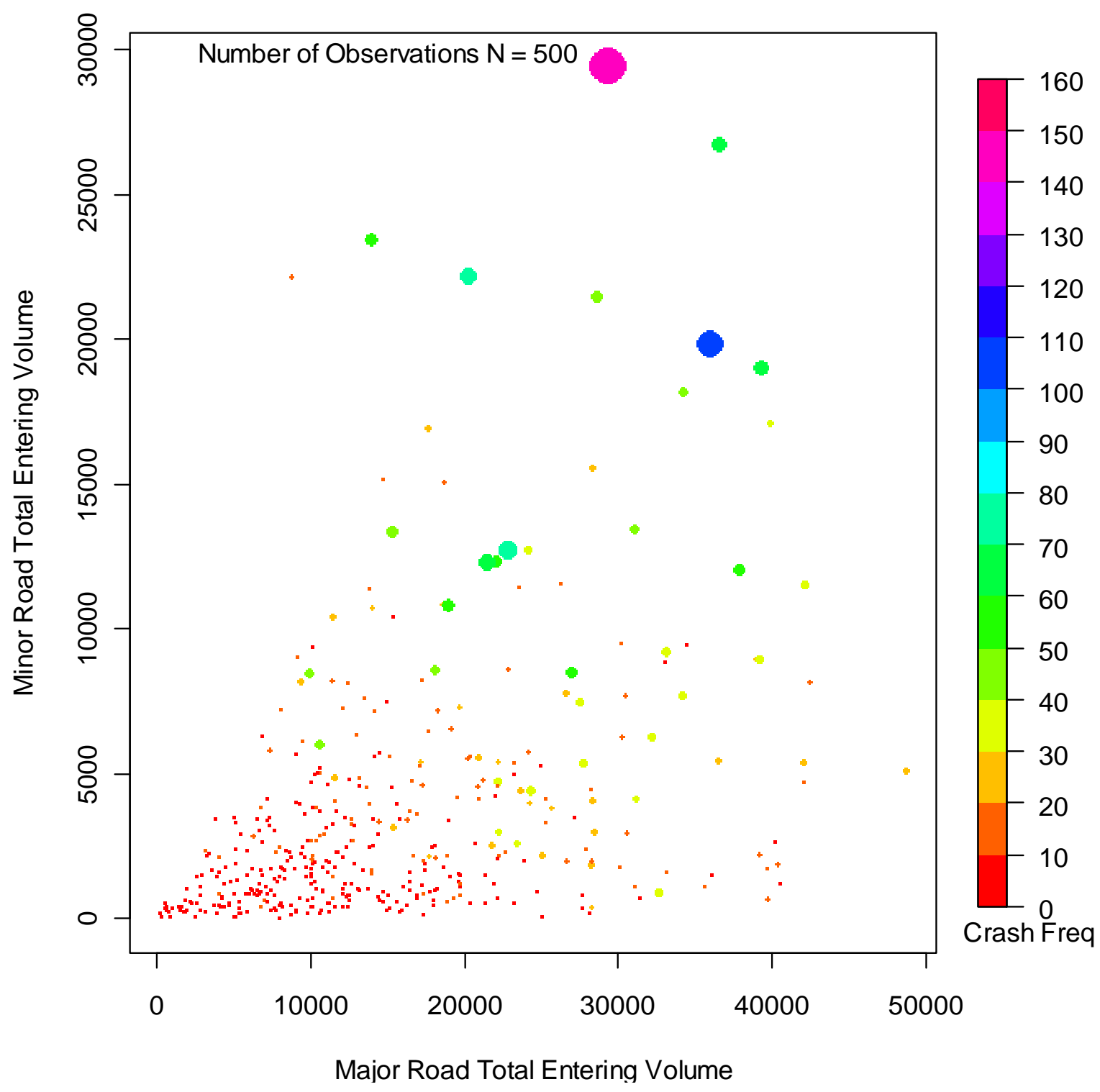

Figure 4.3: Crash Frequency (Dots And Color Proportional To Crash Frequency) Plotted Against Major And Minor Entering Average Volume

Though using crash rate to assess the intersection's safety performance is cautioned (see section 2.6.3 in literature review), it is still useful to calculate rates in advance of more detailed modeling efforts described later in this chapter. For the sampled intersections, intersection crash rates per million entering vehicles were calculated using the standard formula:

$$
\text { Crash Rate }=\frac{C * 10^{6}}{V * D}
$$

- $C=$ number of crashes in study period

- $V=$ the sum of volumes entering from all approaches, in vehicles per day (usually AADT)

- $D=$ number of days in study period 
The rates were calculated for each of the eight land use-intersection type - traffic control configuration. The results of the analysis are presented in Table 4.1 which includes the number of intersections in the sample, the mean, median and standard deviation, coefficient of variation (standard deviation/mean), and $90^{\text {th }}$ percentile rate of the crash rate. Table 4.2 provides the same information, expect each intersection type is divided by entering volume groups.

First, it useful to compare average (mean) crash rates for intersections in the sample. Overall, the mean crash rates are all below 1.0 crashes per MEV. Inspection of Table 4.1 confirms observations in the previous literature that 3-leg intersections have lower average crash rates then 4-leg intersections. With the exception of 4-leg stop-control, all rural intersections have lower crash rates than their urban of the same configuration and traffic control. In Table 4.2 it can be seen that when comparing across all intersection types, rural intersections have higher crash rates from all volume groups except the highest volume group (>22,500 entering vehicles) where urban rates are higher.

Second, it is of interest to compare the distribution of the intersection crash rates. The standard deviation and coefficient of variation statistics are provided in the tables. Graphically, the distribution of crash rates is best shown by kernel density plots. The density plots are nonparametric estimates of the distribution. For interpretation purposes, the reader can consider these plots are akin to histograms. Density plots for 3-leg intersections are shown in Figure 4.4 and 4-leg intersections in Figure 4.5. In the plots, signalized intersections are solid lines; stopcontrolled intersections are dashed lines. Urban intersections are blue (requires color print) and heavier weight lines; rural are black. Of interest on the plots are the shape of the estimated density function (location of peak and the overall width).

The intersection types with the most variability are rural 3-ST and rural 4-ST (seen in the long tails of the density estimates). This is also identified in Table 4.1 by the coefficient of variation (rural 3-ST intersection (1.602) and rural 4-ST intersection type (1.230)). With the exception of the long tail on the rural 3-ST types, the figures show that 3-leg intersections have less variability than the 4-leg intersections. As a final measure of the variability, the tables provide the $90^{\text {th }}$ percentile crash rates. In this sample only $10 \%$ of the intersections exceed this rate.

Finally, it is of interest to quantify if the distributions of crash rates are normally distributed. Included in the Appendix A are Q-Q normality plots as a graphical test for normality for each distribution. In general, the distributions are reasonable fits to the normal distribution with the exceptions of some of the lower tails. As such, it would be reasonable to estimate confidence intervals of the mean crash rate. 
Table 4.1: Intersection Crash Rates by Land Type and Traffic Control

\begin{tabular}{|c|c|c|c|c|c|c|c|c|}
\hline & \multicolumn{4}{|l|}{ Rural } & \multicolumn{4}{|l|}{ Urban } \\
\hline & 3SG & 3ST & 4SG & 4ST & 3SG & 3ST & 4SG & 4ST \\
\hline $\mathrm{N}$ of Intersections & 7 & 115 & 20 & 60 & 55 & $\begin{array}{c}77 \\
0.13\end{array}$ & 106 & 60 \\
\hline Mean Crash Rate & 0.226 & 0.196 & 0.324 & 0.434 & 0.275 & $\begin{array}{c}1 \\
0.10\end{array}$ & 0.477 & 0.198 \\
\hline Median Crash Rate & 0.163 & 0.092 & 0.320 & 0.267 & 0.252 & $\begin{array}{c}5 \\
0.12\end{array}$ & 0.420 & 0.145 \\
\hline Standard Deviation & 0.185 & 0.314 & 0.223 & 0.534 & 0.155 & $\begin{array}{c}1 \\
0.92\end{array}$ & 0.273 & 0.176 \\
\hline Coefficient of Variation & 0.819 & 1.602 & 0.688 & 1.230 & 0.564 & 4 & 0.572 & 0.889 \\
\hline $90^{\text {th }}$ percentile rate & 0.464 & 0.475 & 0.579 & 1.080 & 0.509 & $\begin{array}{c}0.29 \\
3\end{array}$ & 0.860 & 0.408 \\
\hline
\end{tabular}

Table 4.2: Intersection Crash Rates by Type and Aggregated Volume Group

\begin{tabular}{|c|c|c|c|c|c|c|c|c|}
\hline & \multicolumn{4}{|l|}{ Rural } & \multicolumn{4}{|l|}{ Urban } \\
\hline & $\begin{array}{l}x< \\
7500 \\
\end{array}$ & $\begin{array}{l}x>7500 \\
x<15000\end{array}$ & $\begin{array}{l}x>15000 \\
x<22500\end{array}$ & $\begin{array}{l}x> \\
22500 \\
\end{array}$ & $\begin{array}{l}\mathbf{x}< \\
7500 \\
\end{array}$ & $\begin{array}{l}x>7500 \\
x<15000\end{array}$ & $\begin{array}{l}x>15000 \\
x<22500 \\
\end{array}$ & $\begin{array}{l}x> \\
22500 \\
\end{array}$ \\
\hline $\mathrm{N}$ of Intersections & 110 & 62 & 17 & 13 & 20 & 80 & 90 & 108 \\
\hline Mean Crash Rate & 0.288 & 0.254 & 0.332 & 0.273 & 0.141 & 0.204 & 0.281 & 0.400 \\
\hline Median Crash Rate & 0.090 & 0.160 & 0.332 & 0.273 & 0.103 & 0.167 & 0.243 & 0.354 \\
\hline Standard Deviation & 0.490 & 0.257 & 0.218 & 0.187 & 0.180 & 0.178 & 0.245 & 0.264 \\
\hline Coefficient of Variation & 1.701 & 1.012 & 0.657 & 0.685 & 1.277 & 0.873 & 0.872 & 0.660 \\
\hline
\end{tabular}

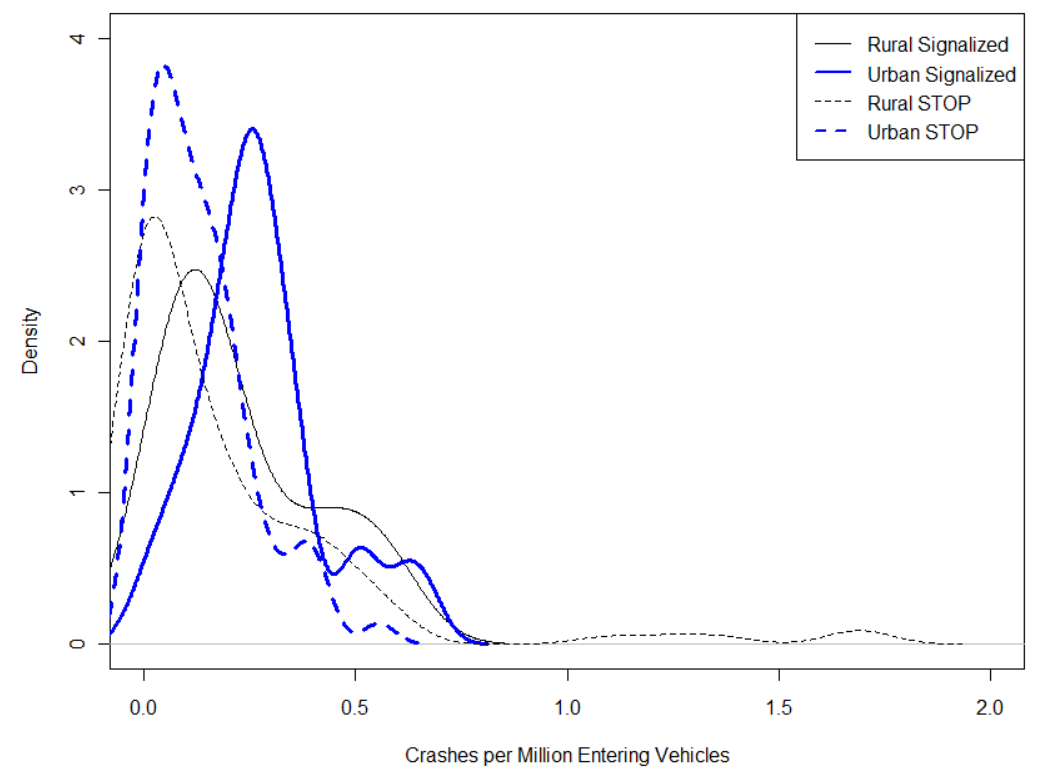

Figure 4.4: Three-Leg Crash Rate Density Plot 


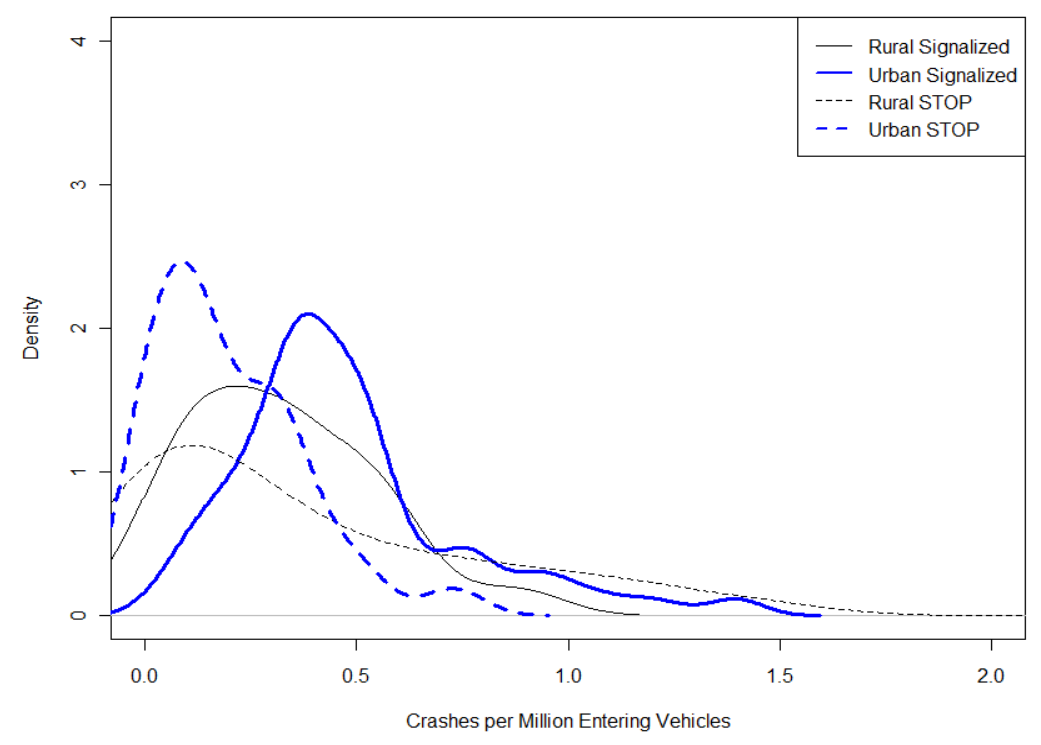

Figure 4.5: Four-Leg Crash Rate Density Plot

For easy cross-reference, the summary of the unpublished internal Oregon DOT memorandum dated Sept 2, 1994 (TRA-03-01) by Eric Bonn summarized in literature review is duplicated below in Table 4.3. These rates were calculated from a total of 413 intersections - consisting of the intersection of two state highways and those where recent manual counts had been conducted. The rates in our sample appear to be comparable in general, though Bonn's are somewhat higher. Much has changed (e.g. reporting thresholds) since 1994 so it would be reasonable to expect that the rates would be different. Bonn's sample focused primarily on the intersection of two state highways. For the experience with the pilot study, higher volume stateto-state intersection would produce higher rates.

In comparison to other published crash rates aggregated at the state-level, the Oregon crash rates determined in this research are generally well below those of other states. For example, the Knapp and Campbell (2005) study in Wisconsin found average crash rates near 1.0 crashes per million entering vehicles for rural urban intersections. Reported average crash rates in Massachusetts were 0.80 for signalized intersections and 0.60 for unsignalized intersections. Only crash rate reported by Agent and Pigman (2003) were comparable to the calculated Oregon rates (rural rates 0.26-0.37 and urban rates from 0.43-0.57).

While it is tempting to draw conclusions about the relative safety of Oregon's intersections are a large share of this difference, it is likely due to the reporting thresholds. In a recent effort to calibrate the Highway Safety Manual models to Oregon conditions, Xie et al. (2011) found convincing evidence that there is substantial underreporting of crashes due to the self-reporting nature of Oregon's crash reports. 
Table 4.3: Average Intersection Crash Rates (Bonn 1994)

\begin{tabular}{||c|r|r|r|r||}
\hline \multicolumn{5}{||c|}{ BY RURALURBAN AND SIGNALIZEDIUNSIGNALIZED } \\
\hline \hline Classification & $\begin{array}{c}\text { Number of } \\
\text { Intersections }\end{array}$ & $\begin{array}{c}\text { Average } \\
\text { Rate }\end{array}$ & $\begin{array}{c}95 \% \\
\text { Confidence } \\
\text { Interval }\end{array}$ & $\begin{array}{c}\text { Top- } \\
10 \% \\
\text { Cut-Off }\end{array}$ \\
\hline Total & 413 & 0.34 & \pm 0.05 & 0.98 \\
Signalized & 128 & 0.40 & \pm 0.06 & 0.81 \\
Unsignalized & 285 & 0.31 & \pm 0.07 & 1.03 \\
Beacon & 44 & 0.45 & \pm 0.19 & 1.24 \\
\hline Total Urban & 171 & 0.34 & \pm 0.05 & 0.75 \\
Signalized & 98 & 0.40 & \pm 0.06 & 0.80 \\
Unsignalized & 73 & 0.27 & \pm 0.07 & 0.68 \\
\hline Total Rural & & & & 1.11 \\
Signalized & 242 & 0.34 & \pm 0.08 & 0.89 \\
Unsignalized & 30 & 0.42 & \pm 0.13 & 1.03 \\
\hline
\end{tabular}

* Accidents per million entering vehicles

\subsubsection{Discussion on Applications of Rates}

Based on the rates calculated in this study, the common assumption in Oregon that intersections with greater than 1.0 MEV are "hazardous" as a rule of thumb might not be a good one. Only one intersection has a 90th percentile rate near 1.0 (rural 4ST) in Table 4.1. Further, it is clear that different intersections have very different rates - a one-size fits all threshold rate does not recognize this. It would be appropriate to use the $90^{\text {th }}$ percentile rates as a rule-of-thumb test for each intersection type.

A possible use of the mean crash rates would be to use them in calculations of the critical crash rate. The critical rate is calculated as:

$$
R_{C}=R_{A}+K \sqrt{\frac{R_{A}}{M}}+\frac{1}{2 M} \text {, where }
$$

$\mathrm{R}_{\mathrm{C}}=$ critical rate

$\mathrm{R}_{\mathrm{A}}=$ the average rate for similar facility

$\mathrm{K}=$ probability constant based on desired level of significance (1.645 for 95\%)

$\mathrm{M}=$ millions of VMT or entering vehicles

If the crash rate at the study location exceeds the critical rate, it is a possible indication to whether the location is exceeding average crash rates. In the above formula $\mathrm{R}_{\mathrm{A}}$ would be obtained from Table 4.1. 


\subsection{CRASH PATTERNS}

In the "direct diagnostics” work by Kononov and Janson (2002), they argue that an overrepresentation of one type of crash relative to other crash types is a better indicator of possible improvements than a high frequency relative to other locations. For example, a high proportion of fixed-object crashes relative to all crashes on a highway segment might mean the location is a good candidate for shoulder rumble strips or enhanced delineation.

In order to do this type of analysis, a tabulation of typical distributions for various crash classifications needed to be developed for average intersections in a jurisdiction. In this section, patterns were developed for a variety of crash and driver related factors for each of the eight intersection categories. These expected proportions were generated for the sample intersections for a five-year period (2003-2007). In the subsections that follow, proportions of crashes by each factor are presented in both a table format and a stacked bar plot. The table reports percentages (and a total number of crashes proportioned in the last row). Each figure displays the column percentages such that each bar sums to 1.00 (100\%). A legend for each category is shown in the figures. The order of the legend top-to-bottom matches the order of the stacked bar left-to-right. This order also matches the corresponding table.

\subsubsection{Crash Severity}

Proportions of crash severity by intersection type are shown in Table 4.4. The same data are shown in a stacked bar plot (Figure 4.6). In the figure, each bar sums to 1.00 and legend for each category is shown in the figure. Inspection of the table and the figure reveal that across the intersection types, there are minor differences in the distributions of crash type (with the exception of the R-4ST intersection which has higher proportion of fatal and injury A crashes and the U-4ST type which has a smaller proportion of fatal and injury A crashes). Another observation is that minor stop-controlled intersections tend to have higher proportions of severe crashes. To test whether the proportions differ by statistically by intersection category, a Pearson's chi-square test of independence was run on the underlying count data. The test indicates that at the $95 \%$ confidence the patterns of severity by intersection type are different $\left(\chi^{2}\right.$ $=59.99, \mathrm{df}=14, \mathrm{p}$-value $=1.173 \mathrm{e}-07)$.

Table 4.4: Crash Severity Proportions by Intersection Type, 2003-2007 Data

\begin{tabular}{r|rrrr|rrrr}
\hline & \multicolumn{5}{|c}{ Urban } & \multicolumn{5}{c}{ Rural } \\
Pattern & 4-ST & 4-SG & 3-ST & 3-SG & 4-ST & 4-SG & 3-ST & 3-SG \\
\hline FAT+INJA & $1.4 \%$ & $2.3 \%$ & $4.1 \%$ & $2.4 \%$ & $7.8 \%$ & $0.8 \%$ & $3.2 \%$ & $3.7 \%$ \\
INJB+C & $44.2 \%$ & $41.0 \%$ & $44.0 \%$ & $41.0 \%$ & $51.2 \%$ & $46.9 \%$ & $42.8 \%$ & 46.3 \\
& & & & & & $\%$ \\
PDO & $54.4 \%$ & $56.7 \%$ & $51.9 \%$ & $56.5 \%$ & $41.0 \%$ & $52.2 \%$ & $54.0 \%$ & 50.0 \\
& 283 & 2659 & 318 & 743 & 295 & 245 & 278 & 54 \\
\hline Total Crashes & & & & & & &
\end{tabular}




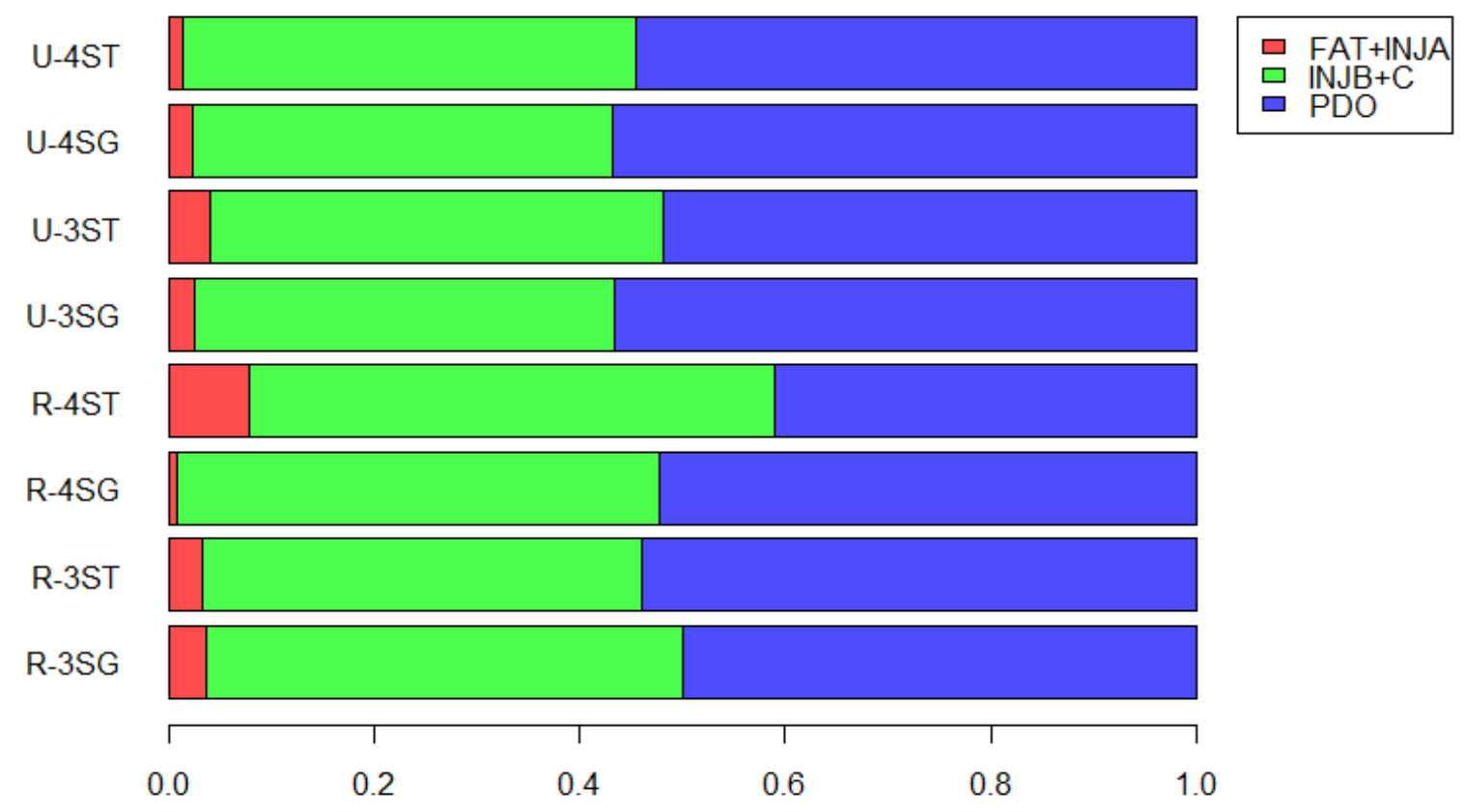

Figure 4.6: Stacked Barplot of Crash Severity Proportions by Intersection Type, 2003-2007 Data

\subsubsection{Collision Types (All)}

Proportions of crash severity by intersection type are shown in Table 4.5 and in the stacked bar plot Figure 4.7. Patterns of crash type across intersection types are clearly different (as expected). The differences in patterns can largely explained by the difference in geometry and volumes at these intersections. At the signalized intersections, the most common crash type is the rear-end crash. However, at the 4-leg minor stop-controlled intersections in both rural and urban setting, the most common crash type is angle. When comparing 3-leg and 4-leg configurations, the proportion of angle crashes differs significantly (at 3-leg intersections turning crashes are more common than angle crashes). A Pearson's chi-square test of independence confirms that the proportions differ significantly by intersection category $\left(\chi^{2}=942.86\right.$, $\mathrm{df}=77$, p-value $<2.2 \mathrm{e}-$ 16). 
Table 4.5: Collision Types (All Crashes) Proportions by Intersection Type, 2003-2007 Data

\begin{tabular}{r|rrrr|rrrr}
\hline & \multicolumn{5}{|c|}{ Urban } & \multicolumn{4}{c}{ Rural } \\
Pattern & 4-ST & 4-SG & 3-ST & 3-SG & 4-ST & 4-SG & 3-ST & 3-SG \\
\hline ANGL & $29.7 \%$ & $17.7 \%$ & $3.8 \%$ & $4.7 \%$ & $40.3 \%$ & $20.0 \%$ & $6.1 \%$ & $1.9 \%$ \\
BACK & $1.1 \%$ & $0.8 \%$ & $0.3 \%$ & $1.3 \%$ & $0.7 \%$ & $1.2 \%$ & $1.1 \%$ & $1.9 \%$ \\
FIX & $2.1 \%$ & $1.4 \%$ & $5.3 \%$ & $3.5 \%$ & $8.5 \%$ & $2.4 \%$ & $23.0 \%$ & $3.7 \%$ \\
HEAD & $0.0 \%$ & $0.2 \%$ & $0.0 \%$ & $0.1 \%$ & $0.7 \%$ & $0.0 \%$ & $0.4 \%$ & $0.0 \%$ \\
NCOL & $0.4 \%$ & $0.2 \%$ & $0.0 \%$ & $0.1 \%$ & $1.4 \%$ & $0.4 \%$ & $1.1 \%$ & $1.9 \%$ \\
OTH & $0.0 \%$ & $0.2 \%$ & $1.3 \%$ & $0.9 \%$ & $0.3 \%$ & $0.4 \%$ & $2.9 \%$ & $0.0 \%$ \\
PARK & $0.0 \%$ & $0.1 \%$ & $0.0 \%$ & $0.1 \%$ & $0.0 \%$ & $0.0 \%$ & $0.0 \%$ & $0.0 \%$ \\
PED & $1.8 \%$ & $1.7 \%$ & $0.6 \%$ & $0.8 \%$ & $0.7 \%$ & $0.8 \%$ & $0.0 \%$ & $0.0 \%$ \\
REAR & $28.3 \%$ & $47.2 \%$ & $31.1 \%$ & $54.0 \%$ & $16.9 \%$ & $42.4 \%$ & $26.3 \%$ & $79.6 \%$ \\
SS-M & $0.4 \%$ & $0.3 \%$ & $0.9 \%$ & $0.5 \%$ & $1.4 \%$ & $0.0 \%$ & $0.7 \%$ & $0.0 \%$ \\
SS-O & $2.8 \%$ & $4.4 \%$ & $3.1 \%$ & $4.6 \%$ & $1.0 \%$ & $5.3 \%$ & $2.2 \%$ & $1.9 \%$ \\
TURN & $33.6 \%$ & $25.9 \%$ & $53.5 \%$ & $29.2 \%$ & $28.1 \%$ & $26.9 \%$ & $36.3 \%$ & $9.3 \%$ \\
\hline Total Crashes & 283 & 2659 & 318 & 743 & 295 & 245 & 278 & 54 \\
\hline
\end{tabular}

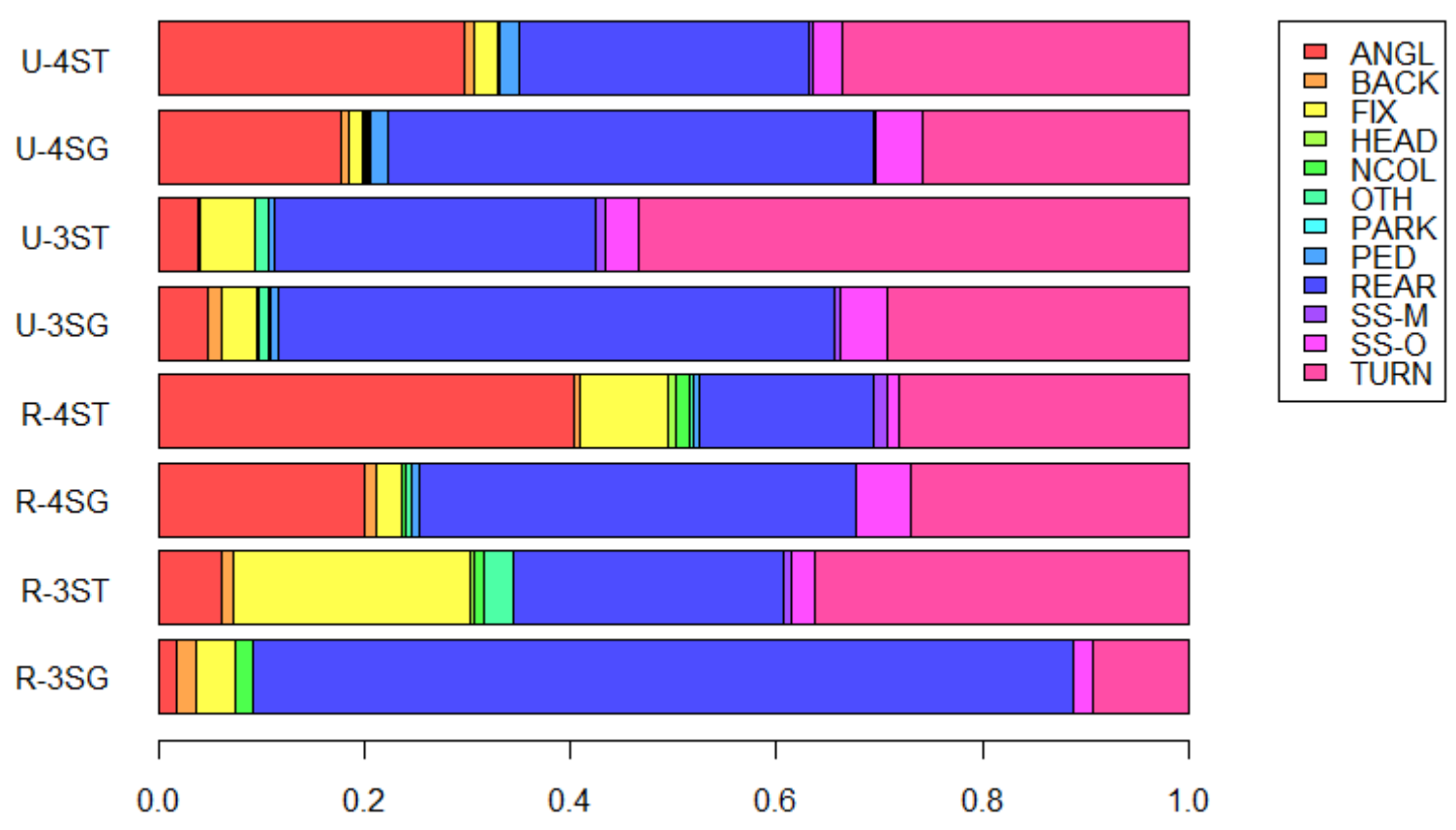

Figure 4.7: Collision Type Proportions by Intersection Type (All crashes), 2003-2007 Data

\subsubsection{Collision Types (Fatal and Injury A)}

Proportions of crash severity by intersection type are shown in Table 4.6. The same data are shown in a stacked bar plot (Figure 4.8). There were 132 fatal and injury A crashes reported at the sample intersections, so proportioning by the 12 collision types across the 8 intersection types leaves many cells with zero observations. Two intersection types have 20 or more crashes 
(U4-SG and R4-ST). At the urban intersections, pedestrian crashes are only $1.8 \%$ of all crashes but $13.6 \%$ of fatal and injury A crashes. Angle crashes also contribute more towards fatal and injury proportions than the total. At the rural 4-ST intersections, angle crashes are 39.5\% of total crashes but $65 \%$ of the fatal and injury A crashes. For both intersection types, rear-end crashes are a lower proportions of fatal and injury A crashes than total crashes. The difference in the collision type patterns is not unexpected - angle crashes are more likely to produce injury than a collision with a parked vehicle. The many cells with zero counts preclude a chi-square test.

Table 4.6: Collision Types Proportions by Intersection Type (Fatal and Injury A Crashes), 2003-2007 Data

\begin{tabular}{r|rrrr|rrrr}
\hline & \multicolumn{4}{|c}{ Urban } & \multicolumn{3}{c}{ Rural } \\
Pattern & 4-ST & 4-SG & 3-ST & 3-SG & 4-ST & 4-SG & 3-ST & 3-SG \\
\hline ANGL & $25.0 \%$ & $31.1 \%$ & $7.7 \%$ & $0.0 \%$ & $56.5 \%$ & $50.0 \%$ & $11.1 \%$ & $0.0 \%$ \\
BACK & $0.0 \%$ & $0.0 \%$ & $0.0 \%$ & $0.0 \%$ & $0.0 \%$ & $0.0 \%$ & $0.0 \%$ & $0.0 \%$ \\
FIX & $0.0 \%$ & $4.9 \%$ & $15.4 \%$ & $16.7 \%$ & $8.7 \%$ & $0.0 \%$ & $22.2 \%$ & $0.0 \%$ \\
HEAD & $0.0 \%$ & $1.6 \%$ & $0.0 \%$ & $0.0 \%$ & $0.0 \%$ & $0.0 \%$ & $0.0 \%$ & $0.0 \%$ \\
NCOL & $33.3 \%$ & $0.0 \%$ & $0.0 \%$ & $5.6 \%$ & $0.0 \%$ & $0.0 \%$ & $0.0 \%$ & $50.0 \%$ \\
OTH & $0.0 \%$ & $0.0 \%$ & $0.0 \%$ & $0.0 \%$ & $0.0 \%$ & $0.0 \%$ & $0.0 \%$ & $0.0 \%$ \\
PARK & $0.0 \%$ & $2.4 \%$ & $0.0 \%$ & $0.0 \%$ & $0.0 \%$ & $0.0 \%$ & $0.0 \%$ & $0.0 \%$ \\
PED & $0.4 \%$ & $13.1 \%$ & $7.7 \%$ & $5.6 \%$ & $0.0 \%$ & $0.0 \%$ & $0.0 \%$ & $0.0 \%$ \\
REAR & $0.4 \%$ & $19.7 \%$ & $0.0 \%$ & $11.1 \%$ & $8.7 \%$ & $0.0 \%$ & $0.0 \%$ & $1.8 \%$ \\
SS-M & $0.0 \%$ & $0.0 \%$ & $0.0 \%$ & $0.0 \%$ & $0.0 \%$ & $0.0 \%$ & $0.0 \%$ & $0.0 \%$ \\
SS-O & $0.0 \%$ & $1.6 \%$ & $0.0 \%$ & $0.0 \%$ & $0.0 \%$ & $0.0 \%$ & $11.1 \%$ & $0.0 \%$ \\
TURN & $0.0 \%$ & $26.2 \%$ & $69.2 \%$ & $61.1 \%$ & $26.1 \%$ & $50.0 \%$ & $55.6 \%$ & $0.0 \%$ \\
\hline Total Crashes & 4 & 61 & 13 & 18 & 23 & 2 & 9 & 2 \\
\hline
\end{tabular}
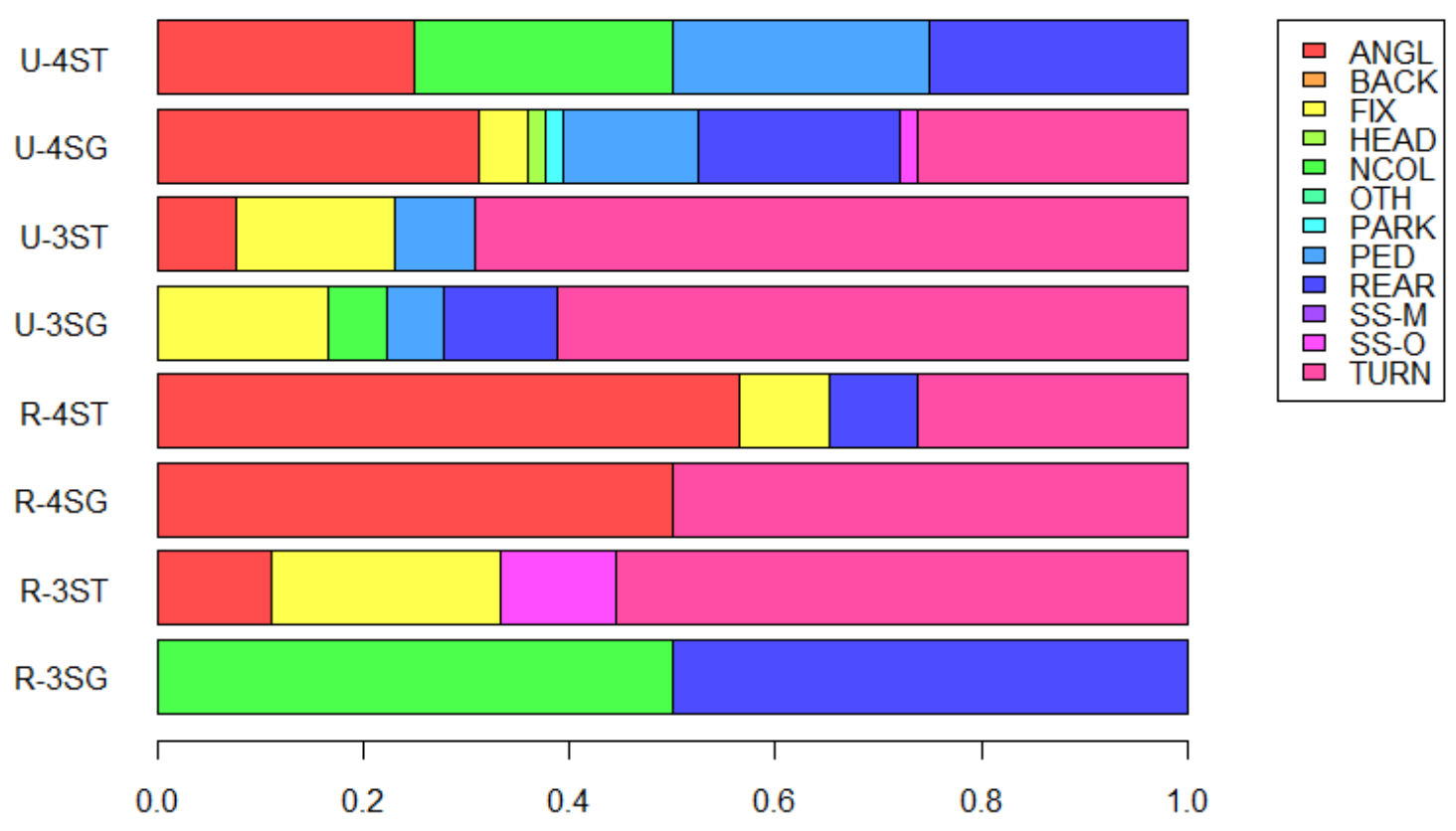

Figure 4.8: Collision Type Proportions by Intersection Type (Fatal and Injury A Crashes), 2003-2007 Data 


\subsubsection{Number of Vehicles Involved}

Proportions of crash severity by intersection type are shown in Table 4.7 and in a stacked bar plot (Figure 4.9). Not surprisingly most intersection crashes involve multiple vehicles. Those crashes that do involve single vehicles crashes will be coded as fixed-object, non-collision, other, or pedestrian crash types (as well as few miscoded vehicles). Rural intersections tend to have higher proportions of single-vehicle crashes - with rural 3-ST having nearly $25 \%$ of total crashes involving a single vehicle. Of the 72 crashes coded single vehicle 61 were fixed object and 3 were non-collision. A Pearson's chi-square test of independence confirms that the proportions differ significantly by intersection category $\left(\chi^{2}=193.37, \mathrm{df}=7\right.$, $\mathrm{p}$-value $\left.<2.2 \mathrm{e}-16\right)$.

Table 4.7: Crash Proportions for Number of Vehicles Involved by Intersection Type, 2003-2007 Data

\begin{tabular}{r|rrrr|rrrr}
\hline & \multicolumn{4}{|c|}{ Urban } & \multicolumn{4}{c}{ Rural } \\
Pattern & 4-ST & 4-SG & 3-ST & 3-SG & 4-ST & 4-SG & 3-ST & 3-SG \\
\hline MULTIPLE & $95.4 \%$ & $95.3 \%$ & $91.5 \%$ & $93.9 \%$ & $89.2 \%$ & $94.7 \%$ & $74.1 \%$ & $94.4 \%$ \\
SINGLE & $4.6 \%$ & $4.7 \%$ & $8.5 \%$ & $6.1 \%$ & $10.8 \%$ & $5.3 \%$ & $25.9 \%$ & $5.6 \%$ \\
\hline Total Crashes & 283 & 2659 & 318 & 743 & 295 & 245 & 278 & 54 \\
\hline
\end{tabular}

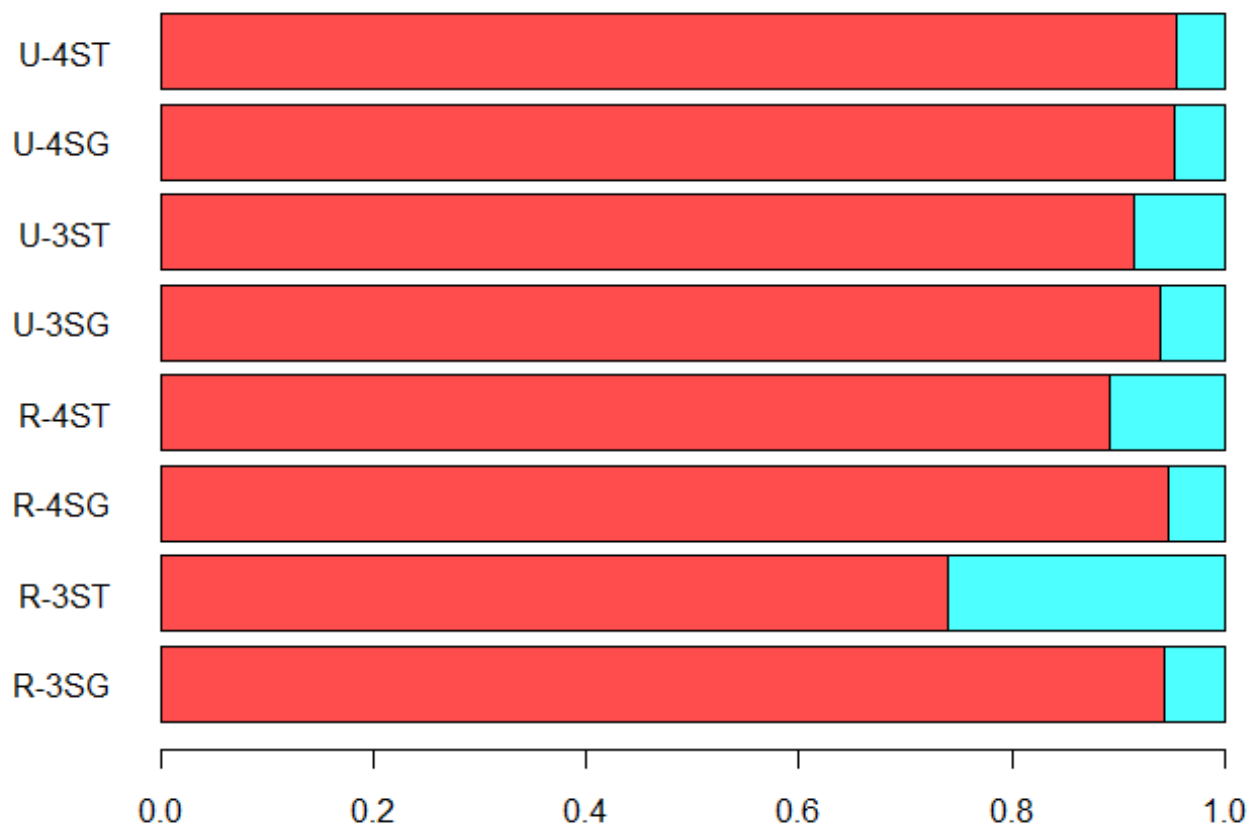

Figure 4.9: Crash Proportions for Number of Vehicles Involved by Intersection Type, 2003-2007 Data

\subsubsection{Time of Day}

Proportions of crash severity by intersection type are shown in Table 4.8 and in the stacked bar plot Figure 4.10. The patterns are reasonable - they follow typical volume patterns in traffic demand. The crash patterns by hour of day are remarkably similar given the varying intersection 
locations (urban and rural). In fact, when comparing all rural and all urban intersections there is little difference in pattern distribution. However, a Pearson's chi-square test of independence indicates that the proportions do differ significantly at the $95 \%$ confidence interval $\left(\chi^{2}=72.36\right.$, $\mathrm{df}=56$, $\mathrm{p}$-value $=0.06948$ ) across all intersection classes. It should be noted that with a p-value of 0.07 , these patterns are not significantly different at the $90 \%$ confidence level. Given the consistency of these proportions, deviations from these patterns might highlight a nearby traffic generator, sun glare or other issue could be a contributor to a safety performance issue.

Table 4.8: Crash Proportions by Hour Group by Intersection Type, 2003-2007 Data

\begin{tabular}{r|rrrr|rrrr}
\hline & \multicolumn{5}{|c|}{ Urban } & \multicolumn{5}{c}{ Rural } \\
Pattern & 4-ST & 4-SG & 3-ST & 3-SG & 4-ST & 4-SG & 3-ST & 3-SG \\
\hline A 12-3AM & $0.7 \%$ & $1.8 \%$ & $0.9 \%$ & $1.7 \%$ & $2.4 \%$ & $0.4 \%$ & $3.6 \%$ & $0.0 \%$ \\
B 3-6AM & $1.1 \%$ & $0.9 \%$ & $1.6 \%$ & $0.9 \%$ & $2.4 \%$ & $2.0 \%$ & $2.9 \%$ & $0.0 \%$ \\
C 6-9AM & $7.8 \%$ & $10.3 \%$ & $10.4 \%$ & $13.6 \%$ & $13.6 \%$ & $11.8 \%$ & $11.2 \%$ & $14.8 \%$ \\
D 9-Noon & $15.2 \%$ & $15.2 \%$ & $15.7 \%$ & $16.2 \%$ & $14.2 \%$ & $13.9 \%$ & $15.1 \%$ & $13.0 \%$ \\
E Noon-3PM & $23.7 \%$ & $21.8 \%$ & $23.3 \%$ & $23.8 \%$ & $20.3 \%$ & $24.5 \%$ & $19.1 \%$ & $22.2 \%$ \\
F 3-6PM & $33.2 \%$ & $28.6 \%$ & $32.4 \%$ & $26.5 \%$ & $31.5 \%$ & $30.6 \%$ & $31.7 \%$ & $38.9 \%$ \\
G 6-9PM & $13.4 \%$ & $16.2 \%$ & $10.7 \%$ & $12.9 \%$ & $11.2 \%$ & $12.2 \%$ & $11.9 \%$ & $5.6 \%$ \\
H 9-Mid & $4.6 \%$ & $4.9 \%$ & $4.7 \%$ & $4.2 \%$ & $4.1 \%$ & $4.1 \%$ & $4.7 \%$ & $5.6 \%$ \\
UNK & $0.4 \%$ & $0.3 \%$ & $0.3 \%$ & $0.1 \%$ & $0.3 \%$ & $0.4 \%$ & $0.0 \%$ & $0.0 \%$ \\
\hline Total & 283 & 2659 & 318 & 743 & 295 & 245 & 278 & 54 \\
\hline
\end{tabular}

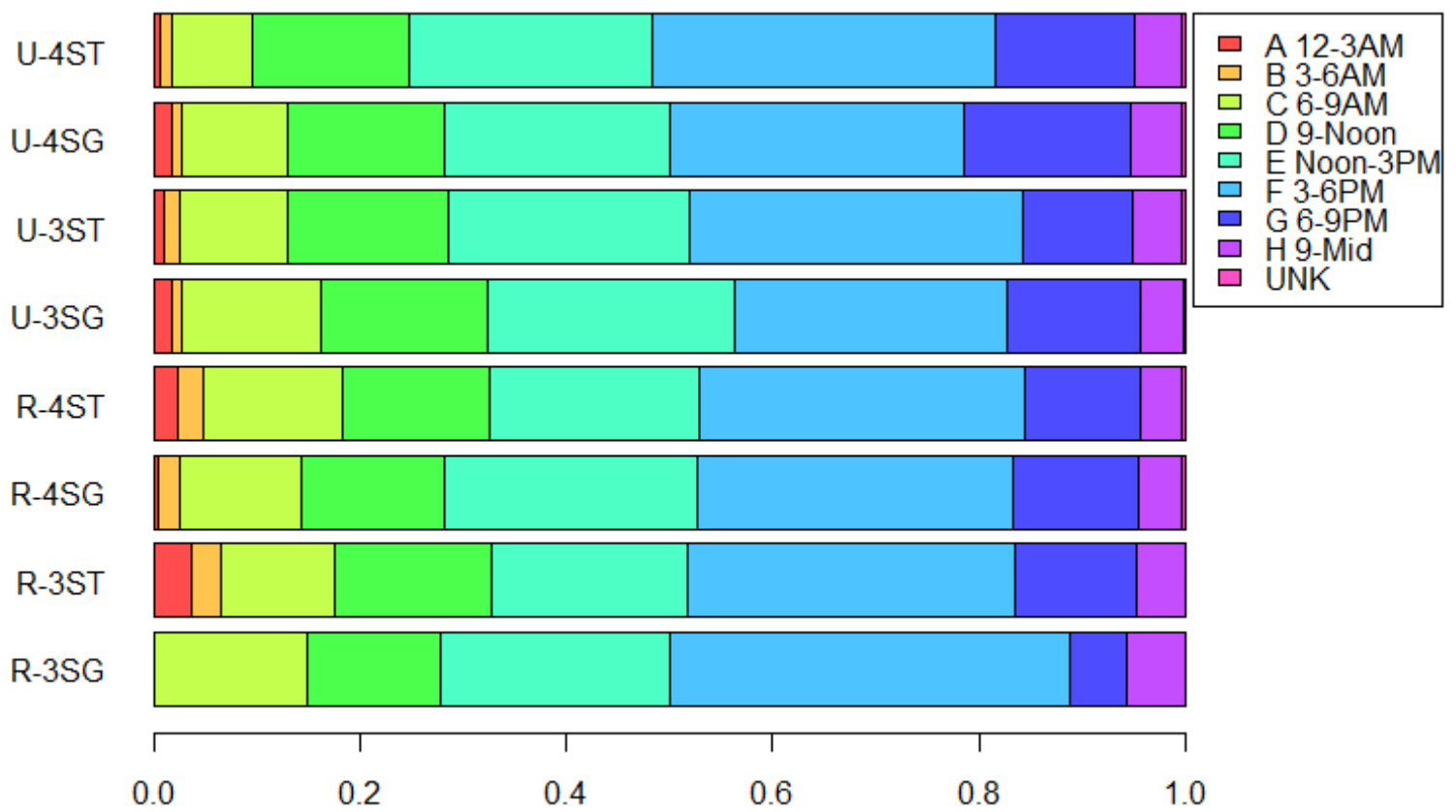

Figure 4.10: Crash Proportions for Hour Group by Intersection Type, 2003-2007 Data 


\subsubsection{Light Conditions}

Proportions of crashes by light conditions by intersection type are shown in Table 4.9 and in a stacked bar plot (Figure 4.11). Since the previous section highlighted that crashes do not vary much by time of day across intersection types, the primary difference in these tabulations are whether lighting is present at the intersection. When combining crashes coded as dark and dark with streetlights (DLIT) there is little difference between rural and urban locations or across intersection types for crashes occurring during day or night (which is similar conclusion to the crashes by hour). However, crashes in rural locations are much less likely to occur at intersections with overhead lighting (4.1\% to $11.0 \%$ coded as DLIT). A Pearson's chi-square test of independence indicates that the proportions do differ significantly at the $95 \%$ confidence interval $\left(\chi^{2}=311.11\right.$, df $=35$, p-value $\left.<2.2 \mathrm{e}-16\right)$.

Table 4.9: Crash Proportions for Lighting Condition by Intersection Type, 2003-2007 Data

\begin{tabular}{r|rrrr|rrrr}
\hline & \multicolumn{4}{|c|}{ Urban } & \multicolumn{4}{c}{ Rural } \\
Pattern & 4-ST & 4-SG & 3-ST & 3-SG & 4-ST & 4-SG & 3-ST & 3-SG \\
\hline DARK & $5.7 \%$ & $2.0 \%$ & $3.8 \%$ & $3.6 \%$ & $13.2 \%$ & $6.5 \%$ & $19.4 \%$ & $7.4 \%$ \\
DLIT & $9.9 \%$ & $16.7 \%$ & $13.8 \%$ & $13.6 \%$ & $4.1 \%$ & $11.0 \%$ & $5.4 \%$ & $7.4 \%$ \\
DAWN & $1.4 \%$ & $1.3 \%$ & $2.2 \%$ & $1.7 \%$ & $1.7 \%$ & $1.2 \%$ & $1.8 \%$ & $5.6 \%$ \\
DAY & $78.8 \%$ & $76.3 \%$ & $75.5 \%$ & $78.7 \%$ & $78.3 \%$ & $78.8 \%$ & $71.6 \%$ & $72.2 \%$ \\
DUSK & $3.9 \%$ & $3.5 \%$ & $4.7 \%$ & $2.0 \%$ & $2.4 \%$ & $2.4 \%$ & $1.8 \%$ & $7.4 \%$ \\
UNK & $0.4 \%$ & $0.2 \%$ & $0.0 \%$ & $0.3 \%$ & $0.3 \%$ & $0.0 \%$ & $0.0 \%$ & $0.0 \%$ \\
\hline Total & 283 & 2659 & 318 & 743 & 295 & 245 & 278 & 54 \\
Crashes & & & & & & & \multirow{2}{*}{$5 \%$}
\end{tabular}

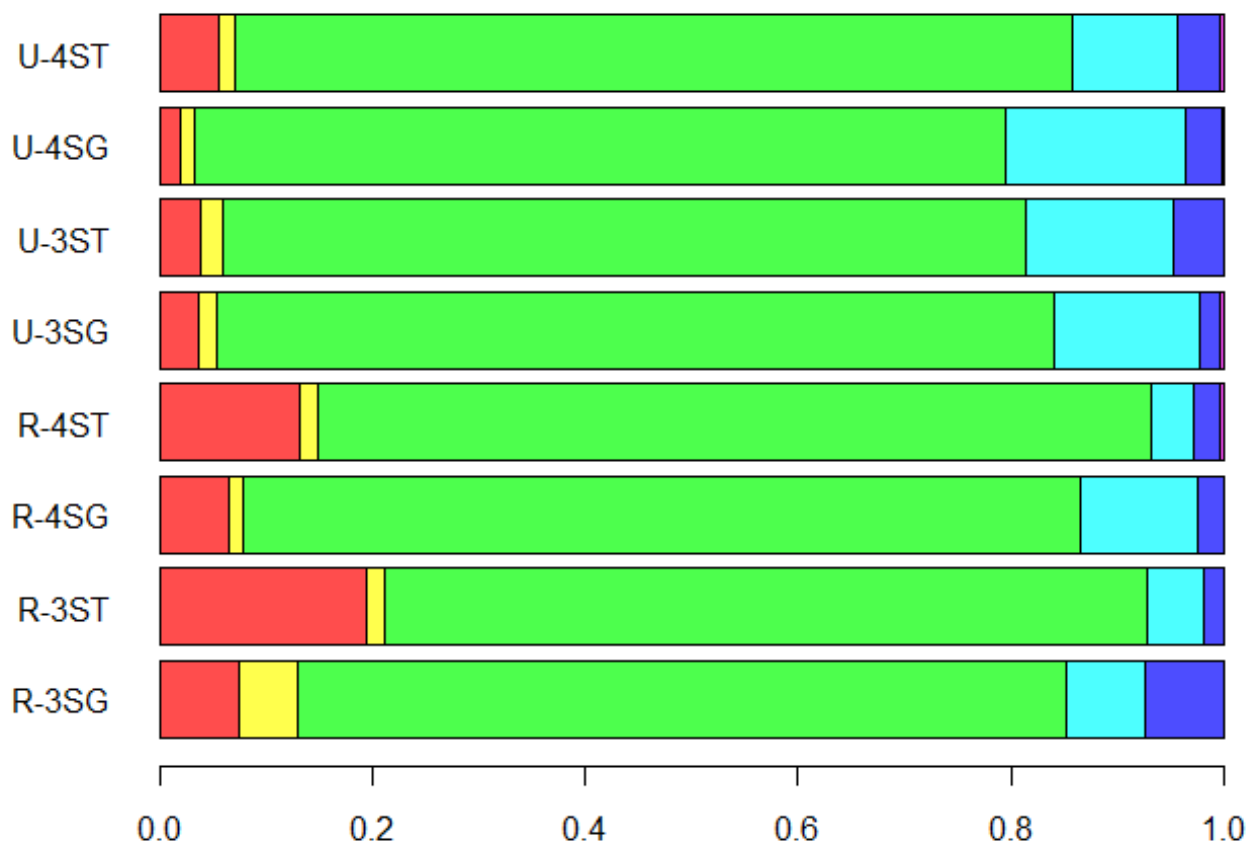

Figure 4.11: Crash Proportions for Lighting Conditions by Intersection Type, 2003-2007 Data 


\subsubsection{Surface Conditions}

Proportions of crash surface condition by intersection type are shown in Table 4.10 and in a stacked bar plot (Figure 4.12). The surface conditions are consistent across land use and intersection type. A Pearson's chi-square test of independence indicates that the proportions do differ significantly at the $95 \%$ confidence interval $\left(\chi^{2}=84.26, \mathrm{df}=28\right.$, p-value $\left.=1.521 \mathrm{e}-07\right)$. Given the statewide nature of the random sample, it is not surprising to find a small percentage of crashes occurring on snow and ice conditions. Clearly though this will vary by the typical weather experienced in a particular location of the state. To explore further, the stacked barplot of crashes by surface condition and county shown in Figure 4.13 was created. As one might expect, the crash proportions by surface condition does vary by location. The small number of intersections sampled in some counties, however, would not support proportioning of these data intersection type.

Table 4.10: Crash Proportions for Surface Conditions by Intersection Type, 2003-2007 Data

\begin{tabular}{r|rrrr|rrrr}
\hline & \multicolumn{6}{|c|}{ Urban } & \multicolumn{4}{c}{ Rural } \\
Pattern & 4-ST & 4-SG & 3-ST & 3-SG & 4-ST & 4-SG & 3-ST & 3-SG \\
\hline DRY & $80.2 \%$ & $77.3 \%$ & $73.6 \%$ & $71.2 \%$ & $75.9 \%$ & $78.4 \%$ & $74.5 \%$ & $50.0 \%$ \\
ICE & $1.4 \%$ & $0.9 \%$ & $2.8 \%$ & $2.2 \%$ & $3.1 \%$ & $0.8 \%$ & $4.3 \%$ & $3.7 \%$ \\
SNO & $1.4 \%$ & $0.5 \%$ & $0.3 \%$ & $0.5 \%$ & $0.7 \%$ & $0.0 \%$ & $1.1 \%$ & $0.0 \%$ \\
UNK & $1.1 \%$ & $1.6 \%$ & $1.3 \%$ & $0.8 \%$ & $1.4 \%$ & $0.0 \%$ & $0.0 \%$ & $1.9 \%$ \\
WET & $15.9 \%$ & $19.6 \%$ & $22.0 \%$ & $25.3 \%$ & $19.0 \%$ & $20.8 \%$ & $20.1 \%$ & $44.4 \%$ \\
\hline Total Crashes & 283 & 2659 & 318 & 743 & 295 & 245 & 278 & 54 \\
\hline
\end{tabular}

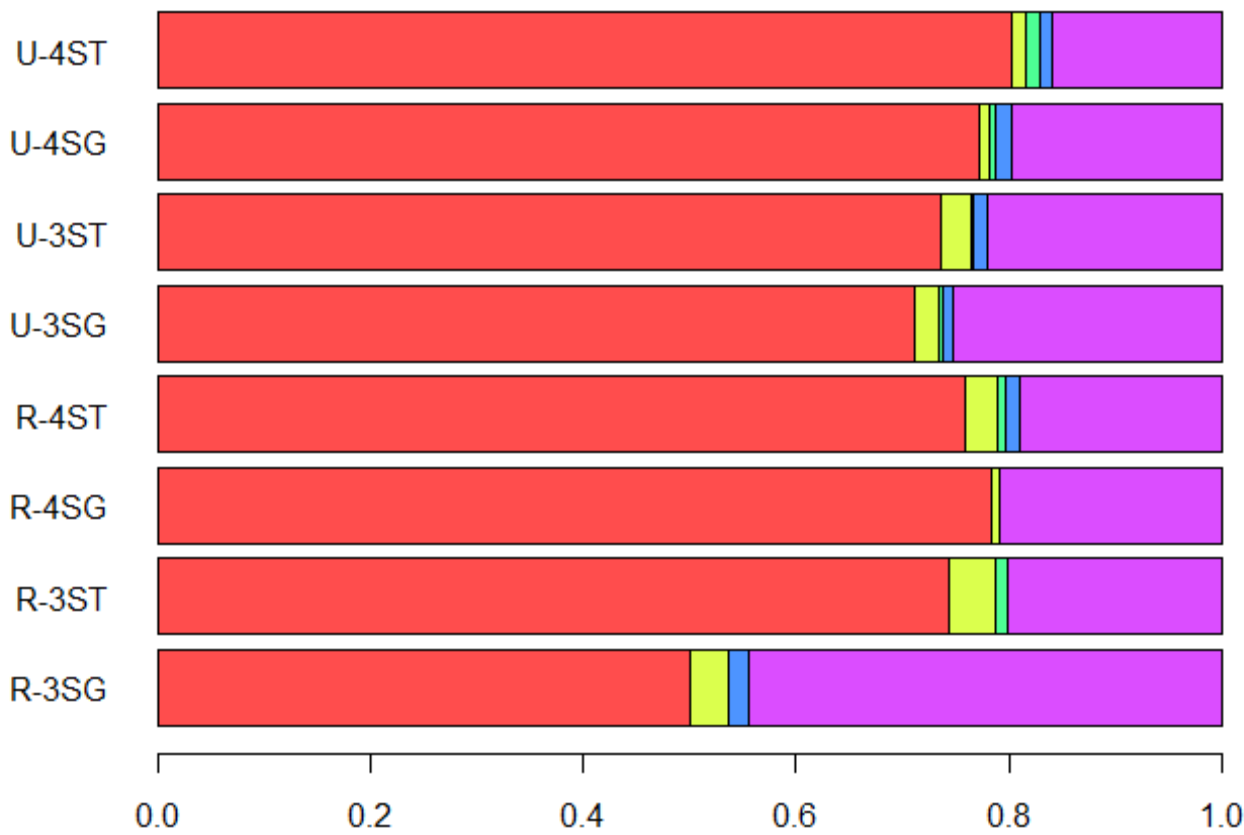

Figure 4.12: Crash Type Proportions for Surface Conditions by Intersection Type, 2003-2007 Data 


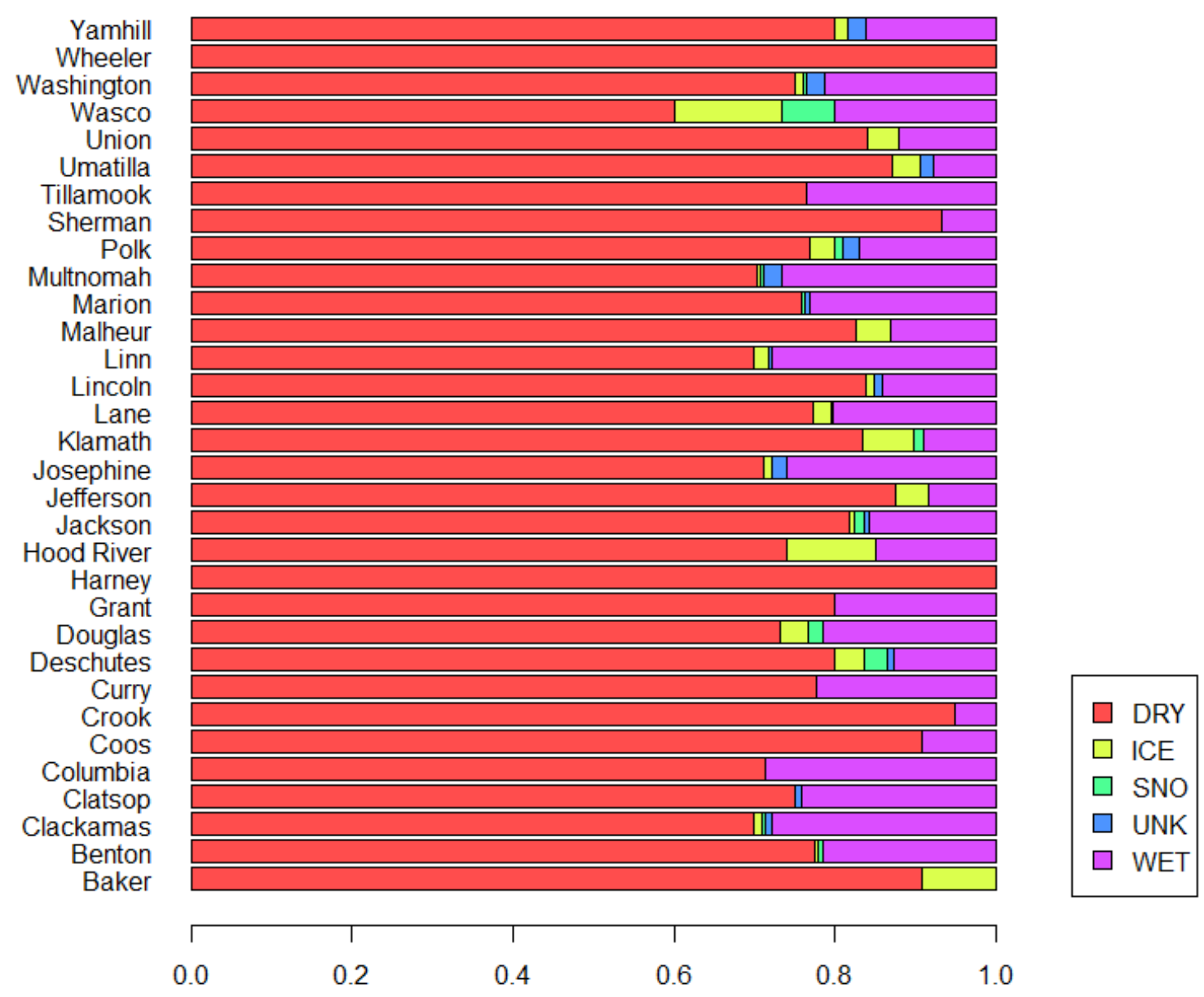

Figure 4.13: Crash Type Proportions for Surface Conditions by County, 2003-2007 Data

\subsubsection{Day of Week}

Proportions of crashes by day of the week by intersection type are shown in Table 4.7 and in a stacked bar plot Figure 4.14. There are some differences in the day of the week trends, primarily on the weekend days between urban and rural configurations. The day of week might be related to key traffic generators (e.g. school) or be different for recreational route. A Pearson's chisquare test of independence indicates that the proportions do differ significantly at the $95 \%$ confidence interval $\left(\chi^{2}=62.99, \mathrm{df}=42\right.$, p-value $\left.=0.01959\right)$. 
Table 4.11: Crash Proportions for Day of the Week by Intersection Type, 2003-2007 Data

\begin{tabular}{r|rrrr|rrrr}
\hline & \multicolumn{5}{|c|}{ Urban } & \multicolumn{4}{c}{ Rural } \\
Pattern & 4-ST & 4-SG & 3-ST & 3-SG & 4-ST & 4-SG & 3-ST & 3-SG \\
\hline 1 Sun & $9.9 \%$ & $9.9 \%$ & $6.9 \%$ & $10.8 \%$ & $11.9 \%$ & $8.6 \%$ & $14.0 \%$ & $18.5 \%$ \\
2 Mon & $12.7 \%$ & $16.2 \%$ & $14.2 \%$ & $16.3 \%$ & $12.5 \%$ & $14.7 \%$ & $12.9 \%$ & $9.3 \%$ \\
3 Tue & $14.5 \%$ & $15.8 \%$ & $15.4 \%$ & $16.3 \%$ & $14.6 \%$ & $13.1 \%$ & $16.9 \%$ & $11.1 \%$ \\
4 Wed & $18.0 \%$ & $12.3 \%$ & $14.5 \%$ & $12.4 \%$ & $15.6 \%$ & $18.8 \%$ & $10.4 \%$ & $20.4 \%$ \\
5 Thu & $14.5 \%$ & $16.0 \%$ & $12.9 \%$ & $16.8 \%$ & $14.2 \%$ & $16.3 \%$ & $15.8 \%$ & $16.7 \%$ \\
6 Fri & $19.8 \%$ & $18.0 \%$ & $20.4 \%$ & $15.2 \%$ & $21.0 \%$ & $15.1 \%$ & $14.0 \%$ & $16.7 \%$ \\
7 Sat & $10.6 \%$ & $11.8 \%$ & $15.7 \%$ & $12.2 \%$ & $10.2 \%$ & $13.5 \%$ & $15.8 \%$ & $7.4 \%$ \\
\hline Total Crashes & 283 & 2659 & 318 & 743 & 295 & 245 & 278 & 54 \\
\hline
\end{tabular}

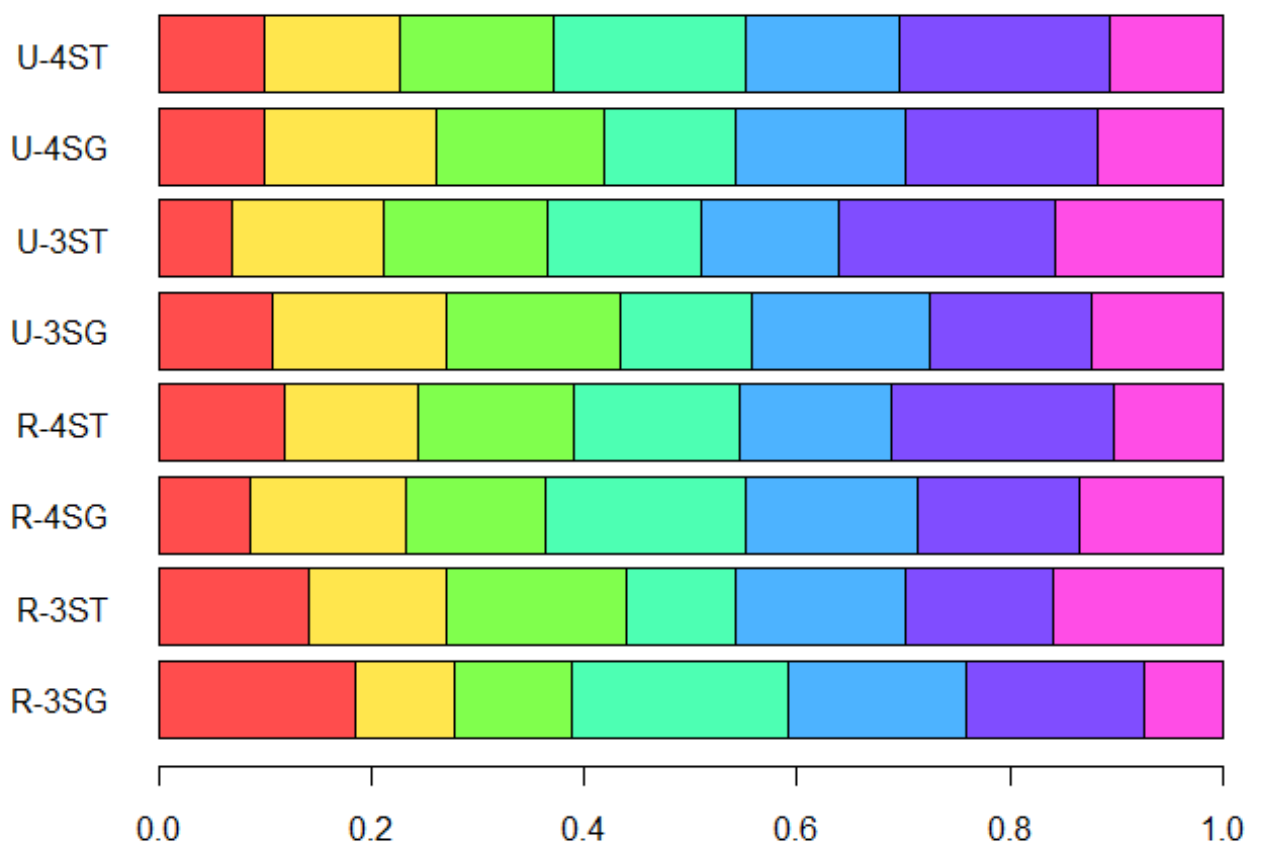

Figure 4.14: Crash Type Proportions By Intersection Type, 2003-2007 Data

\subsubsection{Age of Driver}

For each driver involved in the reported crash, the driver's age was binned into one of the threeyear bins listed in Table 4.12 and shown in the stacked bar plot Figure 4.15. Though the patterns appear consistent across intersection types, one interesting observation is that the proportion of young (presumably novice) drivers aged 15-18 is much higher for the stop-controlled intersections than for the signalized intersection (both rural and urban). One speculation is that this is possibly related to the well known human factor that younger drivers more likely to make mistake in gap selections. Differences in age-related patterns at a location under study might indicate a nearby traffic generator (e.g. school) or perhaps some behavioral problem (e.g. risk taking). 
For reference, population proportions from the 2000 US Census are provided in Table 4.13. The age cohorts do not match Table 4.12 unless age categories 15-19 and 19-24 are combined and 55-59 and 60-64. Persons aged 15-24 represent 13.8\% of the population but in Table 4.12, drivers in that age group are more crash involved $(24 \%(10.1+8.0+5.9)$ for Rural 4-ST). Likewise, persons aged 55-64 represent $8.9 \%$ of the population but are more crash involved (14.2\% of crashes at Rural 4-ST). Finally, a Pearson's chi-square test of independence indicates that the proportions do differ significantly at the $95 \%$ confidence interval across intersection types $\left(\chi^{2}=164.43, \mathrm{df}=70\right.$, p-value $\left.=1.440 \mathrm{e}-09\right)$.

Table 4.12: Crash Proportions for Age Cohort of Driver by Intersection Type, 2003-2007 Data

\begin{tabular}{r|rrrr|rrrr}
\hline & \multicolumn{6}{|c|}{ Urban } & \multicolumn{4}{c}{ Rural } \\
Pattern & 4-ST & 4-SG & 3-ST & 3-SG & 4-ST & 4-SG & 3-ST & 3-SG \\
\hline$<14$ & $0.2 \%$ & $0.0 \%$ & $0.0 \%$ & $0.0 \%$ & $0.0 \%$ & $0.0 \%$ & $0.0 \%$ & $0.0 \%$ \\
$15-18$ & $12.0 \%$ & $6.3 \%$ & $9.4 \%$ & $7.7 \%$ & $10.1 \%$ & $8.5 \%$ & $11.0 \%$ & $3.7 \%$ \\
$19-21$ & $7.7 \%$ & $8.0 \%$ & $7.3 \%$ & $6.0 \%$ & $8.0 \%$ & $8.7 \%$ & $8.5 \%$ & $4.7 \%$ \\
$22-24$ & $8.0 \%$ & $6.6 \%$ & $5.7 \%$ & $4.8 \%$ & $5.9 \%$ & $5.7 \%$ & $6.9 \%$ & $7.5 \%$ \\
$25-34$ & $16.8 \%$ & $17.8 \%$ & $19.8 \%$ & $18.3 \%$ & $15.5 \%$ & $18.5 \%$ & $15.9 \%$ & $19.6 \%$ \\
$35-44$ & $12.9 \%$ & $16.3 \%$ & $14.3 \%$ & $16.8 \%$ & $14.1 \%$ & $14.6 \%$ & $13.2 \%$ & $15.9 \%$ \\
$45-54$ & $13.6 \%$ & $16.6 \%$ & $14.9 \%$ & $16.3 \%$ & $16.5 \%$ & $16.9 \%$ & $16.7 \%$ & $13.1 \%$ \\
$55-64$ & $10.4 \%$ & $11.4 \%$ & $13.3 \%$ & $11.6 \%$ & $14.2 \%$ & $8.7 \%$ & $13.2 \%$ & $12.1 \%$ \\
$65-74$ & $7.7 \%$ & $4.7 \%$ & $5.2 \%$ & $5.6 \%$ & $6.6 \%$ & $7.3 \%$ & $6.7 \%$ & $10.3 \%$ \\
$>75$ & $5.7 \%$ & $4.0 \%$ & $4.1 \%$ & $5.3 \%$ & $5.4 \%$ & $4.9 \%$ & $4.7 \%$ & $7.5 \%$ \\
UNK & $5.2 \%$ & $8.3 \%$ & $5.9 \%$ & $7.4 \%$ & $3.8 \%$ & $6.1 \%$ & $3.1 \%$ & $5.6 \%$ \\
\hline Total Drivers & 560 & 5481 & 630 & 1524 & 576 & 492 & 508 & 107 \\
\hline
\end{tabular}

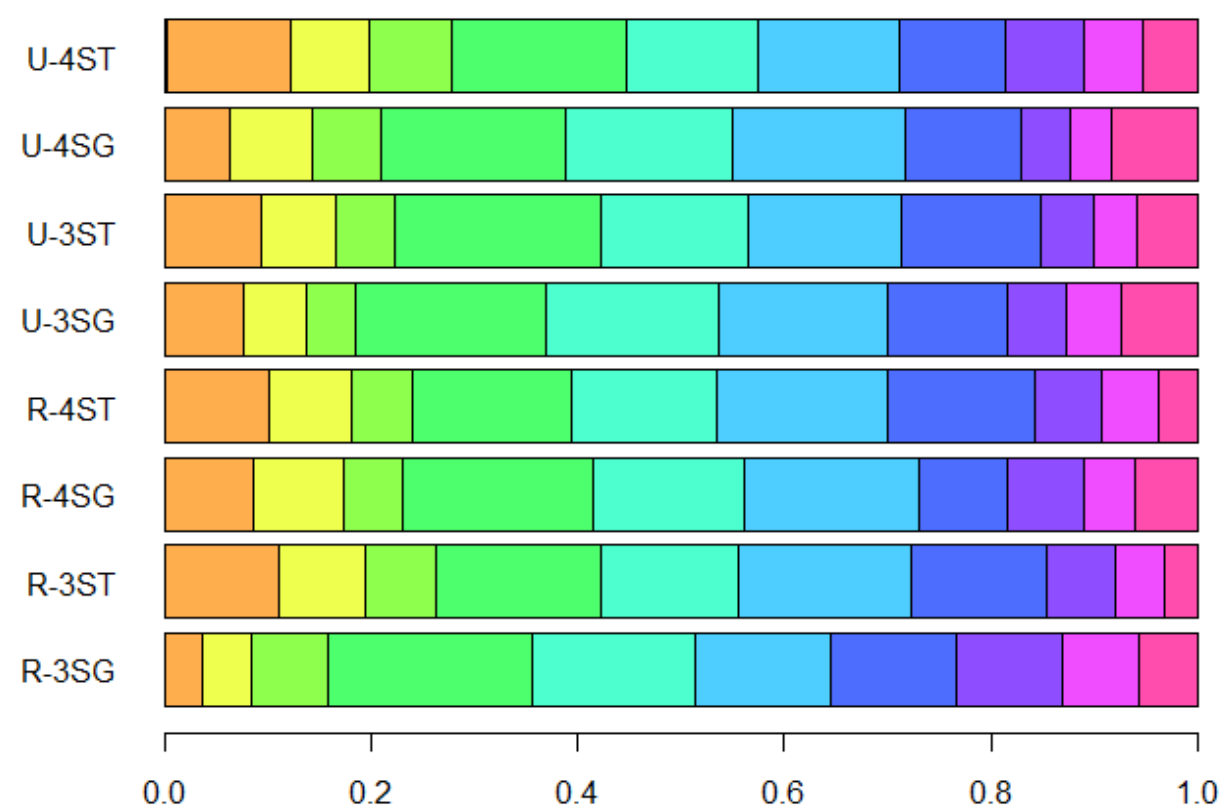

Figure 4.15: Crash Proportions for Age Cohort of Driver by Intersection Type, 2003-2007 Data 
Table 4.13: US Census, Oregon Population by Age Cohort, 2000

\begin{tabular}{rrr} 
Age Group & $\begin{array}{r}\text { Numbe } \\
\text { r }\end{array}$ & Percent \\
\hline Under 5 years & 223,005 & 6.5 \\
5 to 9 years & 234,474 & 6.9 \\
10 to 14 years & 242,098 & 7.1 \\
15 to 19 years & 244,427 & 7.1 \\
20 to 24 years & 230,406 & 6.7 \\
25 to 34 years & 470,695 & 13.8 \\
35 to 44 years & 526,574 & 15.4 \\
45 to 54 years & 507,155 & 14.8 \\
55 to 59 years & 173,008 & 5.1 \\
60 to 64 years & 131,380 & 3.8 \\
65 to 74 years & 219,342 & 6.4 \\
75 to 84 years & 161,404 & 4.7 \\
85 years and over & 57,431 & 1.7 \\
\hline
\end{tabular}

\subsubsection{Sex of Driver}

Proportions of crash severity by intersection type are shown in Table 4.14 and in the stacked bar plot (Figure 4.16). The sex of the driver is fairly consistent across all intersection types. For reference, the 2000 Census reports Oregon's population is $49.6 \%$ male and $50.4 \%$ female. Overall, male drivers are crash-involved at a higher proportion than the population proportion (not controlling for other factors). In rural locations, crash-involved drivers are much more likely to be male than in urban locations. Research indicates that males, especially young males are more likely to take risks and are over-involved in many crash patterns. The rural-urban difference may reflect the different nature of urban and rural travel behaviors or cultural norms. A Pearson's chi-square test of independence indicates that the proportions do differ significantly at the $95 \%$ confidence interval $\left(\chi^{2}=48.24\right.$, $\mathrm{df}=14$, $\mathrm{p}$-value $\left.=1.198 \mathrm{e}-05\right)$.

Table 4.14: Crash Proportions for Sex of Driver by Intersection Type, 2003-2007 Data

\begin{tabular}{r|rrrr|rrrr}
\hline & \multicolumn{6}{|c|}{ Urban } & \multicolumn{4}{c}{ Rural } \\
Pattern & 4-ST & 4-SG & 3-ST & 3-SG & 4-ST & 4-SG & 3-ST & 3-SG \\
\hline MALE & $52.1 \%$ & $55.0 \%$ & $57.6 \%$ & $52.6 \%$ & $65.5 \%$ & $57.9 \%$ & $58.9 \%$ & $63.6 \%$ \\
FEMALE & $47.0 \%$ & $42.9 \%$ & $41.0 \%$ & $45.7 \%$ & $33.2 \%$ & $40.7 \%$ & $40.2 \%$ & $36.4 \%$ \\
UNK & $0.9 \%$ & $2.1 \%$ & $1.4 \%$ & $1.7 \%$ & $1.4 \%$ & $1.4 \%$ & $1.0 \%$ & $0.0 \%$ \\
\hline Total Drivers & 560 & 5481 & 630 & 1524 & 576 & 492 & 508 & 107 \\
\hline
\end{tabular}




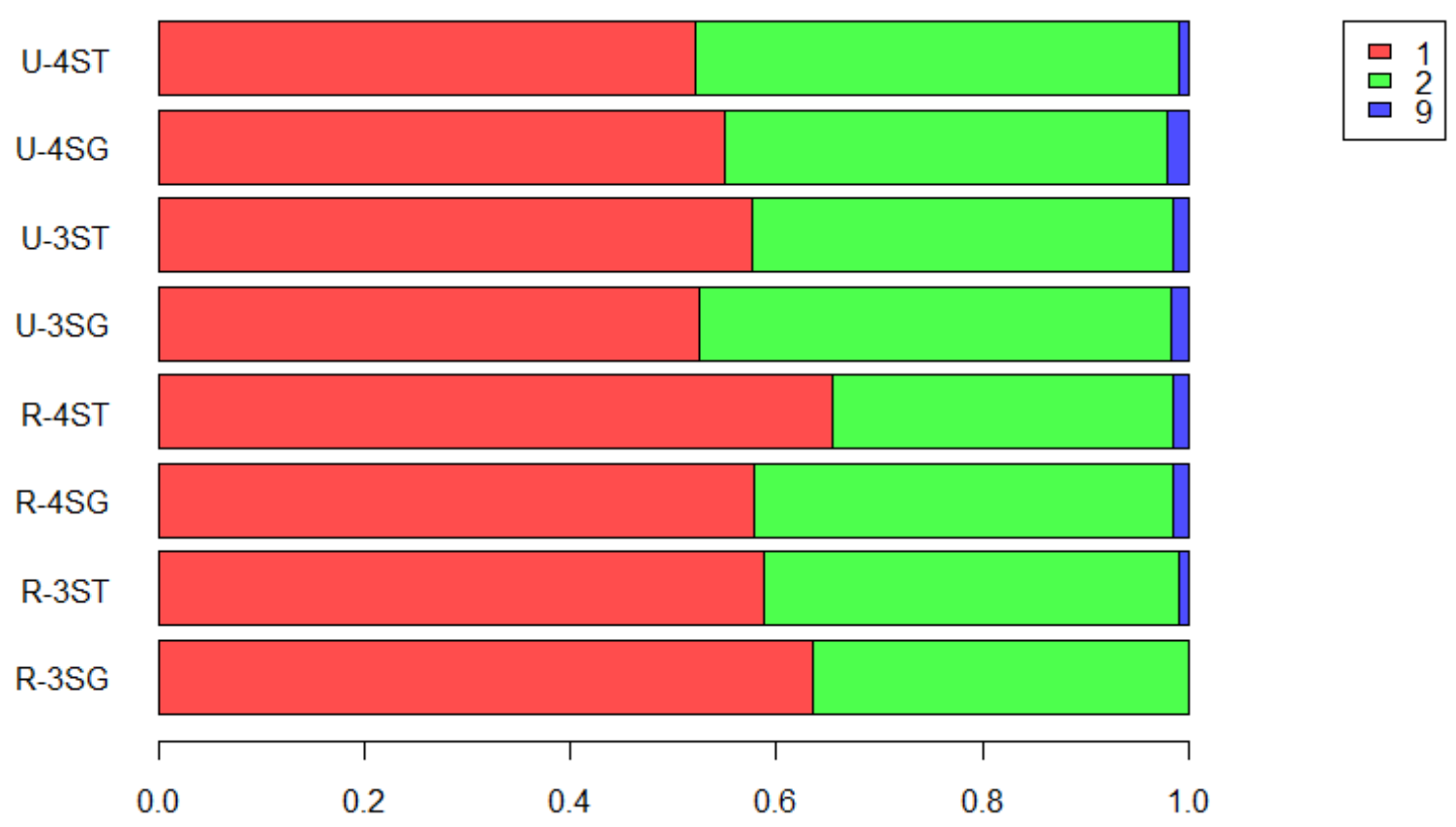

Figure 4.16: Crash Proportions for Sex of Driver by Intersection Type, 2003-2007 Data

\subsubsection{Residence of Driver}

Proportions of crashes by driver residence are shown in Table 4.15 and are shown in a stacked bar plot (Figure 4.17). The residence of driver summary might highlight if non-local drivers were overrepresented, indicating that driver expectancy or other unfamiliar situations might be present $(\mathrm{N}-\mathrm{RES}=$ non resident, $\mathrm{OR}<25=$ licensed Oregon driver crash involved less than 25 miles from home address, OR>25=licensed Oregon driver crash involved more than 25 miles from home address, OR-?=Oregon license, location unknown). In the urban environment, nearly 85\% of crash-involved drivers are likely to be within 25 miles of their home address. The percentage is lower in rural environments (70-80\%) reflecting the longer travel distances in a rural environment and greater recreational use. A Pearson's chi-square test of independence indicates that the proportions do differ significantly at the $95 \%$ confidence interval $\left(\chi^{2}=155.31\right.$, $\mathrm{df}=21$, p-value $<2.2 \mathrm{e}-16)$.

Table 4.15: Crash Proportions for Residence of Driver by Intersection Type, 2003-2007 Data

\begin{tabular}{r|rrrr|rrrr}
\hline & \multicolumn{4}{|c|}{ Urban } & \multicolumn{4}{c}{ Rural } \\
Pattern & 4-ST & 4-SG & 3-ST & 3-SG & 4-ST & 4-SG & 3-ST & 3-SG \\
\hline N-RES & $3.9 \%$ & $4.3 \%$ & $3.5 \%$ & $4.8 \%$ & $8.5 \%$ & $4.3 \%$ & $4.9 \%$ & $13.1 \%$ \\
OR-? & $0.0 \%$ & $0.1 \%$ & $0.2 \%$ & $0.1 \%$ & $0.0 \%$ & $0.0 \%$ & $0.2 \%$ & $0.0 \%$ \\
OR $<25$ & $84.5 \%$ & $83.2 \%$ & $85.4 \%$ & $84.9 \%$ & $74.3 \%$ & $81.9 \%$ & $76.0 \%$ & $70.1 \%$ \\
OR $>25$ & $9.1 \%$ & $7.1 \%$ & $6.8 \%$ & $5.2 \%$ & $14.2 \%$ & $10.4 \%$ & $16.9 \%$ & $13.1 \%$ \\
UNK & $2.5 \%$ & $5.3 \%$ & $4.1 \%$ & $4.9 \%$ & $3.0 \%$ & $3.5 \%$ & $2.0 \%$ & $3.7 \%$ \\
\hline Total Drivers & 560 & 5481 & 630 & 1524 & 576 & 492 & 508 & 107 \\
\hline
\end{tabular}




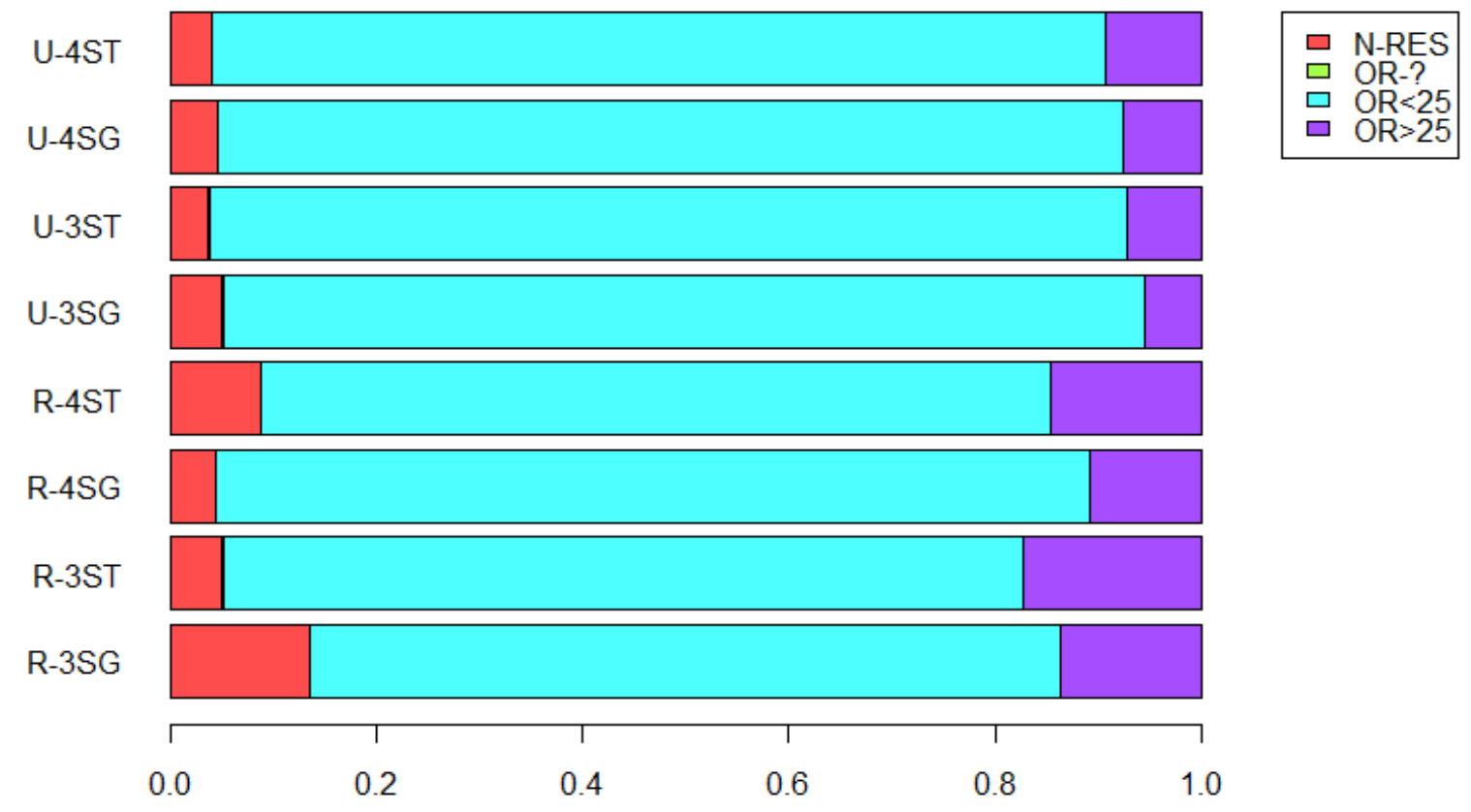

Figure 4.17: Crash Proportions for Driver Residence by Intersection Type, 2003-2007 Data

\subsubsection{Cause Codes}

Proportions of crash cause codes by intersection type are shown in Table 4.16 and in a stacked bar plot (Figure 4.18). For each crash record, up to three crash causations can be coded. The proportions for these cause codes were generated considering all three possible codes for each crash. For that reason, the total cause codes will not match the total crash counts. From the table and figure below, stop-controlled and signalized intersections have different common crash cause codes. At stop-controlled intersection, $30-43 \%$ of crash causes are listed as "No Yield". At signalized intersection 20.8-47.8\% of crash causes are coded as "Too close". Both of these cause codes relate to the common crash types at the intersections (turning and angle at stopcontrolled and rear-end at signalized intersections). Given the large number of cells with zero recorded crash causes, a Pearson's chi-square test of independence was not conducted though it is clear that there are substantial differences in the patterns of crash causes by intersection type. 
Table 4.16: Crash Proportions for Crash Cause Code by Intersection Type, 2003-2007 Data

\begin{tabular}{r|rrrr|rrrr}
\hline & \multicolumn{7}{|c|}{ Urban } & \multicolumn{4}{c}{ Rural } \\
Pattern & 4-ST & 4-SG & 3-ST & 3-SG & 4-ST & 4-SG & 3-ST & 3-SG \\
\hline CARELESS & $1.5 \%$ & $0.5 \%$ & $0.3 \%$ & $0.7 \%$ & $0.6 \%$ & $2.3 \%$ & $1.7 \%$ & $0.0 \%$ \\
DEF BRKE & $0.0 \%$ & $0.5 \%$ & $0.0 \%$ & $0.7 \%$ & $0.6 \%$ & $1.3 \%$ & $0.3 \%$ & $0.0 \%$ \\
DEF STER & $0.0 \%$ & $0.0 \%$ & $0.0 \%$ & $0.0 \%$ & $0.3 \%$ & $0.0 \%$ & $0.0 \%$ & $0.0 \%$ \\
DIS TCD & $0.0 \%$ & $0.1 \%$ & $0.3 \%$ & $0.0 \%$ & $0.0 \%$ & $0.0 \%$ & $0.0 \%$ & $0.0 \%$ \\
DIS-RAG & $1.2 \%$ & $15.3 \%$ & $0.8 \%$ & $9.8 \%$ & $1.2 \%$ & $16.9 \%$ & $0.6 \%$ & $6.0 \%$ \\
FATIGUE & $0.3 \%$ & $0.0 \%$ & $0.0 \%$ & $0.1 \%$ & $0.6 \%$ & $0.0 \%$ & $0.0 \%$ & $1.5 \%$ \\
IMP LN C & $0.9 \%$ & $1.7 \%$ & $1.4 \%$ & $2.3 \%$ & $0.0 \%$ & $1.0 \%$ & $1.2 \%$ & $1.5 \%$ \\
IMP-OVER & $3.3 \%$ & $2.0 \%$ & $2.2 \%$ & $1.4 \%$ & $2.0 \%$ & $1.3 \%$ & $1.2 \%$ & $1.5 \%$ \\
IMP-TURN & $3.9 \%$ & $4.6 \%$ & $5.4 \%$ & $5.2 \%$ & $5.8 \%$ & $5.5 \%$ & $7.3 \%$ & $0.0 \%$ \\
IN RDWY & $0.0 \%$ & $0.3 \%$ & $0.3 \%$ & $0.0 \%$ & $0.0 \%$ & $0.0 \%$ & $0.0 \%$ & $0.0 \%$ \\
INATTENT & $5.0 \%$ & $7.5 \%$ & $5.4 \%$ & $7.3 \%$ & $3.8 \%$ & $8.4 \%$ & $4.7 \%$ & $9.0 \%$ \\
LEFT-CTR & $0.0 \%$ & $0.3 \%$ & $1.4 \%$ & $0.8 \%$ & $0.9 \%$ & $0.6 \%$ & $0.3 \%$ & $0.0 \%$ \\
LOADSHFT & $0.0 \%$ & $0.1 \%$ & $0.0 \%$ & $0.1 \%$ & $0.0 \%$ & $0.0 \%$ & $0.0 \%$ & $0.0 \%$ \\
MECH-DEF & $0.0 \%$ & $0.1 \%$ & $0.0 \%$ & $0.2 \%$ & $0.0 \%$ & $0.0 \%$ & $0.0 \%$ & $0.0 \%$ \\
NO-YIELD & $43.6 \%$ & $18.7 \%$ & $41.7 \%$ & $16.0 \%$ & $44.4 \%$ & $16.6 \%$ & $27.9 \%$ & $4.5 \%$ \\
NT VISBL & $0.0 \%$ & $0.0 \%$ & $0.0 \%$ & $0.0 \%$ & $0.0 \%$ & $0.0 \%$ & $0.0 \%$ & $0.0 \%$ \\
OTHER & $0.0 \%$ & $0.4 \%$ & $0.5 \%$ & $0.5 \%$ & $0.3 \%$ & $0.3 \%$ & $3.2 \%$ & $0.0 \%$ \\
OTHR-IMP & $9.8 \%$ & $5.5 \%$ & $5.7 \%$ & $5.6 \%$ & $5.0 \%$ & $10.1 \%$ & $8.1 \%$ & $10.4 \%$ \\
PAS-STOP & $5.0 \%$ & $0.4 \%$ & $4.9 \%$ & $0.2 \%$ & $10.5 \%$ & $0.6 \%$ & $4.1 \%$ & $0.0 \%$ \\
PHANTOM & $0.6 \%$ & $0.5 \%$ & $0.5 \%$ & $0.3 \%$ & $2.0 \%$ & $0.6 \%$ & $2.0 \%$ & $0.0 \%$ \\
RECKLESS & $0.0 \%$ & $0.1 \%$ & $0.3 \%$ & $0.1 \%$ & $0.0 \%$ & $0.3 \%$ & $0.3 \%$ & $0.0 \%$ \\
SPEED & $0.6 \%$ & $0.2 \%$ & $0.3 \%$ & $0.1 \%$ & $0.6 \%$ & $0.3 \%$ & $0.3 \%$ & $0.0 \%$ \\
TOO-CLOS & $13.6 \%$ & $28.3 \%$ & $15.2 \%$ & $31.4 \%$ & $9.4 \%$ & $20.8 \%$ & $13.7 \%$ & $47.8 \%$ \\
TOO-FAST & $10.7 \%$ & $12.9 \%$ & $13.6 \%$ & $17.1 \%$ & $12.0 \%$ & $13.0 \%$ & $23.3 \%$ & $17.9 \%$ \\
WRNG WAY & $0.0 \%$ & $0.0 \%$ & $0.0 \%$ & $0.0 \%$ & $0.0 \%$ & $0.0 \%$ & $0.0 \%$ & $0.0 \%$ \\
\hline Total Cause & 337 & 3100 & 369 & 885 & 342 & 308 & 344 & 67 \\
Codes & & & & & $0.0 \%$ \\
\hline
\end{tabular}




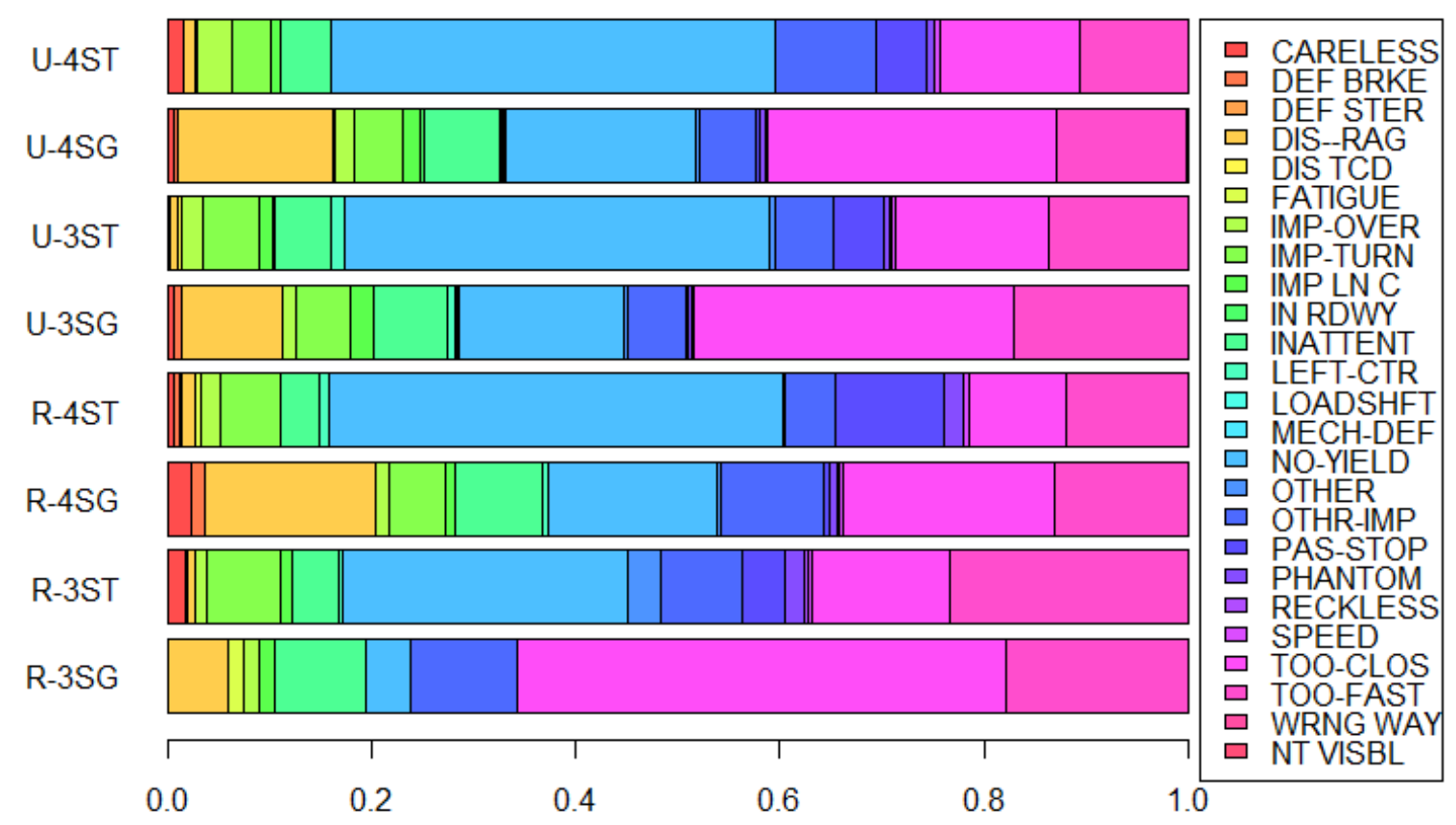

Figure 4.18: Crash Type Proportions by Crash Cause Code, 2003-2007 Data

\subsubsection{Discussion on Applications of Patterns}

It is important to recognize that these proportions are meant to categorize the expected pattern at each intersection type. While it is interesting to make comparisons between intersection types (and those differences are presented in the text), the intended use of these patterns are to test whether a pattern at a particular intersection is different from the average patterns presented here. For example, if the study intersection has $60 \%$ angle crashes while all other sites have an average of $29 \%$ crashes it will likely be flagged as "unusual” using the direct diagnostics methods.

As part of another project for the Oregon DOT, analysis of these crash patterns for diagnostic purposes have been automated in an Excel workbook. Tutorials and other materials are available at this url: http://www.oregon.gov/ODOT/HWY/TRAFFIC-ROADWAY/highway_safety.shtml. 


\subsection{DEVELOPMENT OF SAFETY PERFORMANCE FUNCTIONS}

As part of the SPF development process, all of the collected data elements (independent variables) were examined for distributions and relationships to the number of crashes per year. The average of three years of crash data (2005-2007) were used as the dependent variable. Preliminary models were run to identify the variables that were likely to have significant coefficients estimated in the model building process. The important variables identified for inclusion in the model building process include:

- Annual total crash rate,

- Annual fatal and injury crash rate,

- Annual property damage only crash rate,

- Average AADT on major street for 3 years per intersection,

- Average AADT on minor street for 3 years per intersection,

- Posted speed limit on major street,

- Intersection skew,

- Presence of lighting; and

- Left/right/approach lane number per approach.

Summary statistics for each of these variables for all 8 intersections types are shown in Table 4.17. In the following subsections, SPFs are developed for the 2 intersection with the largest sample (R3ST and USG). In each subsection, a description of the model variable is provided followed by the output of the negative binomial regression modeling. 
Table 4.17: Summary Statistics for Model Variables for Each Intersection Type

\begin{tabular}{|c|c|c|c|c|c|c|c|c|c|c|c|c|}
\hline \multirow[b]{2}{*}{ Variable Name } & \multicolumn{3}{|l|}{ R4ST } & \multicolumn{3}{|l|}{ R4SG } & \multicolumn{3}{|l|}{ R3ST } & \multicolumn{3}{|l|}{ R3SG } \\
\hline & Mean & Std. Dev. & Range & Mean & $\begin{array}{l}\text { Std. } \\
\text { Dev. }\end{array}$ & Range & Mean & $\begin{array}{l}\text { Std. } \\
\text { Dev. }\end{array}$ & Range & Mean & $\begin{array}{l}\text { Std. } \\
\text { Dev. }\end{array}$ & Range \\
\hline SUM_TOT & 2.87 & 3.07 & $0 \sim 13$ & 7.85 & 7.5 & $0 \sim 25$ & 1.43 & 2.5 & $0 \sim 18$ & 5 & 4.51 & $1 \sim 13$ \\
\hline SUM_FI & 1.82 & 2.08 & $0 \sim 7$ & 4.25 & 3.96 & $0 \sim 13$ & 0.7 & 1.39 & $0 \sim 10$ & 2.71 & 3.25 & $0 \sim 9$ \\
\hline SUM_PDO & 1.05 & 1.58 & $0 \sim 8$ & 3.6 & 3.83 & $0 \sim 13$ & 0.74 & 1.34 & $0 \sim 8$ & 2.29 & 1.38 & $1 \sim 4$ \\
\hline AVG_ADT_MAJ & 6378.92 & 5793.24 & $\begin{array}{r}185 \sim \\
30816.67\end{array}$ & $\begin{array}{r}13792.8 \\
8\end{array}$ & $\begin{array}{r}7146.3 \\
8\end{array}$ & $\begin{array}{r}4866.67 \\
\sim \\
34033.33\end{array}$ & 5775.2 & $\begin{array}{r}5399.7 \\
9\end{array}$ & $\begin{array}{r}200 \sim \\
27966.67\end{array}$ & $\begin{array}{r}14514.2 \\
9\end{array}$ & $\begin{array}{r}7157.5 \\
6\end{array}$ & $\begin{array}{r}4183.33 \\
\sim \\
22716.67\end{array}$ \\
\hline AVG_ADT_MNR & 1405.11 & 1460.19 & $\begin{array}{l}96.67 \sim \\
8133.33\end{array}$ & 5592.83 & $\begin{array}{r}5091.6 \\
6\end{array}$ & $\begin{array}{r}917.33 \sim \\
18833.33\end{array}$ & 770.84 & 856.83 & $\begin{array}{l}14.67 \sim \\
3445.33\end{array}$ & 3159.62 & $\begin{array}{r}1665.3 \\
9\end{array}$ & $\begin{array}{r}1166.67 \\
\sim \\
5756.33\end{array}$ \\
\hline POST_SPEED_MA & 49.42 & & $20 \sim 55$ & 41.25 & & $25 \sim 55$ & 50.91 & & $20 \sim 55$ & 38.57 & & $25 \sim 55$ \\
\hline \multirow[t]{2}{*}{ SKEW } & 11.33 & & $0 \sim 68$ & 11.6 & & $0 \sim 72$ & 16.18 & & $0 \sim 75$ & 14.29 & & $0 \sim 63$ \\
\hline & & U4ST & & & U4SG & & & U3ST & & & U3SG & \\
\hline Variable Name & Mean & Std. Dev. & Range & Mean & $\begin{array}{l}\text { Std. } \\
\text { Dev. }\end{array}$ & Range & Mean & $\begin{array}{l}\text { Std. } \\
\text { Dev. }\end{array}$ & Range & Mean & $\begin{array}{l}\text { Std. } \\
\text { Dev. }\end{array}$ & Range \\
\hline SUM_TOT & 2.67 & 2.87 & $0 \sim 12$ & 14.06 & 12.8 & $0 \sim 79$ & 2.21 & 2.49 & $0 \sim 13$ & 7.64 & 5.18 & $0 \sim 23$ \\
\hline SUM_FI & 1.27 & 1.7 & $0 \sim 8$ & 6.26 & 6.11 & $0 \sim 39$ & 1.09 & 1.48 & $0 \sim 7$ & 3.36 & 3.06 & $0 \sim 13$ \\
\hline SUM_PDO & 1.4 & 1.6 & $0 \sim 7$ & 7.79 & 7.27 & $0 \sim 40$ & 1.12 & 1.33 & $0 \sim 6$ & 4.27 & 2.88 & $0 \sim 14$ \\
\hline AVG_ADT_MAJ & $\begin{array}{r}10988.7 \\
5\end{array}$ & 5662.63 & $\begin{array}{l}1766.67 \\
\sim 22200\end{array}$ & $\begin{array}{r}19409.0 \\
7\end{array}$ & $\begin{array}{r}9585.7 \\
8\end{array}$ & $\begin{array}{l}4933.33 \\
\sim 48100\end{array}$ & $\begin{array}{r}14876.1 \\
9\end{array}$ & 7895.7 & $\begin{array}{r}2733.33 \\
\sim \\
40533.33\end{array}$ & 23264.7 & $\begin{array}{r}9900.7 \\
6\end{array}$ & $\begin{array}{l}8183.33 \\
\sim 41300\end{array}$ \\
\hline AVG_ADT_MNR & 1782.8 & 1484.49 & $\begin{array}{r}410.67 \sim \\
7295.33\end{array}$ & 7503.55 & $\begin{array}{r}5845.6 \\
5\end{array}$ & $\begin{array}{r}740.67 \sim \\
28733.33\end{array}$ & 1270.34 & $\begin{array}{r}1088.1 \\
5\end{array}$ & $\begin{array}{r}198 \sim \\
6696.33\end{array}$ & 3836.38 & $\begin{array}{r}2469.4 \\
2\end{array}$ & $\begin{array}{l}325 \sim \\
11300\end{array}$ \\
\hline POST_SPEED_MA & 33.75 & & $20 \sim 55$ & 34.01 & & $20 \sim 55$ & 37.6 & & $25 \sim 55$ & 37.73 & & $20 \sim 55$ \\
\hline SKEW & 6.93 & & $0 \sim 46$ & 8.18 & & $0 \sim 38$ & 10.99 & & $0 \sim 60$ & 10.45 & & $0 \sim 51$ \\
\hline
\end{tabular}




\subsubsection{Rural 3-legged Stop-Controlled (R3ST)}

\subsubsection{Descriptive Statistics of Variables}

There are 115 rural 3-legged stop controlled intersections in the data set. On those intersections, a total of 165 crashes occurred during 3-year period from 2005 to 2007 (0.48 annual crashes per intersection), with a total of 80 fatal and injury crashes and a total of 85 property damage only crashes. The average annual crashes per intersection is shown in for total, fatal and injury and PDO crashes in Figure 4.19,Figure 4.20, and Figure 4.21 respectively. Since crashes were being modeled as count data, the distribution of crashes is shown in bins of 1 crash/year increments. Those bins are intervals of the form [a, b). For instance, the first bin labeled 0 represents the interval of $[0,1)$. The majority of intersections represented in the data set had less than 1 total crashes per year. Figure 4.22 displays the distribution of AADT on major approach; Figure 4.23 shows the distribution in the minor approach. Below each histogram, the same data are shown in a horizontal boxplot. The boxplot represents the median value by the solid vertical line, the edge of the box represents the interquartile range (i.e. the 25th and 75th percentile values), the whiskers (fence) the last data point within 1.5 times the IQR. Points outside the fence are possible outliers. The mean AADT on the major street was approximately 5000 vehicles per day and its distribution was skewed to the right. The average AADT on the minor street was approximately 500 vehicles per day and its distribution was skewed to the right.

As shown in Figure 4.24, the majority of intersections had a posted speed limit of $55 \mathrm{mph}$ on the major street. Most intersection (98) were without the presence of lighting (17 had lighting). Figure 4.25 shows the distribution of intersection skew for the R3ST intersections. Most intersections have no skew (50) and the remaining intersections are uniformly distributed from 8 to 75 degrees of skew. Figure 4.26 is a summary of the left/right/approach lanes configurations by major and minor approach. In the figure, those lane numbers for a certain street of an intersection were calculated by dividing the total number of a certain type lane by the number of approach on that street. For example, if there are 1.5 approach lanes per major approach it can be interpreted that there is one approach lane in one direction, two approach lanes in the other (note that data collection procedures gathered total approach, left and right turn lanes by major and minor approaches). The mean, standard deviation and range for the variables described above are shown in Table 4.17 for R3ST. 


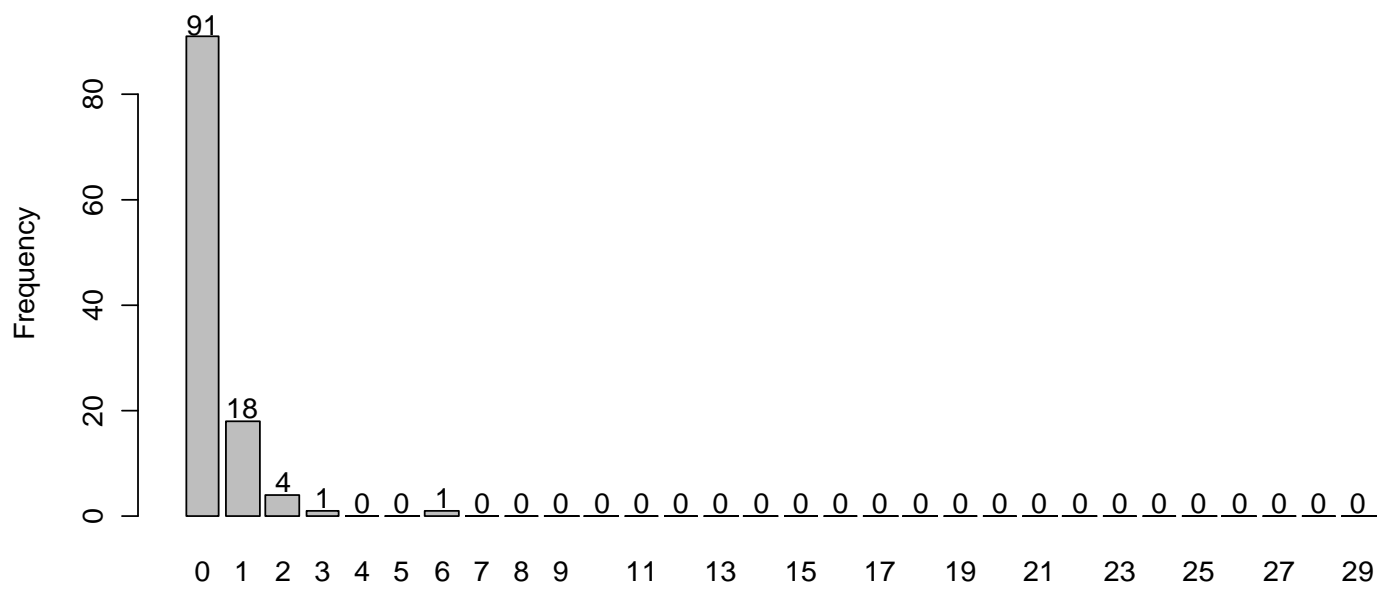

$\mathrm{X}$-Axis is in $1 \mathrm{crash} / \mathrm{year} / \mathrm{intersection}$ bins, initial column is the data for 0-1 crashes/year/intersection

Figure 4.19: Distribution of Total Crashes for R3ST, n=115

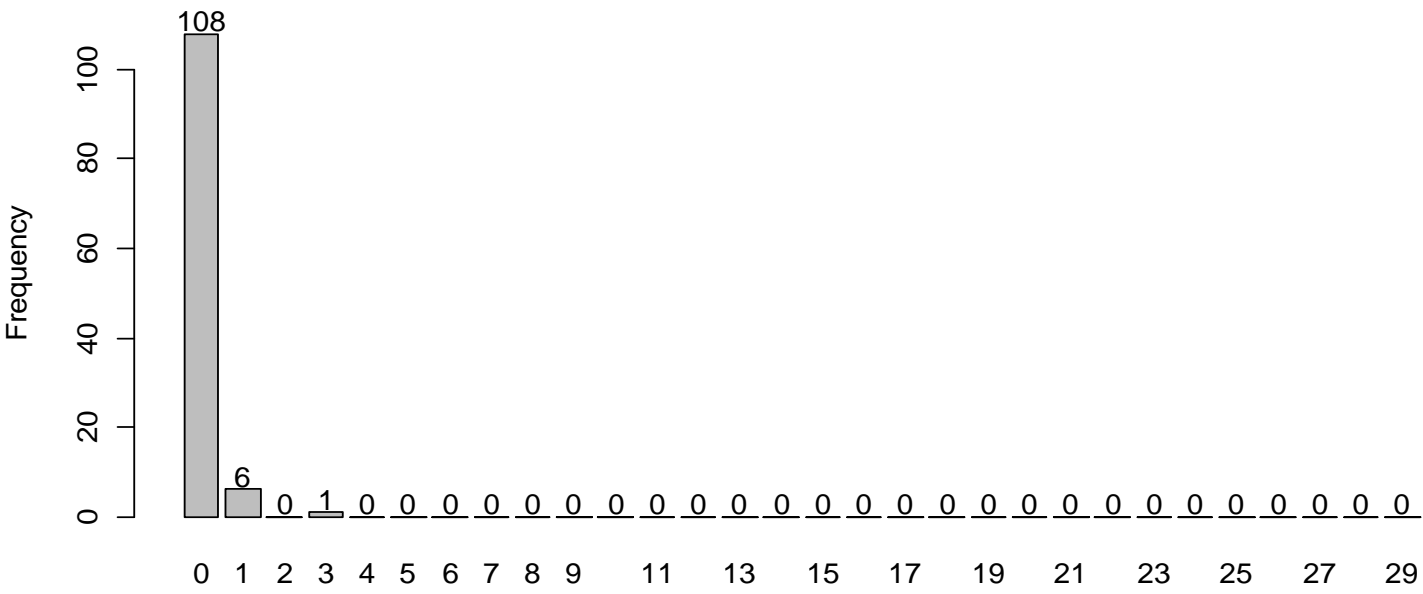

$\mathrm{X}$-Axis is in $1 \mathrm{crash} / \mathrm{year} / \mathrm{intersection}$ bins, initial column is the data for $0-1$ crashes/year/intersection

Figure 4.20: Distribution of Fatal and Injury Crashes for R3ST, n=115 


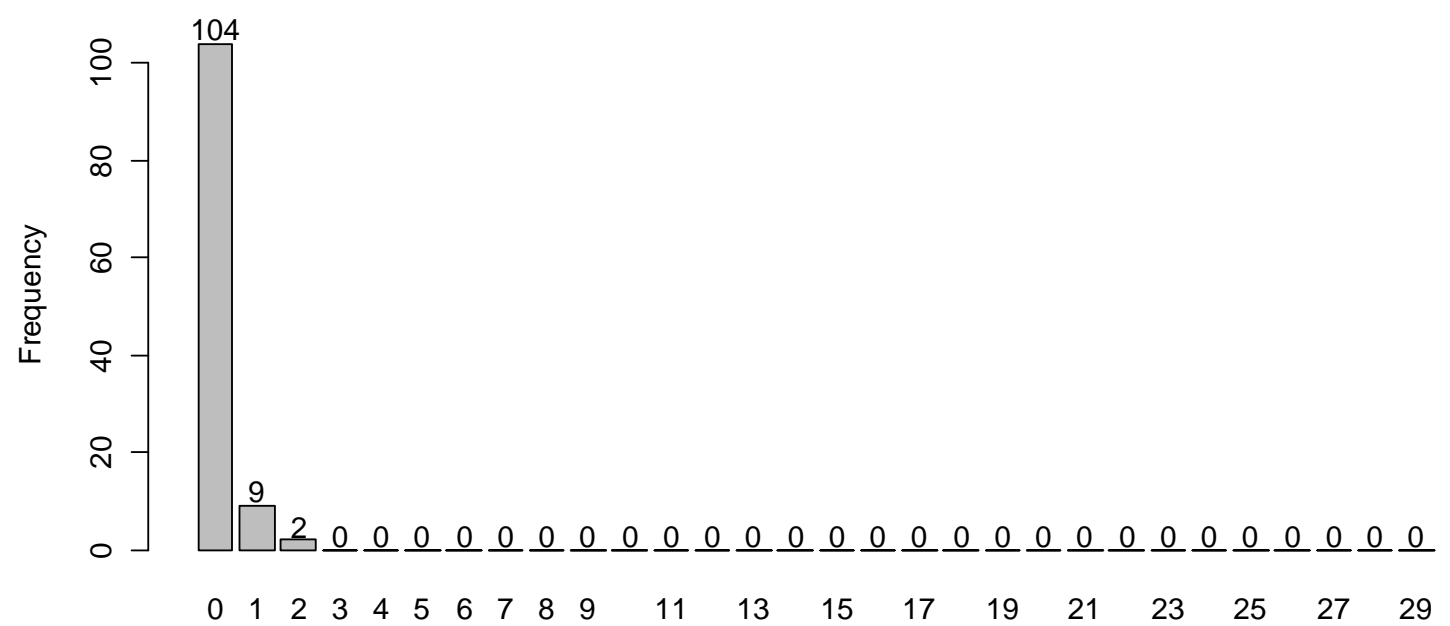

$\mathrm{X}$-Axis is in $1 \mathrm{crash} / \mathrm{year} / \mathrm{intersection}$ bins, initial column is the data for 0-1 crashes/year/intersection

Figure 4.21: Distribution of PDO Crashes for R3ST, $n=115$

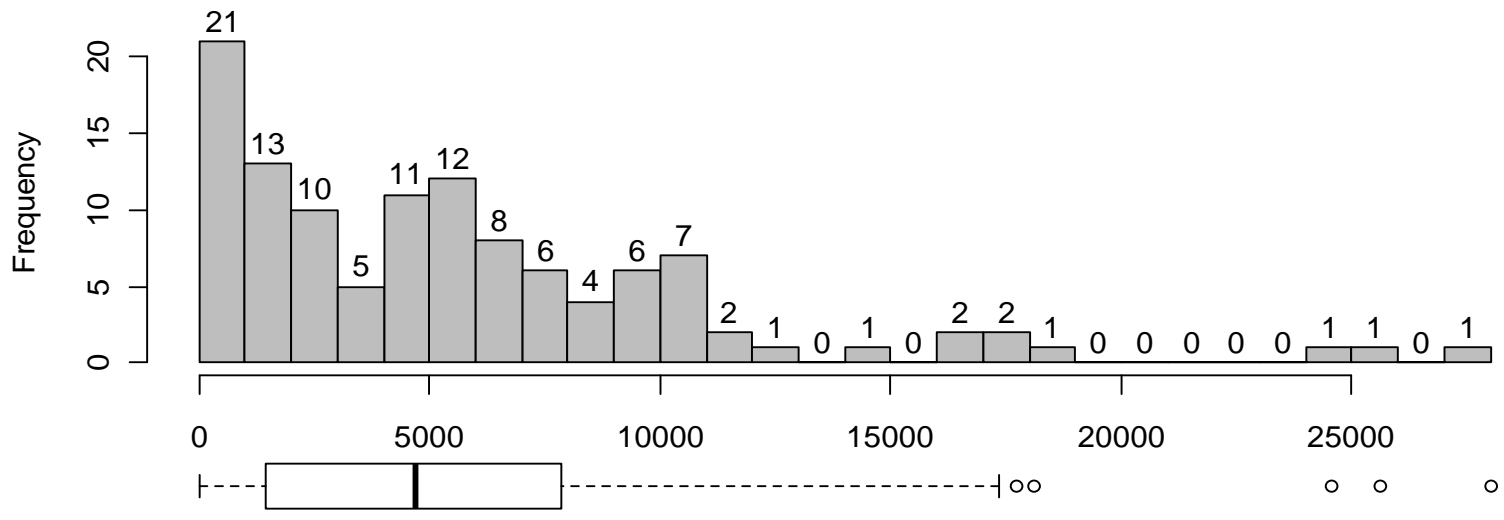

Figure 4.22: Distribution of Major Street AADT for R3ST, n=115

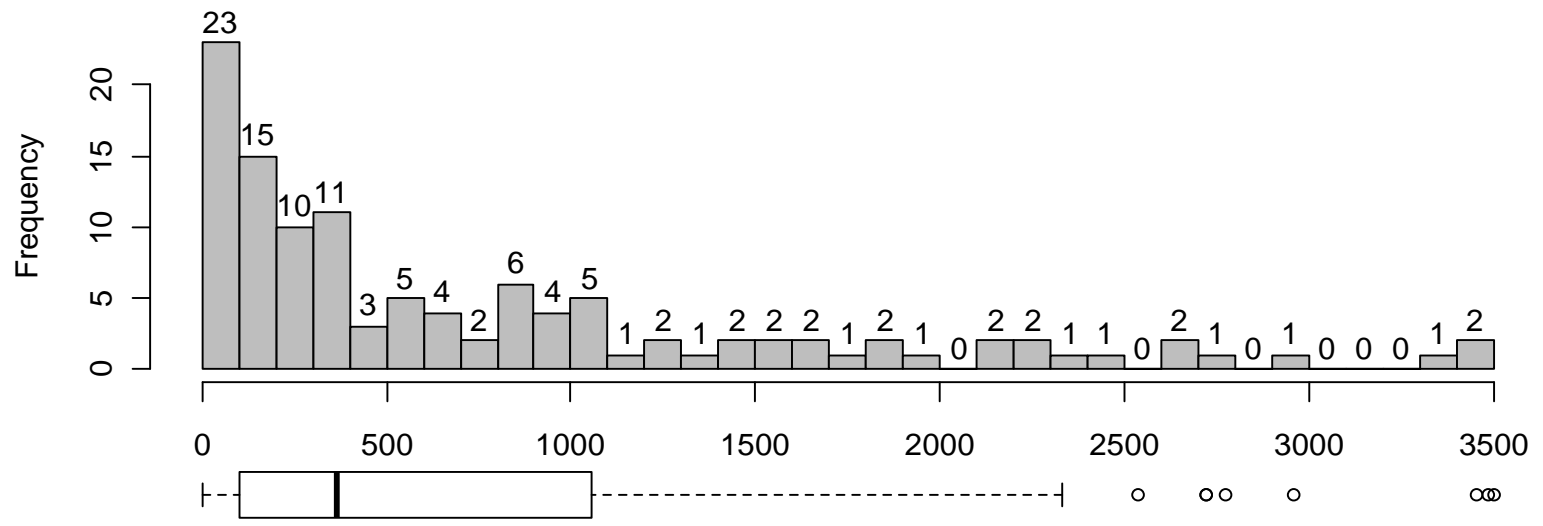

Figure 4.23: Distribution of Minor Street AADT for R3ST, $n=115$ 


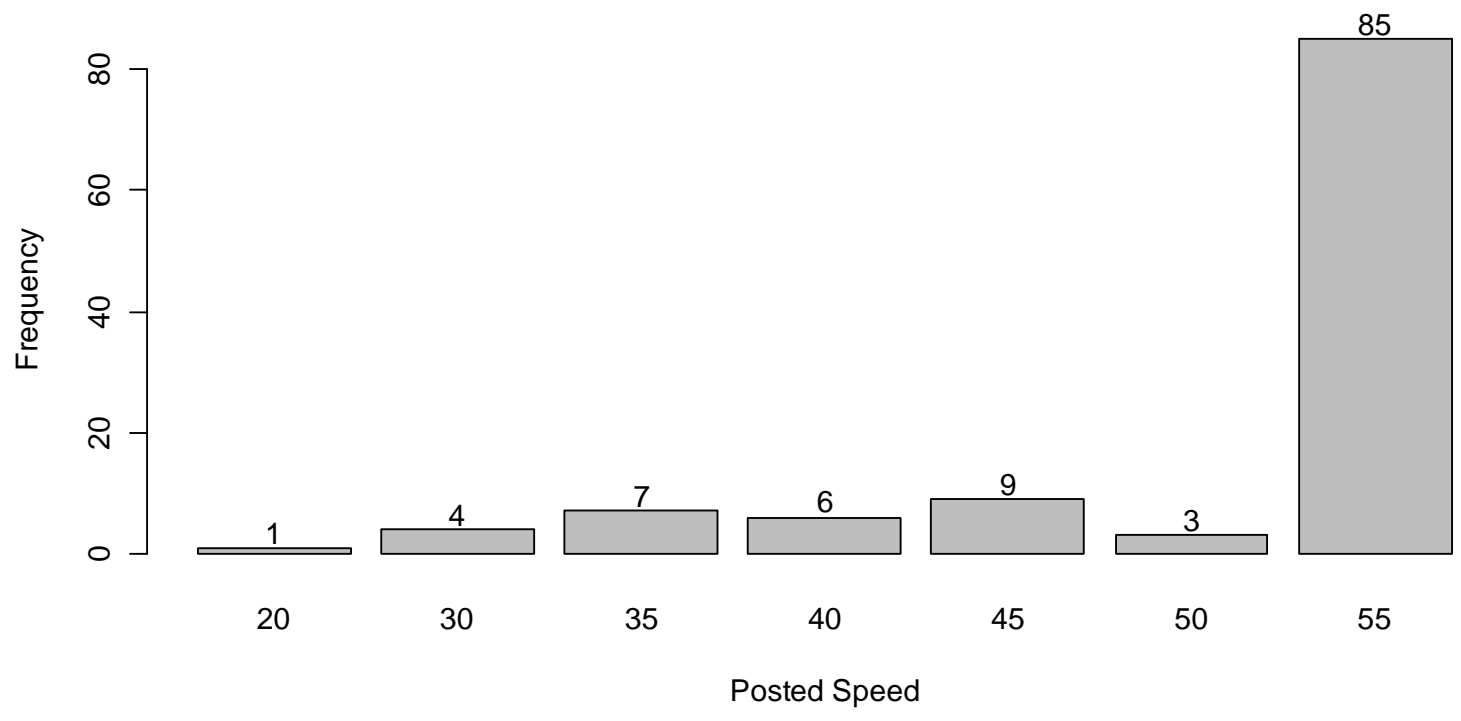

Figure 4.24: Distribution of Major Approach Posted Speed for R3ST, n=115

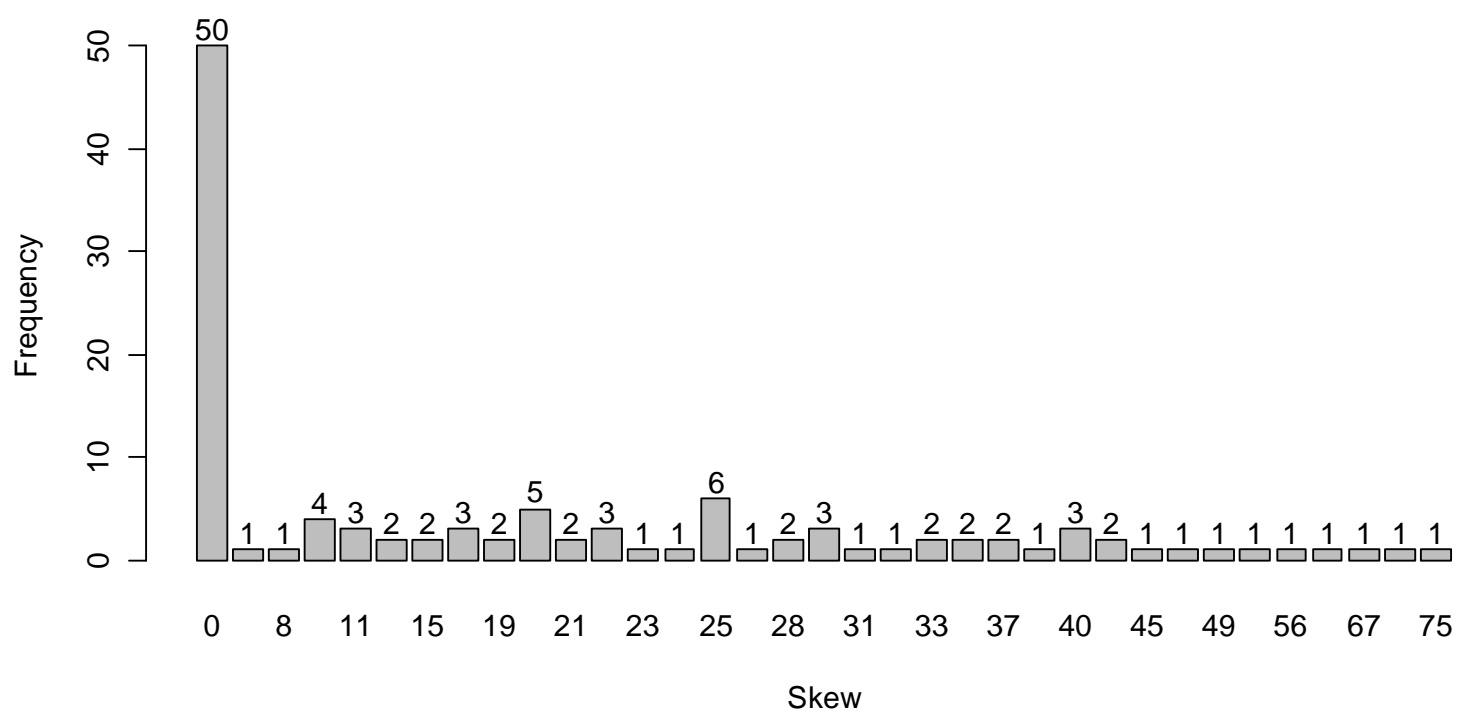

Figure 4.25: Distribution of Intersection Skew for R3ST, n=115 

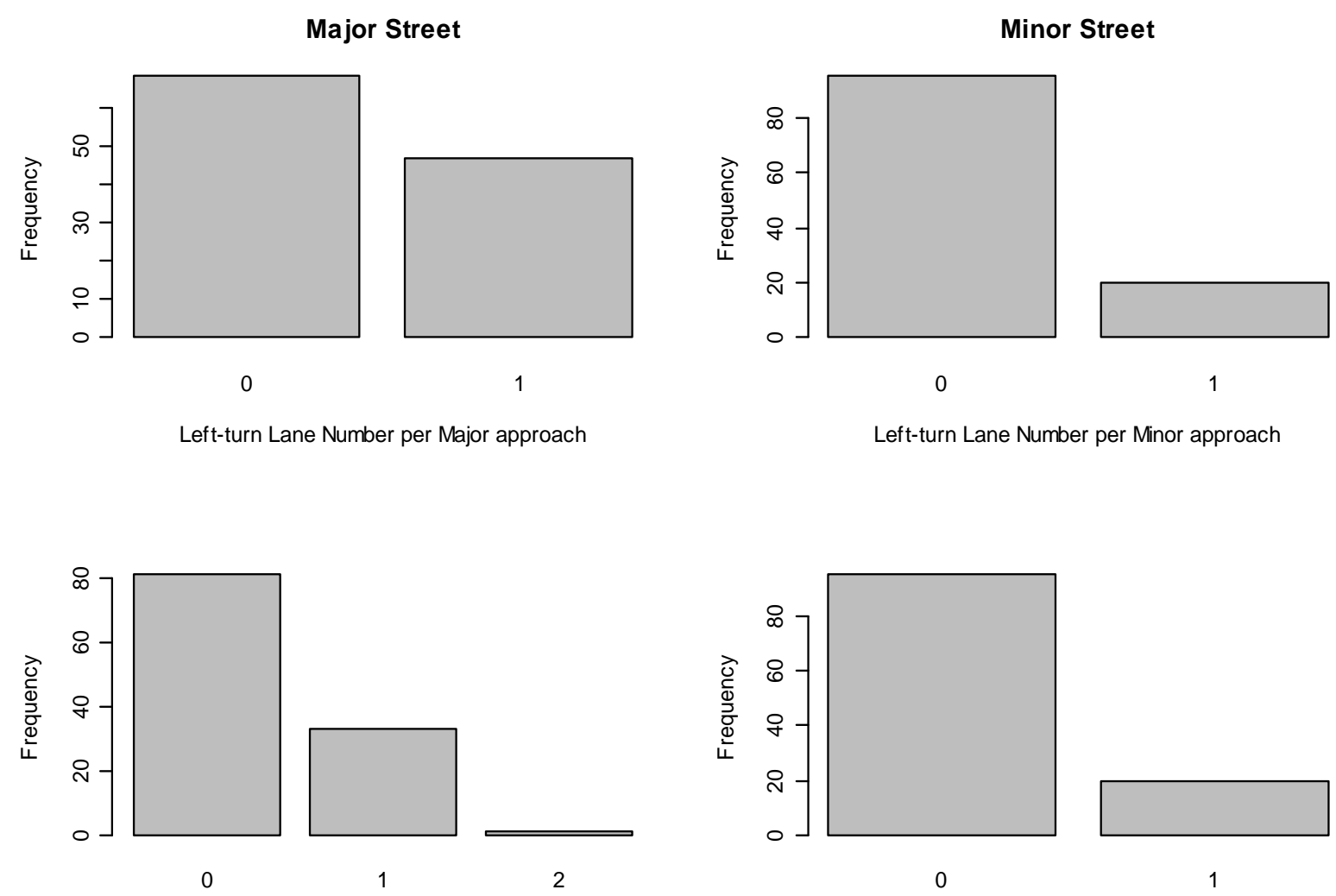

Right-turn Lane Number per Major approach

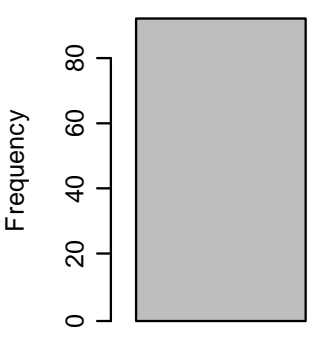

1

Approach Lane Number per Major approach

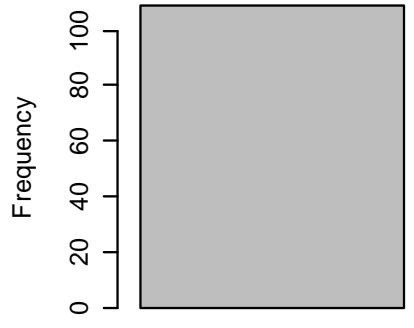

1

Approach Lane Number per Minor approach

Figure 4.26: Distribution of the Number of Left, Right, and Approach Lanes for R3ST

\subsubsection{Negative Binomial Regression Model}

The question of interest was to use the negative binomial regression to get a prediction model of annual total crashes happened on rural 3-legged stop controlled intersection. Candidate variables that may have influence on the total crashes were included into a full model. Candidate variables were listed below: 
- Major Street AADT (continuous variable)

- Minor Street AADT (continuous variable)

- Posted speed limit on Major Street (continuous variable)

- Presence of left-turn lane on Major Street (category variable: 1=presence; $0=$ absence)

- Presence of right-turn lane on Major Street (category variable: 1=presence; $0=$ absence)

- Intersection skew (continuous variable)

- Presence of lighting (category variable: $1=$ presence; $0=$ absence)

Using backward elimination model selection method based on AIC criterion, the negative binomial model indicated that the variables major AADT, minor AADT and posted speed limit remained in the model. The intersection skew was not included in the final model, possibly due to the disproportionate distribution of skew variables in the data set. The presence of lighting may affect night crashes, but failed to prove to be significant in the evaluation of the total crashes that included both day and night collision. Although the backward elimination model selection model recommended the inclusion of the posted speed limit, this variable was not strongly significant. This may be due to the disproportionate distribution of the speed limits (most were $55 \mathrm{mph}$ ). Additional efforts are recommended for strengthening the distribution of this variable in the data set and subsequently re-evaluating the model. For the purposes of this effort, the research team elected to remove the speed limit variable from the final fitted SPF. As a result, the recommended model simply includes the major and minor AADT variables for the final model for the rural 3-legged stop controlled intersection:

Predicted Total Crash per Year $=e^{-10.58+0.78 \ln (\text { AADTmaj })+0.47 \ln (\text { AADTmrr })}$

Model diagnostics and outputs are summarized inTable 4.18. The estimated SPF is shown graphically in Figure 4.27. In the figure, the $x$-axis represents the traffic volume on the major approach and $y$-axis represents the predicted total average annual crashes per year. The box plot below the $x$-axis represents the distribution of the actual traffic volume on the major street in the model data. To represent the influence of the minor street AADT, the plot includes fitted models for the minor AADT in 200 vehicles per day increments. The lines indicated that the crash rate would increase along with the increase of traffic volume on the major street. It was estimated that a doubling of traffic volume on the major street was associated with a change in the mean of total crash rate by a factor of 1.71. The influence on crash rate was shown below when traffic volume on the minor street changed. The crash rate would increase along with the increase of traffic volume on the minor street. It was estimated that a doubling of traffic volume on minor street was associated with a change in the mean of crash rate by a factor of 1.39 . 
Table 4.18: Summary Model Output for R3ST

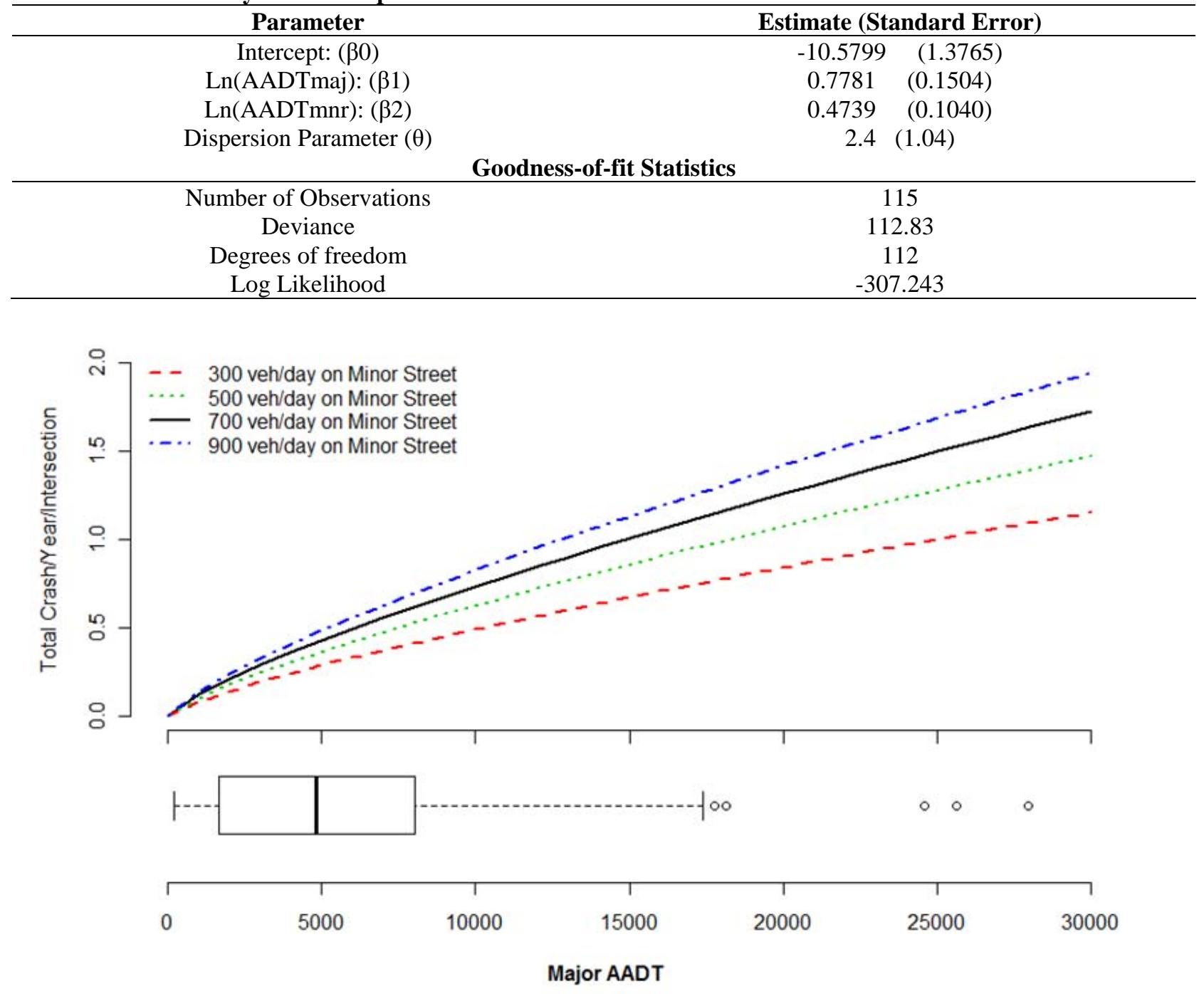

Figure 4.27: Crash Prediction Model for R3ST

\subsubsection{Urban 4-legged Signalized Intersection}

\subsubsection{Descriptive Statistics of Variables}

There are 106 urban 4-legged signalized intersections in the data set. On those intersections, a total of 1490 crashes occurred during 3-year period from year 2005 to year 2007 (4.69 annual crashes per intersection), with a total of 664 fatal and injury crashes and a total of 826 property damage only crashes. As previously presented, Figure 4.28, Figure 4.29 and Figure 4.30 show the distribution of the annual average number of crashes per intersection in bins of $1 \mathrm{crash} /$ year increments were used. As compared to the R3ST intersections, U4SG have much more crash experience though the majority of intersections represented in the data set had less than 6 total crashes per year. Figure 4.31 
shows the average AADT on major street was around 20000 vehicles per day and its distribution was skewed to the right. Figure 4.32 presents the average AADT on the minor street (approximately 7000 vehicles per day) and skewed right. The majority of intersections had lighting present (95 out of 11). Figure 4.33 presents the distribution of major street posted speed limit. As expected, there is more variation in the urban environment than the rural. The common posted speed was $35 \mathrm{mph}$ on the major approach. Figure 4.34 presents the distribution of intersection skew. Most (66) intersections have no skew and the remaining intersections have skews distributed from 2 to 38 degrees. Figure 4.35 is the left/right/approach lane distribution figure, those lane numbers for a certain street of an intersection were calculated by dividing the total number of a certain type lane by the number of approach on that street. Finally, the mean, standard deviation and range for the variables described above are shown in Table 4.17 for U4SG.

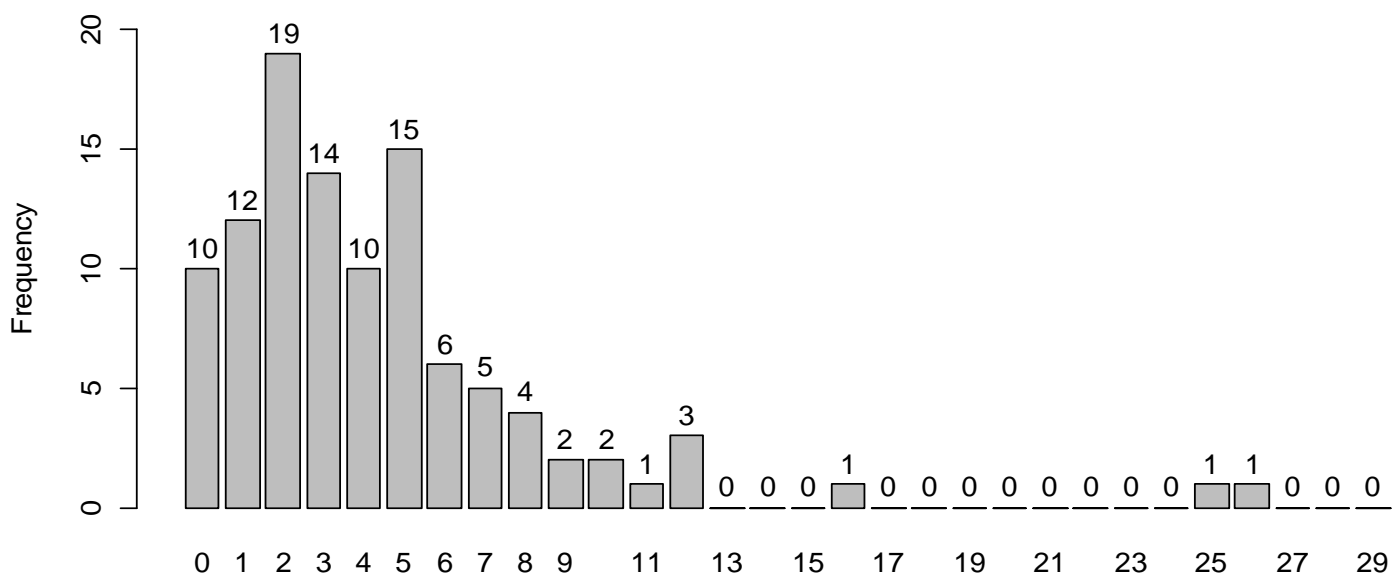

$\mathrm{X}$-Axis is in $1 \mathrm{crash} / \mathrm{year} / \mathrm{intersection}$ bins, initial column is the data for 0-1 crashes/year/intersection

Figure 4.28: Distribution of Total Crashes for U4SG, n=106

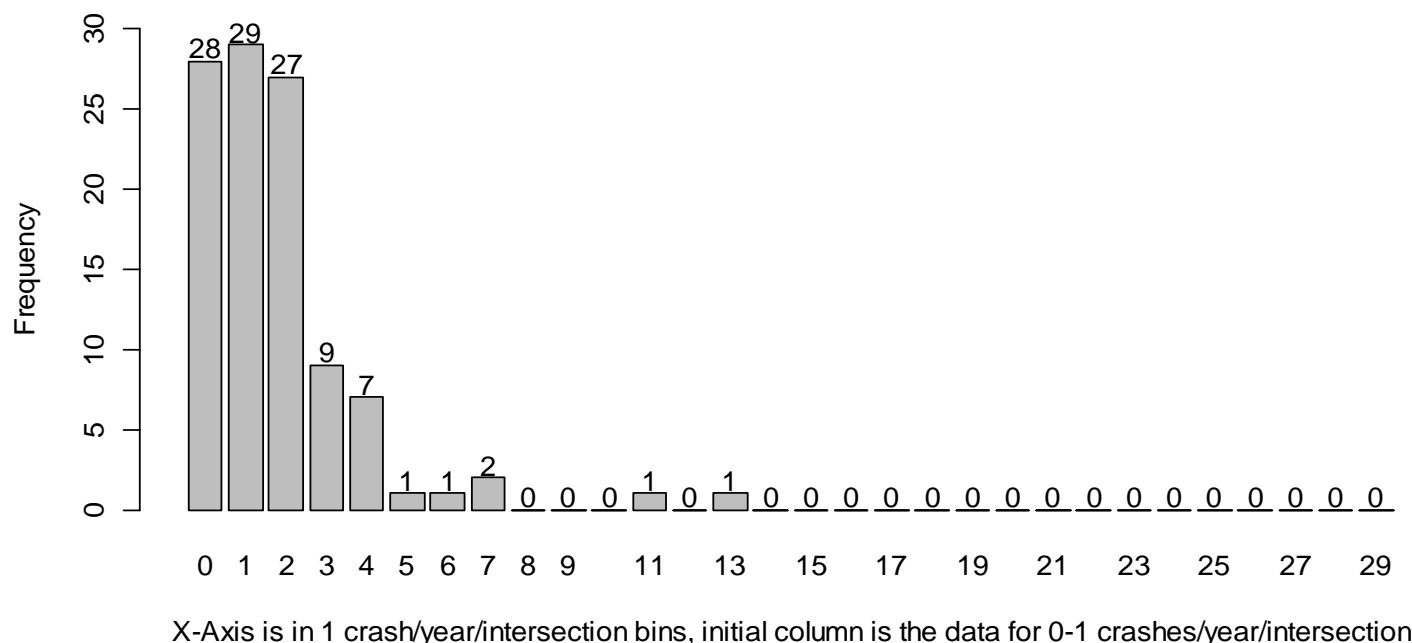

Figure 4.29: Distribution of Fatal and Injury Crashes for U4SG, n=106 


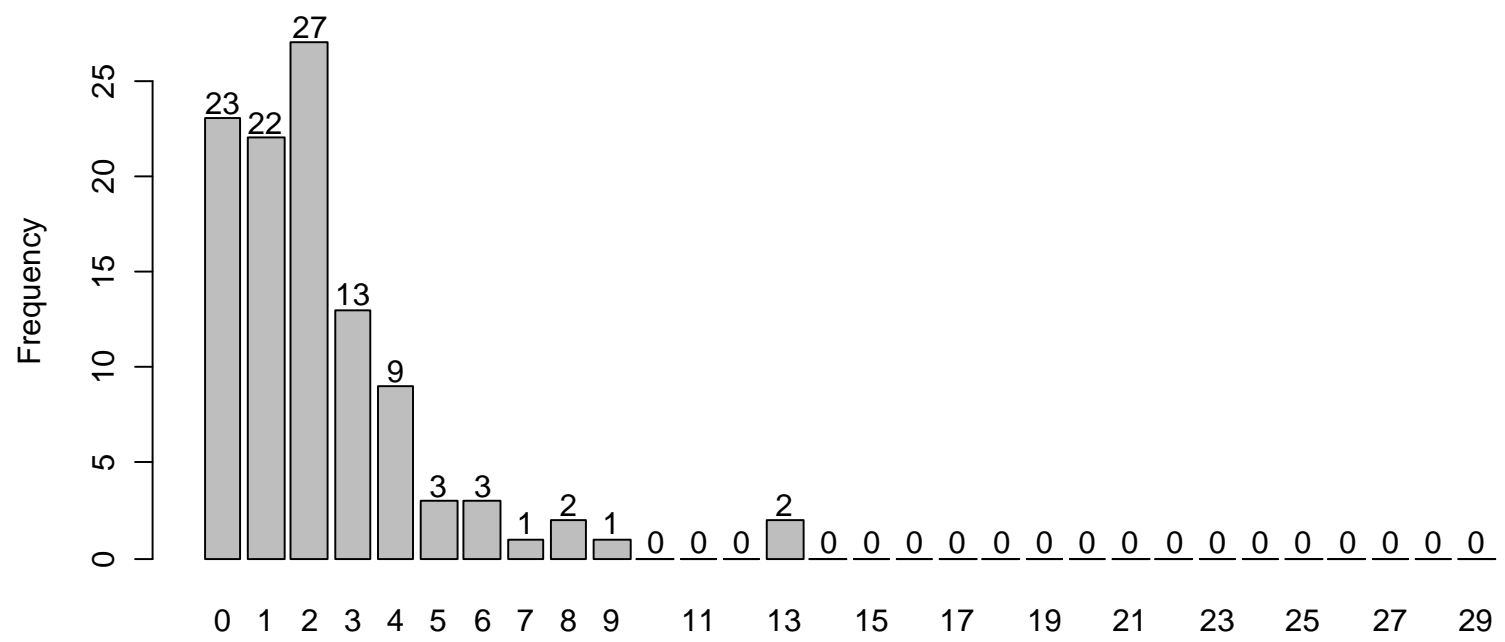

$\mathrm{X}$-Axis is in $1 \mathrm{crash} / \mathrm{year} / \mathrm{intersection}$ bins, initial column is the data for 0-1 crashes/year/intersection

Figure 4.30: Distribution of PDO Crashes for U4SG, n=106

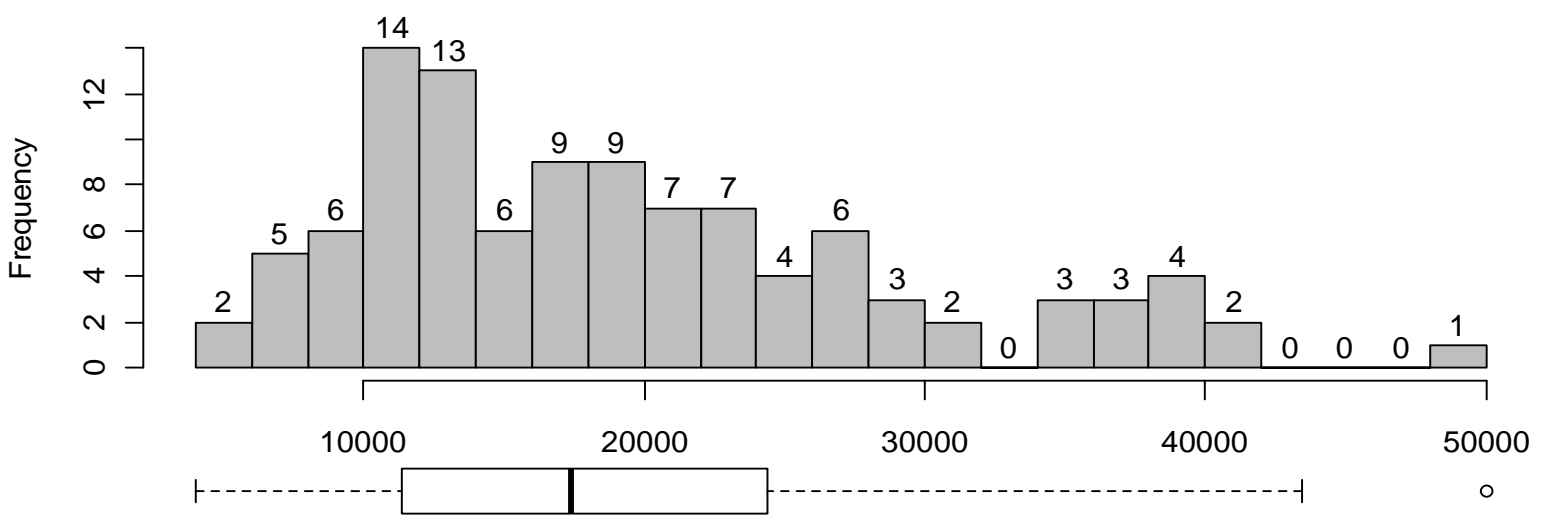

Figure 4.31: Distribution of Major Street AADT for U4SG, n=106

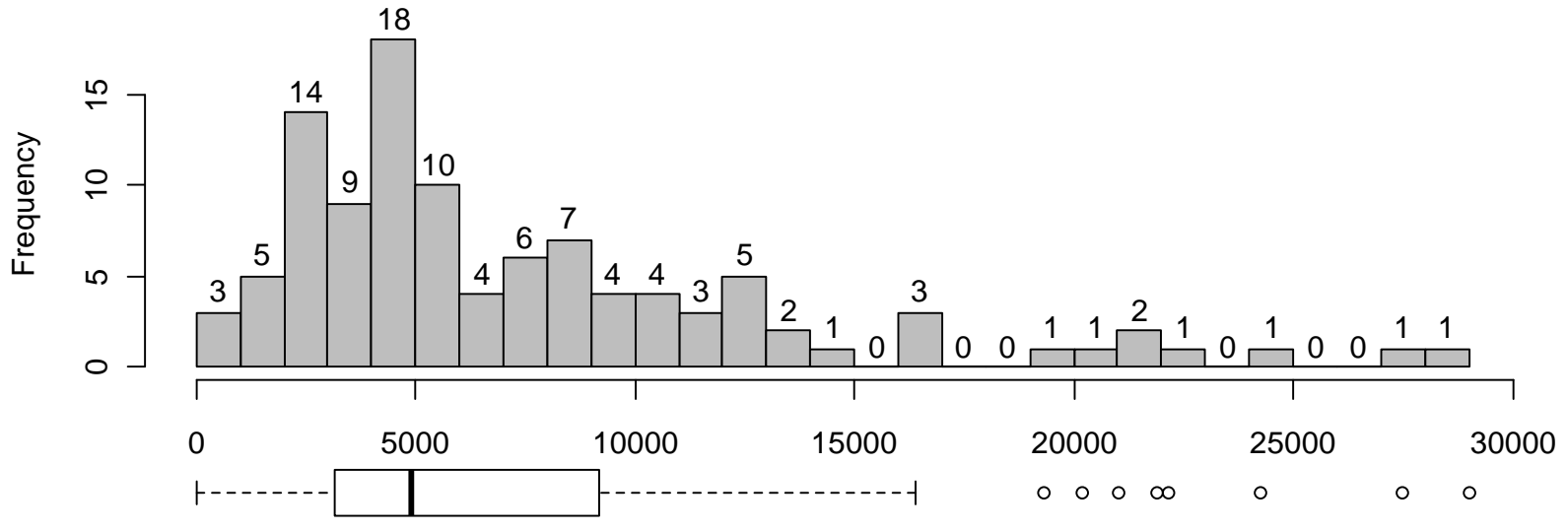

Figure 4.32: Distribution of Minor Street AADT for U4SG, $n=106$ 


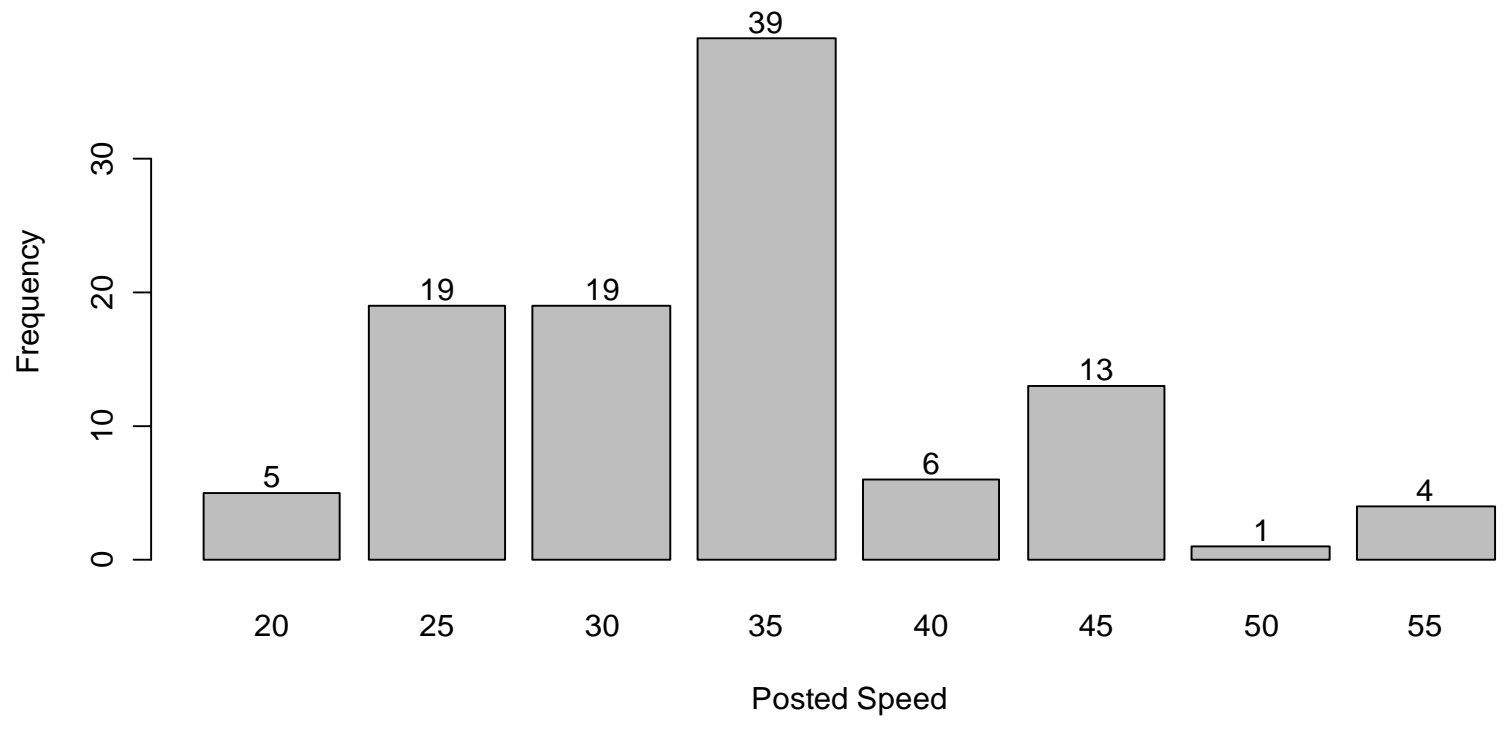

Figure 4.33: Distribution of Major Street Posted Speed for U4SG, n=106

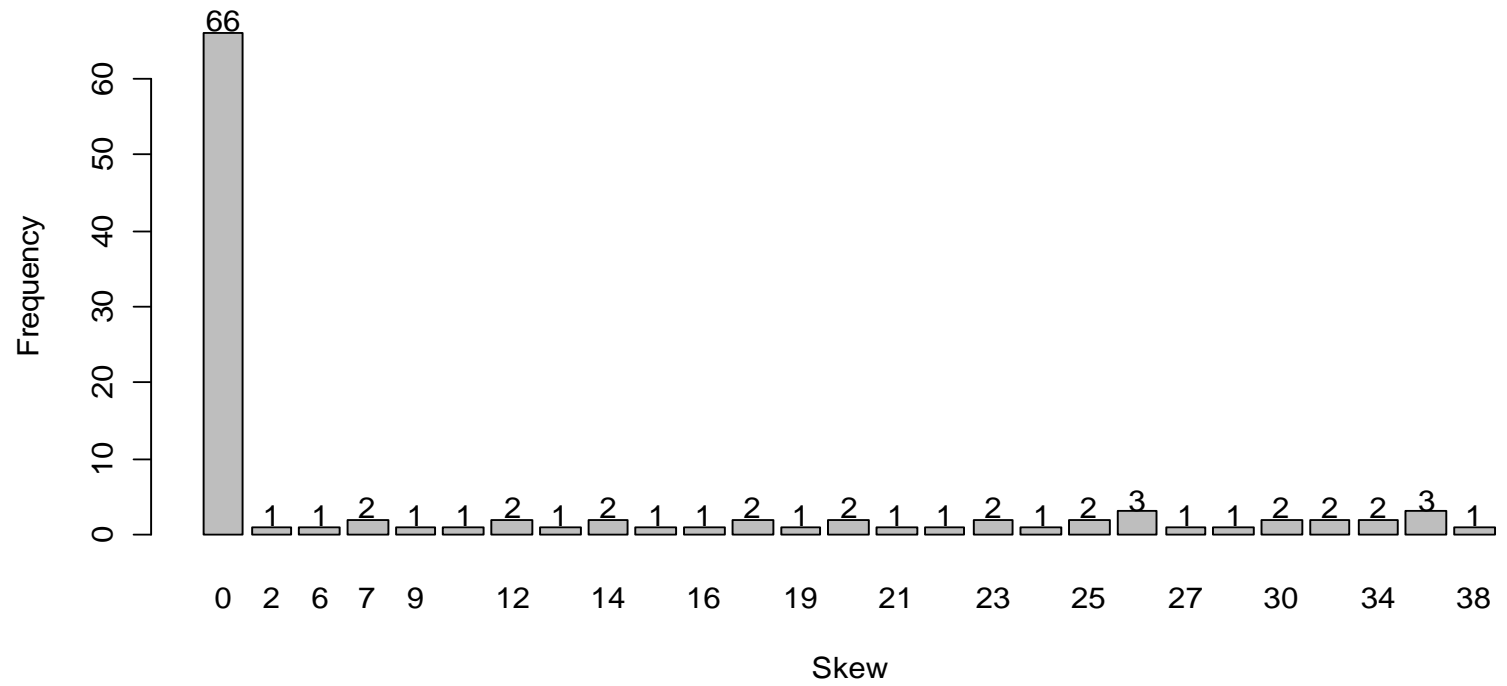

Figure 4.34: Distribution of Intersection Skew for U4SG, n=106 

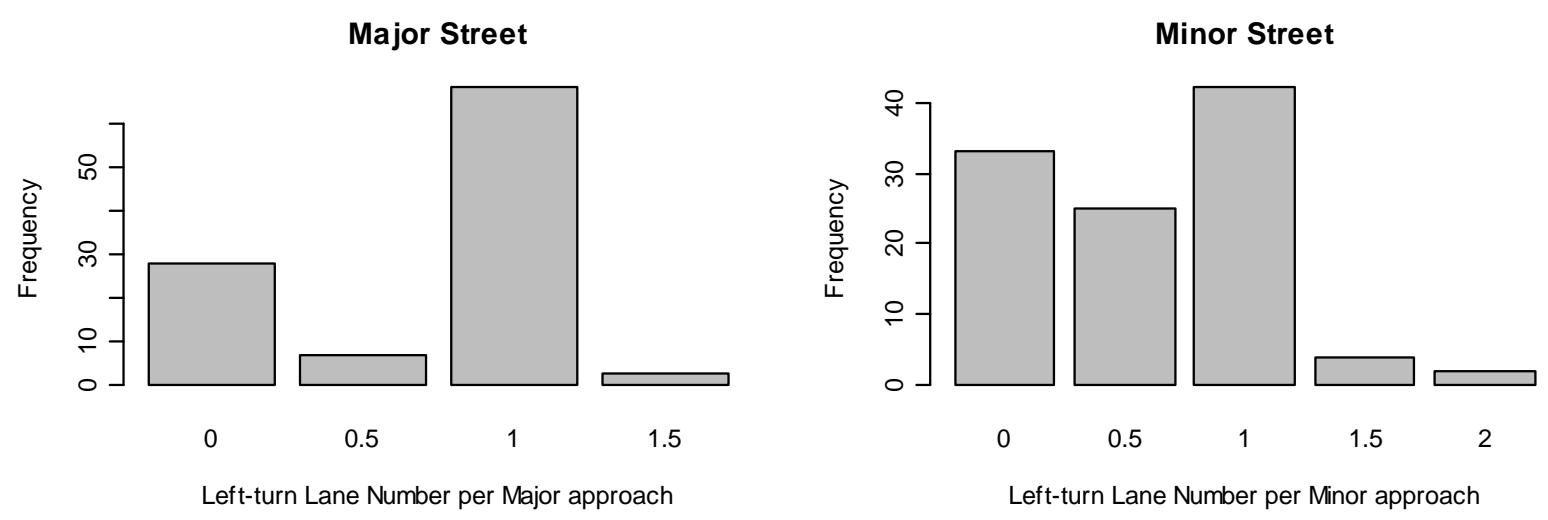

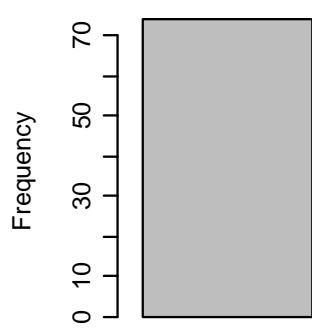

0

Right-turn Lane Number per Major approach

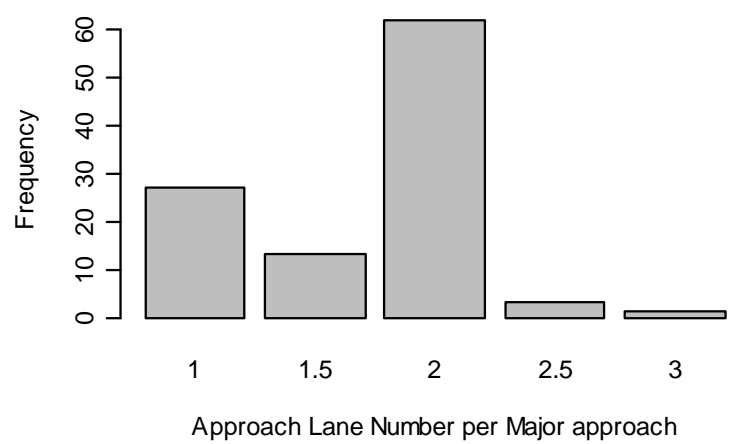

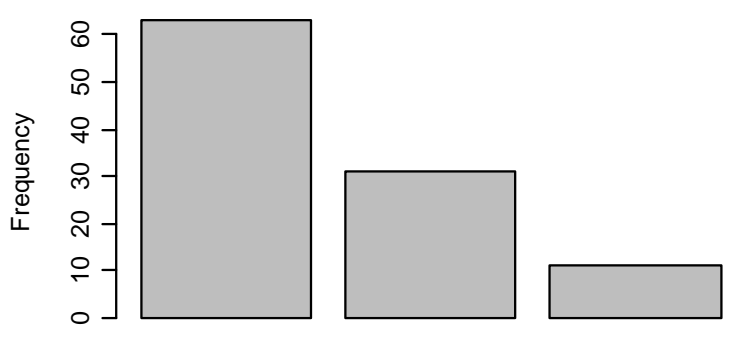

0

0.5

1

Right-turn Lane Number per Minor approach

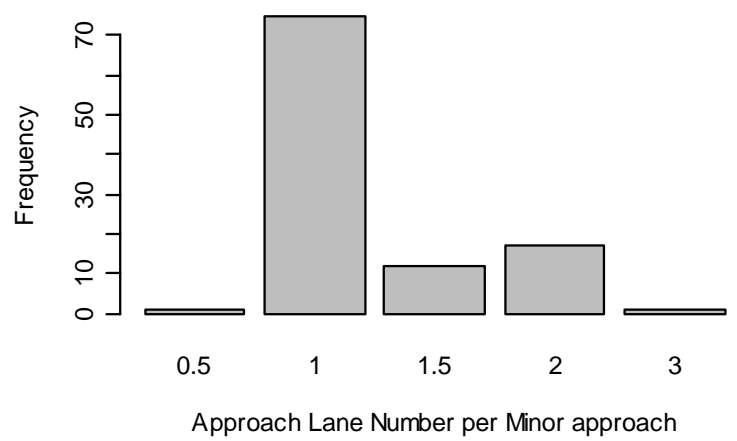

Figure 4.35: Distribution of the Number of Left, Right, and Approach Lanes for U4SG

\subsubsection{Negative Binomial Regression Model}

The question of interest was to use the negative binomial regression to get a prediction model of annual total crashes happened on urban 4-legged signalized intersection.

Candidate variables that may have influence on the total crashes were included into a full model. Candidate variables were listed below:

- Major Street AADT (continuous variable)

- Minor Street AADT (continuous variable) 
- Posted speed limit on major street (continuous variable)

- Number of directions with left-turn lane on major street (category variable: $0=$ none; 1 =one direction; 2 =both directions)

- Number of directions with left-turn lane on minor street (category variable: $0=$ none; $1=$ one direction; 2 =both directions)

- Number of directions with right-turn lane on major street (category variable: $0=$ none; $1=$ one direction; 2 =both directions)

- Number of directions with right-turn lane on minor street (category variable: $0=$ none; 1 =one direction; 2 =both directions)

- Intersection skew (continuous variable)

- Presence of lighting (category variable: $1=$ presence; $0=$ =absence)

Using backward elimination model selection method based on AIC criterion, the negative binomial model indicated that the variables the major street AADT, the minor street AADT and intersection skew remain in the model. Due to the mitigating influence of traffic signal, the posted speed limit may not have great influence on entering speeds, which likely influences the safety performance of an intersection. The presence of lighting may affect night crashes, but failed to prove to be significant in the evaluation of the total crashes that included both day and night collision. Although the final model included the intersection skew, this variable was not strongly significant. This may be due to the disproportionate distribution of the intersection skew (most were not skew). For the reason of this fact, the search team elected to remove the intersection skew variable from the recommended model. As a result, the recommended model simply includes the major and minor AADT variables for the final model for the urban 4-leg signalized intersection:

$$
\text { Predicted Total Crash per Year }=e^{-10.26+0.72 \ln (\text { AADTmaj })+0.53 \ln (\text { AADTmnr })}
$$

Model diagnostics and outputs are summarized in Table 4.19. The estimated SPF is shown graphically in Figure 4.36. In the figure, the x-axis represents the traffic volume on the major approach and $y$-axis represents the predicted total average annual crashes per year. The box plot below the $x$-axis represents the distribution of the actual traffic volume on the major street in the model data. To represent the influence of the minor street AADT, the plot includes fitted models for the minor AADT in 2500 vehicles per day increments. In the plot, the lines indicated that the crashes per year would increase along with the increase of traffic volume on major street. It was estimated that a doubling of traffic volume on Major Street was associated with a change in the mean of total crash rate by a factor of 1.64. The influence on crash rate was shown below when traffic volume on Minor Street changed. The crash rate would increase along with the increase of traffic volume on Minor Street. It was estimated that a doubling of traffic volume on Minor Street was associated with a change in the mean of crash rate by a factor of 1.45. 
Table 4.19: Summary Model Output for U4SG

\begin{tabular}{|c|c|}
\hline Parameter & Estimate (Standard Error) \\
\hline Intercept: $(\beta 0)$ & $\begin{array}{ll}-10.26466 \quad(1.09244) \\
\end{array}$ \\
\hline Ln(AADTmaj): ( $\beta 1)$ & $0.71725 \quad(0.11634)$ \\
\hline Ln(AADTmnr): ( $\beta 2)$ & $0.53405 \quad(0.07709)$ \\
\hline Dispersion Parameter $(\theta)$ & $4.957 \quad(0.984)$ \\
\hline \multicolumn{2}{|c|}{ Goodness-of-fit Statistics } \\
\hline Number of Observations & 106 \\
\hline Deviance & 111.41 \\
\hline Degrees of freedom & 103 \\
\hline Log Likelihood & -675.103 \\
\hline
\end{tabular}

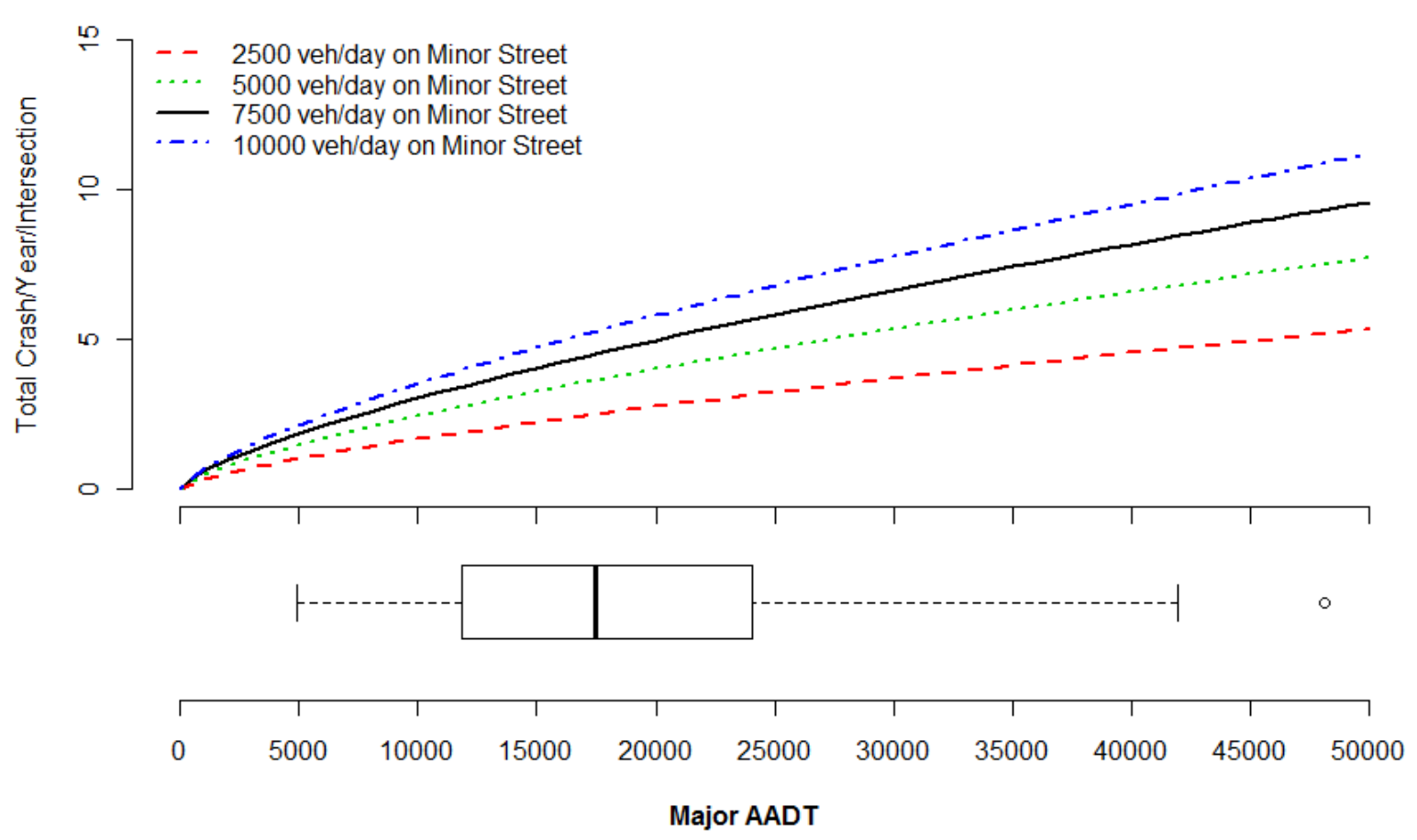

Figure 4.36: Crash Prediction Model for U4SG

\subsubsection{Comparison to Calibrated HSM Models}

The HSM provides two models for 3-leg stop controlled in the rural environment (2-lane highways and multilane facilities). The majority of intersections in the SPF data set are on rural 2-lane facilities, thus, the comparison was made to the HSM model for rural 3-leg stop controlled intersections in the 2-lane chapter. That model (with the Oregon calibration factor of $0.32)$ is:

HSM Predicted Total Crashes per Year $=0.32\left(e^{-9.86+0.79 \ln (\text { AADTmaj })+0.49 \ln (\text { AADTMnr })}\right)$

The HSM model is applicable for volume ranges up to 19,500 vehicles per day on the major and up to 4,300 vehicles per day on the minor approach. As shown in Figure 4.22 and Figure 4.23, the data used t0o develop the SPF models includes volumes up to 27,000 on the major and 3,500 
on the minor but the practical predictive limits should be considered up to 15,000 vehicles per day on the major and 1,000 vehicles per day on the minor.

The SPF and the HSM calibrated models are plotted together in Figure 4.37. The black lines are for minor ADTs of 700 vehicles per day, the red lines are for minor ADTs of 1,500 vehicles per day. The solid lines are estimated by the SPF; the dashed lines by the HSM calibrated base model. The 1,500 minor ADT is outside the SPF predictive range but well within the HSM range. As shown in the plot, the functional shape of the SPF and HSM calibrated base model are very similar. To explore the further, Figure 4.38 is an isocontour plot showing the predicted number of crashes for all combinations of major and minor ADTs. To interpret the plot, the 1.0 isocontour line shows all combinations of major and minor ADTs that result in 1.0 predicted crash per year. This figure also conveys a reasonable relationship between the SPF and calibrated HSM base model since the shapes/slopes and locations of the isocontours are generally similar.

It should be noted that a perfect correlation between these models is not expected. The HSM predictions are for an intersection with the "base conditions" specified in the HSM. The base conditions are no skew, no right-turn lanes, no left-turn lanes, and no lighting. In the HSM methodology, predictions of the base models are adjusted with CMFs. The SPFs are developed based on all intersections in the database which contain a variety of conditions (not just base conditions). So, some difference is expected.

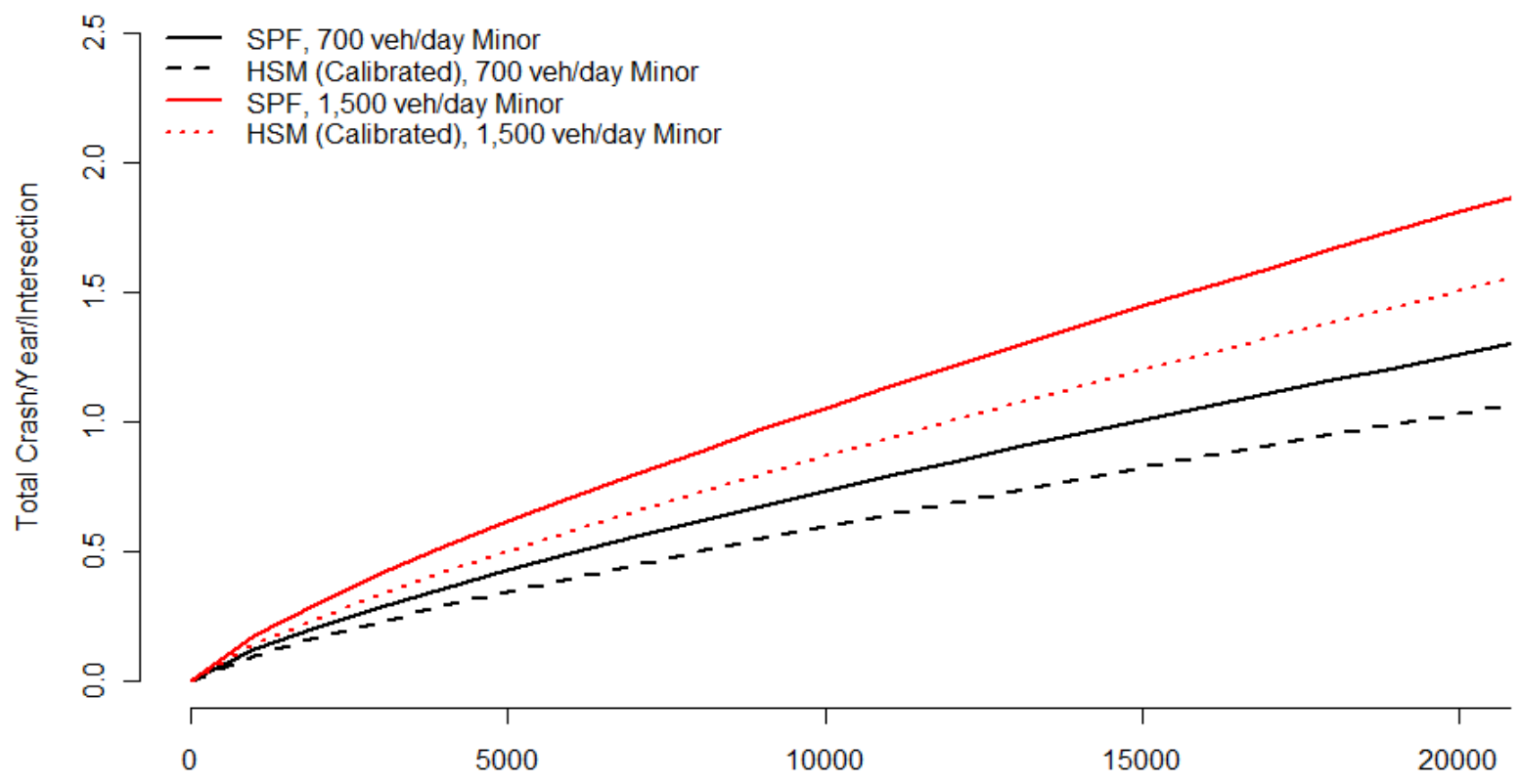

Figure 4.37: Comparison of SPF Model and HSM Calibrated Model for Oregon, R3ST 

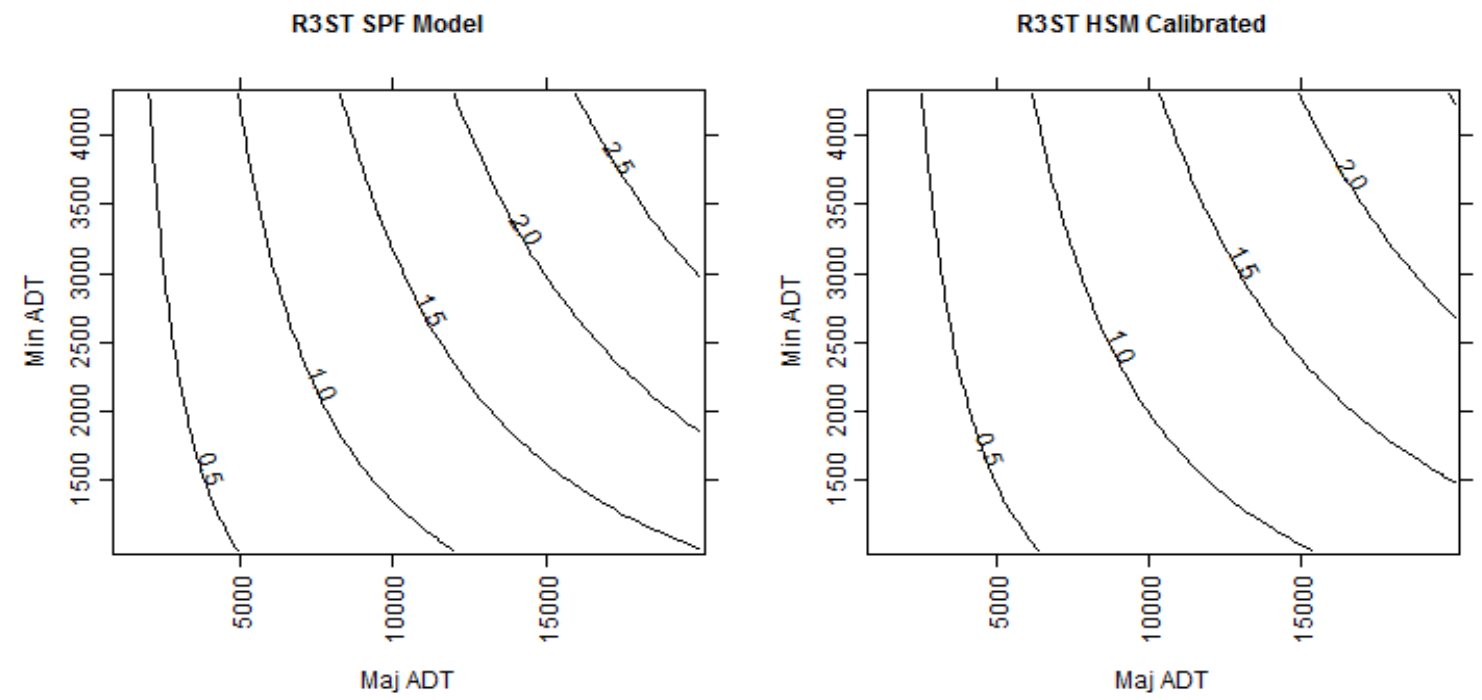

Figure 4.38: Isocontour Plots of Total Crashes Estimated by the SPF Model and HSM Calibrated Base Model, R3ST

A comparison was also made between the HSM calibrated base model for urban 4-leg signalized intersections and the SPF developed in this research. The HSM model includes sub-models for multiple-vehicle, single-vehicle, vehicle-bicycle, and vehicle-pedestrian collisions that must be added together to predict total crashes. Ignoring the bicycle and pedestrian models (which are generally very small) the calibrated equation for total crashes estimated by the HSM is:

$$
\begin{aligned}
& \text { HSM Predicted Total Crashes per Year } \\
& \qquad \begin{array}{l}
=1.054\left(e^{-10.99+1.07 \ln (\text { AADTmaj })+0.23 \ln (\text { AADTmnr })}\right. \\
\left.+e^{-10.21+0.68 \ln (\text { AADTmaj })+0.27 \ln (\text { AADTmnr })}\right)
\end{array}
\end{aligned}
$$

where the Oregon-derived calibration factor is 1.054. The HSM models are applicable up to major volumes of 67,700 and minor volumes of 33,400 vehicles per day. The SPF models were developed on data sets that have a practical predictive limit of 42,000 on the major and 15,000 on the minor approach (see Figure 4.31 and Figure 4.32).

As before, the SPF and the HSM calibrated models are plotted together in Figure 4.39. The black lines are for minor ADTs of 7,500 vehicles per day, the red set is for minor ADTs of 20,000 vehicles. The solid lines are estimated by the SPF; the dashed lines by the HSM calibrated base model. Both minor ADTs are within predictive ranges. The isocontour plot is presented in Figure 4.40 (see previous paragraph for description). There is a significant divergence between the models and not nearly as similar as the R3ST models. The differences in the estimated total crashes are even more pronounced in the isocontour plot - the HSM calibrated base models predict more total crashes, particularly in the higher major ADT and lower minor ADT values. Some of this difference is due to the fact that the HSM calibrated models represent base conditions while the SPF models reflect the variety of intersection characteristics. In the HSM models base conditions must be adjusted for left and right turn lanes, type of left-turn phasing, right-turn on red prohibitions, red-light enforcement cameras, lighting, and other adjustments for 
pedestrians. In general, most of the intersections in the SPF data set have features that will adjust the HSM base model lower (CMFs less than one). However, it is still not clear how well the calibrated HSM base models compare. Further research is needed to investigate whether Oregonspecific SPFs have advantages over calibrated HSM models.

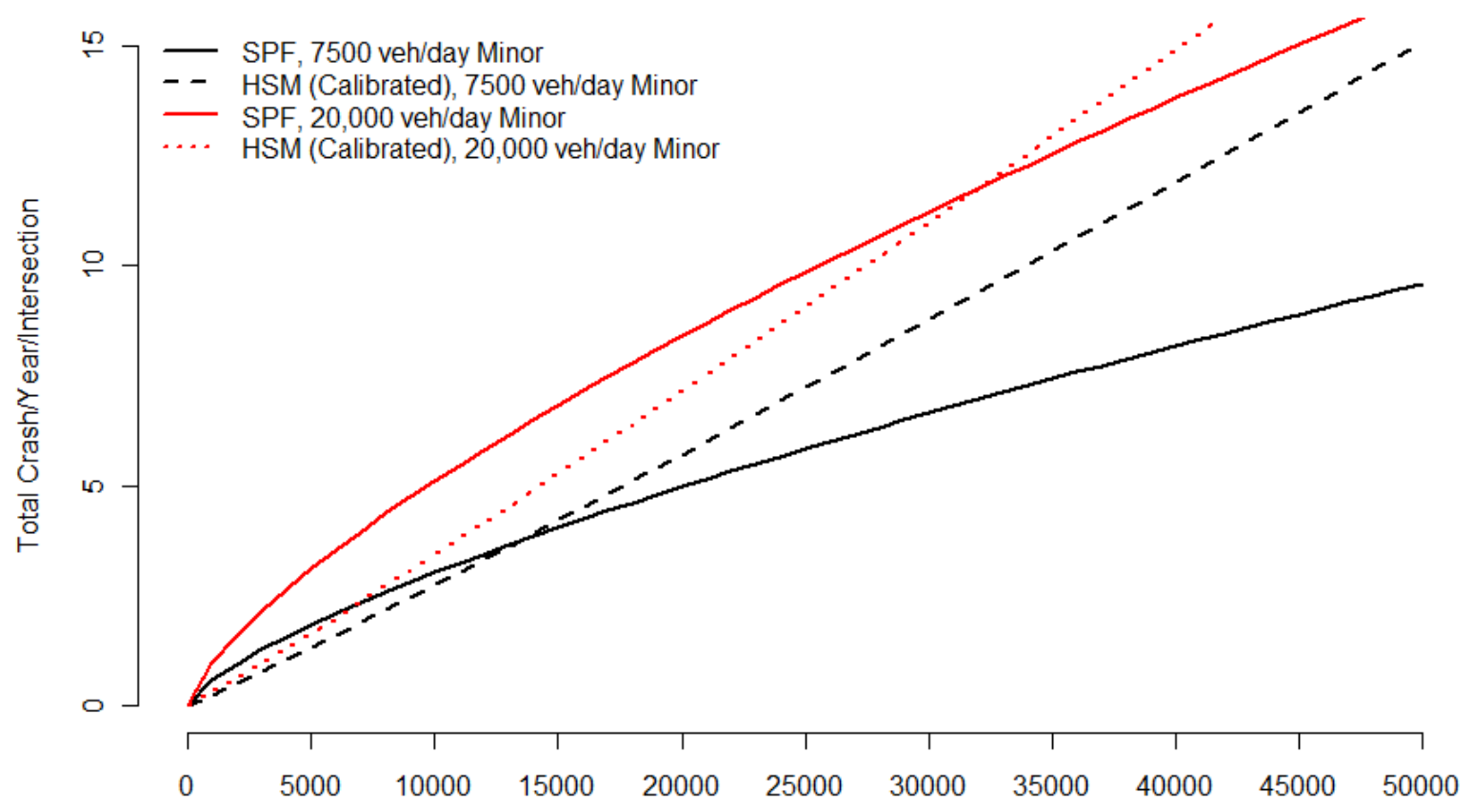

Figure 4.39: Comparison of SPF Model and HSM Calibrated Model for Oregon, U4SG
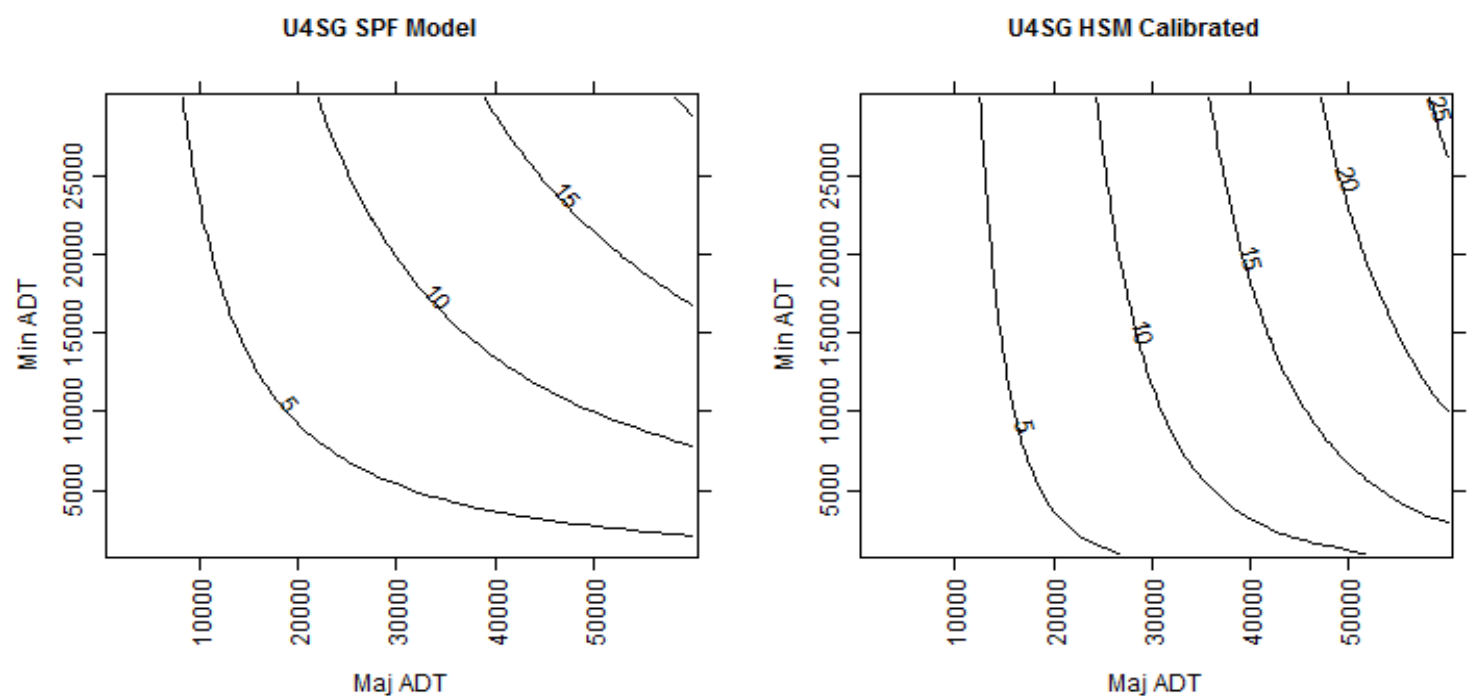

Figure 4.40: Isocontour Plots of Total Crashes Estimated by the SPF Model and HSM Calibrated Base Model, U4SG 


\subsection{CONCLUSIONS}

This report summarizes the results of an analysis of the safety performance of Oregon's intersections. The review of the literature has identified a long list of potential intersection elements that affect crash potential. Many of these elements are not routinely collected as part of state data activities and can only be obtained through manual data collection efforts. A pilot study was conducted to focus the data collection on elements balancing data collection effort with anticipated safety effects. Following the pilot study, a unique database of intersection features created for this research, safety performance was analyzed in a number of different ways. This database consisted of 500 intersections from around the state of Oregon in both urban and rural environments. These intersections were categorized into eight types based on number of legs (3 and 4), land use (urban or rural) and traffic control (signalized or minor stop-control). These categories were chosen to align with the intersection types in AASHTO's recently released Highway Safety Manual. These geometric and traffic control elements were supplemented by compiling crash data and volumes on the major and minor approaches.

Rural and urban intersections of the following geometry and traffic control were analyzed:

- 3-leg signalized 3SG

- 3-leg minor stop-control 3ST

- 4-leg signalized $\quad 4$ SG

- 4-leg minor stop-control 4ST

The safety performance was analyzed by three methods. First, crash rates were calculated and analyzed for each intersection groups. The distributions were described statistically and were tested for normality. Crash rates determined for Oregon intersections were generally well below rates found published for other states (though were comparable to Kentucky's published rates). Since it is unlikely that such a significant difference exists in the safety performance between states, it is more likely explanation is the different reporting thresholds and Oregon's reliance on self-reporting. This highlights the challenge of making direct comparisons of state-to-state safety performance based on differing crash reporting data. The rate analysis also confirmed expected safety performance differences between urban and rural locations and traffic control.

Second, crash patterns were tabulated for a number of crash and driver involved variables. These patterns, not before generated, will be very useful in the diagnostic procedures that require longterm averages based on similar intersections. The primary use of these data will be to improve identification of high crash intersection locations and improve diagnosis of these locations. Results of this research have already been incorporated in an automated spreadsheet for diagnosis of crash problems on state highways. 
Third, safety performance functions were created for intersections where sufficient data exist. For the purposes of this research SPFs were estimated for the rural 3-leg stop controlled and urban 4-leg signalized intersections. These intersections were the largest sample in the collected database. SPFs were modeled using negative binomial regression. In the literature, nearly every model reviewed was found to have major and minor volumes as significant variables. SPFs developed here were no different. While many of the data elements collected certainly influence the safety performance of intersections, they were not found to be significant in the model building efforts. In many cases, these is most likely due to the lack of sufficient variation and the number of intersections sampled, rather than a lack of safety influence. The SPFs developed in this modeling exercise were compared to the HSM base models calibrated to Oregon. The rural 3-leg stop models compare favorably. Within the volume range of the data used to generate the SPFs, the models compare well. The urban signalized intersection SPFs did not compare as well to the HSM base models. Further research is needed to investigate whether Oregon-specific SPFs have advantages over calibrated HSM models.

The results of this analysis can be used to improve the diagnosis and identification of unusual safety performance at intersections in Oregon. The average rates are useful for peer comparisons and in calculation of critical rates. The crash patterns can be directly applied in diagnostic efforts to detect unusual patterns at intersections. The SPF modeling effort is the groundwork for further explorations and model development for Oregon facilities. 


\subsection{REFERENCES}

American Association of State Transportation Officials. Highway Safety Manual. AASHTO, Washington, D.C., 2010.

Abdel-Aty, M. and J. Keller. Exploring the Overall and Specific Crash Severity Levels at Signalized Intersections. Accident Analysis \& Prevention, 2005, pp. 37, 417-425.

Agent, K R; J G. Pigman. Analysis of Traffic Accident Data In Kentucky (1988-1992). University of Kentucky, Lexington, 1993, p. 136.

Allen, D. P., J. E. Hummer, N. M. Rouphail, and J. S. Milazzo. Effect of Bicycles on Capacity of Signalized Intersections. Transportation Research Record: Journal of Transportation Research Board, No. 1646, 1998, pp. 87-95.

Antonucci, N. D., K. K. Hardy, K. L. Slack, R. Pfefer, and T. R. Neuman. Guidance for Implementation of the AASHTO Strategic Highway Safety Plan. Volume 12: A Guide for Reducing Collisions at Signalized Intersections. NCHRP Report, No. 500, Vol.12, Transportation Research Board, Washington D.C., 2004.

Bahar, G., M. Masliah, T. Erwin, E. Tan, and E. Hauer. NCHRP Web Only Document 92: Pavement Marking Materials and Markers: Real-World Relationship between Retroreflectivity and Safety Over Time. Transportation Research Board of the National Academies, Washington, D.C., 2006.

Bauer, K. M., \& D. W. Harwood. Statistical Models of At-Grade Intersection Accidents Addendum. FHWA, Washington, D.C., 1998.

Bauer, K. M., and D. W. Harwood. Statistical Models of at-Grade Intersection Accidents. 1996.

Bonn, E. Intersection Accident Rates. Unpublished internal Oregon DOT memorandum. File TRA-03-01, Dated September 4, 1994.

Box, P.C. and P.A. Mayer. Intersections, in Traffic Control and Roadway Elements - Their Relationship to Highway Safety. Highway Users Federation for Safety and Mobility. Washington, D.C., 1970.

Bray, J. S. Skid Accident Reduction Program (SKARP): Targeted Crash Reductions. Institute of Transportation Engineers 2003 Technical Conference and Exhibit. Fort Lauderdale, FL, 2003.

Brich, S. C., and B. H. Cottrell Jr. Guidelines for the Use of No U-Turn and No-Left Turn Signs. VTRC 95-R5, Virginia Department of Transportation, Richmond, VA, 1994. 
Burchett, G. D., and T. H. Maze. Rural Expressway Intersection Characteristics that Contribute to Reduced Safety Performance. Proceedings of the 2005 Mid-Continent Transportation Research Symposium, Ames, Iowa., 2005.

Carter, D. L, W. W Hunter, C. V Zegeer, J. R Stewart, and H. Huang. Bicyclist intersection safety index. Transportation Research Record: Journal of the Transportation Research Board No. 2031, 2007, pp. 18-24.

Caltrans. 1988 Accident Data on California State Highways. California Department of Transportation, 1989, p. 27

Cottrell, W., and S. Mu. Utah Intersection Safety Recurrent Crash Sites: Identification, Issues and Factors. Mountain-Plains Consortium, 2005.

Council, F. M., B. Persaud, K. Eccles, C. Lyon, and M. S. Griffith. Safety Evaluation of RedLight Cameras. Publication FHWA-HRT-05-048, FHWA, McLean, VA, 2004.

Council, F. M., D. L. Harkey, D. L. Carter, and B. Whit. Model Minimum Inventory of Roadway Elements-MMIRE. Publication FHWA-HRT-07-046, FHWA, McLean, VA, 2007.

Dahir, S. H. and W. L. Gramling. Wet-Pavement Safety Programs. NCHRP Synthesis of Highway Practice, No. 158. Transportation Research Board. Washington, D.C., 1990.

Debaillon, C., P. Carlson, Y. He, T. Schnell, and F. Aktan. Updates to Research on Recommended Minimum Levels for Pavement Marking Retroreflectivity to Meet Driver Night Visibility Needs. Publication FHWA-HRT-07-059, FHWA, McLean, VA, 2007.

Decina, L. E. (Larry E.), Libby Thomas,Raghavan Srinivasan, and L. K. Staplin. Automated Enforcement : A Compendium of Worldwide Evaluations of Results. National Highway Traffic Safety Administration. Office of Research and Technology, Washington D.C., 2007.

Elvik, R., and T. Vaa. The Handbook of Road Safety Measures. Elsevier, 2004.

Federal Highway Administration. Highway Design Handbook for Older Drivers and Pedestrians. Publication FHWA-RD-01-051, FHWA, 2000.

Gibby, A.R., S.P. Washington, and T.C. Ferrara. Evaluation of High-Speed Isolated Signalized Intersections in California. Transportation Research Record, No. 1376. Transportation Research Board. Washington, D.C., 1992, pp. 45-56.

Gluck, J., H. S. Levinson, and V. Stover. Impacts Of Access Management Techniques. Transportation Research Board, 1999.

Golias, J. C. Establishing Relationships Between Accidents and Flows at Urban Priority Road Junctions. Accident Analysis \& Prevention, No. 24 (6), 1992, pp. 689-694. 
Green, E. and K. Agent. Crash Rates at Intersections. Kentucky Transportation Center in Cooperation with the Kentucky Transportation Cabinet and FHWA, Research Report KTC 0321-SPR 25803-21, 2003.

Federal Highway Administration. Intersection Safety. http://safety.fhwa.dot.gov/intersection. Accessed on June 21, 2011.

Gibby, A.R., S.P. Washington, and T.C. Ferrara. Evaluation of High-Speed Isolated Signalized Intersections in California. Transportation Research Record, No. 1376. Transportation Research Board. Washington, D.C., 1992, pp. 45-56.

Gluck, J., H. S. Levinson, and V. Stover. Impacts Of Access Management Techniques. Transportation Research Board, 1999.

Golias, J. C. Establishing Relationships Between Accidents and Flows at Urban Priority Road Junctions. Accident Analysis \& Prevention, No. 24 (6), 1992, pp. 689-694.

Green, E. and K. Agent. Crash Rates at Intersections. Kentucky Transportation Center in Cooperation with the Kentucky Transportation Cabinet and FHWA, Research Report KTC 0321-SPR 25803-21, 2003.

Hanley, K. E., A. R. Gibby, and T. C. Ferrara. Analysis of Accident Reduction Factors on California State Highways. Transportation Research Record, No. 1717. Transportation Research Board. Washington, D.C., 2000. pp. 37-45.

Hanna, J.T., T. Flynn, and W. Tyler. Characteristics of Intersection Accidents in Rural Municipalities. Transportation Research Record, No. 601, Transportation Research Board, National Research Council, Washington D.C., 1976, pp. 79-81.

Harwood, D. W., F. M. Council, E. Hauer, W. E. Hughes, and A. Vogt. Prediction of the Expected Safety Performance of Rural Two-Lane Highways. FHWA, U.S. Department of Transportation, Research, Development, and Technology, Turner-Fairbank Highway Research Center, The National Technical Information Service, 2000.

Harwood, D. W., K. M. Bauer, I. B. Potts, D. J. Torbic, K. R. Richard, E. R. K. Rabbani, E. Hauer, and L. Elefteriadou. Safety Effectiveness of Intersection Left- and Right-Turn Lanes. Publication FHWA-RD-02-089. FHWA, Office of Safety Research and Development, McLean, Virginia, 2002.

Harwood, D. W., M. T. Pietrucha, M. D. Wooldridge, R. E. Brydia, and K. Fitzpatrick. Median Intersection Design. National Cooperative Highway Research Program, No. 375, Transportation Research Board, 1995.

Hauer, E. Left Turn Protection, Safety, Delay, and Guidelines: A Literature Review, October 4, 2004. http://www.roadsafetyresearch.com/. Accessed February 9, 2009. 
Hauer, E., D. W. Harwood, F. M. Council, and M. S. Griffith. Estimating Safety by the Empriical Bayes method: A Ttutorial. Transportation Research Record, No. 1784, 2002, pp. 126-131.

Hauer, E., Kononov, J., Allery, B., \& Griffith, M. S. Screening the Road Network for Sites with Promise. Transportation Research Record, No. 1784, 2002, pp. 27-32.

Heydecker, B. J., and J. Wu. Using the Information in Road Accident Records. Proc., 19th PTRC Summer Annual Meeting, London, 1991.

Johnson, R. S. Pedestrian Safety Impacts Of Curb Extensions: A Case Study. Publication FHWA-0R-DF-06-01, Oregon Department of Transportation, Salem, Oregon, 2005.

Kim, D.-G., Y. Lee, S. Washington, and K. Choi. Modeling Crash Outcome Probabilities at Rural Intersections: Application of Hierarchical Binomial Logistic Models. Accident Analysis \& Prevention, No. 39, 2007, pp. 125-134.

Knapp, K. K., and J. Campbell. Intersection Crash Summary Statistics for Wisconsin. FHWA/WisDOT, Wisconsin Department of Transportation, Madison, WI, 2005.

Kononov, J and Janson, B. Diagnostic Methodology for the Detection of Safety Problems at Intersections, Journal of the Transportation Research Board: Transportation Research Record 1784, National Research Council, Washington, D.C., 2003, pp. 51-56.

Kweon, Y. Development of a Safety Evaluation Procedure for Identifying High-Risk Signalized Intersections in the Virginia Department of Transportation's Northern Virginia District. Publication FHWA/VTRC 08-R1. Virginia Department of Transportation, Richmond, VA, 2007.

Lyon, C., B. Gotts, W. Wong, and B. Persaud. Comparison of Alternative Methods for Identifying Sites with High Proportion of Specific Accident Types. In Transportation Research Record: Journal of the Transportation Research Board, No. 2019, Transportation Research Board of the National Academies, Washington, D.C., 2007, pp. 212-218.

Lyon, C., B. Persaud, S. P. Washington, and J. Bared. Empirical Investigation of the IHSDM Accident Prediction Algorithm for Rural Intersections. Transportation Research Record, No. 1840, 2003, pp. 78-86.

Miaou, S. Measuring the Goodness-of-Fit of Accident Prediction Models. Publication FHWARD-96-040, FHWA, McLean, VA, 1996.

Monsere, C. Safety Comparison of 4-Way Cross and Offset T Intersections. Publication TRA 10-05-12, Oregon Department of Transportation, 2001.

Naik, B. Offsetting Opposing Left-Turn Lanes at Signalized Intersections: A Safety Assessment Case Study in Lincoln, Nebraska, 2005.

NHTSA Office of Traffic Safety Programs. The Safety Impact of Right-Turn-on-Red: Report to Congress. Report to Congress as Required by Energy Policy Act of 1992. February 1995, U.S. 
Department of Transportation National Highway Traffic Safety Administration, Washington D.C., 1995.

Ogden, K.W. Safer Roads: A Guide to Road Safety Engineering. Aldershot, Hants, England, Brookfield, Vt.: Avebury Technical, 1996.

Oh, J., C. Lyon, S. P. Washington, B. Persaud, and J. Bared. Validation of the FHWA Crash Models for Rural Intersections: Lessons Learned. Transportation Research Record, No. 1840, 2003, pp. 41-49.

Oh, J., S. P. Washington, and K. Choi. (2004). Development of Accident Prediction Models for Rural Highway Intersections. Transportation Research Record, No. 1897, 2004, pp. 18-27.

Oregon Department of Transportation. Oregon Bicycle and Pedestrian Plan: Design Standards and Guidelines: Chapter 4: Walkways. Salem, Oregon, 2007.

Oregon Department of Transportation. Crash Summary Book. Crash Analysis and Reporting Unit, Salem, OR, 2007.

Oregon Department of Land Conservation and Development. Urban Growth Boundaries http://arcweb.sos.state.or.us/rules/OARS_600/OAR_660/660_024.html,2009.

Ourston Roundabout Engineering, http://www.roundabout-interchange.com/safety.html. Accessed October 17, 2001.

Pant, P.; C Kashayi. Crash Base Rates for Intersections in Ohio. University of Cincinnati; Ohio Department of Transportation; Federal Highway Administration, 2007, p.155.

Persaud, B., and T. Nguyen. Disaggregate Safety Performance Models for Signalized Intersections on Ontario Provincial Roads. Transportation Research Record, No. 1635, 1998, pp. 113-120.

Persaud, B., F. M. Council, C. Lyon, K. Eccles, and M. Griffith. Multijurisdictional Safety Evaluation of Red Light Cameras. Transportation Research Record, No. 1922, 2005, pp. 29-37.

Poch, M., and F. Mannering. Negative Binomial Analysis of Intersection-Accident Frequencies. Journal of Transportation Engineering, Vol. 122, No. 2, 1996, pp. 105-113.

Potts, I. B., D. W. Harwood, and K. R. Richard. Relationship of Lane Width to Safety for Urban and Suburban Arterials. Proceedings of the 86th Annual Meeting of the Transportation Research Board, Washington, D.C., 2007, pp. 63-82.

Retting, R.A. and M. Greene. Influence of Traffic Signal Timing on Red-Light Running and Potential Vehicle Conflicts at Urban Intersections. Transportation Research Record, No. 1595. Transportation Research Board. Washington, D.C., 1997. 
Retting, R.A., J.F. Chapline, and A.F. Williams. Changes in Crash Risk Following Re-timing of Traffic Signal Change Intervals. Accident Analysis and Prevention, No. 34(2), 2002, pp. 215220.

Rodegerdts, L. A. Roundabouts in the United States. Transportation Research Board, American Association of State Highway and Transportation Officials, National Research Council, and F. H. Administration, 2007.

Rodegerdts, L., B. Nevers, B. Robinson, J. Ringert, P. Koonce, J. Bansen, T. M. Nguyen John, D. Stewart, J. Suggett, T. Neuman, N. Antonucci, K. Hardy, and K. Courage. Signalized Intersections: Informational Guide. Publication FHWA-HRT-04-091, FHWA, McLean, VA, 2004.

Roper, B.A., J.D. Fricker, R.E. Montgomery, and K.C. Sinha. The Effects of the All-Red Clearance Interval on Accident Rates in Indiana. ITE 1991 Compendium of Technical Papers. Washington, D.C., 1991.

Sayed, T., H. Vahidi, and F. Rodriguez. Advance Warning Flashers: Do They Improve Safety? Transportation Research Record, No. 1692. Transportation Research Board. Washington, D.C., 1999, pp. 30-38.

Smith, D., J. Melntyre, and M. Anderson. Handbook of Simplified Practice for Traffic Studies. Publication IOWA DOT Project TR-455, Iowa State University, 2002.

Souleyrette, R.R., M.M. O’Brien, T. McDonald, H. Preston, and R. Storm. Effectiveness of AllRed Clearance Interval on Intersection Crashes. Minnesota Department of Transportation. St. Paul, MN, 2004.

Squires, C. A., and P. S. Parsonson. Accident Comparison of Raised Median and Two-Way Left-Turn Lane Median Treatments. Transportation Research Record, No. 1239, 1989.

Stover, Vergil G. Functional Intersection Area, Discussion Paper No. 7, Oregon Dept. of Transportation, Salem, OR, 1996.

Tustin, B.H., H. Richard, H. McGee, and R. Patterson. Railroad-Highway Grade Crossing Handook, Second Edition. Federal Highway Adminstration, Report FHWA TS-86-215, 1986, p. 273.

Vogt, A., \& J. Bared. Accident Models for Two-Lane Rural Segments and Intersections. Transportation Research Record, No. 1635, 1998, pp. 18-29.

Walker, F W; S E Roberts. Influence Of Lighting On Accident Frequency At Highway Intersections. Transportation Research Record, Issue 562, 1976, p. 73-78

Washington, S. P., B. Persaud, C. Lyon, and J. Oh. Validation of Accident Models for Intersections. FHWA, Washington, D.C., 2005a. 
Washington, S. P., B. Persaud, J. Oh, and C. Lyon. Validation and Recalibration of Accident Prediction Models for Rural Intersections. Transportation Research Board, Washington, D.C. 2005b

Xie, F., Gladhill, K., Dixon, K. K., Monsere, C.M. Calibrating the Highway Safety Manual Predictive Models for Oregon State Highways Transportation Research Record: Journal of the Transportation Research Board, No. X, Transportation Research Board of the National Academies, Washington, D.C., 2011. In Press.

Yu, L. Left-Turn Lane Design and Operation, 2007, p. 226.

Zador, P., H. Stein, S. Shapiro, and P. Tarnoff. Effect of Signal Timing on Traffic Flow and Crashes at Signalized Intersections. Transportation Research Record, No. 1010. Transportation Research Board. Washington, D.C., 1984, pp. 1-8.

Zegeer, C. V., and M. J. Cynecki. Methods of Increasing Pedestrian Safety at Right-Turn-on-Red Intersections. FHWA, Office of Safety and Traffic Operations Research \& Development; National Technical Information Service, 1985.

Zegeer, C. V., J. R. Stewart, and H. H. Huang. Safety Effects of Marked Versus Unmarked Crosswalks at Uncontrolled Locations: Final Report and Recommended Guidelines. Publication FHWA-HRT-04-100, FHWA, McLean, VA, 2005. 



\section{APPENDIX A: Q-Q PLOTS OF CRASH RATES}




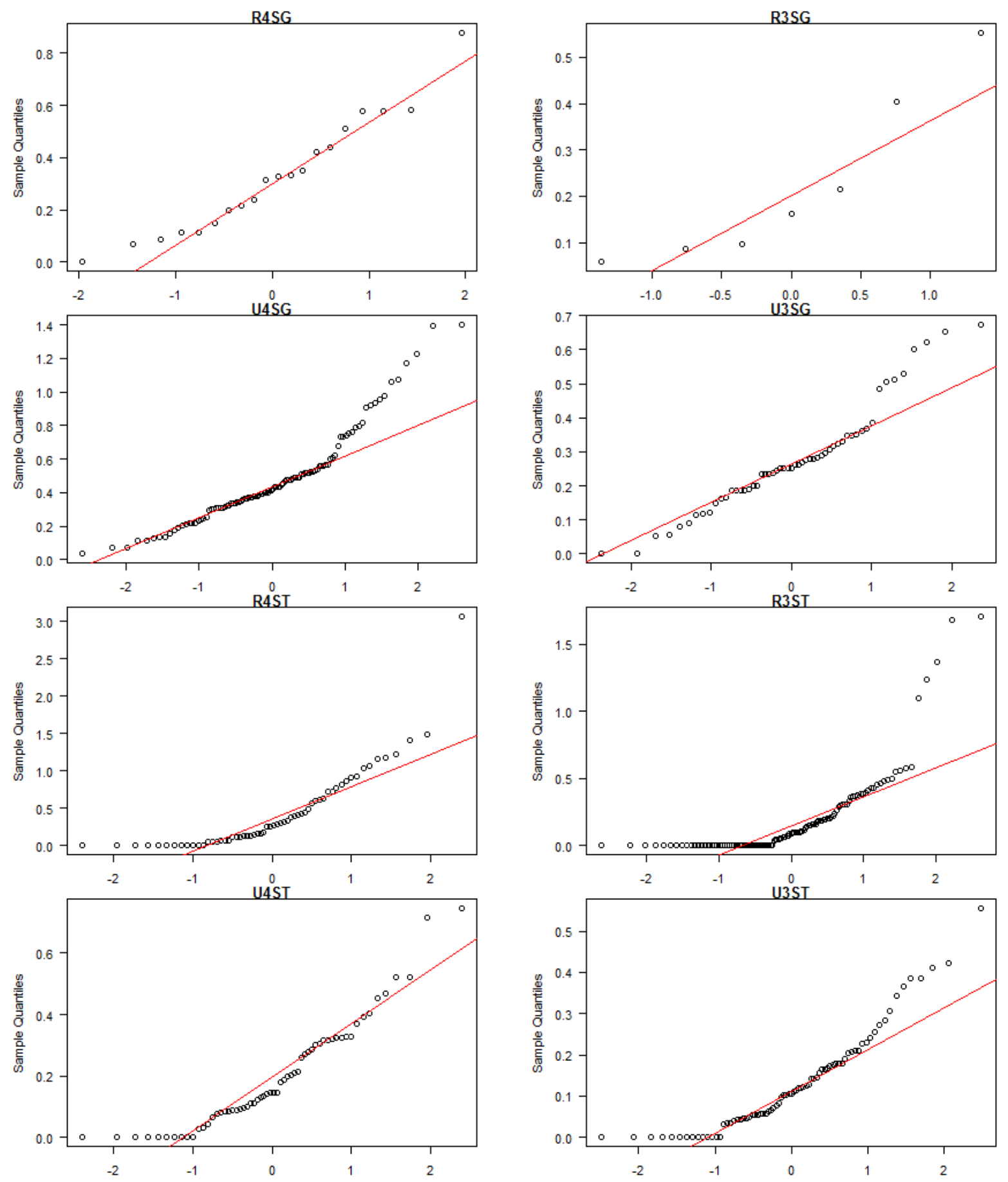

Figure A.1: Q-Q Plots of CRASH RATES 



\section{APPENDIX B: ANALYSIS OF PERFORMANCE BY SPECIFIC ELEMENTS}



Describe the plots and the influence was explored by a series of three box plots showing the element plotted by entering volume, crash frequency, and crash rate. Box plots represent the median value by the solid horizontal line, the box represents the interquartile range (i.e. the 25th and 75th percentile values, the whiskers represent 1.5 times the IQR. Points outside the whisker are outside the IQR. The number of intersections in each category is represented by the $\mathrm{N}=$ above the figure
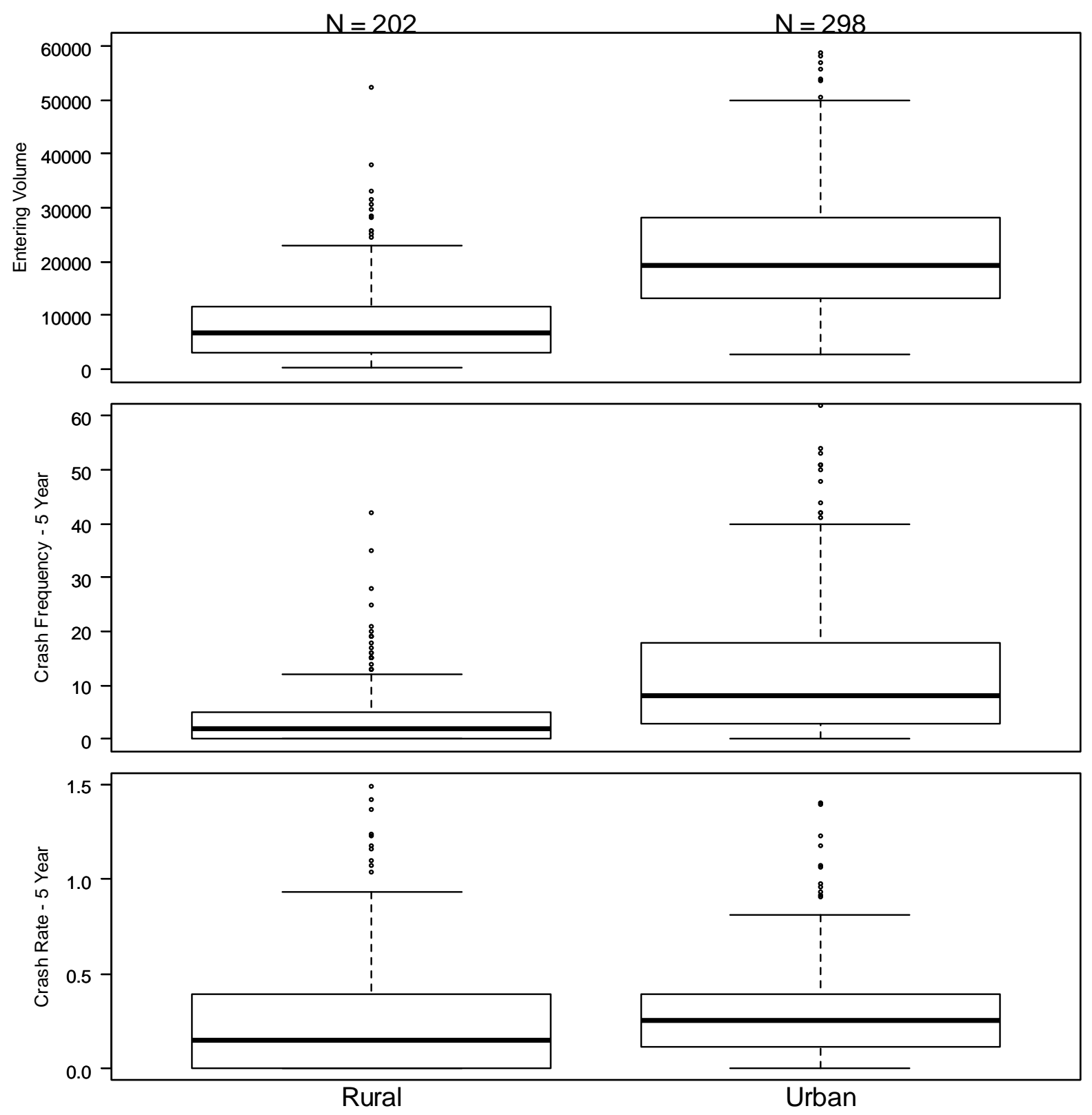

Figure B.1: Land Use Type 

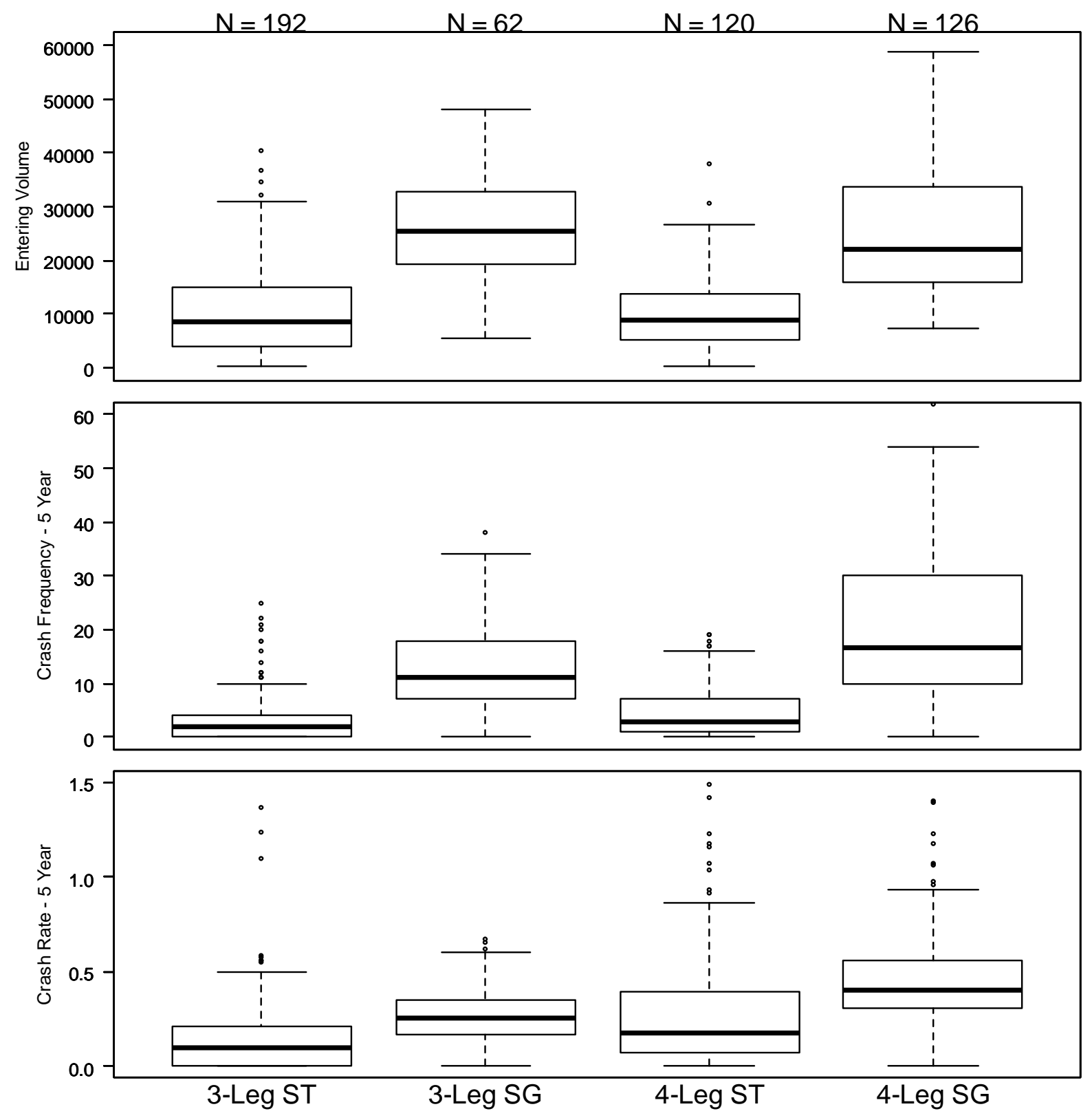

Figure B.2: Type of Intersection 

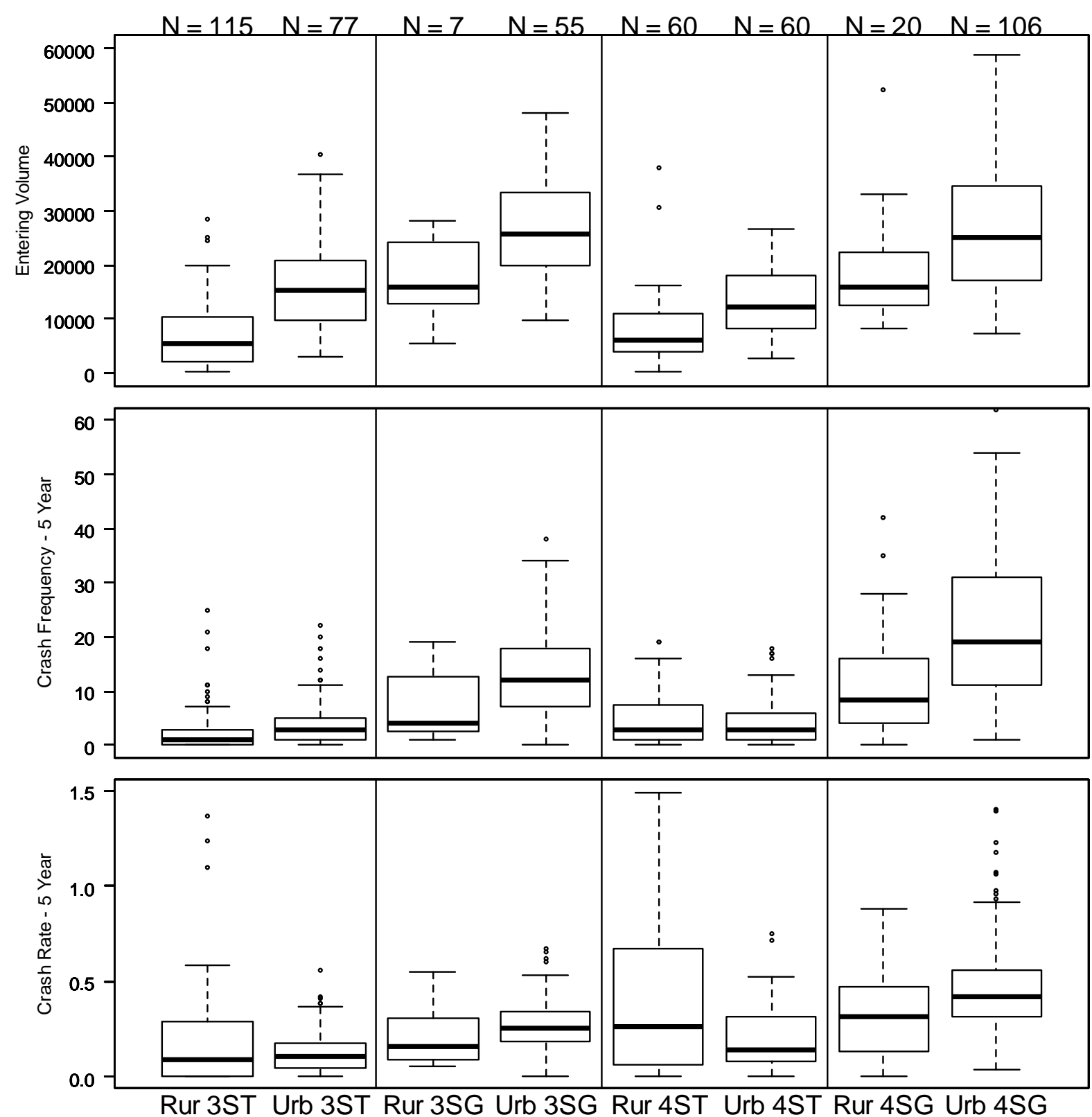

Figure B.3: Type of Intersection by Land Use Type 

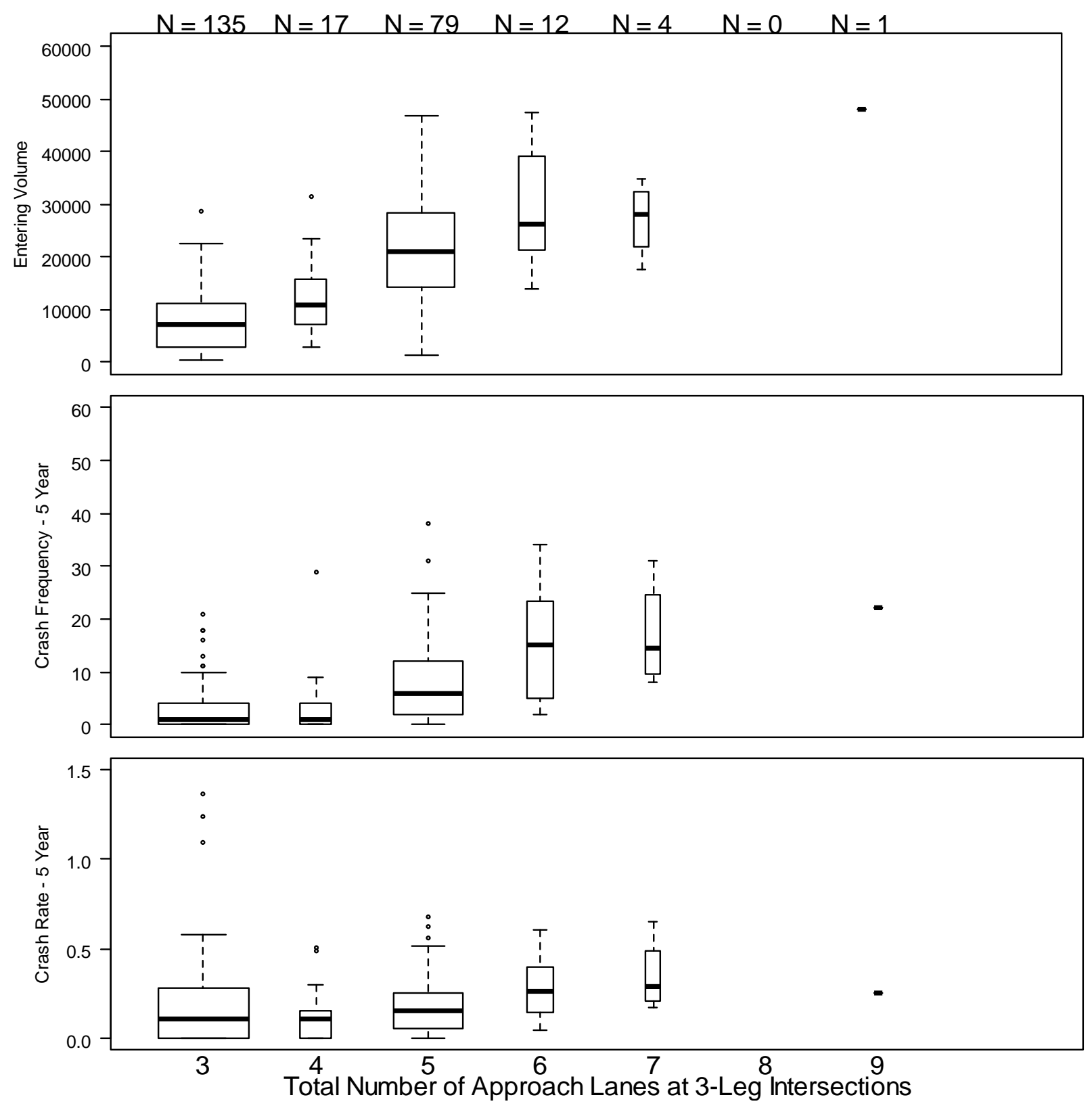

Figure B.4: Total Number of Approach Lanes at 3-Leg Intersections 

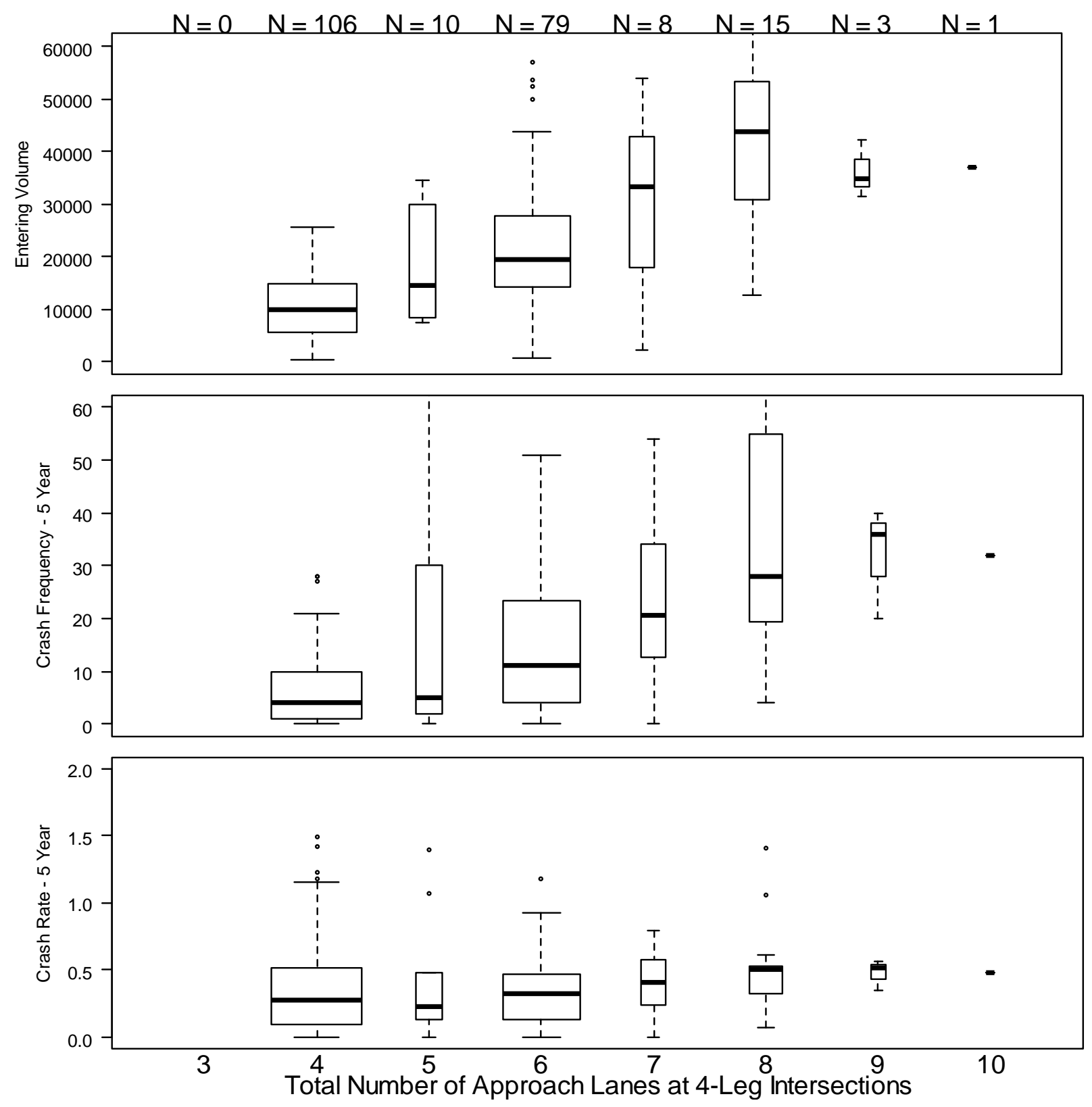

Figure B.5: Total Number of Approach Lanes at 4-Leg Intersections 

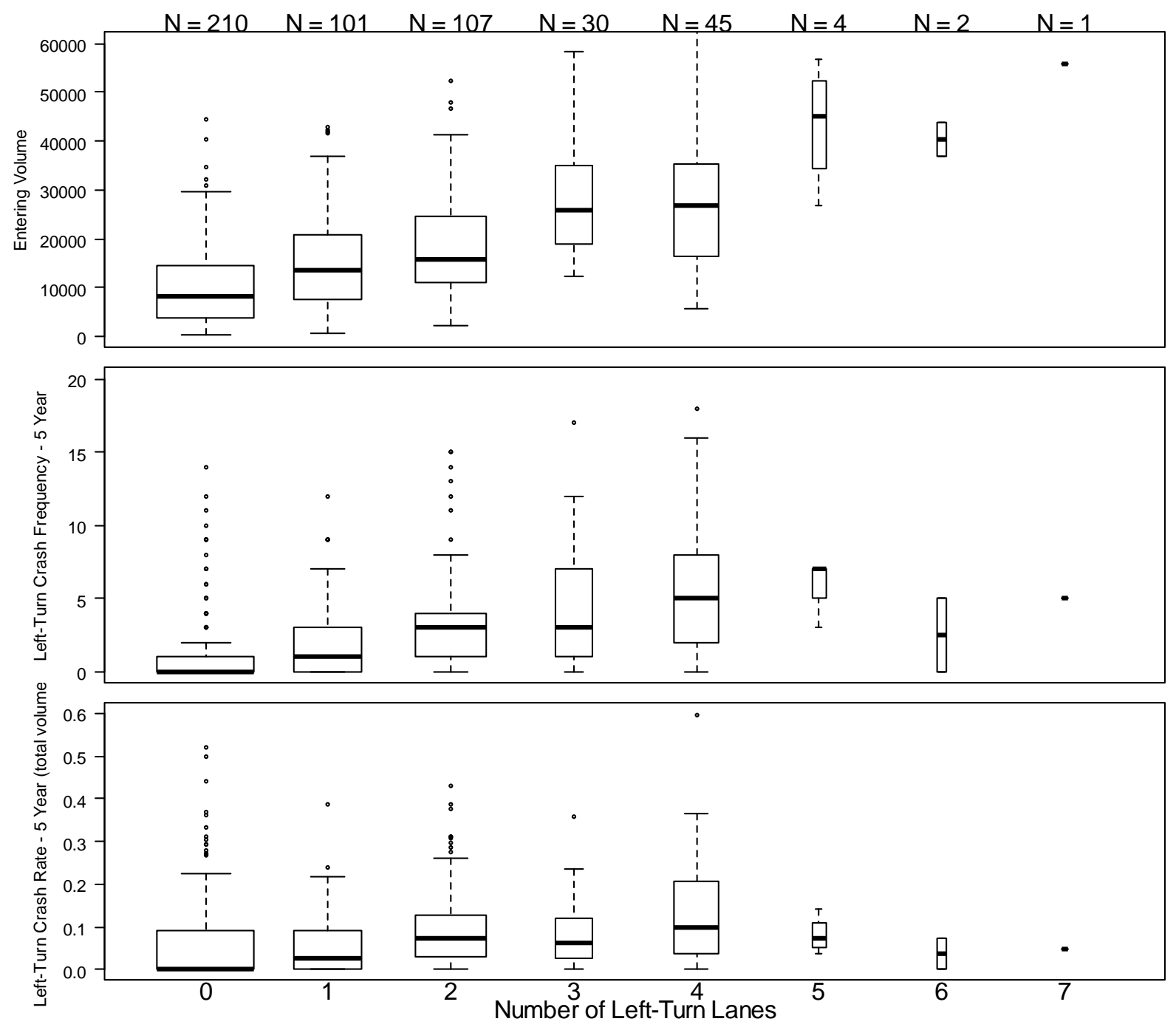

Figure B.6: Total Number of Left-Turn Lanes 

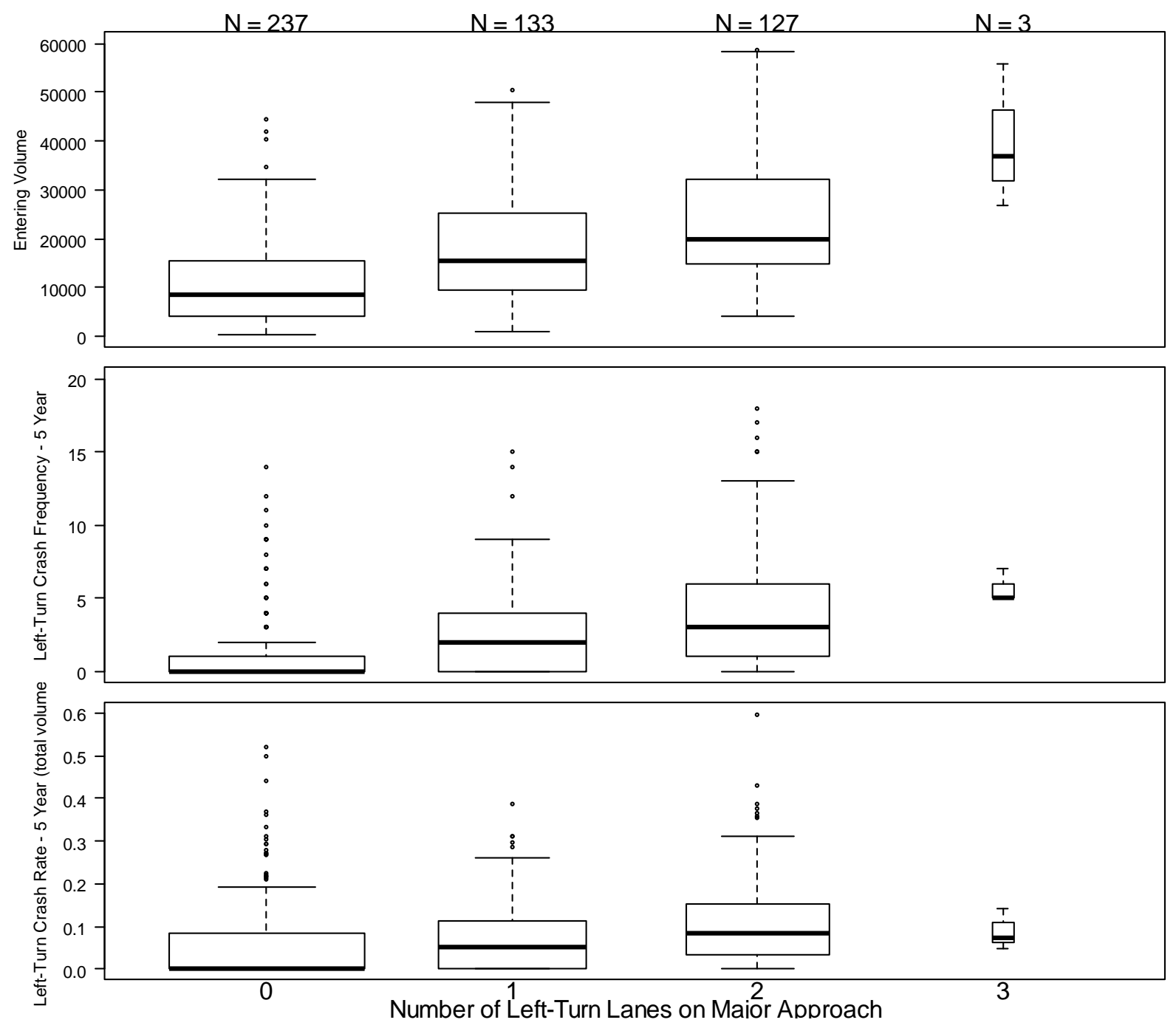

Figure B.7: Number of Left Turn Lanes on Major Approach 

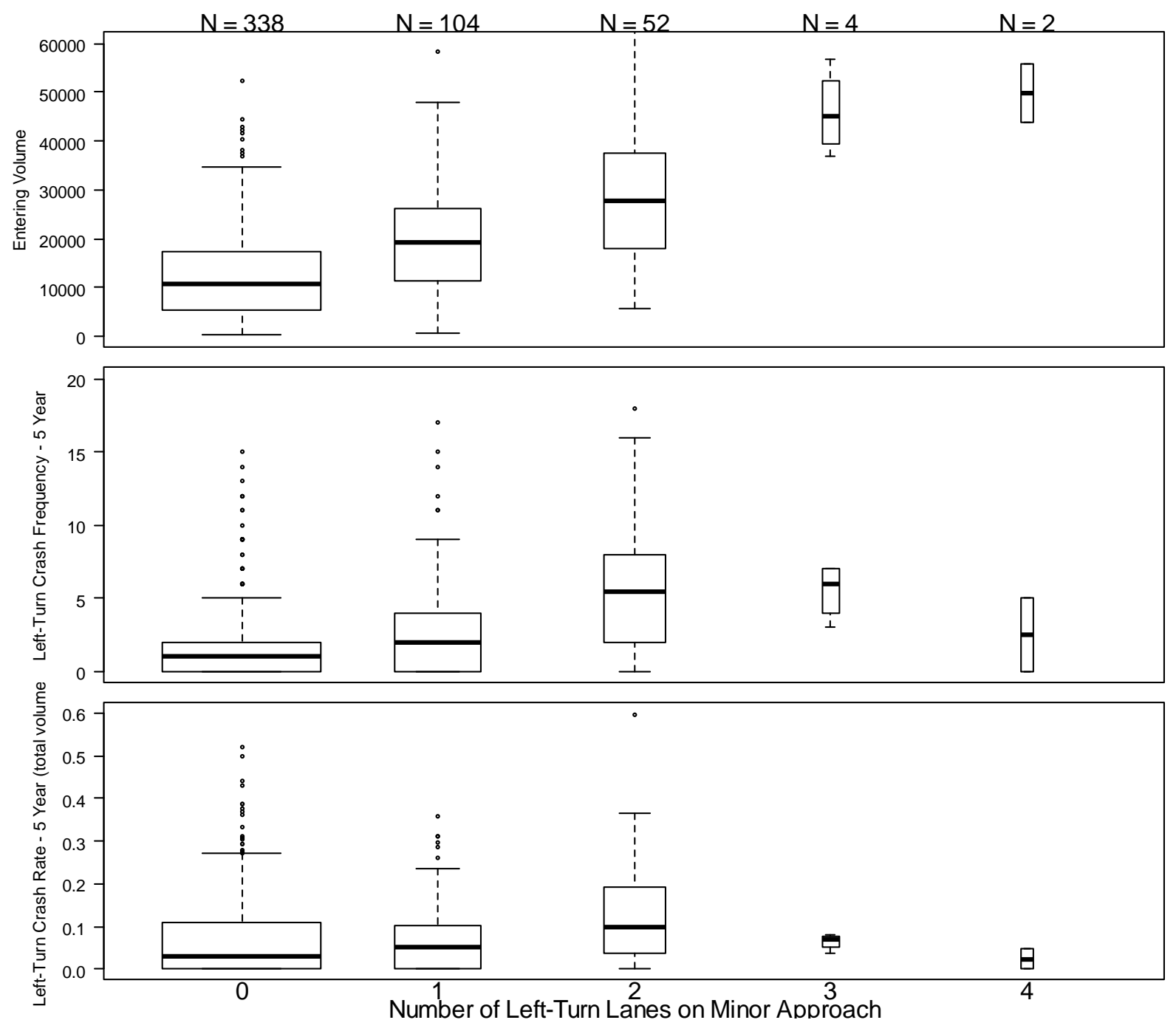

Figure B.8: Number of Left Turn Lanes on Minor Approach 

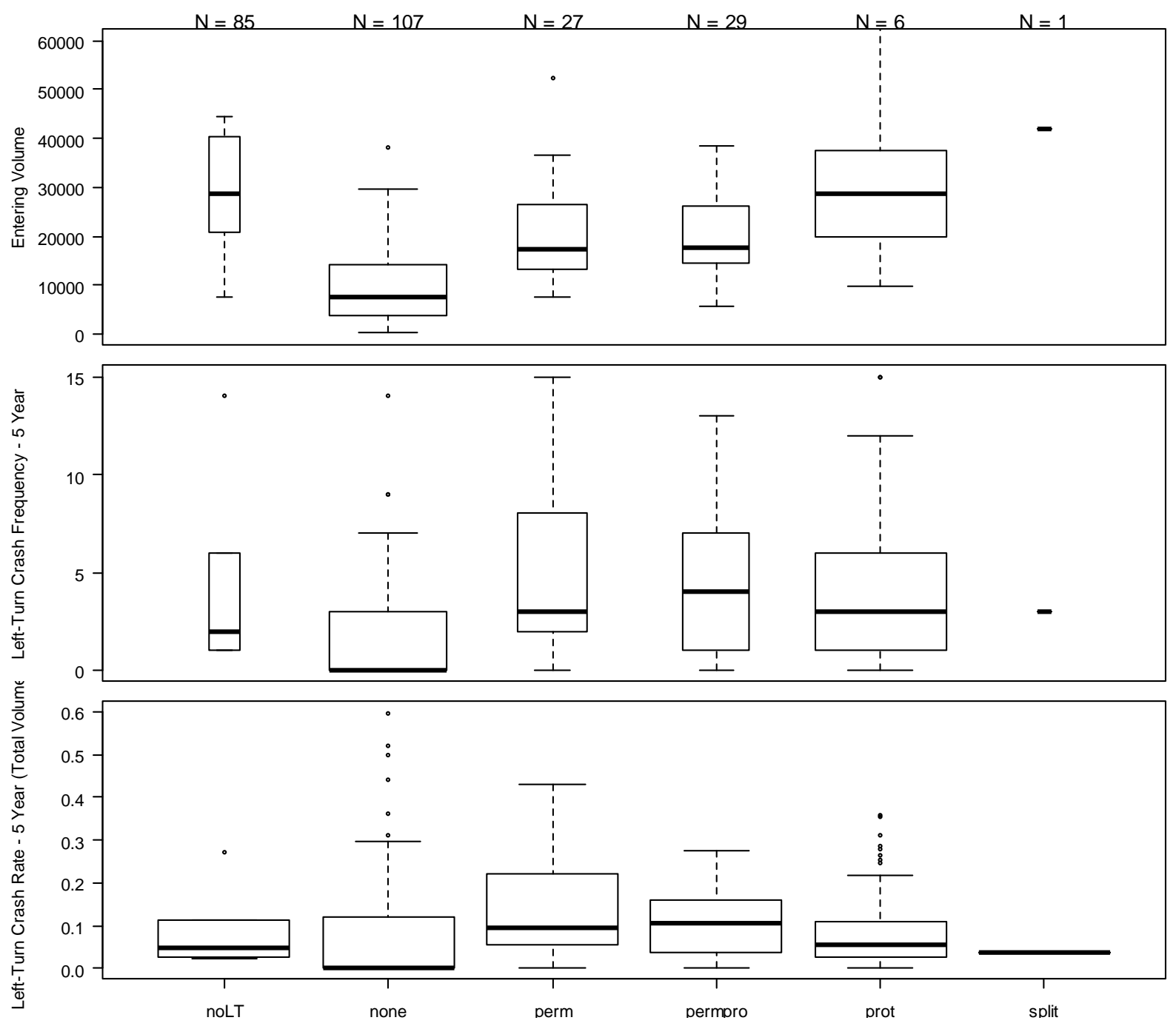

Figure B.9: Left-Turn Phase on Major Approach 

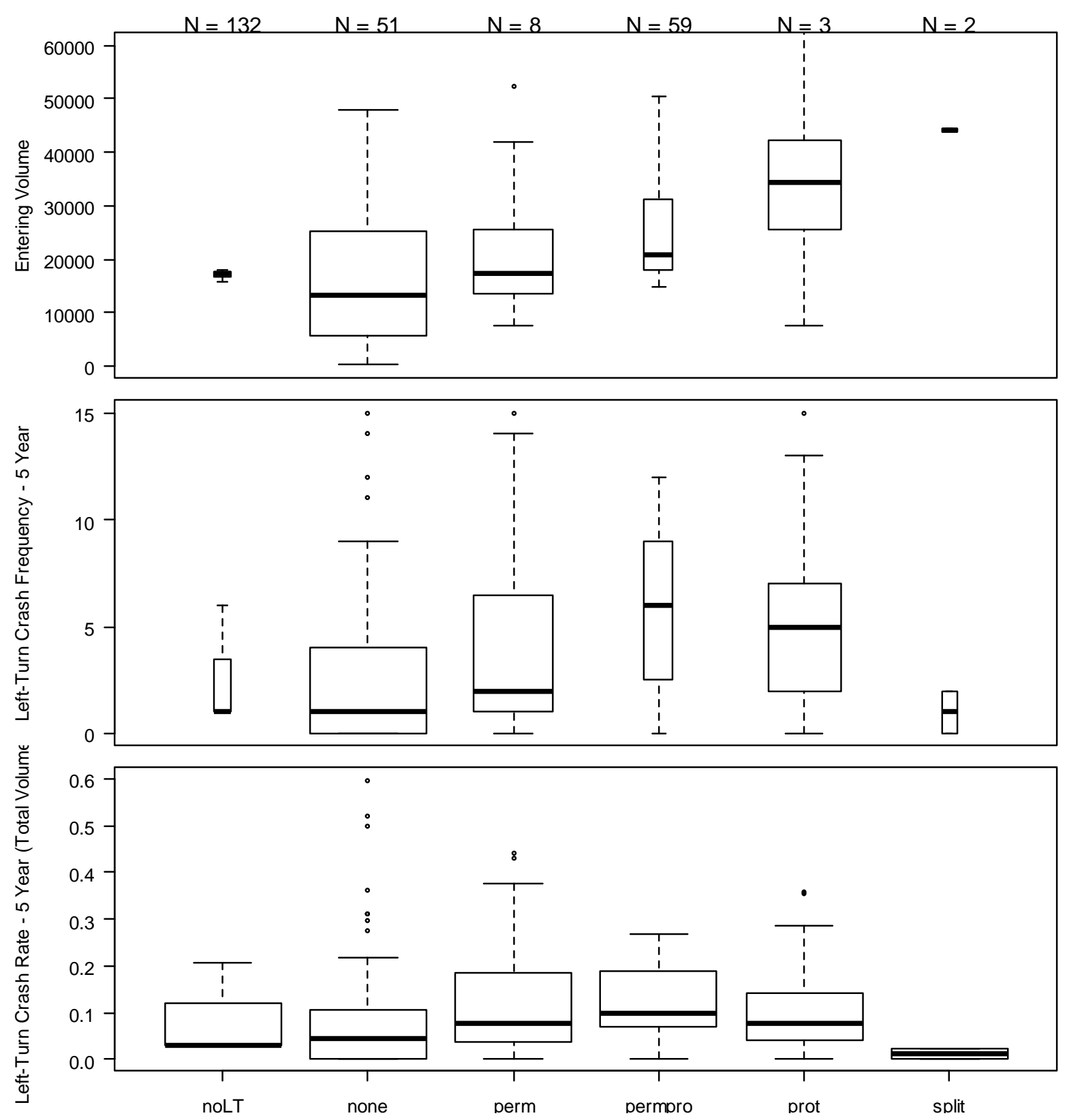

Figure B.10: Left-Turn Phase on Minor Approach 

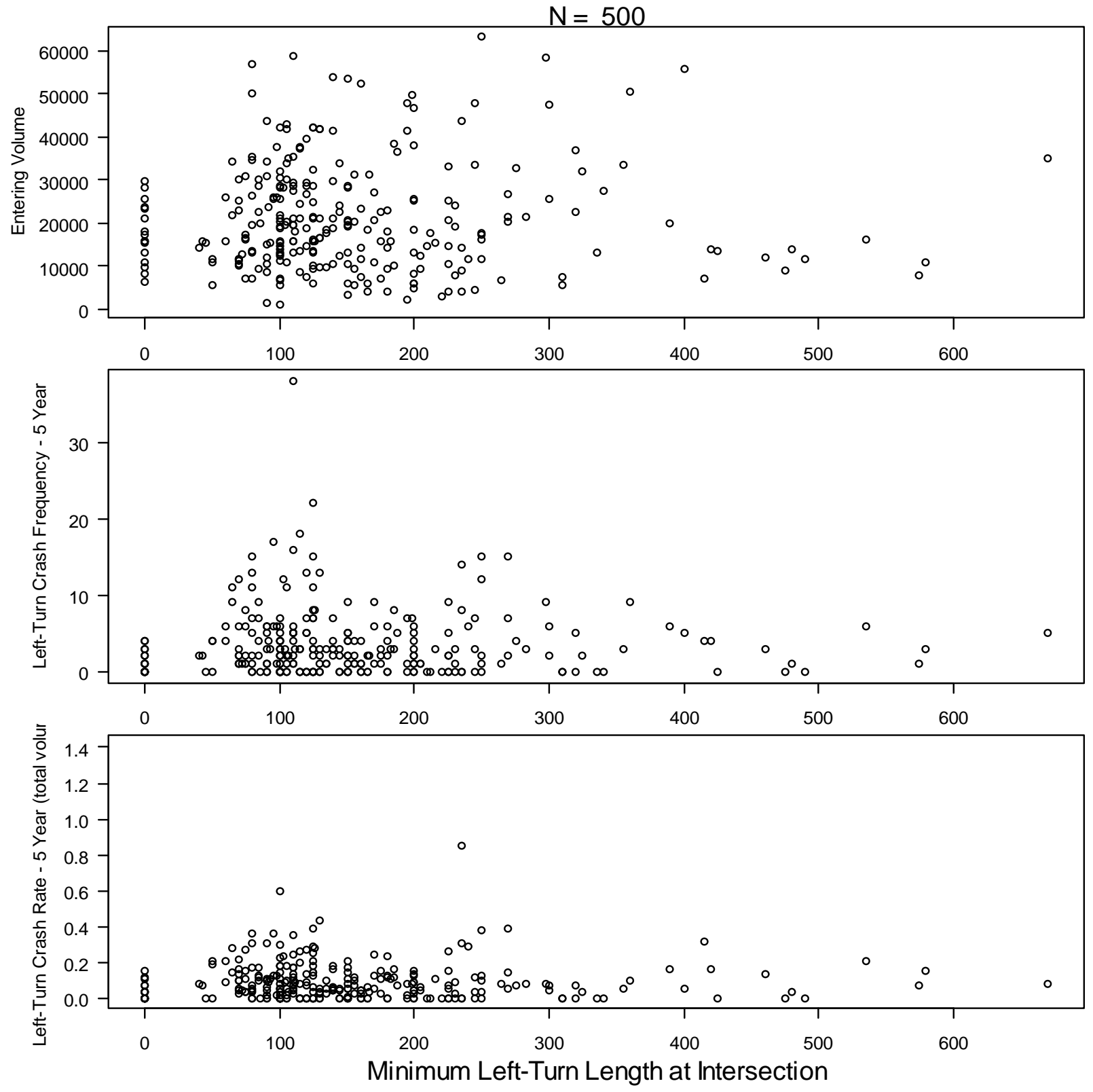

Figure B.11: Minimum Length of Left-Turn Lane 

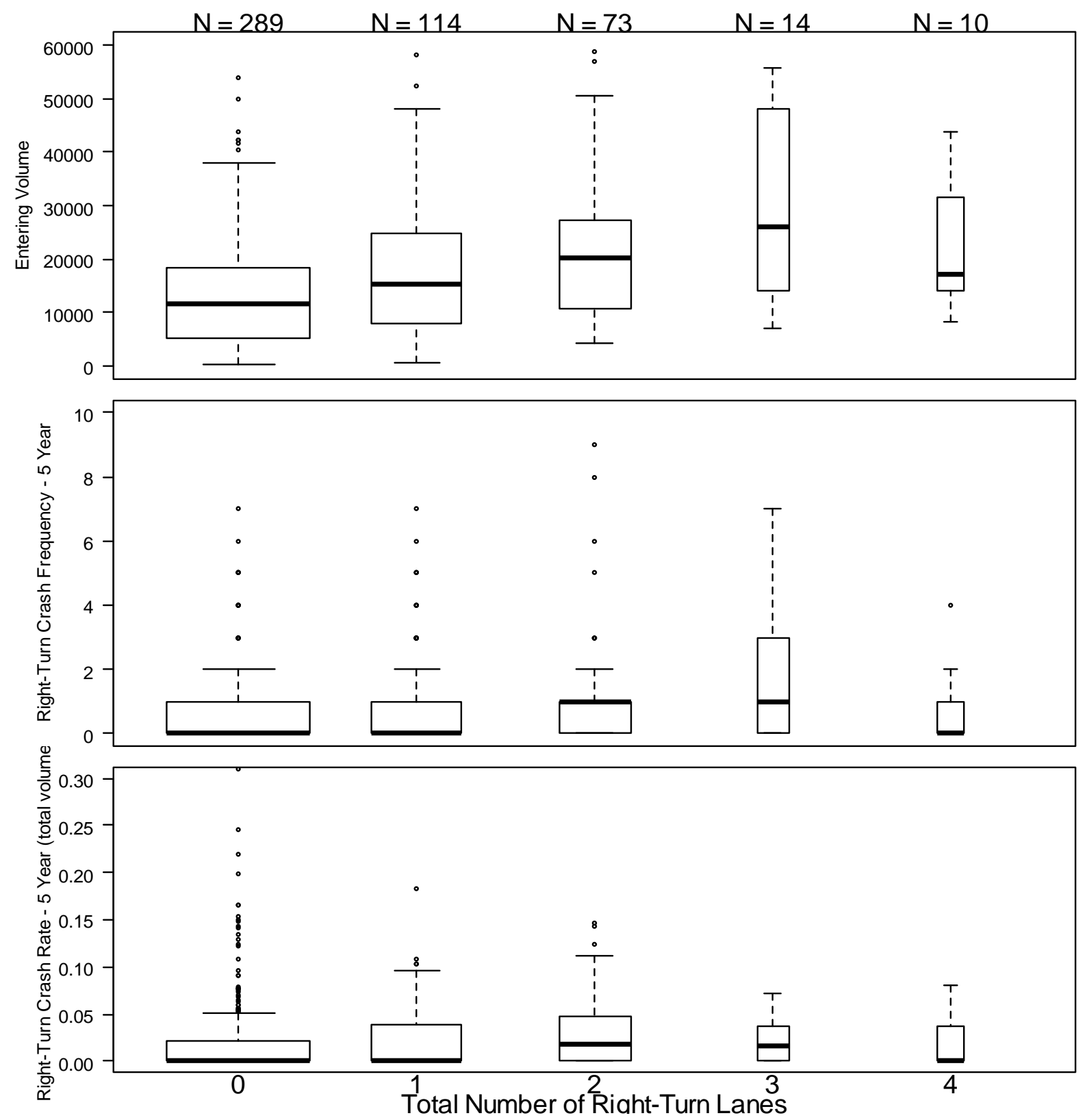

Figure B.12: Total Number of Right-Turn Lanes 

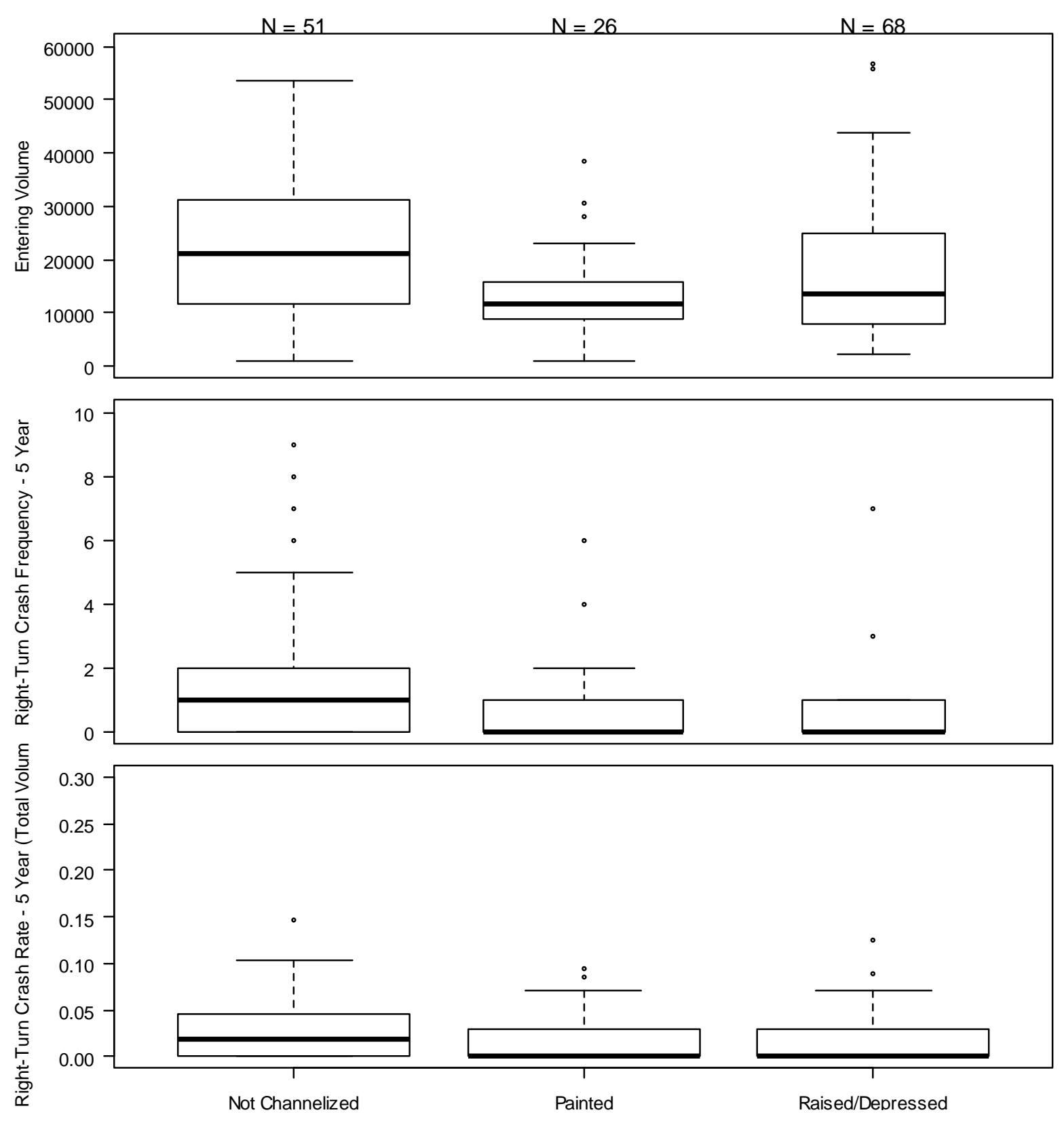

B.13: Type of Right Turn Treatment on Major Road 

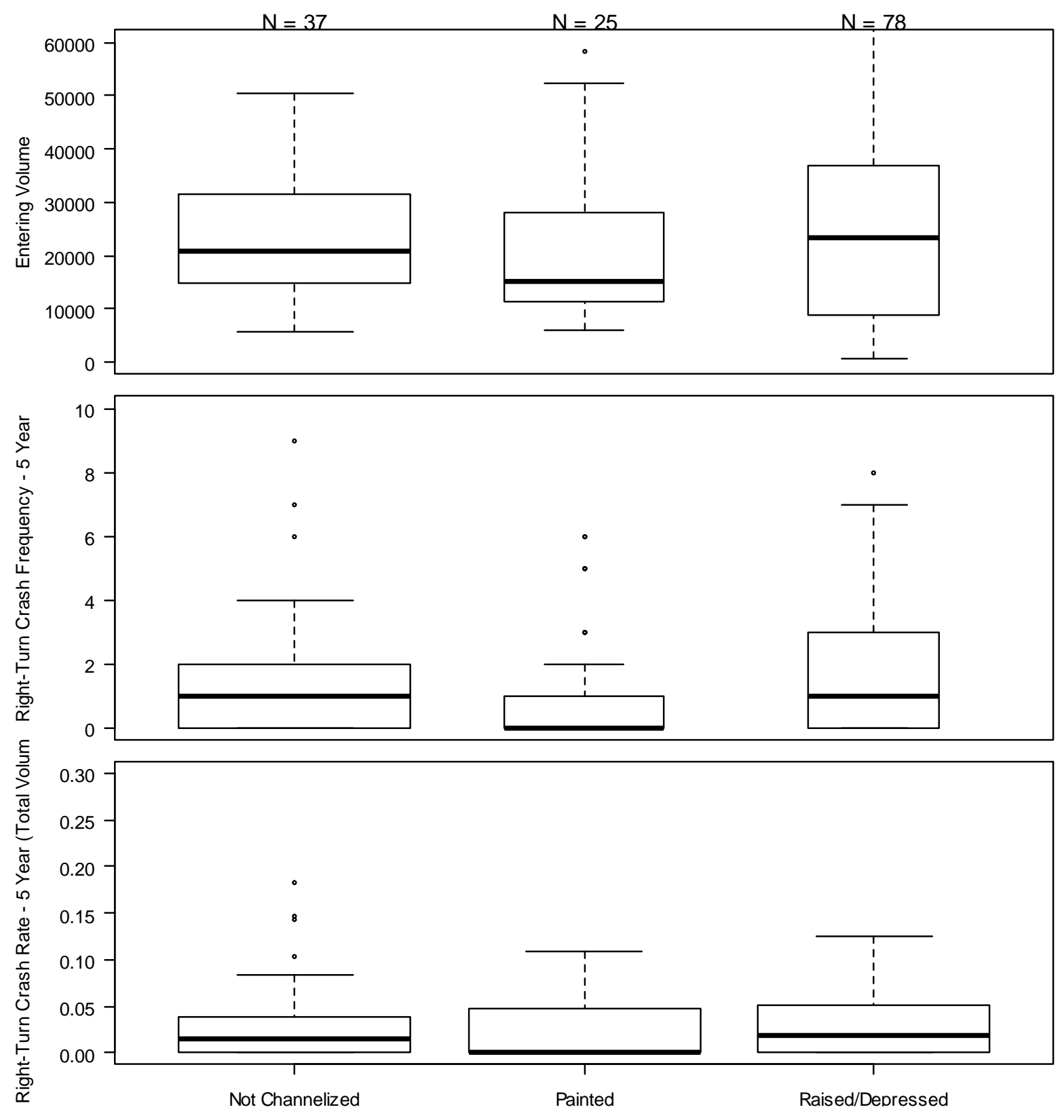

Figure B.14: Type of Right Turn Treatment on Minor Road 

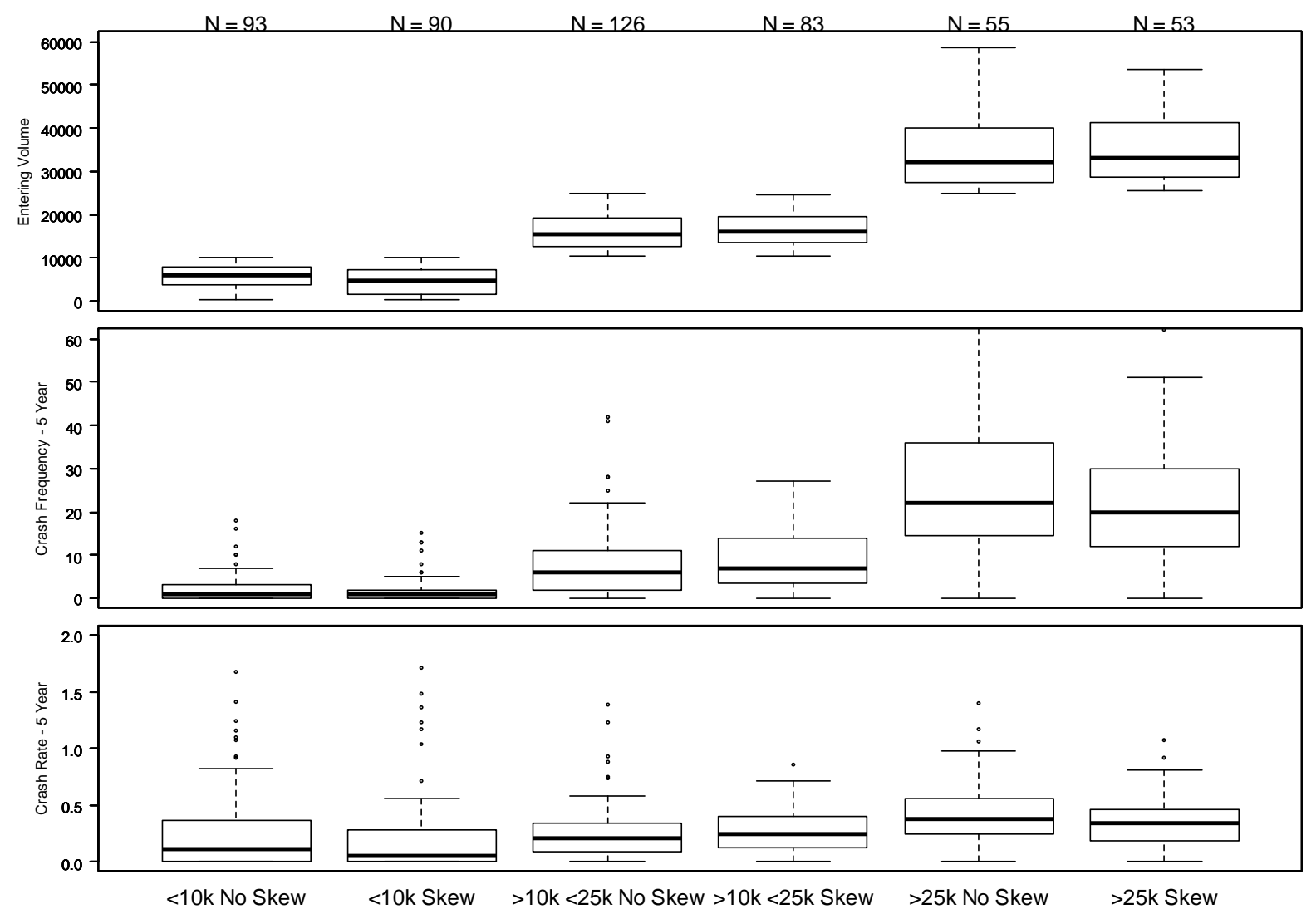

Figure B.15: Skew Aggregated by Low ( $<10,000$ AADT), Medium ( $>=10,000<25,000$ AADT), and High Volumes $(>=25,000$ AADT $)$ 

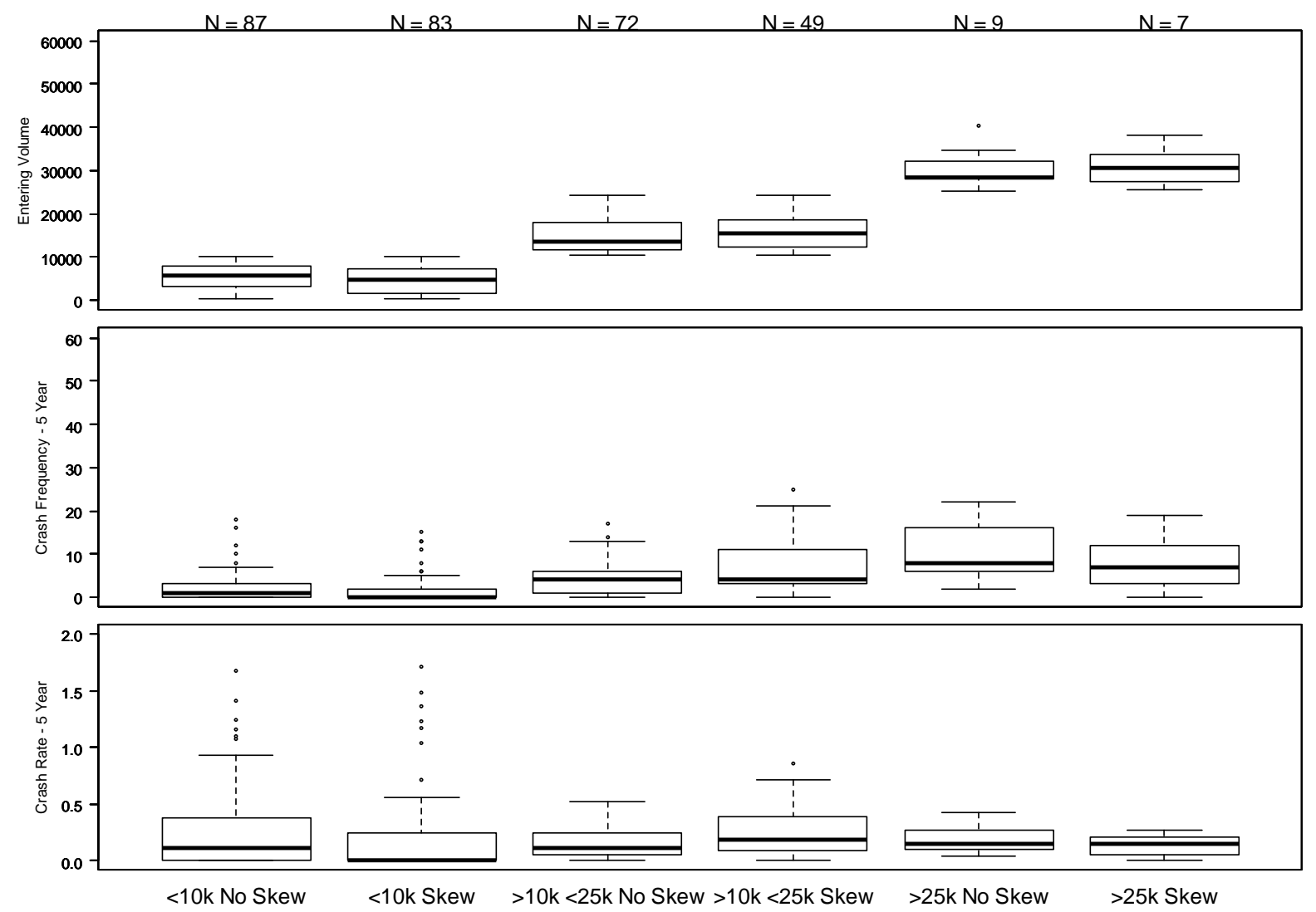

Figure B.16: Two-Way STOP Controlled Skew Aggregated by Low $(<10,000$ AADT), Medium ( $>=10,000<25,000$ AADT), and High Volumes ( $>=25,000$ AADT) 

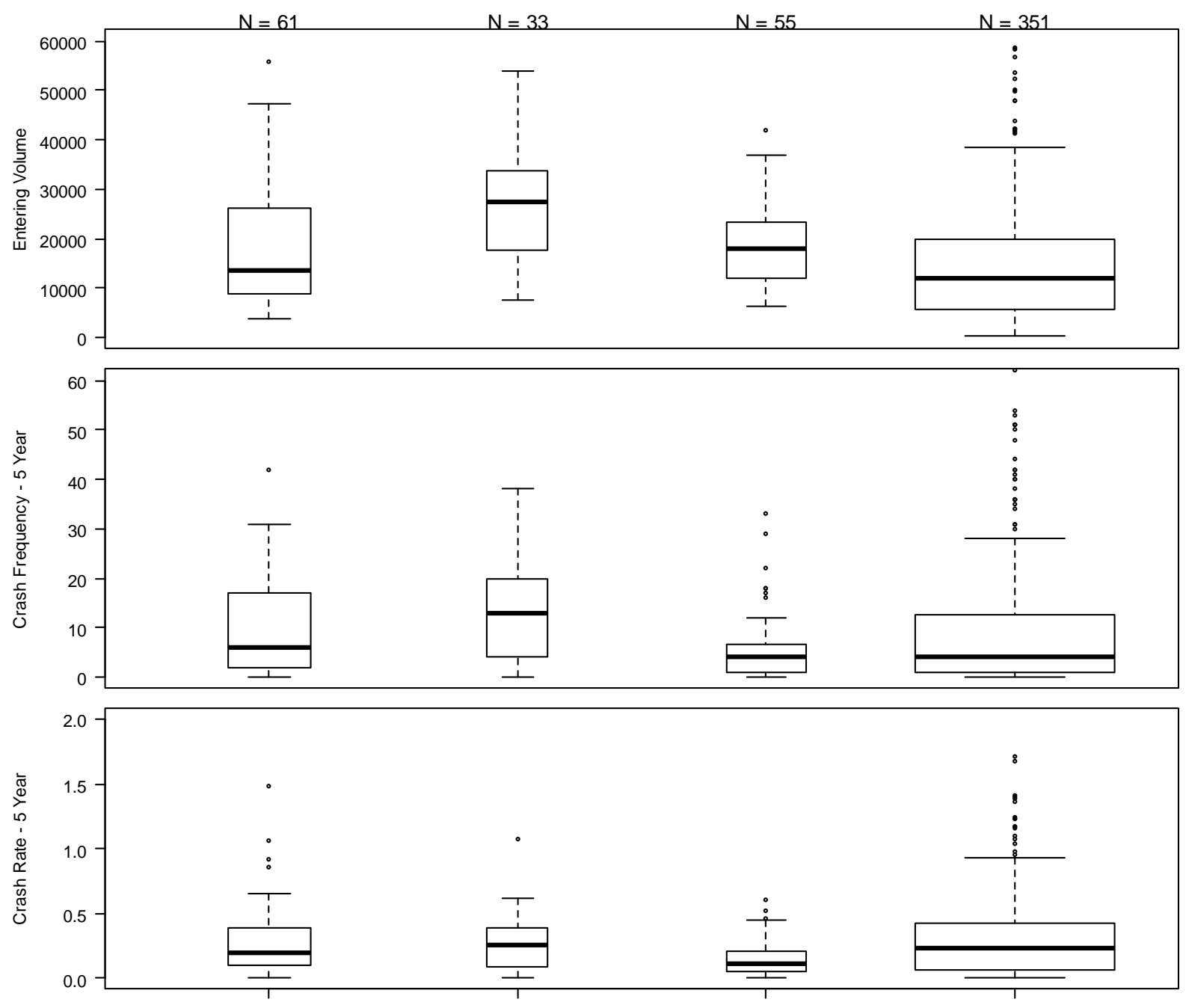

Earth. arass or paved median $>2 \mathrm{ft} \quad$ Solid Median Barrier

Tw o Wav Turn Lane

Road is not phvsicallv divided

Figure B.17: Median Type 

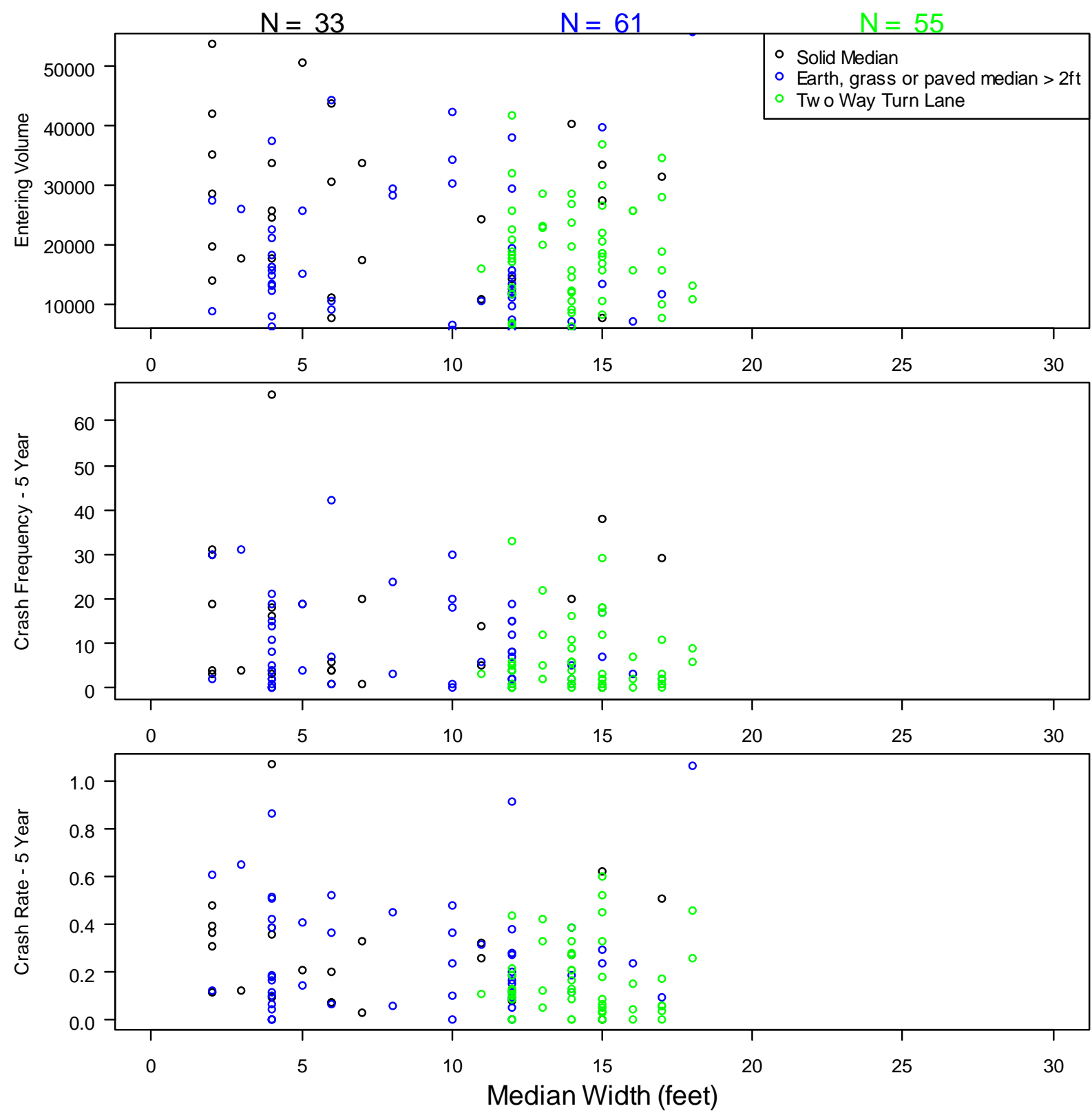

Figure B.18: Width of Median 

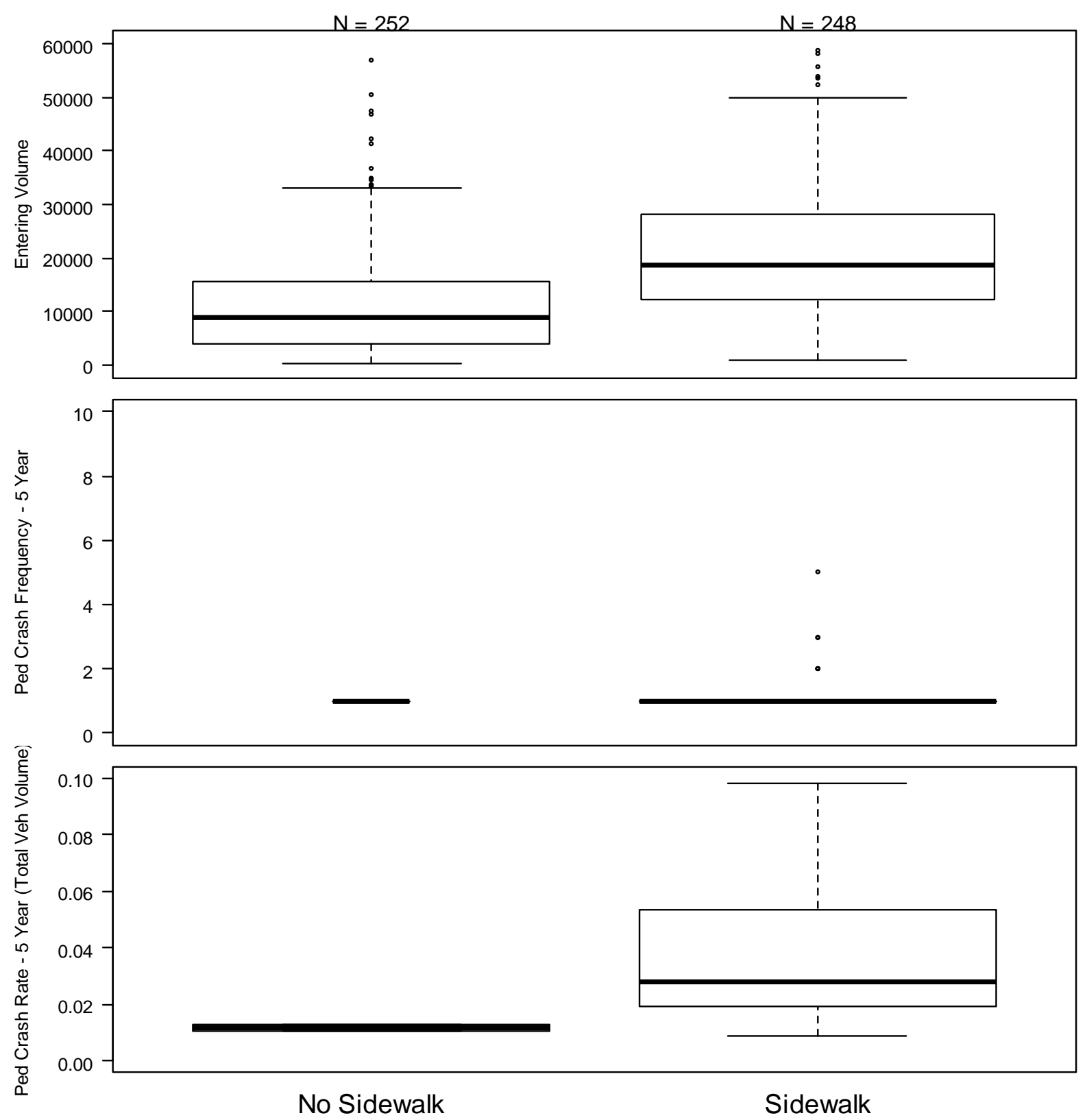

Figure B.19: Sidewalk on Major Road 

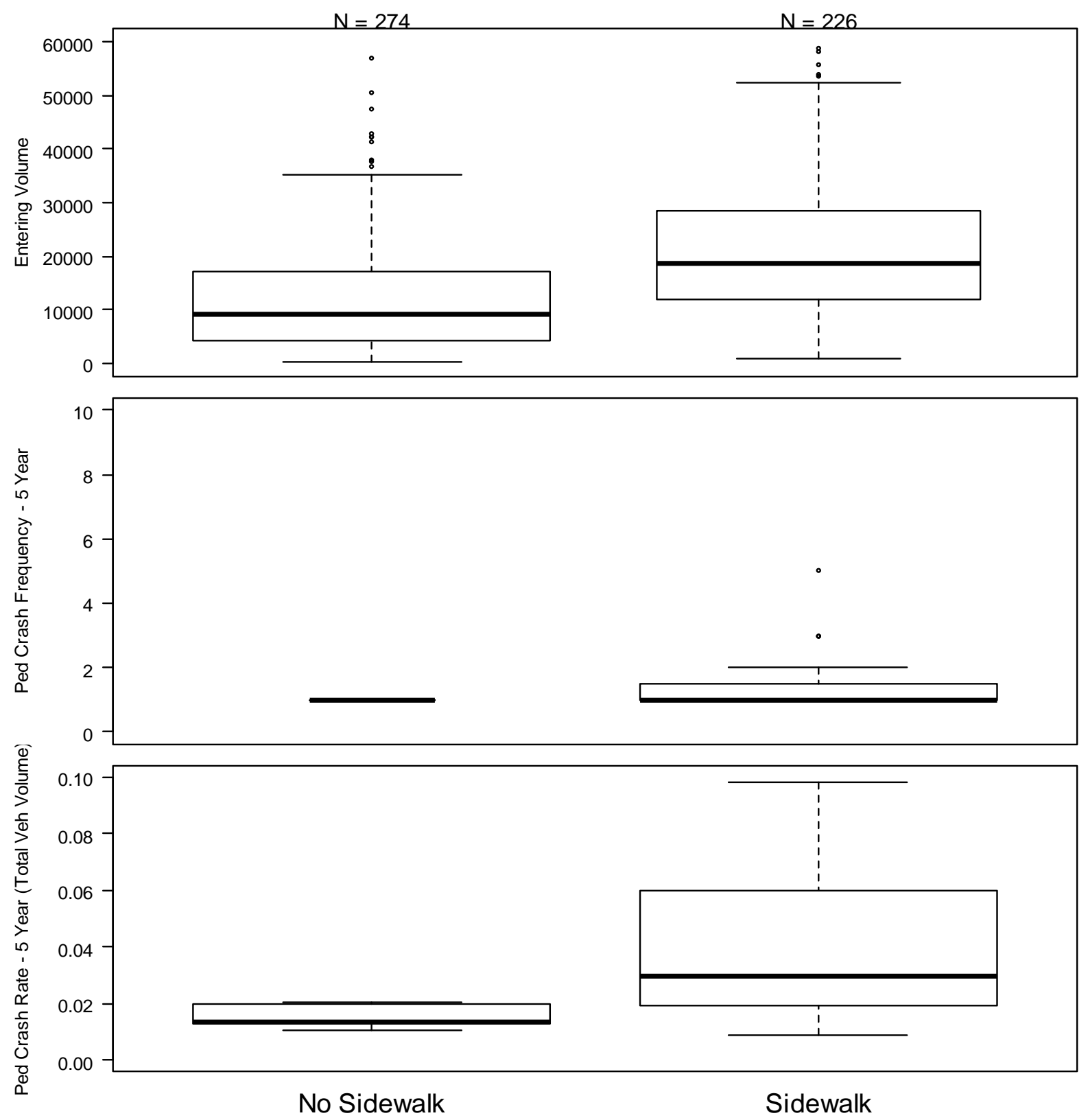

Figure B.20: Sidewalk on Minor Road 

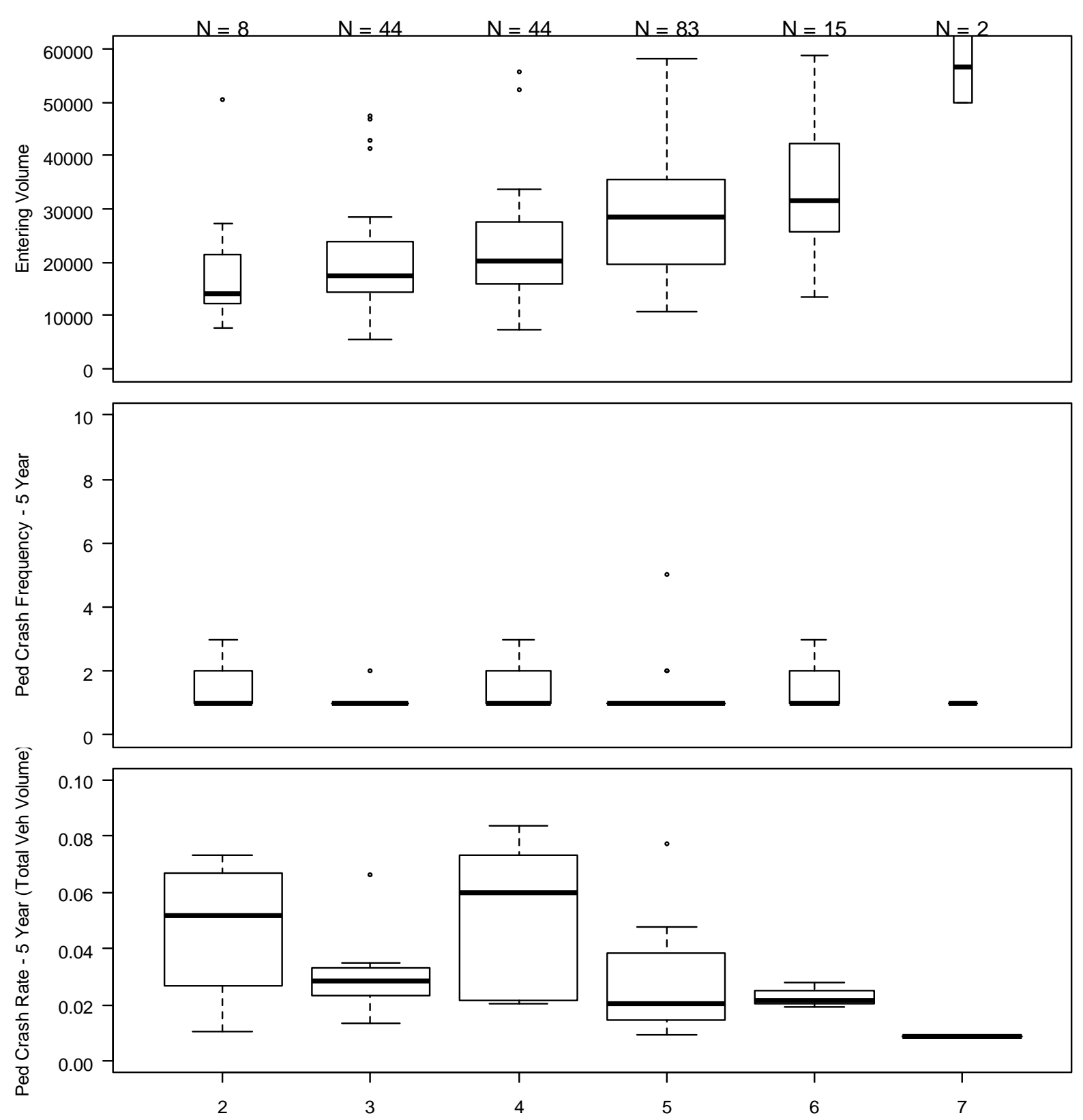

Figure B.21: Pedestrian Crashes by Number of Lanes Crossed at Signalized Intersections 

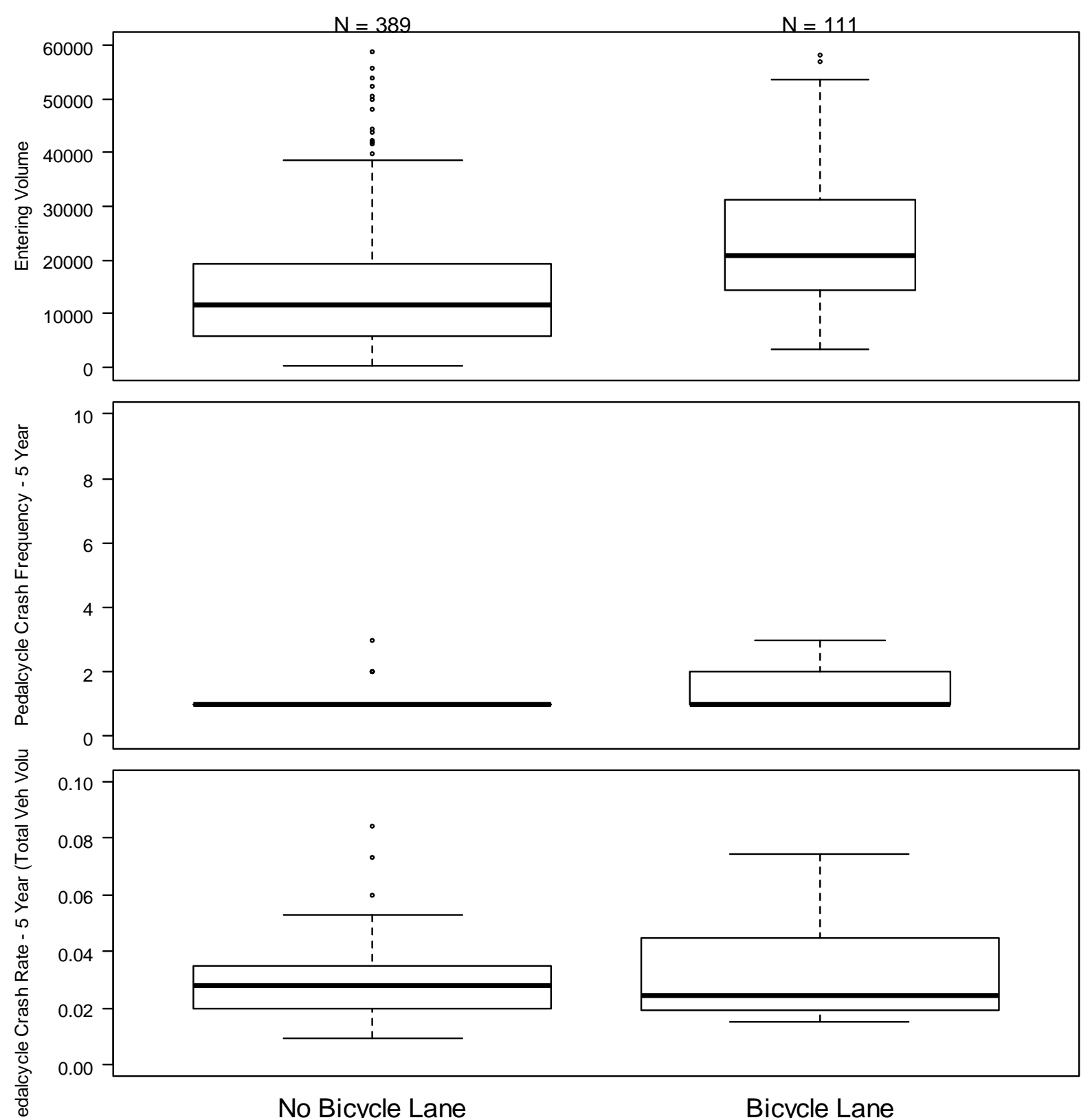

Figure B.22: Bicycle Lane on Major Road 

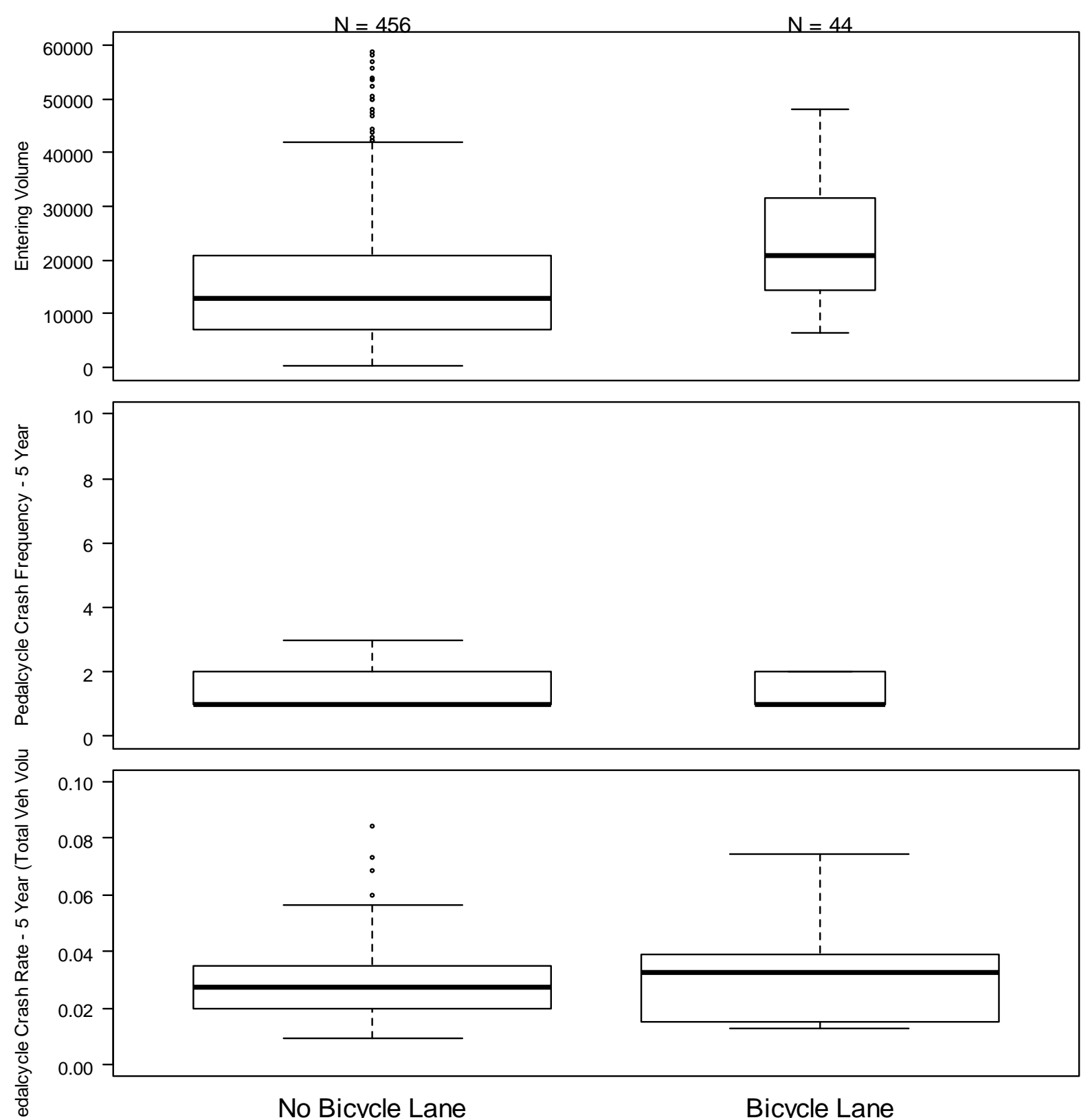

Figure B.23: Bicycle Lane on Minor Road 

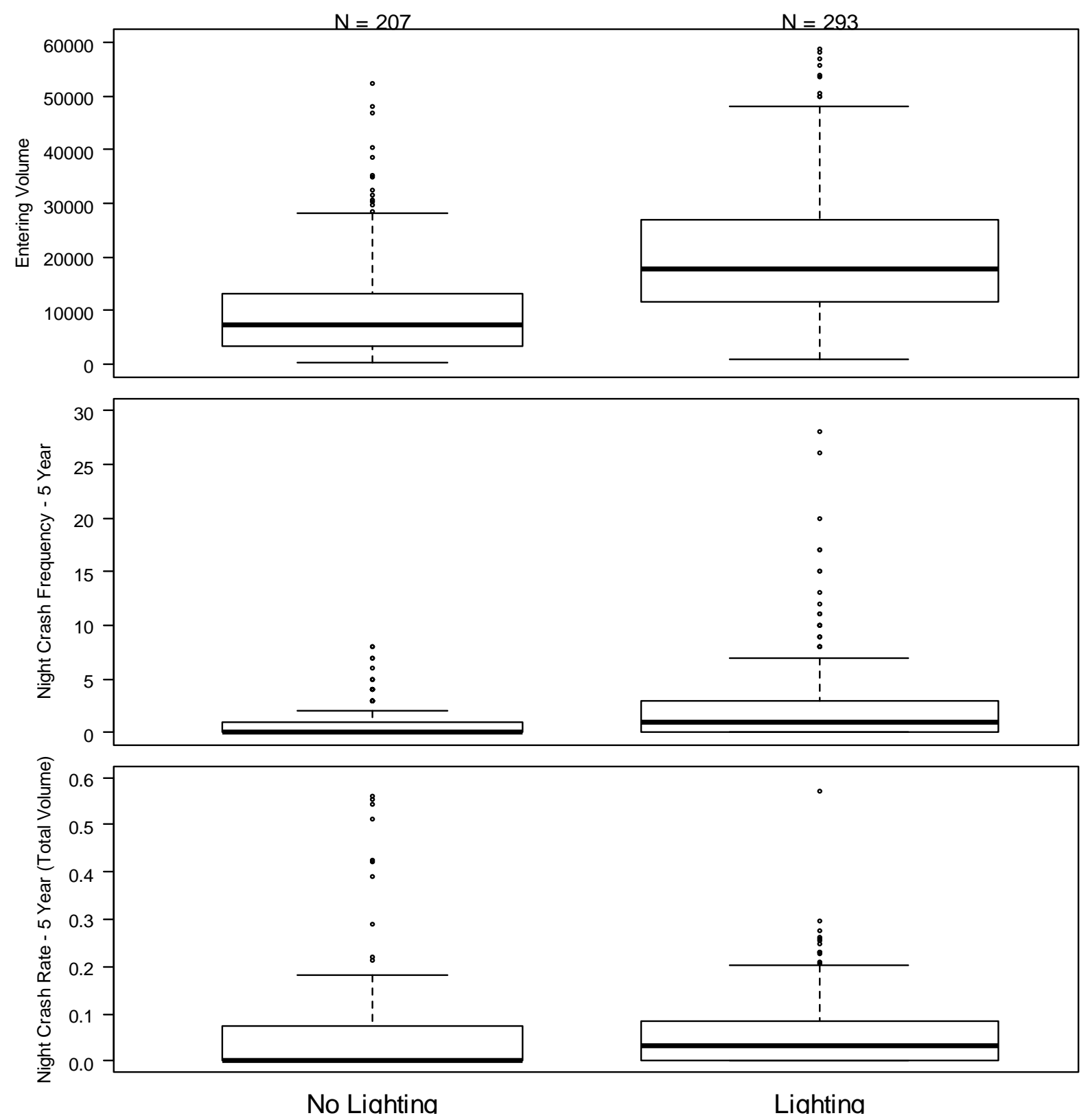

Figure B.24: Presence of Lighting 

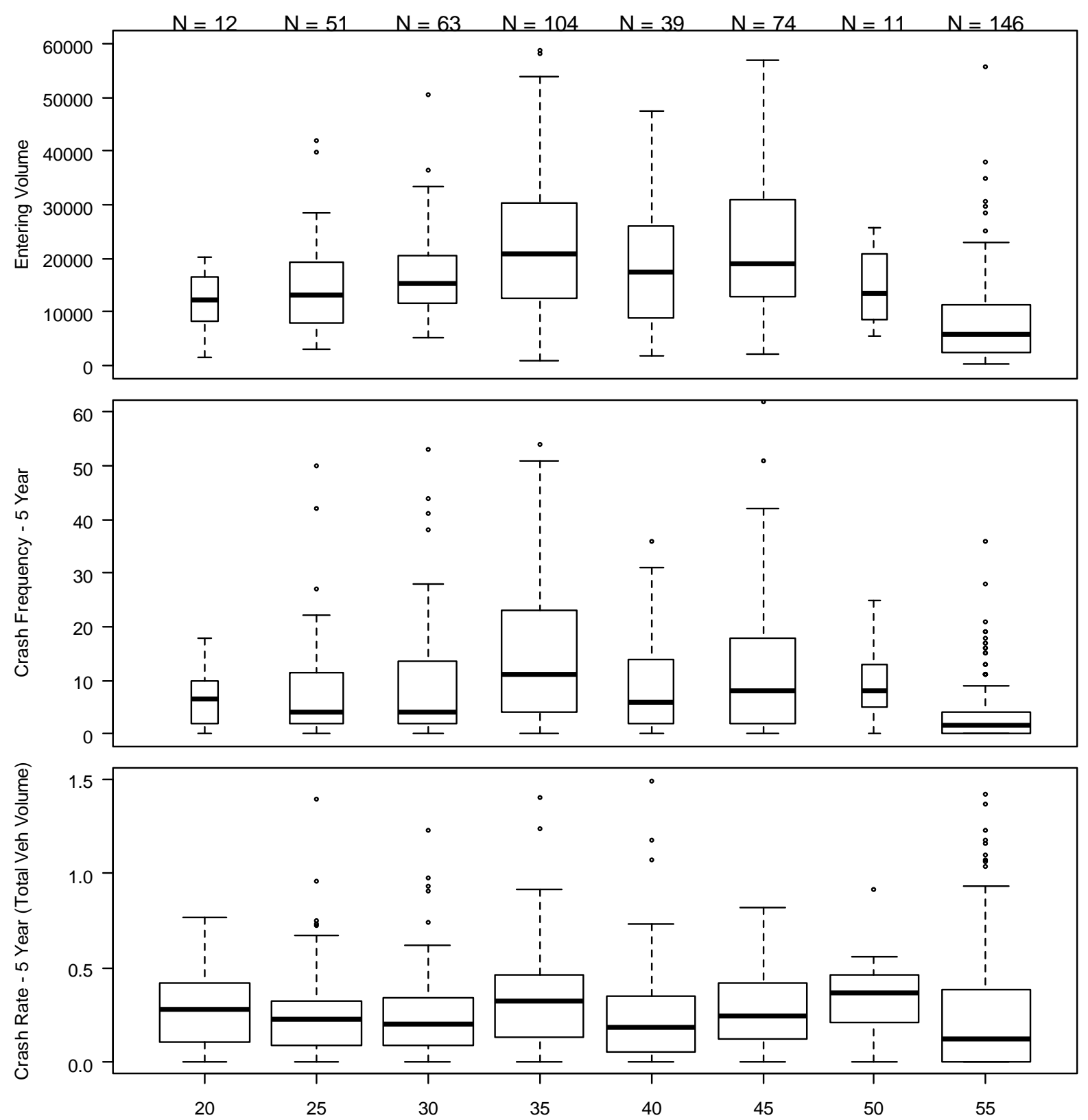

Figure B.25: Posted Speed on Major Approach 

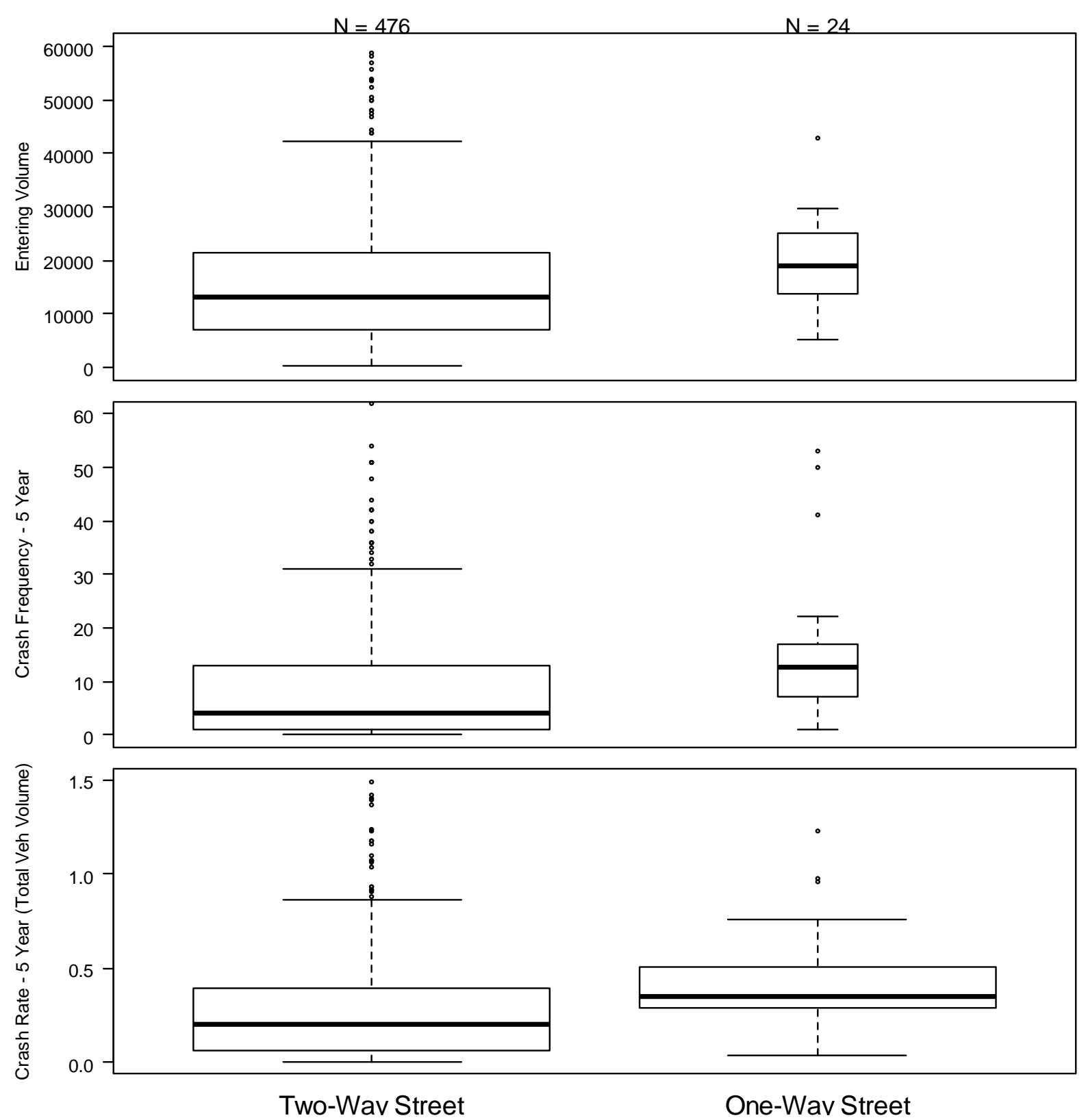

Figure B.26: One-Way Street on Major Road 

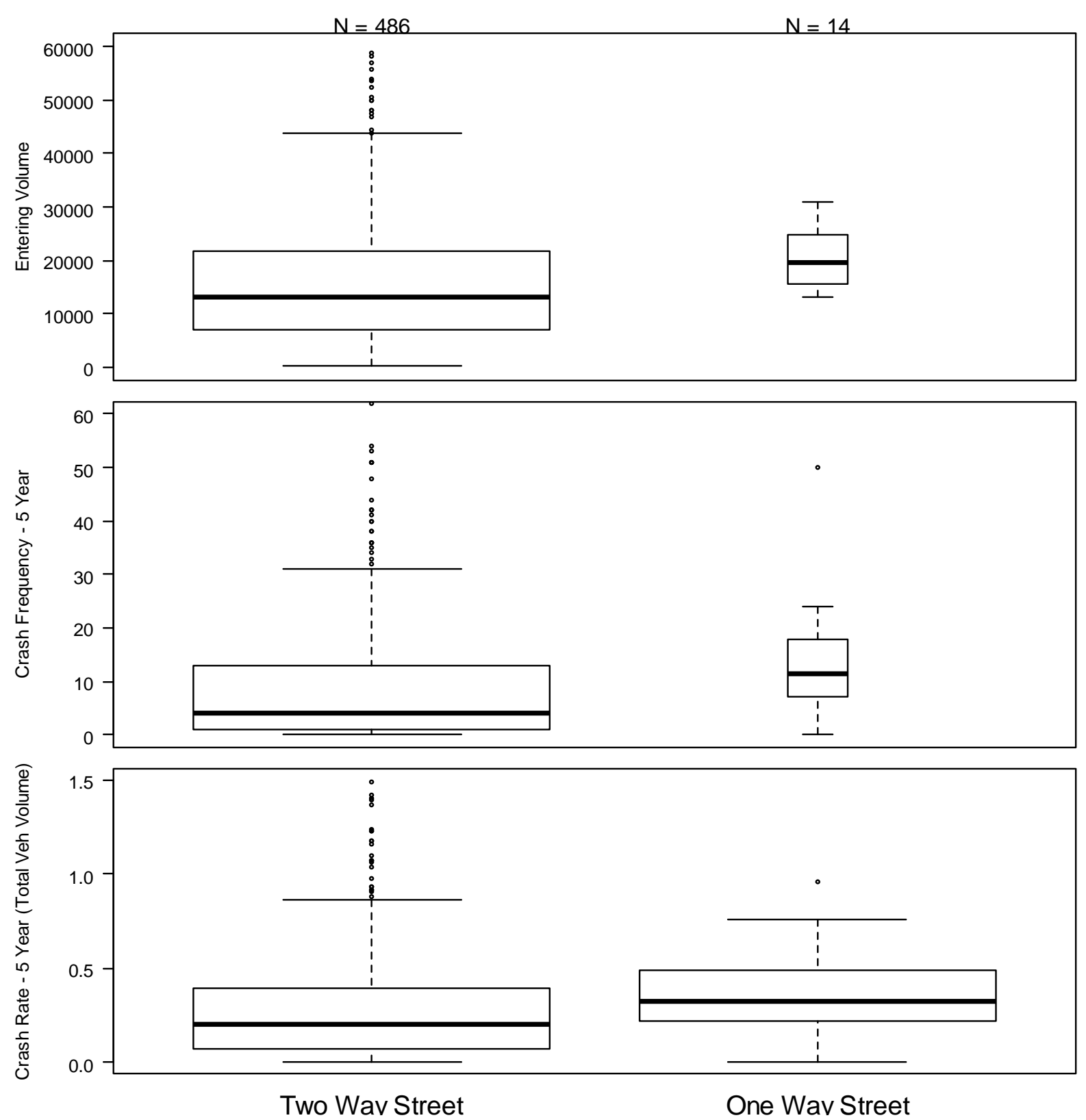

Figure B.27: One-Way Street on Minor Road 

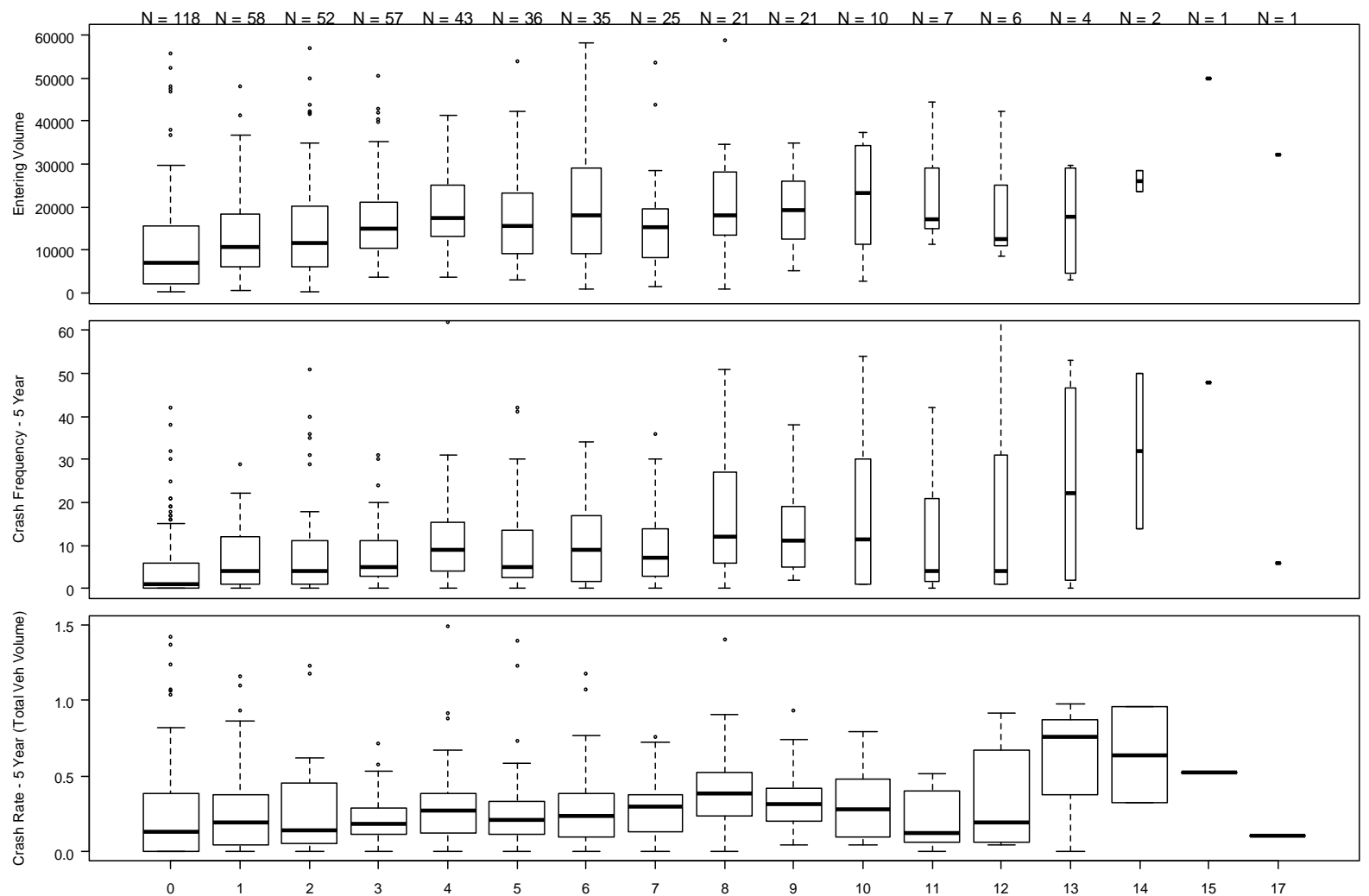

Figure B.28: Number of Total Driveways within 250 feet 

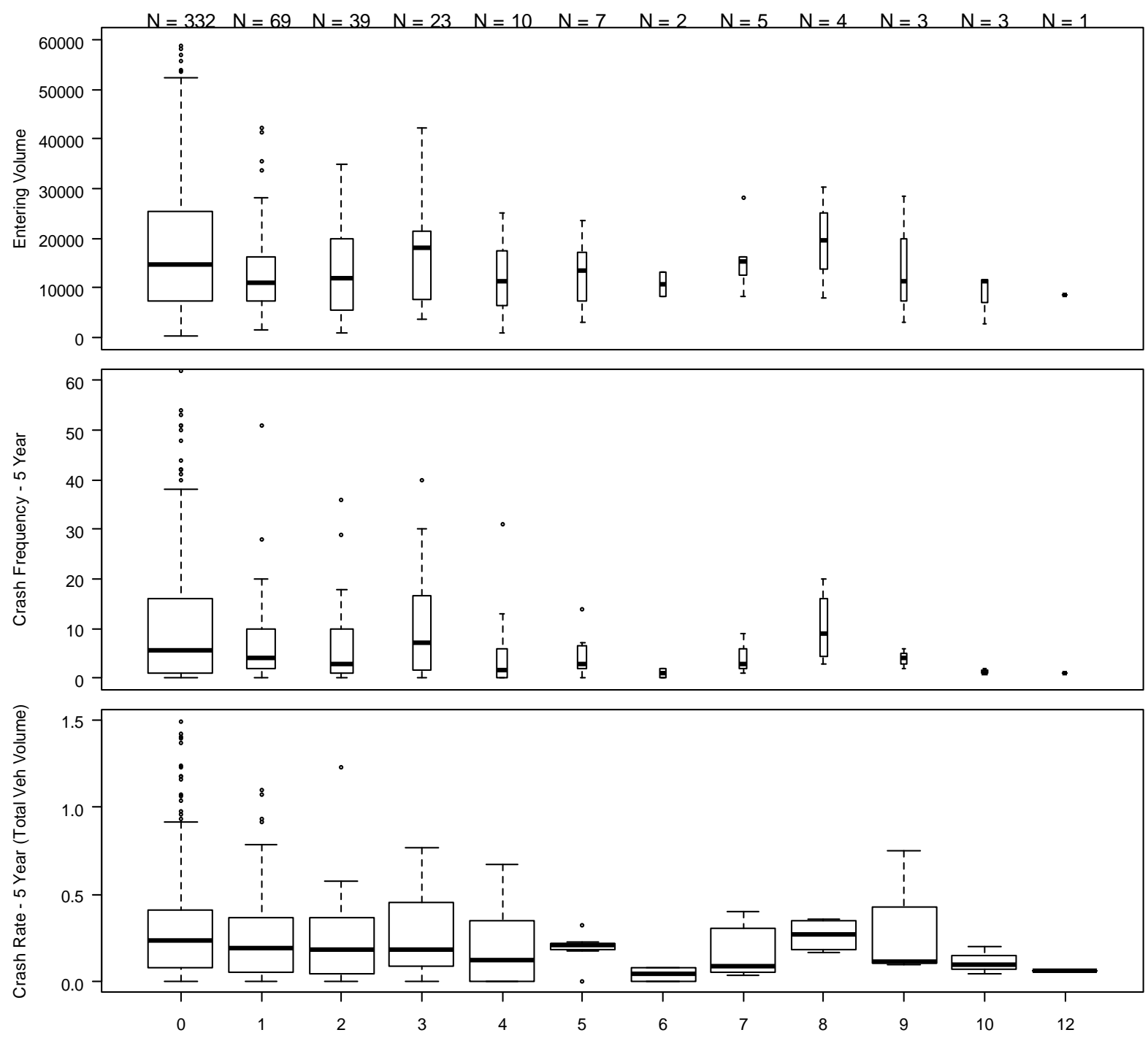

Figure B.29: Number of Residential Driveways within 250 feet 

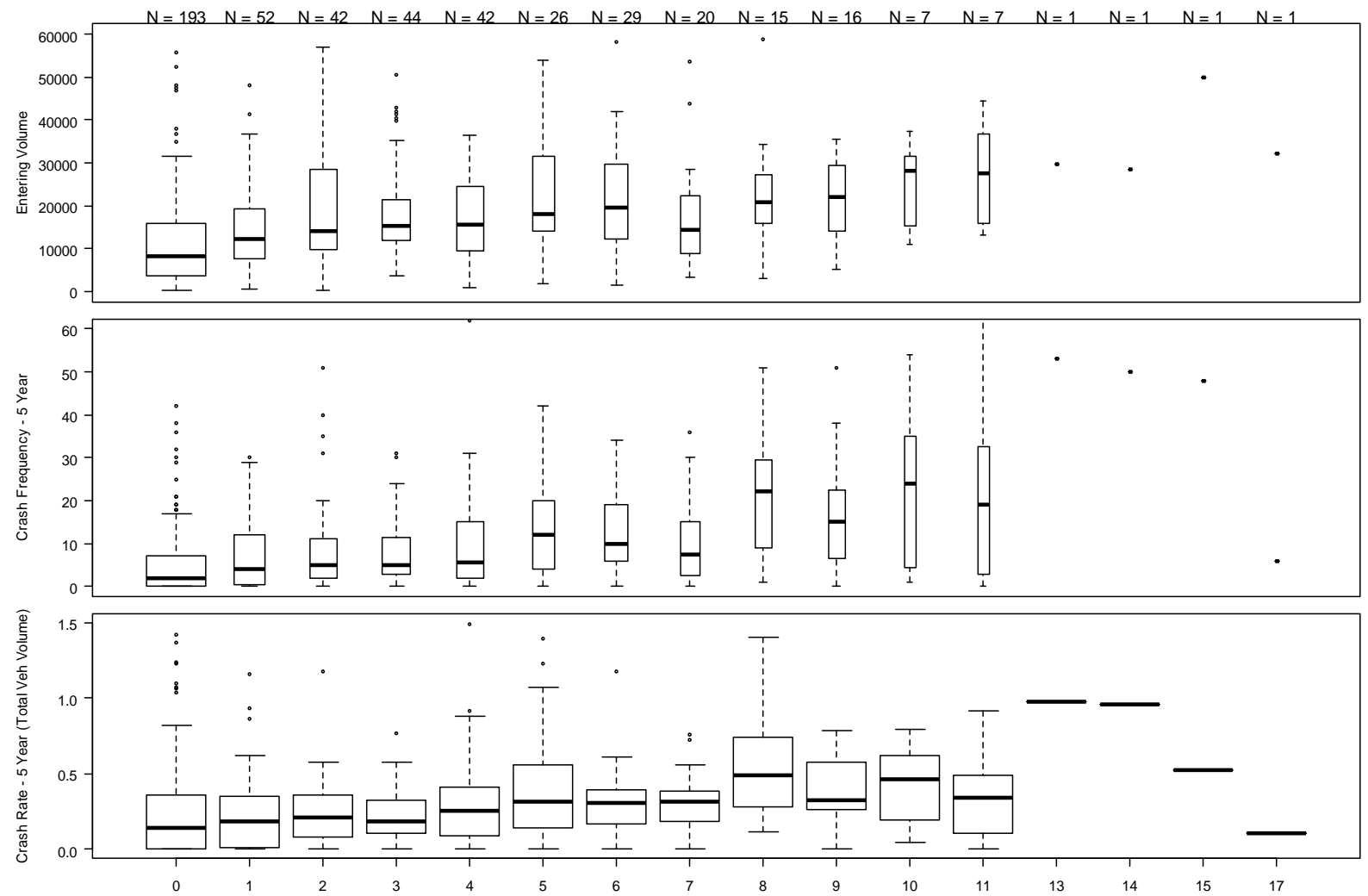

Figure B.30: Number of Commercial Driveways within 250 feet 

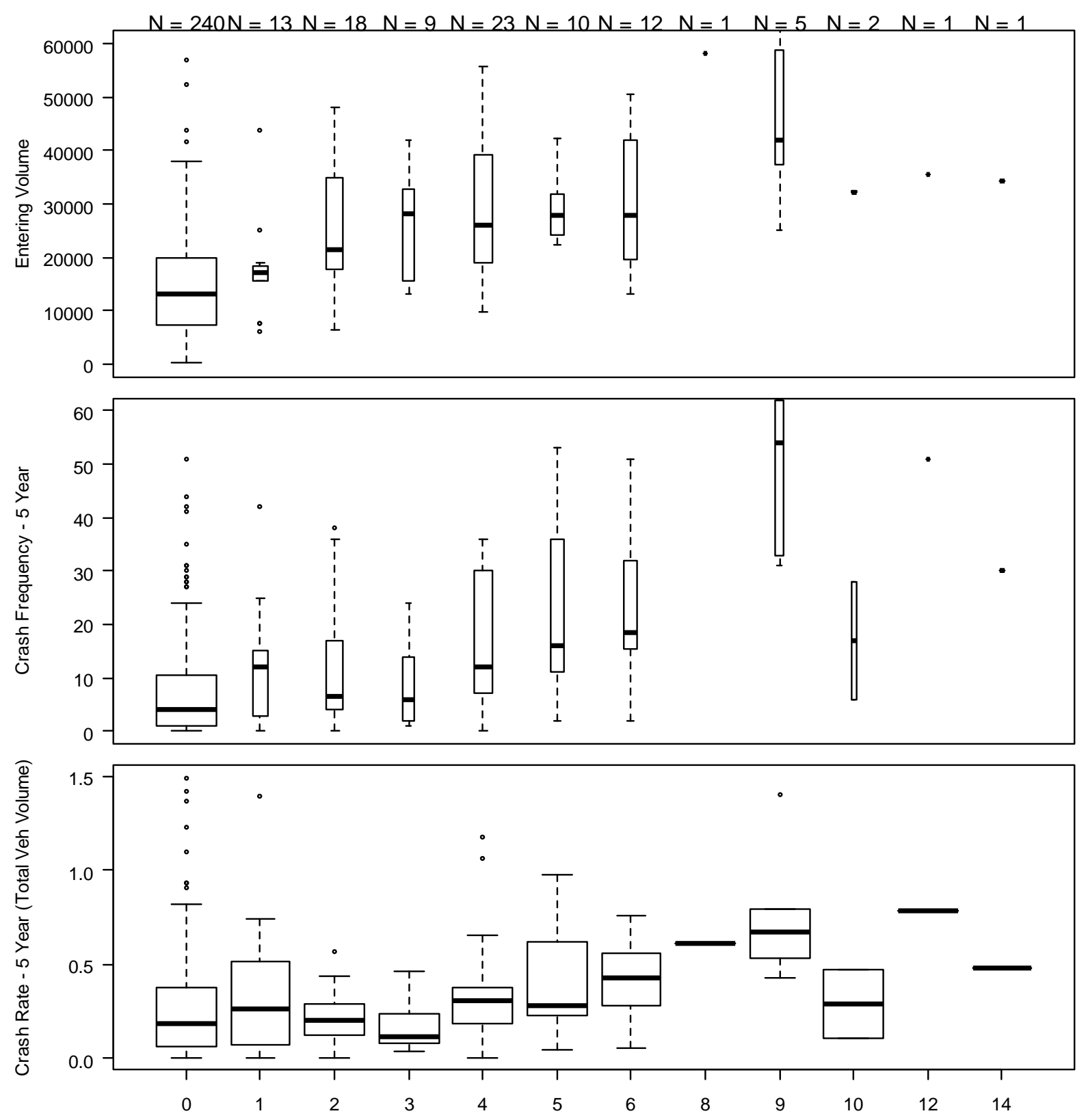

Figure B.31: Number of Bus Stops within 1000 feet - Total Crashes 

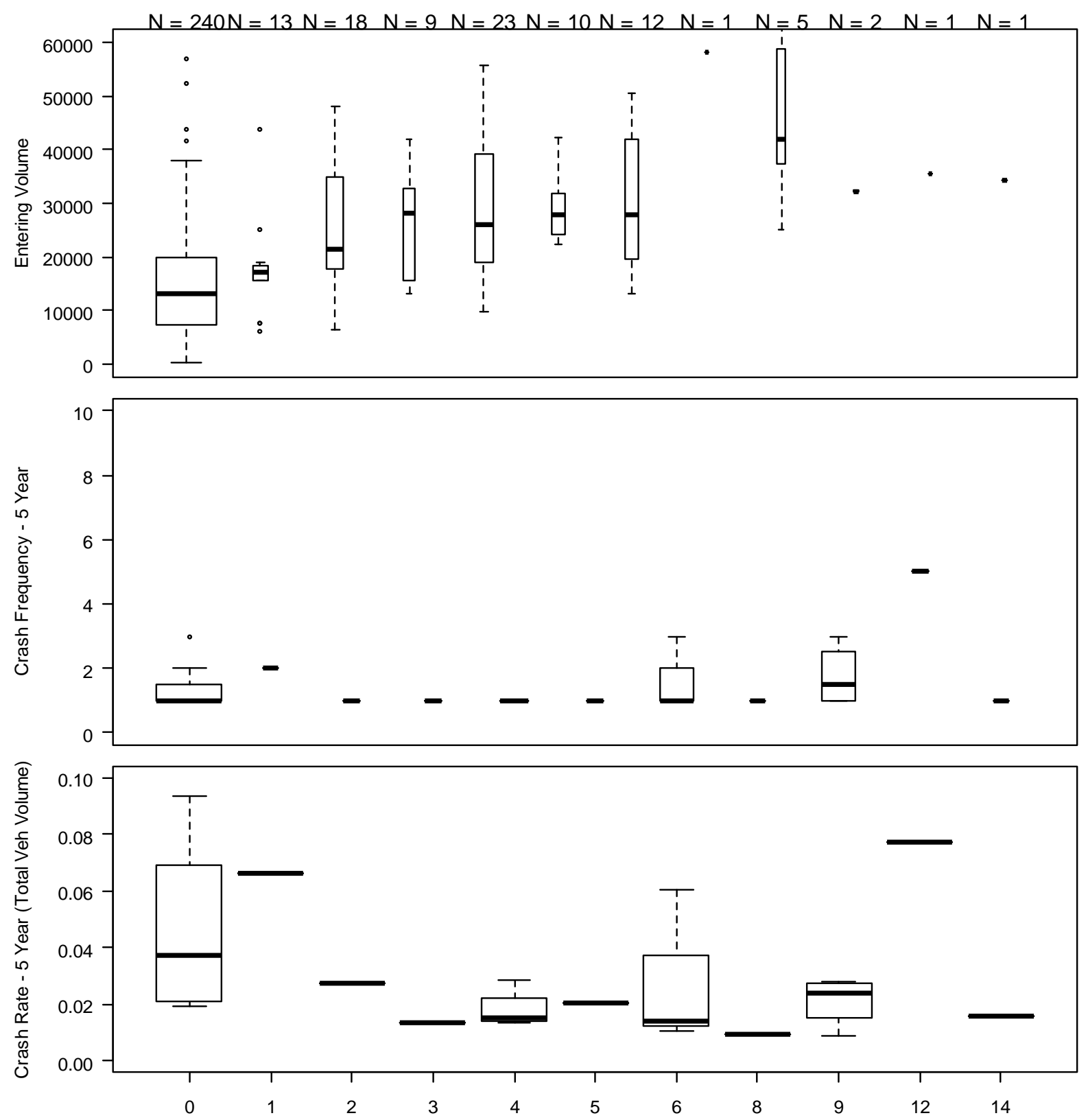

Figure B.32: Number of Bus Stops within 1000 feet - Pedestrian Crashes 